\title{
A HYDROXYAPATITE PHANTOM MATERIAL FOR THE CALIBRATION OF IN VIVO X-RAY FLUORESCENCE SYSTEMS OF BONE STRONTIUM AND LEAD QUANTIFICATION
}

by

\author{
Eric Da Silva \\ B.Sc., Ryerson University, 2007 \\ M.Sc., Ryerson University, 2009 \\ Toronto, Ontario, Canada
}

\begin{abstract}
A dissertation
presented to Ryerson University

in partial fulfillment of the

requirements for the degree of

Doctor of Philosophy

in the Program of

Biomedical Physics

Toronto, Ontario, Canada, 2017
\end{abstract}

(C) Eric Da Silva 2017 


\section{AUTHOR'S DECLARATION}

I hereby declare that I am the sole author of this dissertation. This is a true copy of the dissertation, including any required final revisions, as accepted by my examiners.

I authorize Ryerson University to lend this dissertation to other institutions or individuals for the purpose of scholarly research.

I further authorize Ryerson University to reproduce this dissertation by photocopying or by other means, in total or in part, at the request of other institutions or individuals for the purpose of scholarly research.

I understand that my dissertation may be made electronically available to the public. 
ABSTRACT

\title{
A HYDROXYAPATITE PHANTOM MATERIAL FOR THE CALIBRATION OF IN VIVO X-RAY FLUORESCENCE SYSTEMS OF BONE STRONTIUM AND LEAD QUANTIFICATION
}

\author{
Doctor of Philosophy \\ 2017 \\ Biomedical Physics \\ Ryerson University \\ Eric Da Silva
}

A hydroxyaptite [HAp; $\left.\mathrm{Ca}_{5}\left(\mathrm{PO}_{4}\right)_{3} \mathrm{OH}\right]$ phantom material was developed with the goal of improving the calibration protocol of the ${ }^{125}$ I-induced in vivo X-ray fluorescence (IVXRF) system of bone strontium quantification with further application to other IVXRF bone metal quantification systems, particulary those associated with bone lead quantification. It was found that calcium can be prepared pure of inherent contamination from strontium (and other elements) through a hydroxide precipitation producing pure $\mathrm{Ca}(\mathrm{OH})_{2}$, thereby, allowing for the production of a blank phantom which has not been available previously. The pure $\mathrm{Ca}(\mathrm{OH})_{2}$ can then be used for the preparation of pure $\mathrm{CaHPO}_{4} \cdot 2 \mathrm{H}_{2} \mathrm{O}$. A solid state pure HAp phantom can then be prepared by reaction of $\mathrm{Ca}(\mathrm{OH})_{2}$ and $\mathrm{CaHPO}_{4} \cdot 2 \mathrm{H}_{2} \mathrm{O}$ mixed as to produce a $\mathrm{Ca} / \mathrm{P}$ mole ratio of 1.67 , that in $\mathrm{HAp}$ and the mineral phase of bone, in the presence of a setting solution prepared as to raise the total phosphate concentration of the solution by increasing the solubility $\mathrm{CaHPO}_{4} \cdot 2 \mathrm{H}_{2} \mathrm{O}$ and thereby precipitating HAp. The procedure can only be used to prepare phantoms in which doping with the analyte does not disturb the $\mathrm{Ca} / \mathrm{P}$ ratio substantially. In cases in which phantoms are to be prepared with high concentrations of strontium, the cement mixture can be modified as to introduce strontium in the form of $\mathrm{Sr}(\mathrm{OH})_{2} \cdot 8 \mathrm{H}_{2} \mathrm{O}$ as to maintain a $(\mathrm{Ca}+\mathrm{Sr}) / \mathrm{P}$ ratio of 1.67 . It was found by both X-ray diffraction spectrometry and Raman spectroscopy studies that strontium substitutes for calcium as in bone when preparing phantoms by this route. The necessity for 
the blank bone phantoms was assessed through the first blank bone phantom measurement and Monte Carlo simulations. It was found that for the ${ }^{125}$ I-induced IVXRF system of bone strontium quantification, the source, ${ }^{125} \mathrm{I}$ brachytherapy seeds may be contributing coherently and incoherently scattered zirconium X-rays to the measured spectra, thereby requiring the use of the blank bone phantom as a means of improving the overall quantification methodology. Monte Carlo simulations were employed to evaluate any improvement by the introduction of HAp phantoms into the coherent normalization-based calibration procedure. It was found that HAp phantoms remove the need for a coherent conversion factor (CCF) thereby potentially increasing accuracy of the quantification. Further, it was found that in order for soft tissue attenuation corrections to be possible using spectroscopic information alone, HAp along with a suitable soft tissue surrogate material need to be employed. The HAp phantom material was used for the evaluations of portable X-ray analyzer systems for their potential for IVXRF quantification of lead and strontium with a focus on a comparison between tungsten, silver and rhodium target systems. Silver and rhodium target X-ray tube systems were found to be comparable for this quantification. 


\section{ACKNOWLEDGEMENTS}

This dissertation contains a portion of work completed over a period of several years. The completion of the work herein overlapped with some good times, and, some rather [unexpected] bad times. The completion of this dissertation would not have been possible if it were not for the help and support of several individuals who are acknowledged herein. I have done my best to ensure that this list is as complete as possible. A heartfelt thank you for your help and support to anyone who may have been missed.

For financial support, several bodies are acknowledged. The Natural Science and Engineering Research Council of Canada (NSERC) is acknowledged for providing me with an Alexander Graham Bell Canadian Graduate Scholarship (NSERC CGS-D3). The Ontario Government is acknowledged for providing me with a Queen Elizabeth II Graduate Scholarship in Science and Technology (QEII-OGSST). Ryerson University is acknowledged for providing me with a Ryerson University Graduate Scholarship and a Doctoral Completion Award. My doctoral advisor (Dr. Ana Pejović-Milić) is acknowledged for providing the added stipends to the mentioned scholarships from the seemingly never-ending pit of cash which financed the majority of the the work presented herein as well as the many international conferences I attended. Ryerson University is acknowledged for providing a series of funds which helped me attend several international conferences. Dr. David E.B. Fleming, is ac- 
knowledged for financing the rental of the silver-target portable X-ray tube system used throughout this work as well as for financing the individuals who helped with data collection at Mount Allison University (Sackville, New Brunswick, Canada).

Aside from the research presented herein - and other work published elsewhere - a portion of my time during the doctoral program was dedicated to the teaching and training of several students. I would like to thank Ryerson University and McMaster University for allowing me to develop my teaching skills by providing me the opportunity to work as a graduate teaching assistant throughout the course of this doctoral program and for allowing me the opportunity to help with the development of curricula whenever possible. I would also like to thank the Department of Physics and the Faculty of Science at Ryerson University for entrusting me with the development and teaching of my first courses while undertaking my doctoral studies (PCS 407: Radiation Therapy; PCS 211: Mechanics; PCS 354/BP8112: Radiation Biology).

I cannot express my gratitude in any particular set of words to the several undergraduate and graduate students that I bench supervised and helped guide in their research experience over the last several years and who had, at times, to endure my intensity and eccentricity during their own research training. These include, in no particular order: Tian Tian Yan (Physics), Ameen Mohammed (Physics), Matthew Brandt (Physics), Gabriella Mankovskii (Chemistry \& Biology), David Broughton (Physics), Shivani Sharma (Physics), Carolyn Halar (Physics), Justin Kosalka (Chemistry \& Biology), Raphael Jakubovic (Physics), Brian Kirkham (Physics), Melissa Martinez (Physics), Oksana Dubova (Chemistry \& Biology), Diana Schwendener Forkel (Chemistry \& Biology), Xuan Nghiem (Chemistry \& Biology), Nadan Ruben Pinto (Physics), Bisma Rizvi (Physics), Danny Jang (Physics), Hazra Sokoli (Physics), Jimmy Ng (Physics), Shirin Khanna (Biochemistry - U of Waterloo) and Danica 
Dy (Biology - U of North Carolina). Much thanks to all of you for your patience as I developed my teaching and supervisory skills. I hope that at the least working with me helped you all discern your own vocations and inspired you to keep on researchin'. A special thank you goes out to Mr. Tolis Panagiotopoulos (independent data analyst and computer programming specialist) who volunteered a significant portion of his time in helping me develop and validate my computer code used for large portions of this work. By and large, this was by far the most tedious and time consuming task related to this dissertation given the volumes of data resulting in numerous delays into its completion. Many thanks, my dude.

At the onset of this doctoral program, I made a sort of "career change"; rather, I made the decision to focus my studies and career in biomedical physics after completing degrees with a stronger emphasis on chemistry and biology. With an undergraduate degree in Applied Chemistry \& Biology and a master's degree in Molecular Sciences, entering this program required that I complete several courses within the field of biomedical physics as a means of filling an educational void. This was not an easy or trivial task. As such, I would like to acknowledge the wonderful instructors who delivered the courses I took during this doctoral program as a means of bringing me up to par in the area of biomedical physics; these include: Dr. Soo-Hyun Byun (McMaster University; Advanced Radiation Physics/Radiation and Radioisotope Methodology), Dr. Andrew Rainbow (McMaster University; Radiation Biology), Mr. David Tucker (McMaster University; Operational Health Physics), Dr. Emily Heath (Ryerson/Carelton University; Radiation Therapy), Dr. Yuan Xu (Ryerson University; Advanced Imaging) and Dr. Michael Kolios (Ryerson University; Communications).

From the point of view of research training, there are several that deserve to be heavily acknowledged. Firstly, my doctoral advisor, Dr. Ana Pejović-Milić. I have had the pleasure of 
working with Dr. Pejović-Milić for almost fourteen years in various capacities; a time period in which she has seen me grow as an academic while also watching my waistline expand, my bald spot enlarge and my blood sugar levels rise. Thank you for all of your support over the last several years and for all of your help with regards to my development as an academic, Dr. Pejović-Milić! I am also indebted to my graduate committee - Dr. Darrick V. Heyd (Chemistry \& Biology) and Dr. David R. Chettle (McMaster University) - for their support and useful discussions whenever needed. I am particularly indebted to Dr. Darrick V. Heyd who provided much moral and well as research support during the last year of my doctoral studies. Aside from those directly involved in this doctoral dissertation, I also thank various others who helped shape my research training, particularly, Dr. Derick Rousseau (Chemistry \& Biology), Dr. Alison Matthews David (Fashion), Dr. Michael J. Farquharson (McMaster University) and Dr. Luisa Carvalho (University of Lisbon). Thank you all for your help over the years, the many useful discussions and the moral support when needed!

The final year of my doctoral studies was particularly difficult as I was faced with many significant personal challenges. The completion of this dissertation would not have been possible if it were not for the immense support of several individuals who deserve a special acknowledgement here. These include Dr. Carl Kumaradas (Graduate Program Director, Physics), Dr. Jennifer Mactavish (Dean, Yeates School of Graduate Studies) and Dr. Imogen Coe (Dean, Faculty of Science). I cannot thank you all enough for your support and patience, believe me.

Finally, this work would not have been possible if it were not for the overall unconditional support of my own friends and family who were always there for me through the "thick and thin" of the last several years. To my parents, Alfredo and Maria Isabel Da Silva, thank you for your support and for being there through everything while understanding the 
trials and tribulations of the last several years, in your own way. To my siblings, Nezia and Brian Da Silva, thank you for your support and for being little rocks which I could confide in and depend on at any time. To my nieces, Nina and Lyla Bettencourt, Tio loves ya and thanks for making me smile. To my spiritual directors, Sr. Mary Mcintyre, CSJ, Fr. Philip Shano, SJ, Dr. Adam Hincks, SJ and Fr. Peter Turrone, thank you for the immense support and unconditional availability and generosity over the last several years. To my good friends and confidants, Brian Kirkham, Rajat Singh, James Gräfe, Elstan Desouza, Alex Panagiotopoulos and Aaron Zboch-Alves, thanks for always being available when a beer was required. And of course, to my partner in crime, Josie Abate - thanks for not leaving me and for all of your love and support. 
5 "Get used to saying No." 63 "You - you think - you have a lot of personality: your studies - your research work, your publications -, your social standing - your family background -, your political activities - the positions you hold -, your wealth..., your age, you're no longer a child!... Precisely because of all that, you, more than others, need a Director for your soul." 160 "Tell me, honestly: is that... a friendship, or is it a chain?" 174 "Don't say: 'That person gets on my nerves.' - Think: 'That person is making a saint of me." 239 "A look back at the past. To...bewail it? No: that's useless. - To learn: which is fruitful." 251 "Tomorrow!': sometimes it may be prudence; very often it is the adverb of the defeated." 263 "Don't lose heart. - I have seen you struggle...: your defeat today is training for final victory." 266 "Never make a decision without stopping to consider the matter in the presence of God." 282 "Paradox: Sanctity is more attainable than learning, but it's easier to be learned than to be a saint." 316 "You tell me, 'Yes', that you want to. -Fine, but... do you want to as a miser cherishes his gold, as a mother loves her child, as a man of ambition craves for honours or as a wretched sensualist seeks his pleasure? -No? - Then, you don't want to." 332 "When a person can become learned we cannot excuse him if he does not." 365 "If you feel and impulse to be a leader, your aim should be this: among your brothers, to be the last; among others, the first." 456 "To criticise, to destroy, is not difficult: even the rawest labourer can drive his pick into the noble and finely-hewn stone of a cathedral. - To construct: that is what requires the skill of a master." 486 "Work...there's plenty to be done. - The instruments mustn't be left to grow rusty. - And there are standard procedures to avoid mildew and rust. - Just put them into practice."

- Selected Passages from The Way -St. Josemaría Escrívá

"Act as if everything depended on you; trust as if everything depended on God."

-St. Ignatius of Loyola 
Author's Declaration ..................... ii

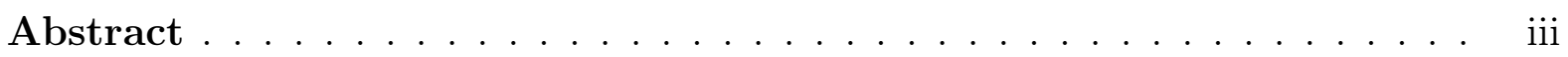

Acknowledgements .....................

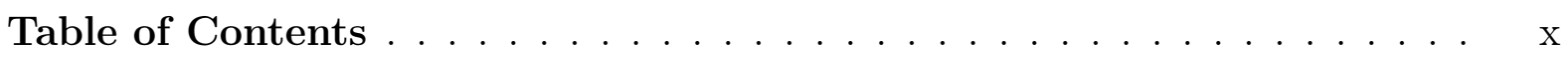

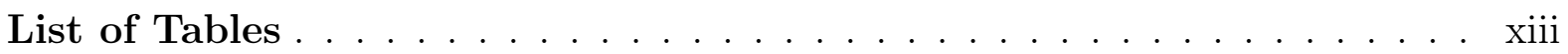

List of Figures . . . . . . . . . . . . . . . . . xiv

1 Introduction 1

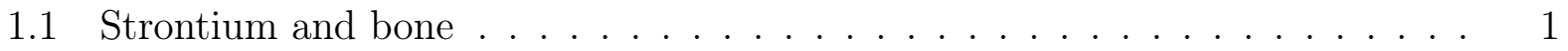

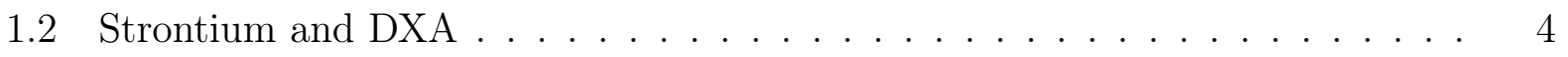

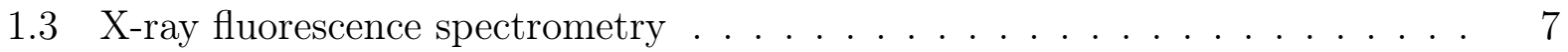

1.4 In Vivo XRF . . . . . . . . . . . . . . . . . . . . . . . . . 9

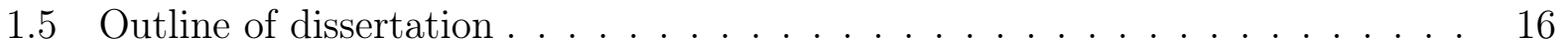

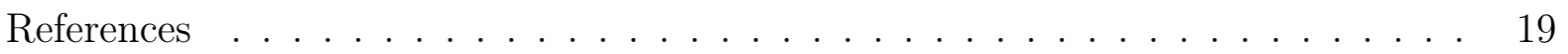

2 A proposed matrix reference material for X-ray fluorescence systems of $\begin{array}{ll}\text { bone metal quantification } & \mathbf{2 7}\end{array}$

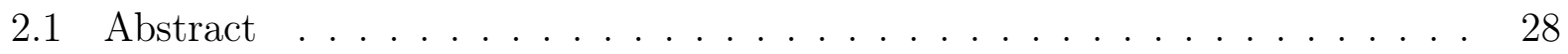

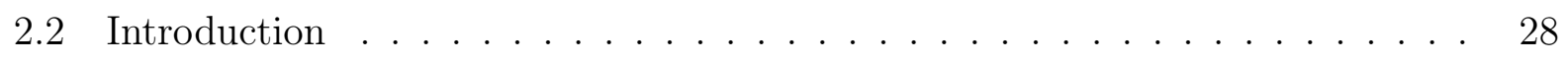

2.3 Experimental . . . . . . . . . . . . . . . . . . . . . 32

2.3.1 Preparation of pure calcium compounds . . . . . . . . . . . 32

2.3.2 Preparation of hydroxyapatite phantoms . . . . . . . . . . . 33

2.3.3 Total reflection X-ray fluorescence spectrometry . . . . . . . . . . 35

2.3.4 Energy dispersive X-ray fluorescence spectrometry . . . . . . . . . 36

2.3 .5 Powder X-ray diffraction spectrometry . . . . . . . . . . . . 37

2.4 Results and discussion . . . . . . . . . . . . . . . . . . . . 37

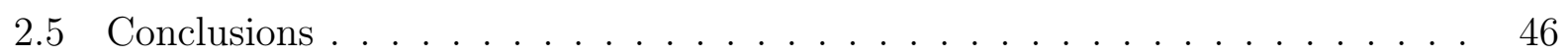

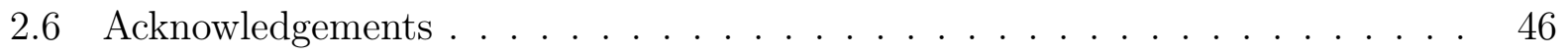

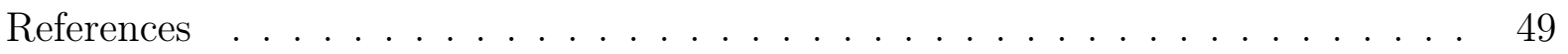


3 The preparation of strontium-substituted hydroxyapatite bone phantoms with high strontium concentrations $\quad 55$

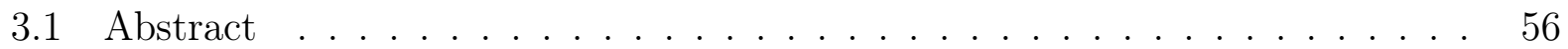

3.2 Introduction . . . . . . . . . . . . . . . . . 57

3.3 Materials and methods . . . . . . . . . . . . . . . . . . . 59

3.3.1 Phantom preparation . . . . . . . . . . . . . . . . . . 59

3.3.2 Powder X-ray diffraction spectrometry . . . . . . . . . . . . . . . 60

3.3 .3 Raman spectroscopy . . . . . . . . . . . . . . . . . . . . . 60

3.4 Results and discussion . . . . . . . . . . . . . . . . . . . . 61

3.5 Conclusions . . . . . . . . . . . . . . . . . . . . 71

3.6 Acknowledgements . . . . . . . . . . . . . . . . . . . . . . 72

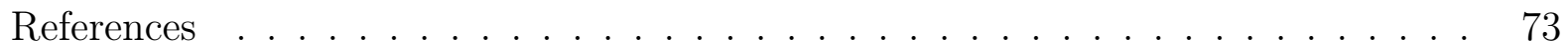

4 Application of the blank hydroxyapatite phantom to assess spectral background in the context of an in vivo XRF bone strontium measurement $\quad 79$

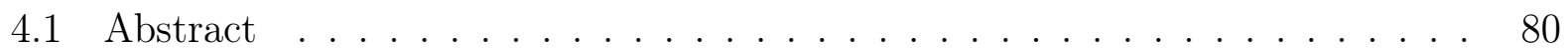

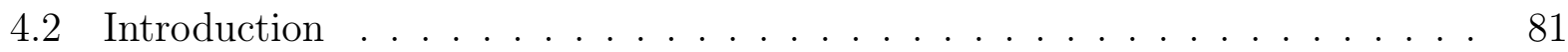

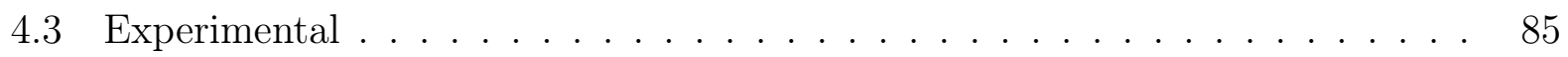

4.3 .1 Blank Bone Phantom . . . . . . . . . . . . . . . . . . . . . 85

4.3 .2 Brachytherapy Seeds . . . . . . . . . . . . . . . . . . 85

4.3.3 Qualitative elemental analysis of brachytherapy seeds . . . . . . . 86

4.3.4 Direct Source and Blank Phantom Measurement . . . . . . . . . . 87

4.3.5 Monte Carlo Simulations . . . . . . . . . . . . . . . . . . . . . 88

4.4 Results and Discussion . . . . . . . . . . . . . . . . . . . 89

4.5 Conclusions . . . . . . . . . . . . . . . . . . . . . 100

4.6 Acknowledgements . . . . . . . . . . . . . . . . . . . . . 101

References . . . . . . . . . . . . . . . . . . . . 102

5 Secondary excitation of the lead L-series by the strontium K-series in cases $\begin{array}{lr}\text { of high bone strontium concentrations } & 106\end{array}$

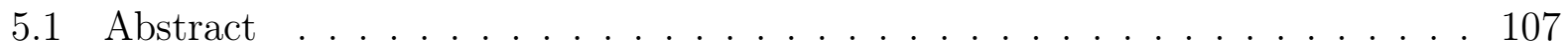

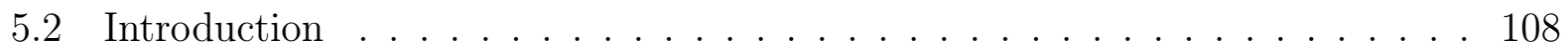

5.3 Monte Carlo Simulations . . . . . . . . . . . . . . . . . . . . . 110

5.4 Results and Discussion . . . . . . . . . . . . . . . . . . 111

5.5 Conclusions . . . . . . . . . . . . . . . . . . . . . . 118

5.6 Acknowledgement . . . . . . . . . . . . . . . . . . . . . . . . . 119

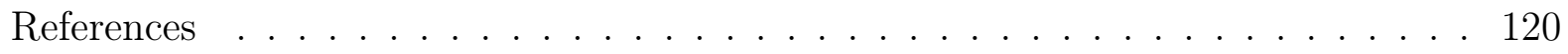

6 Calibration of the ${ }^{125}$ I-induced X-ray fluorescence spectrometry-based system of in vivo bone strontium determinations using hydroxyapatite as a 
phantom material: A simulation study $\quad 125$

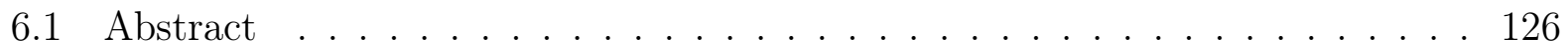

6.2 Introduction . . . . . . . . . . . . . . . . . . . 127

6.3 Methods. . . . . . . . . . . . . . . . . . . . . . . . . . . . . 129

6.4 Results and Discussion . . . . . . . . . . . . . . . . . . . . 131

6.5 Conclusions . . . . . . . . . . . . . . . . . . . . . . . . . . . . . . 149

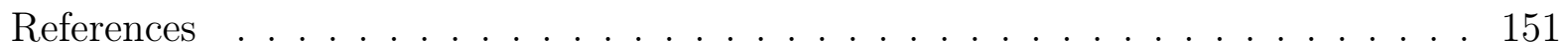

7 Compton-based soft tissue thickness determinations in the context of an ${ }^{125}$ I-induced bone strontium measurement: A simulation study $\quad \mathbf{1 5 6}$

7.1 Abstract . . . . . . . . . . . . . . . . . . . 157

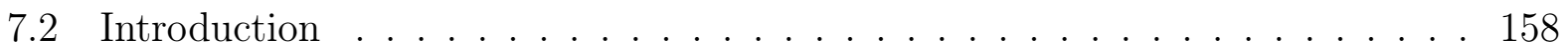

7.3 Methods. . . . . . . . . . . . . . . . . . . . . . 160

7.4 Results and Discussion . . . . . . . . . . . . . . . . . . 162

7.5 Conclusions . . . . . . . . . . . . . . . . . . . . . . . 171

7.6 Acknowledgement . . . . . . . . . . . . . . . . . . . . . . . . . 172

References . . . . . . . . . . . . . . . . . . . . . . 173

8 Evaluation of portable X-ray fluorescence spectrometers for in vivo quantification of bone strontium and lead $\quad 176$

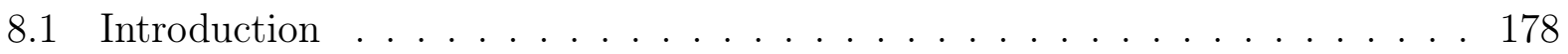

8.2 Experimental . . . . . . . . . . . . . . . . . . . . . . . 180

8.2 .1 Portable X-ray Analysers . . . . . . . . . . . . . . . . . . 180

8.2 .2 Phantom preparation and measurements . . . . . . . . . . . . . 181

8.2 .3 Data processing . . . . . . . . . . . . . . . . . . . . . 182

8.3 Results and Discussion . . . . . . . . . . . . . . . . . . . . 183

8.4 Conclusions . . . . . . . . . . . . . . . . . . . . . . . . . . . . . 192

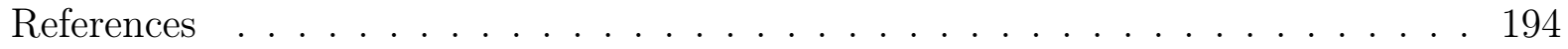

9 Conclusions and Future Directions $\quad 197$

9.1 Development of Phantom Materials . . . . . . . . . . . . . . . . . 197

9.2 Application to quantification methodology . . . . . . . . . . . . 206

9.3 Future Recommendations . . . . . . . . . . . . . . . . . . . . . . . . . . 212

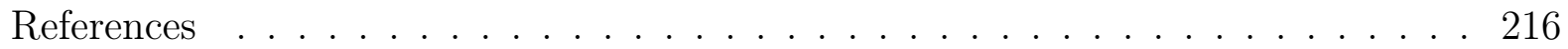




\section{LIST OF TABLES}

2.1 Validation of the TXRF method used for the quantification of contaminants in calcium compounds using NIST bone ash (SRM 1400). . . . . . . . . . .

2.2 Contamination levels in the calcium compounds purchased for the preparation

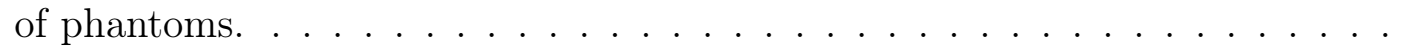

4.1 Characteristic X-ray energies organized by possible spectral overlap for rubidium, strontium and zirconium. ${ }^{21}$ All energies are quoted in units of $\mathrm{keV} .$. .

6.1 Materials and associated physical properties used for the Monte Carlo simulations. Data for HAp and poP taken as basic physical/chemical properties. Data for cortical bone taken from the ICRP. ${ }^{26} \ldots \ldots \ldots \ldots \ldots$

6.2 Rate of change in characteristic X-ray intensity for the strontium K-series as a function of $\rho_{b}$. Computed $p$ values are those computed using a $t$-test about the slope, intercept and correlation coefficient. Tests performed at the $95 \%$ level of confidence $(\alpha=0.05) \ldots \ldots \ldots \ldots$

7.1 Materials and associated physical properties used for the simulations: for HAp and poP data taken as basic physical/chemical properties whereby for cortical bone data taken from the ICRP ${ }^{16}$ and for soft tissue the ICRU. ${ }^{15} \ldots \ldots$

8.1 Filter's available and investigated on the Trace III-SD pXA system. The filter composition is listed in order of material closest to the primary beam. . . . 180

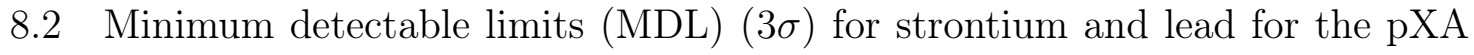
systems evaluated in this work. MDLs were determined on HAp phantoms. . 183 


\section{LIST OF FIGURES}

1.1 Schematic of the clinical in vivo XRF system of in vivo bone strontium quantification. Image taken from Zamburlini $2008^{47}$ and is the geometric arrangement used for all simulations in this work. The system consists of a $\mathrm{Si}(\mathrm{Li})$ detection system encased in an internal aluminum collimator. The external source collimator is composed of tungsten and houses an ${ }^{125} \mathrm{I}$ source in the form of brachytherapy seeds, simulated here as a point source. The image is to scale. Photons that traverse the detector are scored. Simulated spectra can be considered emissions spectra. . . . . . . . . . . . . . . . . .

2.1 The efficiency of calcium hydroxide precipitation within a calcium chloride solution as a method for the separation of strontium from a calcium as a function of the number of equivalents of $\mathrm{OH}^{-}$relative to $\mathrm{Ca}^{2+}$ used for the precipitation reaction. . . . . . . . . . . . . . . .

2.2 An EDXRF spectrum of commercially available $\mathrm{Ca}(\mathrm{OH})_{2}$ (upper spectrum) and the purified $\mathrm{Ca}(\mathrm{OH})_{2}$ (lower spectrum). The purified $\mathrm{Ca}(\mathrm{OH})_{2}$ shows strontium levels below the limit of detection $(3 \sigma)$ of the EDXRF system. . .

2.3 X-ray diffractograms of the prepared $\mathrm{Ca}(\mathrm{OH})_{2}$ and $\mathrm{CaHPO}_{4} \cdot 2 \mathrm{H}_{2} \mathrm{O}$ in comparison to commercially available materials. . . . . . . . . . . .

2.4 X-ray diffractograms of (A) the HAp phantom and (B) NIST bone meal. The phantom material shows a crystal structure indicating the production of HAp similar to bone mineral. The ${ }^{*}$ indicates reflections from unreacted

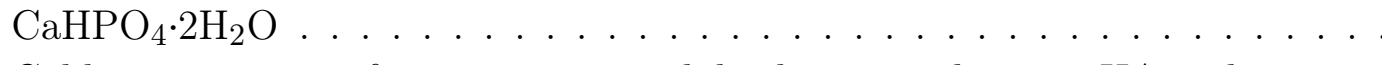

2.5 Calibration curves for strontium and lead prepared using HAp phantoms doped with the respective elements. . . . . . . . . . . . . . . 47 
3.1 Powder X-ray diffraction spectra of $\mathrm{CaHPO}_{4} \cdot 2 \mathrm{H}_{2} \mathrm{O}$ : (a) after mixing with a $1 \mathrm{M} \mathrm{NaOH}$ setting solution at a powder-to-liquid ratio of 2:1 and allowing to set; (b) after mixing with a $1 \mathrm{M} \mathrm{Na}_{2} \mathrm{HPO}_{4}$ setting solution at a powderto-liquid ratio of 2:1 and allowing to set; and (c) prior to the addition of a setting solution. The addition of either setting solution did not result in the formation of an apatitic product after the setting period. No contamination is apparent in (a) or (b). The difference in the diffraction pattern observed for the unreacted $\mathrm{CaHPO}_{4} \cdot 2 \mathrm{H}_{2} \mathrm{O}$ in the region of $2 \theta<32^{\circ}$ may be due to a difference in the particle size of the powders after the sample preparation as well as minor $\mathrm{pH}$ dependant structure changes. . . . . . . . . . . . . . .

3.2 Powder X-ray diffraction spectra of $\mathrm{Ca}(\mathrm{OH})_{2}$ : (a) after mixing with a $1 \mathrm{M}$ $\mathrm{NaOH}$ setting solution (b) after mixing with a $1 \mathrm{M} \mathrm{Na}_{2} \mathrm{HPO}_{4}$ setting solution (c) prior to the addition of a setting solution. In all cases the final product consisted mostly of $\mathrm{Ca}(\mathrm{OH})_{2}$. Setting in the presence of a $1 \mathrm{M} \mathrm{NaOH}$ resulted in the formation of some $\mathrm{CaCO}_{3}$. Setting in the presence of a $1 \mathrm{M} \mathrm{Na}_{2} \mathrm{HPO}_{4}$ solution resulted in the formation of some $\mathrm{Ca}_{10}\left(\mathrm{PO}_{4}\right)_{6}(\mathrm{OH})_{2}$ but no carbonate. $\left(^{*}\right)$ indicates $\mathrm{CaCO}_{3}$ reflections and $(\boldsymbol{\nabla})$ indicates $\mathrm{Ca}_{10}\left(\mathrm{PO}_{4}\right)_{6}(\mathrm{OH})_{2}$ reflections. The difference in the diffraction pattern observed for the unreacted $\mathrm{CaHPO}_{4} \cdot 2 \mathrm{H}_{2} \mathrm{O}$ in the region of $2 \theta<32^{\circ}$ may be due to a difference in the particle size of the powders after the sample preparation as well as minor pH dependant changes. . . . . . . . . . . . . . . . . .

3.3 Powder X-ray diffraction spectra of $\mathrm{Sr}(\mathrm{OH})_{2} \cdot 8 \mathrm{H}_{2} \mathrm{O}$ : (a) after mixing with a $1 \mathrm{M} \mathrm{NaOH}$ setting solution (b) after mixing with a $1 \mathrm{M} \mathrm{Na}_{2} \mathrm{HPO}_{4}$ setting solution (c) prior to the addition of a setting solution. After setting in the presence of either setting solution, the final product was nearly completely $\mathrm{SrCO}_{3}$ when prepared at ambient due to the incorporation of $\mathrm{CO}_{2}$ from air. Curing in the presence of a $1 \mathrm{M} \mathrm{Na}_{2} \mathrm{HPO}_{4}$ setting solution resulted in small quantities of $\mathrm{Sr}_{10}\left(\mathrm{PO}_{4}\right)_{6}(\mathrm{OH})_{2}$ marked by $(\boldsymbol{\nabla}) .{ }^{40} \ldots \ldots \ldots$

3.4 Powder X-ray diffraction spectra of apatite products formed with the aid of a phosphate setting solution for: (a) $0 \% \mathrm{~mol} / \mathrm{mol}$ strontium (b) $33.5 \% \mathrm{~mol} / \mathrm{mol}$ strontium and (c) $67 \% \mathrm{~mol} / \mathrm{mol}$ strontium. In all cases an apatitic product was formed. . . . . . . . . . . . . . . . . . .

3.5 Raman spectra of the strontium-substituted HAps with a focus on the $\mathrm{PO}_{4}$ $\nu_{1}$ band and its change in position with respect to the degree of strontiumsubstitution in the HAp lattice: (a) $0 \mathrm{~mol} / \mathrm{mol} \%$ strontium (b) $33.5 \mathrm{~mol} / \mathrm{mol} \%$ strontium and (c) $67 \mathrm{~mol} / \mathrm{mol} \%$ strontium. . . . . . . . . . . . . . .

3.6 Raman analysis of the $\mathrm{PO}_{4} \nu_{1}$ band position as a function of degree of strontium substitution, $x$. The analysis indicates that strontium is in fact substituting into the HAp lattice as a strontium-substituted HAp. . . . . . . . . . 
4.1 Experimental set-up for the blank phantom measurement. The drawing is not to scale. . . . . . . . . . . . . . . . . . . . .

4.2 Result of a direct measurement of the brachytherapy seeds used as an excitation source for in vivo X-ray fluorescence spectrometry measurements of bone strontium (see section 4.3.4) at $1 \mathrm{~m}$ from the SDD detector window. The figure shows the energy region of analytical interest within the energy range of $13-20 \mathrm{keV}$. The direct measurement collected over a 12 hour live time period shows the presence of rubidium, strontium and zirconium characteristic X-rays presumed to be emitted from the brachytherapy seeds themselves. . .

4.3 Qualitative X-ray fluorescence spectrometry measurement of the three ${ }^{125} \mathrm{I}$ brachytherapy seeds used as a source for in vivo XRF bone strontium measurements $(12.6 \mu \mathrm{Ci}$ total activity at the time of measurement) made on a portable X-ray analyzer known to be void of zirconium. Measurement made of the seeds after they were allowed to sufficiently decay using a portable X-ray analyzer (see Section 4.3.3) The spectrum shows the presence of the zirconium as well as several other light elements (not of interest to this work). The higher energy lines are those of the the Rh K-series as well as the ${ }^{125} \mathrm{I}$ $\gamma$-ray, Te, Ag characteristic X-rays and associated Compton peaks. The inlay shows the zirconium K-series (see Table 4.1). . . . . . . . . . . .

4.4 Result of a Monte Carlo simulation of an IVXRF bone strontium measurement in a $180^{\circ}$ backscatter geometry using an ${ }^{125} \mathrm{I}$ excitation source with zirconium contamination of $10 \%$ of the total source fluence for illustration purposes. The simulation is of a finger phantom that does not contain any strontium. .

4.5 Intensities of zirconium contributions for various fractional proportions of the zirconium K-series to the total source fluence. Once below a $1 \%$ contribution, the simulations indicate that the zirconium contributions become negligible. .

4.6 A preliminary measurement of a blank hydroxyapatite phantom made for a 20 minute live time using an SDD detection system and an off-centre source backscatter geometry. The spectrum is poor statistically due to the use of cold seeds but may indicate the presence of the dominant zirconium Compton scattered X-ray $(*)$, although this peak may be due to strontium contamination that is system dependent as seen from the direct measurement of this system (Figure 4.2). Rubidium is also shown as a contaminant of the system.

4.7 Total reflection X-ray fluorescence spectrum of the clean phantom material. There is no indication of strontium in the material at levels of less than

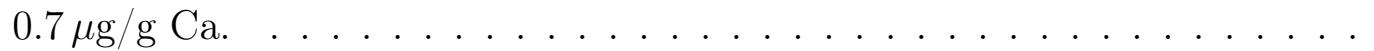


5.1 Strontium $\mathrm{K} \alpha_{1,2}$ and $\mathrm{K} \beta_{1,3}$ intensities as a function of strontium concentration and with a constant bone density of $1.9 \mathrm{~g} / \mathrm{cm}^{3}$. The strontium lines show a non-linear relationship with concentration when approaching high concentrations. The dashed line represents a linear trend based on low concentration data. Concentration of $10 \% \mathrm{~mol} / \mathrm{mol}[\mathrm{Sr} /(\mathrm{Sr}+\mathrm{Ca})]$ equivalent to approximately $4.9 \% \mathrm{w} / \mathrm{w}$ and is selected here as a hypothetical extrema whereby concentrations in humans in the context of DXA studies do not generally exceed $3 \% \mathrm{~mol} / \mathrm{mol}[\mathrm{Sr} /(\mathrm{Sr}+\mathrm{Ca})] \ldots \ldots \ldots \ldots \ldots \ldots$

5.2 Lead $\mathrm{L} \alpha_{1,2}$ and $\mathrm{L} \beta_{1,2}$ intensities as a function of strontium concentration for a bone phantom containing $1,000 \mu \mathrm{g} / \mathrm{g}$ lead. The lead L-series intensities showed no change $(p>0.05)$ with respect to strontium content at a constant lead concentration. . . . . . . . . . . . . . . . . . .

5.3 (a) Percentage differences in the mass attenuation coefficient in the energy region corresponding the lead L-series less than $5 \%$. (b) Total mass attenuation coefficient for bone with no strontium and with a a $10 \% \mathrm{~mol} / \mathrm{mol}[\mathrm{Sr} /(\mathrm{Sr}+$ $\mathrm{Ca})$ ] strontium concentration demonstrating a minimal influence in the mass attenuation coefficient as a function of strontium concentration. . . . . . . . .

6.1 Effect of bone density $\left(\rho_{b}\right)$ variations on the observed strontium $\mathrm{K} \alpha(\mathbf{A})$ and $\mathrm{K} \beta$ (B) lines for a cortical bone phantom containing $400 \mu \mathrm{g} / \mathrm{g}$ strontium. There is only a slight decrease in intensity as a function of $\rho_{b}$ for the $\mathrm{K} \alpha_{1}$ and thus the $\mathrm{K} \alpha_{1,2}$ line (see Table 6.2). . . . . . . . . . . . . . .

6.2 Effect of $\rho_{b}$ on the observed coherent peak intensity from the $35.5 \mathrm{keV}{ }^{125} \mathrm{I}$ source $\gamma$-ray, for a cortical bone phantom containing $400 \mu \mathrm{g} / \mathrm{g}$ strontium. The "physiological range" is between 1.5 and $2.2 \mathrm{~g} / \mathrm{cm}^{326}$ resulting in a $14 \%$ increase in intensity. The range of densities evaluated in this figure extends further from the physiological range to include the density of pure HAp. . . . 135

6.3 Quantification of strontium for a $400 \mu \mathrm{g} / \mathrm{g}$ cortical bone sample, using either the $\mathrm{K} \alpha_{1,2}$ line alone or the $\mathrm{K} \alpha_{1,2} / \mathrm{coh}$ ratio against a cortical bone-based calibration curve. A larger bias is observed in the case of using the $\mathrm{K} \alpha_{1,2} / \mathrm{coh}$ ratio as the analytical measure due to introduction of the density dependence of the coherent scattered photon. The close match in results when using the $\mathrm{K} \alpha_{1,2}$ alone is due to the match in geometry between sample and phantoms and a match in the total mass attenuation coefficients of the sample and phantoms $/$ calibrators. . . . . . . . . . . . . . . . . 136

6.4 Calibration curves prepared against the strontium $\mathrm{K} \alpha_{1,2}$ line only for poP, HAp and cortical bone phantoms. The variation in sensitivity is due to variations in the total mass attenuation coefficients between the materials. . . . . 138 
6.5 Attempts at quantifying strontium concentrations in units of mass strontium per total mass of bone using either poP and HAp calibrators/phantoms and un-normalized strontium $\mathrm{K} \alpha_{1,2}$ intensities. The quantification results in rather larger percentage deviations from known concentrations. The dashed line represents the $1: 1$ point. . . . . . . . . . . . . . . . . .

6.6 Calibration curves prepared against the strontium $\mathrm{K} \alpha_{1,2} /$ coherent ratio for poP, HAp and cortical bone phantoms. The variation in sensitivity is due to variations in the total mass attenuation coefficients between the materials but also influenced by the density effect on the coherent peak previously shown (Figure 6.2)

6.7 Attempts at quantifying strontium concentrations in units of mass strontium per total mass of bone using both poP and HAp phantoms and the K $\alpha_{1,2}$-tocoherent ratio as the analytical measure. The quantification results in rather larger percentage deviations from known concentrations when using either of the two phantoms calibrators. . . . . . . . . . . . . . . . . . 141

6.8 Calibration curves for poP, HAp and cortical bone expressed with concentration units normalized to mass of calcium in the specimen. There is excellent agreement between HAp and cortical bone calibration curves but not between poP and cortical bone calibration curves. . . . . . . . . . . . . . .

6.9 Determined strontium concentrations in relation to mass of calcium in the specimen, for cortical bone, as determined from poP and HAp calibration curves. Normalization to the $35.5 \mathrm{keV} \gamma$ results in excellent agreements for HAp calibration but not poP calibration. The dashed line represents the 1:1

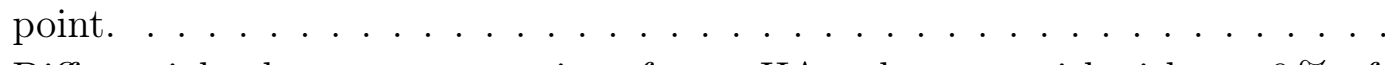

6.10 Differential coherent cross-sections for an HAp phantom with either a $0 \%$ of $100 \%$ conversion ratio to the reaction. A $100 \%$ conversion ration corresponds to pure HAp, while a conversion ratio of $0 \%$ corresponds to a mixture of brushite and calcium hydroxide in a proportion as to produce a $\mathrm{Ca} / \mathrm{P}$ mole

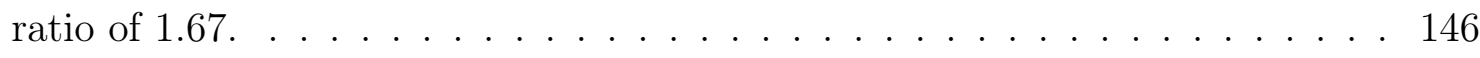

6.11 Differential coherent cross-sections for cortical bone and soft tissue at $35.5 \mathrm{keV}$.

The ratio of the cortical bone cross-section to that of soft tissue at $180^{\circ}$ is 6.2 .147

7.1 Effect of bone diameter on relative Compton intensity of the $20.30 \mathrm{keV}$ peak for a human bone matrix over all of the Compton energies detected in the case of an in vivo bone strontium measurement. Boxed points indicate the range of normalized values. . . . . . . . . . . . . . . . 163 
7.2 Normalized (to max) Compton intensities as a function of soft tissue thickness for various core materials and soft tissue as the envelope material. The top figure corresponds to the Compton intensity of the 22.16 , $\mathrm{keV}$ silver X-ray Compton scattered photon at $20.39 \mathrm{keV}$, the middle figure corresponds to the Compton intensity of the $27.4 \mathrm{keV}$ Te X-ray Compton scattered photon at $24.75 \mathrm{keV}$ and the bottom figure corresponds to the $31 \mathrm{keV}$ Te X-ray Compton scattered photon at $27.65 \mathrm{keV}$. These peaks were selected as they are the clearest peaks least perturbed by overlaying coherently scattered X-rays. . . .

7.3 Normalized (to max) Compton intensities as a function of lucite thickness for various core materials and lucite as the envelope material. The top figure corresponds to the Compton intensity of the $22.16 \mathrm{keV}$ silver X-ray Compton scattered photon at $20.39 \mathrm{keV}$, the middle figure corresponds to the Compton intensity of the $27.4 \mathrm{keV}$ Te X-ray Compton scattered photon at $24.75 \mathrm{keV}$ and the bottom figure corresponds to the $31 \mathrm{keV}$ Te X-ray Compton scattered photon at $27.65 \mathrm{keV}$. These peaks were selected as they are the clearest peaks least perturbed by overlaying coherently scattered X-rays. . . . . . . . . . . 167

7.4 Normalized (to max) Compton intensities of the 22.16,keV silver X-ray Compton scattered photon at $20.39 \mathrm{keV}$ determined using soft tissue as the enveloping material versus lucite as the enveloping material. . . . . . . . . . . . 169

7.5 Normalized (to max) Compton intensities of the 22.16, keV silver X-ray Compton scattered photon at $20.39 \mathrm{keV}$ determined using soft tissue as the enveloping material versus lucite as the enveloping material for the $5 \mathrm{~mm}$ diameter bone specimen shown for clarity. . . . . . . . . . . . . .

8.1 X-ray fluorescence spectra of a strontium (60 $\mu \mathrm{g} / \mathrm{g}$ Ca)- and lead (100 $\mu \mathrm{g} / \mathrm{g}$ Ca) containing HAp bone phantom measured using the tungsten target pXA system. Spectrum acquired for a real time of $180 \mathrm{~s}$. The spectrum is void of any characteristic lines from tungsten with the background being composed of largely scattered bremsstrahlung source photons. . . . . . . . . . . . . . 184

8.2 Spectra of a strontium (60 $\mu \mathrm{g} / \mathrm{g} \mathrm{Ca})$ - and lead (100 $\mu \mathrm{g} / \mathrm{g}$ Ca)-containing HAp phantom collected with $\mathbf{A}$ ) the silver target $\mathrm{pXA}$ system; and $\mathbf{B}$ ) the rhodium target pXA system over a 30 s real time measurement. Spectra $\mathbf{C}$ ) and $\mathbf{D}$ ) are the same spectra corresponding to $\mathbf{A}$ ) and $\mathbf{B}$ ), respectively, zoomed into the region of interest containing the lead L-series and the strontium K-series. For B) and D) the various spectra correspond to those collected with different primary filtration arrangements order according to Table 8.1. . . . . . . . 185

8.3 XRF spectra of a strontium $(60 \mu \mathrm{g} / \mathrm{g} \mathrm{Ca})$ containing HAp bone phantom measured using the silver pXA system as a function of measurement time. . . 187 
8.4 XRF spectrum of a strontium $(60 \mu \mathrm{g} / \mathrm{g}$ Ca) containing phantom for HAp phantoms for different filter combinations at at various counting times centred on the strontium $\mathrm{K}$-series $\left(\mathrm{K} \alpha_{1,2}\right.$ at $14.1 \mathrm{keV}$ and $\mathrm{K} \beta_{1,3}$ at $\left.15.8 \mathrm{keV}\right)$ using the rhodium pXA system as a function of measurement time. . . . . . . . . . 188 
CHAPTER

$\mathrm{ONE}$

\section{INTRODUCTION}

\subsection{Strontium and bone}

Strontium is a group II alkaline Earth metal $(Z=38)$ and thus shares similar chemistry, and by extension biochemistry, to the most abundant of the alkaline Earth metals in the human body, calcium $(Z=20)$. Strontium can substitute for calcium in most of calcium's biological roles (including similar uptake and excretion rates and routes), with some minor favour towards calcium which is generally attributed to strontium's size relative to calcium's. ${ }^{1}$ Although excellent reviews on the biological role of strontium in a general sense are provided elsewhere, ${ }^{1,2}$ in general, the main interest in strontium, and its study in biological systems, is its effect on bone health. ${ }^{1-4}$ Strontium has been shown to be both detrimental to bone health as well as beneficial to overall bone health. For this latter reason, there has been a significant renewed interest in strontium and investigation into the element's possible essentiality to humans in the context of overall bone health.

Strontium is a bone seeking element, like calcium, with the majority of accumulated strontium being found in bone tissue. ${ }^{1,2}$ Strontium is an ubiquitous element to calcium and is acquired through the diet of all humans, thus every person will present some strontium in 
their calcified tissue in the microgram-per-gram range - nominal values in the average human being on the order of approximately $350 \mathrm{ppm}$, with this value being highly dependent on diet (with grains and seafood presenting some of the highest concentrations of strontium). ${ }^{1,2}$ Large excess bone strontium concentrations have been shown to cause bone disorders in both children and adults including rickets and osteomalacia, respectively. ${ }^{5-8}$ Strontium at low levels has however been shown to be beneficial to bone health. ${ }^{3,4}$ Although the true biochemical/molecular mechanism of strontium's action on osteocytes is still not fully understood: strontium has been shown to increase the rate of bone formation while suppressing bone resorption, thus having a direct action on the osteocytes in bone. ${ }^{1-3}$ Given this finding, and the fact that strontium seems to have an anti-osteoporotic effect, strontium has been proposed as a possible therapeutic agent in the treatment of osteoporosis, and the drug, strontium ranelate, has been developed and applied to the treatment of osteoporosis for this purpose. ${ }^{3,4}$ Similarly, individuals have also begun self-supplementing with various strontium salts for the purpose of either osteoporosis treatment or prevention. ${ }^{9,10}$ Regardless of the strontium salt used for the purpose of osteoporosis treatment and/or prevention (i.e. ranelate versus citrate), strontium has been shown to accumulate in bone with similar kinetic behaviour. ${ }^{9,10}$

Osteoporosis is a bone disorder which is characterized by a decrease in bone mineral density (BMD) and an increased risk of various fractures. ${ }^{11}$ The use of strontium ranelate as an anti-osteoporotic drug presents some significant challenges in terms of the evaluation of its effectiveness against osteoporosis which is quantified against changes in BMD over time. Although several other biochemical markers can be used to monitor the effectiveness of anti-osteoporotic drugs, an individual's BMD remains the standard marker of the effectiveness of a given osteoporosis therapy as it relates directly to fracture risk. ${ }^{4,11,12}$ A major 
concern with the use of BMD as a marker of drug effectiveness, in the context of evaluating strontium ranelate therapy (as well as the effectiveness of any other strontium salt used for the same purpose), is that strontium itself, which integrates into bone tissue, will positively bias the determined BMD, determined by the gold standard technique, dual energy X-ray absorptiometry (DXA), presenting higher BMD readings in comparison to true BMDs (see section 1.2). This strontium-induced bias has been well established and it is well known that changes in the $\mathrm{Sr} / \mathrm{Ca}$ mole ratio in bone results in linear changes in observed/apparent BMDs. ${ }^{13}$ As such, it is hard to judge the current work on strontium's effect on BMD as most, if not all, studies report uncorrected DXA-determined BMDs. Given that such a correction for bone strontium content would in theory require that a piece of bone be excised to make such corrections based on a quantitative assessment of the excised bone tissue, it is thus desirable to have a method which can determine bone strontium concentrations in vivo rapidly and accurately for the purpose of making such corrections, monitoring strontium uptake in bone over time, as well as to have available as a general method of determining the concentration of strontium in bone for general epidemiological and population studies. The latter application may be of significant interest as the effect strontium displays on bone health when present at low levels may indicate a possible essential role for strontium in human bone health - a matter to be further studied and defined but requiring large populations studies on bone strontium content. 


\subsection{The influence of bone strontium concentration on BMD determinations}

DXA can be well considered the gold standard method for bone mineral density determinations and is often employed to assess BMDs clinically as well as in academic studies assessing anti-osteoporotic therapies. ${ }^{14}$ In the case of strontium-based osteoporosis therapies, bone strontium concentrations have been clearly shown to bias DXA-determined BMD. ${ }^{13}$ This section briefly discusses the reasoning behind this trend.

The physical basis of DXA, and the standard method of determining BMD is provided by the International Commission on Radiation Units 8 Measurements (ICRU). ${ }^{14}$ A DXA measurement is based on the simple exponential law of photon attenuation. A DXA scan consists of acquiring attenuation measurements at two photon (X-ray) energies, and, in this way, the effect of soft tissue attenuation is accounted for and BMDs can be determined unhindered. If we consider a DXA measurement of some arbitrary sample composed of soft tissue $(s)$ and bone $(b)$, then, if the photons of each energy have an initial intensity $I_{0}$, the intensity of the photons of each energy after passing through the sample $[I(t)]$ is given by

$$
\begin{aligned}
I^{L}(t) & =I_{0}^{L} \exp \left[-(\mu / \rho)_{s}^{L} t_{s}-(\mu / \rho)_{b}^{L} t_{b}\right], \text { and } \\
I^{H}(t) & =I_{0}^{H} \exp \left[-(\mu / \rho)_{s}^{H} t_{s}-(\mu / \rho)_{b}^{H} t_{b}\right]
\end{aligned}
$$

where $(\mu / \rho)$ is the total mass attenuation coefficient of the material, $t$ the thickness (mass thickness, $\mathrm{g} / \mathrm{cm}^{2}$ ) and $H$ and $L$ denote high and low energy photons as per the ICRU ${ }^{14}$ convention.

The BMD determination is in fact an areal BMD $\left(\mathrm{BMD}_{a}\right)$ which is quoted in units of 
$\mathrm{g} / \mathrm{cm}^{2}$ versus the true BMD (per unit of volume) which can be determined by other methods such as quantitative X-ray computed tomography. ${ }^{14}$ The DXA determined BMD is also an average $\mathrm{BMD}$ along the path of the X-rays. The $\mathrm{BMD}_{a}$ is thus the total thickness of the sample $\left(t_{t o t}=t_{s}+t_{b}\right)$ multiplied by the weight fraction of bone within the sample, which cannot be easily determined directly from a DXA scan,

$$
\mathrm{BMD}_{\mathrm{a}}=t_{t o t} w_{b}
$$

A DXA determined $\mathrm{BMD}_{a}$ reading is thus determined by a re-arrangement of the system of equations shown in Eqns. 1.1 and 1.2 with knowledge of Eqn. 1.3 resulting in an expression for the $\mathrm{BMD}_{a}$ which allows for its determination directly from attenuation measurements,

$$
\mathrm{BMD}_{\mathrm{a}}=\frac{\left(\mu_{s}^{L} / \mu_{s}^{H}\right) \ln \left(I / I_{0}\right)^{H}-\ln \left(I / I_{0}\right)^{L}}{(\mu / \rho)_{b}^{L}-(\mu / \rho)_{b}^{H}\left(\mu_{s}^{L} / \mu_{s}^{H}\right)},
$$

where in this case $(\mu / \rho)_{b}$ is the total mass attenuation coefficient of bone.

Assigning a soft tissue correction term $R$ which can be made at an area in which no bone is present ${ }^{14}$

$$
R=\left(\frac{\mu_{s}^{L}}{\mu_{s}^{H}}\right)=\left.\frac{\ln \left(I / I_{0}\right)^{L}}{\ln \left(I / I_{0}\right)^{H}}\right|_{\mu_{b}=0},
$$

then Eqn. 1.4 can be re-written

$$
\mathrm{BMD}_{\mathrm{a}}=\frac{R \ln \left(I / I_{0}\right)^{H}-\ln \left(I / I_{0}\right)^{L}}{(\mu / \rho)_{b}^{L}-R(\mu / \rho)_{b}^{H}}
$$

which allows for an experimentally determined $\mathrm{BMD}_{a}$.

The influence that strontium substitution for calcium has on the $\mathrm{BMD}_{a}$ determination 
can be seen by considering that a $\mathrm{BMD}_{a}$ determination must assume that $(\mu / \rho)_{b}$ is a constant term, spatially and temporally, as it is impossible to know the true bone composition of each individual site of measurement. Although this in itself may very well be a source of error in the $\mathrm{BMD}_{a}$ determinations, the issue with strontium incorporation can be more easily observed by expanding $(\mu / \rho)_{b}$ through the additivity law of mass attenuation coefficients for a specimen containing $N$ elements

$$
(\mu / \rho)_{b}=\sum_{i}^{N}(\mu / \rho)_{i} w_{i},
$$

where $(\mu / \rho)_{i}$ is the mass attenuation coefficient of element $i$ and $w_{i}$ its weight fraction.

In the case that strontium substitutes for calcium, the attenuation of that particular bone specimen begins to increase, as, strontium is a higher $Z$ element than calcium and has a larger mass attenuation coefficient at all energies relevant to DXA scans. As such for a given degree of attenuation of the primary photons, if the mass attenuation of bone is not considered with the inclusion of strontium it will seem as if the bone attenuated more of the photons and thus has a higher BMD than is truly present.

Nielsen et al. ${ }^{13}$ have found that the percentage variation in $\operatorname{BMD}_{(a)}$ as a function of the mole fraction of strontium in bone relative to the mole fraction of calcium follows a positive linear function. As such, the correction model has been proposed

$$
\operatorname{BMD}(a d j)=\frac{\operatorname{BMD}(n)}{1+m C_{S r}},
$$

where $\operatorname{BMD}(a d j)$ is the adjusted, or true, $\mathrm{BMD}$ of the bone, $\operatorname{BMD}(n)$ is the true DXAdetermined BMD of the bone, $C_{S r}$ is the concentration of strontium in the bone and $m$ is the calibration factor determined on the DXA instrument relating the variation in BMD to 
strontium concentration.

The limiting factor here is the determination of $C_{S r}$ of which, to be done effectively clinically, should be estimated as non-invasively as possible. Although the problem of DXA correction is outlined here, bone strontium determinations are not limited to this problem alone. From a clinical viewpoint, uptake of the element in bone and modelling kinetics 9,10 is also of importance in which reliable concentration estimations are necessary, further necessitating in vivo methods of bone strontium assessment.

\subsection{X-ray fluorescence spectrometry}

A full description of the fundamentals of XRF calibration can be found elsewhere which is generally described in the context of flat infinitely thick samples. ${ }^{15-18} \mathrm{XRF}$, in a more general sense, is an analytical methodology which is based fundamentally on the measurement of characteristic X-rays emitted from an excited sample. XRF systems consist of a source which impinges on a sample. The source needs to emit radiation with sufficient energy as to cause photoelectric excitation of the elements in the specimen. When photoelectric excitation has occurred, the atoms relax and emit characteristic X-rays which can be detected using a photon detector. The intensity of these X-rays relate to the concentration of the element in the sample. The relationship between X-ray intensity and concentration is however not a simple relationship. The intensity becomes a complex function of the total sample matrix composition and as a result it is often necessary to be able to quantify the total composition of the sample. An exception to this general rule is one in which the sample composition is relatively constant and one wants to quantify a trace element. In this case, if the analyte composition does not change the mass attenuation coefficient of the sample significantly then the relationship with respect to composition is linear. This is a fundamental assumption in 
in vivo applications of XRF.

$\mathrm{X}$-ray fluorescence spectrometry (XRF) has been successfully applied to the measurement of various trace and minor elements of toxicological and epidemiological interest, namely lead, uranium and strontium, in the bone tissue of human subjects in vivo. ${ }^{19-23}$ Such measurements can be divided into two categories defined by the energy of the characteristic X-ray series measured; namely, those based on the detection of hard characteristic X-ray series, as is the case of the K-XRF measurement of bone lead and uranium, ${ }^{19,21-23}$ and those based on the use of soft characteristic X-rays series, as is the case of the L-XRF measurement of lead ${ }^{24,25}$ and the K-XRF measurement of strontium. ${ }^{26}$ The calibration of in vivo XRF systems of bone metal quantification has traditionally been, and remains, a challenge, largely due to the need for calibrators (phantoms) which are matched to the sample in regards to both composition and geometry.

It is well established - particularly in the context of soft X-ray-based XRF analysis common to conventional XRF spectrometry — that calibration should be performed against calibrators which match the overall composition of the sample matrix as closely as possible. ${ }^{15-18}$ Matrix matching of the calibrators being critical in order to account for the so-called "matrix effects" (absorption/attenuation and in some cases enhancement) which ultimately influence the observed characteristic X-ray intensities, and which form the basis of the Sherman equations and most calibration and quantification algorithms/protocols; ${ }^{15-18}$ if the aim is to estimate concentration values in relation to the mass of the matrix as a whole. The quantitative analysis of bone tissue for trace and minor elements by XRF is however complicated by the fact that the sample, bone, is variable ${ }^{27}$ in its composition and that the majority of the matrix is not measurable by XRF (a "dark matrix") and thus there is no way of knowing the total composition of the specimen as measured through XRF. This was a hindering fact 
at the early onset of in vivo XRF system development for bone lead determinations which required complicated calibration procedures. ${ }^{28,29}$

\subsection{Applications of XRF to the in vivo quantification of lead and strontium in bone}

From a historical standpoint, it can be argued that the earliest in vivo X-ray fluorescence spectrometry (IVXRF)-based system of bone metal quantification was developed for the quantification of bone lead in response to concerns of occupational exposure to the element. The system consisted of a ${ }^{57} \mathrm{Co}$ induced K-IVXRF system which is fully described by Ahlgren et al. ${ }^{28}$ and Ahlgren and Mattsson ${ }^{29}$. The system was originally designed alongside a calibration protocol which was intended to provide concentrations on the basis of total mass of bone.

The calibration of this IVXRF bone lead system was found to be complicated by several factors, including inter-subject variations in bone geometry and bone mineral concentration (i.e., gross bone composition). ${ }^{29}$ Proper calibration, and ultimately the estimation of bone lead concentrations, required that the bone size of the subject be determined via imaging at the measurement site. Phantoms (calibrators) were then either developed or sampled from a preexisting set composed of bone ash and silica wax to mimic both the bone size and the bone mineral concentration of the subject's bone. The estimation of the bone size and bone mineral content for each subject was estimated from the scattered source radiation (both coherently scattered radiation and incoherently scattered radiation) from the subject's IVXRF spectrum. ${ }^{29}$

Given these difficulties in IVXRF system calibration as determined by Ahlgren et al. ${ }^{28}$ 
and Ahlgren and Mattsson ${ }^{29}$, subsequently developed IVXRF-based methods of bone lead and strontium quantification ${ }^{30-34}$ were either hindered by the complete absence of a calibration procedure, or, employed calibration against bone specimens which had been previously assessed for their bone metal concentrations by secondary method of analysis (instead of the currently employed phantom sets). ${ }^{30-34}$ Such an approach resulted in limited concentration ranges included in the calibration and lacked a blank calibrator, which are both undesirable features of a robust and reliable calibration protocol. ${ }^{30-34}$

A major improvement to the K-IVXRF analysis of bone lead, and by extension to other elemental quantifications, was developed after the introduction of a ${ }^{109} \mathrm{Cd}$ source as a replacement for the ${ }^{57}$ Co source in the context of an IVXRF bone lead measurement. ${ }^{35}$

Somervaille et al. ${ }^{36}$ introduced a normalization procedure for the calibration of the ${ }^{109} \mathrm{Cd}-$ induced K-IVXRF system of bone lead quantification. This coherent normalization-based calibration procedure has become standard to IVXRF bone lead analysis and by extension to other IVXRF bone metal analyses-the normalization procedure being based on the coherently scattered ${ }^{109} \mathrm{Cd}$ source photon which has an energy equivalent to the K-edge of lead. In the context of an IVXRF bone lead measurement, it was found that the majority of the coherently scattered ${ }^{109} \mathrm{Cd} \gamma$-rays had origins from scattering events within the bone mineral (namely the calcium). ${ }^{36-38}$ By normalizing the characteristic X-ray intensity of the analyte to that of the coherently scattered ${ }^{109} \mathrm{Cd} \gamma$-ray intensity, various factors, including variations in source activity, source-to-detector distance, soft tissue thickness attenuation, variations in bone shape, size and orientation, subject bone mineral concentration, and minor subject movement during measurement were normalized out. ${ }^{36-38}$ This thus greatly simplified the in vivo quantification of bone lead as it removed the need for imaging and thus allowed for quantification based on spectroscopic data only. This method of calibration is however de- 
pendent on normalization to signal which is predominately originating from the bone mineral only. As a result, concentrations are quoted on a mass of analyte per mass of bone mineral basis. Although this method of calibration does not allow one to estimate the analyte concentration on a mass of bone basis, without a priori knowledge of the bone mineral content, concentrations quoted in this fashion are the most clinically relevant given that these bone seeking elements target the mineral phase of bone only. As such, coherent normalization also acts as a means of providing clinically relevant bone metal concentrations with one less step than previously reported (i.e. as per Ahlgren et al. ${ }^{28}$ and Ahlgren and Mattsson ${ }^{29}$ ).

Given that coherently scattered ${ }^{109} \mathrm{Cd} \gamma$-rays originate predominately in bone mineral, and more specifically predominately from calcium in the bone mineral, the use of single type calibrators (phantoms) are possible, since coherent normalization corrects for variations in bone geometry. These phantoms have traditionally been prepared from the commonly available plaster of Paris $\left(\mathrm{poP}, \mathrm{CaSO}_{4} \cdot \frac{1}{2} \mathrm{H}_{2} \mathrm{O}\right)$ doped with the analyte. Concentrations are estimated from a calibration function determined using the poP phantoms and applying a global-matrix correction to account for the different scattering properties between the phantom (calcium sulphate) and the bone mineral being measured (calcium phosphate).

The matrix correction factor, referred to as the coherent correction factor $(\mathrm{CCF})$, is simply the ratio of the relativistic form factors of both poP and bone mineral, assumed to be pure hydroxyapatite $\left[\mathrm{HAp}, \mathrm{Ca}_{5}\left(\mathrm{PO}_{4}\right)_{3} \mathrm{OH}\right] .{ }^{36,38}$ The $\mathrm{CCF}$ thus allows one to correct the determined analytical sensitivity for the difference in scattering properties largely between the sulphur and phosphorous which although not dominate scatterers, contribute to the intensity of the coherent peak.

Coherent normalization-based calibration has been quite successful in the context of ${ }^{109} \mathrm{Cd}$ induced K-IVXRF bone lead determinations as is apparent by the number of vali- 


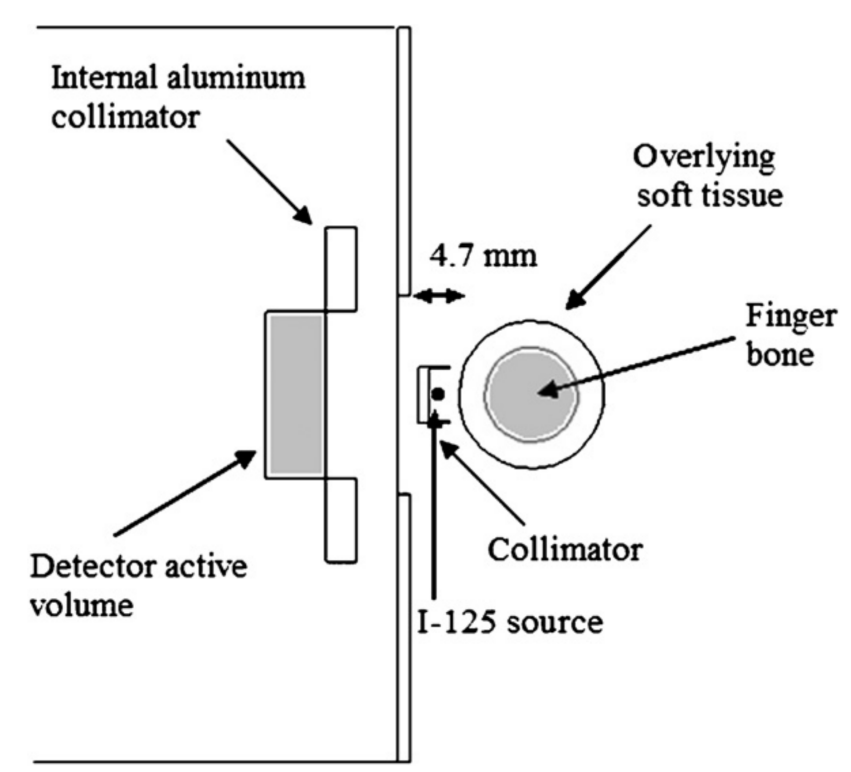

Figure 1.1: Schematic of the clinical in vivo XRF system of in vivo bone strontium quantification. Image taken from Zamburlini $2008^{47}$ and is the geometric arrangement used for all simulations in this work. The system consists of a $\mathrm{Si}(\mathrm{Li})$ detection system encased in an internal aluminum collimator. The external source collimator is composed of tungsten and houses an ${ }^{125}$ I source in the form of brachytherapy seeds, simulated here as a point source. The image is to scale. Photons that traverse the detector are scored. Simulated spectra can be considered emissions spectra.

dation studies. ${ }^{36,39-44}$ As a result, it has become the standard calibration procedure within the calibration protocol of most IVXRF-based systems for quantifying bone uranium, ${ }^{22,23}$ strontium, ${ }^{26,45-48}$ lead via L-IVXRF $24,25,49,50$ and ${ }^{57}$ Co-induced K-IVXRF. ${ }^{51}$

For IVXRF bone strontium measurements, the coherent normalization procedure developed for the K-IVXRF bone lead system, has been largely adapted with modifications including the use of poP-based calibrators/phantoms. From a system design viewpoint, work has been accomplished over the years as to identify a suitable source and system geometry for IVXRF bone strontium measurements. Given that the energy of the strontium K-series is in the $14-16 \mathrm{keV}$ range, the hyper-pure germanium (HPGe) detection system used for the K-IVXRF bone lead system has been replaced by a silicon-drifted lithium $[\mathrm{Si}(\mathrm{Li})]$ detection system more efficient at the detection of soft characteristic X-rays. The use of a $\mathrm{Si}(\mathrm{Li})$ de- 
tection system also allows one to avoid the presence of Ge escape peaks which overlap with the strontium K-series. ${ }^{20}$ Although initial work on source development in the context of an IVXRF bone strontium measurement focused on the application of a ${ }^{109} \mathrm{Cd}$ excitation source, which provides a sufficient fluence of silver X-rays next the K-edge of strontium for IVXRF bone strontium measurements, ${ }^{26}$ it was later identified that ${ }^{125} \mathrm{I}$ in the form of brachytherapy seeds acted as a more suitable source for the excitation of strontium in bone. ${ }^{20,45}{ }^{125} \mathrm{I}$ in the form of brachytherapy seeds produce an emission spectrum with an isolated $35.5 \mathrm{keV}$ $\gamma$-ray from ${ }^{125}$ I which may be useful for coherent normalization while also emitting a series of silver and tellurium X-rays (from the silver beads in the brachytherapy seeds and the decay of ${ }^{125} \mathrm{I}$ ) near the K-edge of strontium ensuring higher efficiency of strontium excitation. Geometrically, various source-sample arrangements have been evaluated, mainly, a $90^{\circ}$ geometry and a $180^{\circ}$ geometry. ${ }^{45}$ The evaluation of geometrical arrangements being made as a means of assessing possible background reduction by removal of background signal from Compton scattered source photons as well as allowing for ease and reproducibility in patient positioning.

Currently, the clinical system used for IVXRF-based bone strontium measurements is composed of a $\mathrm{Si}(\mathrm{Li})$ detection system with ${ }^{125} \mathrm{I}$ seeds as an excitation source positioned in a $180^{\circ}$ backscatter geometry (Figure 1.1). Measurements on this system are made for a period of 30 minutes, resulting in an effective dose to subjects within the range of (64$76) \times 10^{-6} \mathrm{mSv} .{ }^{46}$ Minimum detectable limits $(2 \sigma)$ have been reported on the order of $23 \mu \mathrm{g}$ $\mathrm{Sr} / \mathrm{g}$ Ca. ${ }^{46}$ This clinical system being used for human measurements. ${ }^{9,10,46}$ Quantification is still a limiting factor for this system of IVXRF bone strontium quantification. Coherent normalization (normalization of the strontium $\mathrm{K} \alpha \mathrm{X}$-ray to the coherently scattered ${ }^{125} \mathrm{I}$ $\gamma$-ray) has been evaluated through both simulation and in conjunction with human data and 
has shown that it is able to partially correct for factors such as bone size and geometry but is not a high fidelity normalization procedure. ${ }^{46,52}$ The major effect observed by applying the coherent normalization procedure is the reduction in the total measurement variance which allows one to make inter-subject comparisons of variations in bone strontium concentrations (apparent through normalized intensities), but not quantification. ${ }^{46}$ Coherent normalization and general quantification protocols still remain an area of investigation.

One of the limiting factors to the quantitative power of the in vivo bone strontium system is the lack of a suitable phantom/calibration material. Although the use of poP as a phantom material has been rather successful in the case of K-XRF bone lead quantification, several issues remain with its use. The coherent normalization procedure requires that a conversion factor be applied between the data obtained from humans in order to be comparable to calibration data acquired from poP phantoms (or vice versa) given the different scattering properties of the two materials. This correction factor is simply the ratio of the relativistic form factors for each of the two materials, a compositionally dependent factor, whereby bone mineral is assumed to be pure HAp and poP pure calcium sulphate hemihydrate. ${ }^{36,38}$ This is a feature of the calibration protocol currently used for the in vivo quantification of bone strontium. ${ }^{48}$ Concerns have arisen as to the accuracy of this correction factor given inherent contamination in the poP and given assumption to the phantom's true composition. ${ }^{38,53} \mathrm{~A}$ more severe issue with the use of poP phantoms, in the context of bone strontium quantification, is the extensive degree of contamination from the analyte itself. Strontium, being an ubiquitous element to calcium is present in calcium compounds, including poP, at levels which are near those expected in the bone of human subjects (several hundred parts per million); this is a fact which has been shown to be independent of the quoted degree of purity of calcium compounds. ${ }^{26}$ With such a high level of contamination from the analyte, no true 
blank can be produced limiting the ability to determine accurate analytical figures of merit for the system, and, this also limits calibration in the low strontium concentration range. ${ }^{20,26}$ It is thus desirable to have available a pure HAp phantom which can be used as a phantom material for the calibration of in vivo XRF-based systems of bone metal quantification. Such a material would allow for the proper determination of analytical figures of merit as well as possibly remove the need for the introduction of a phantom-bone conversion factor between the calibration and measurement. This work aims at first developing calibrators to attempt to remedy these issues while also evaluating the use of the blank phantom for the purpose of system background assessment.

In regards to analyte quantification, it is generally desirable that the concentration of the analyte is represented with respect to calcium, as is necessary for DXA correction (see section 1.2); however, there is no calcium signal due to soft tissue attenuation. ${ }^{26}$ The coherent normalization procedure does however normalize analyte concentrations to the amount of bone mineral, and by extension calcium, in the bone being measured, and thus is desirable in the case of extracting clinically relevant concentrations of strontium. ${ }^{20,36}$ The application of the coherent normalization procedure to in vivo bone strontium measurements using the ${ }^{125} \mathrm{I}$ induced system has shown that it is applicable yet with some limitations as it only provides a partial normalization when overlaying soft tissue is present. ${ }^{46-48,52}$ For this reason, this work only assessed the coherent normalization procedure in the context of a bare bone measurement to assess the HAp material's suitability for this purpose in contrast to poP-based calibrations. Soft tissue attenuation of the signal was ignored in this work as to ensure that the assessment was specific to calibration material and not to any other confounding factors affecting the analytical signal, namely, issues with soft tissue attenuation corrections. Although soft tissue attenuation was not considered in the simulation work here 
from a quantitative viewpoint, Compton-based methods of soft tissue thickness estimations, as first described by Nie et al. ${ }^{24}$ were evaluated in this work as a means of identifying a possible spectroscopic means of improving the coherent normalization procedure in future system developments. This work also further assessed portable X-ray analyzers for in vivo bone strontium and lead quantification on the basis of their analytical figures of merit. This assessment was completed in this work using the newly developed phantom material as a means of assessing new systems which may provide a more portable, rapid and inexpensive means of performing bone strontium and lead quantification in humans.

\subsection{Outline of dissertation}

The overall outline of this dissertation is as follows:

Chapter 2: This chapter describes the preparation of a hydroxyapatite phantom material which is chemically free of any interfering analyte concentration. This chapter presents, to the author's knowledge, the first description of the preparation of a bone mineral surrogate material which is free of analyte (namely strontium) contamination. The material being designed such that the final solid phantom material is free of the analyte, thus allowing one to prepare phantoms with a true blank as a means of performing a background assessment, as well as to determine analytical figures of merit properly. This chapter describes the preparation of the phantoms as well as their general chemical assessment.

Chapter 3: This chapter describes the preparation of phantoms which contain a high concentration of the analyte strontium, strontium being the only discernible analyte which would be present in bone mineral at concentrations which would reach the mole-percentage concentration levels. In this chapter, a phantom material is described and assessed which 
contains high concentrations of strontium and which is prepared using a tertiary mixture of salts as to maintain the $(\mathrm{Ca}+\mathrm{Sr}) / \mathrm{P}$ ratio at 1.67 . The high concentrations of strontium in these phantoms also allowed for an assessment of the chemical structure of the apatite which allowed for an assessment of the substitution behaviour of the analyte.

Chapter 4: This chapter demonstrates the necessity of the blank phantom prepared in chapter 2 in the context of an in vivo bone strontium measurement by XRF using the current clinical system. The need for this phantom in the context of a background assessment is discussed and described given excitation source and/or system contamination which has not be assessed in previous system developments.

Chapter 5: This chapter assesses the possible need for the phantoms described in chapter 3 , that is, phantoms with high concentrations. This particular work focuses on the assessment of non-linearity as a function of strontium concentrations while also assessing the possibility of analyte enhancement in the context of a bone lead measurement made using the lead Lseries. This chapter thus provides a critical step in the further development of quantification methodology as it assesses the need for phantoms of high strontium concentration while also assessing the possible reality that bone lead quantification (via the L-series) may need to be completed only with bone strontium quantification.

Chapter 6: This chapter uses Monte Carlo simulations as a means of assessing the quantification protocol used, namely that of coherent normalization, when the hydroxyapatite phantom material is used as the phantom material. It assesses the problem of calibration in the context of bare bone measurements as to remove the complexities associated with overlaying soft tissue thickness corrections. The aim of this chapter was to assess whether the phantom material developed in chapter 2 can be used for the direct measurement of 
the concentration of strontium in bone on a mass of analyte per mass of bone basis and also its effect on the quantification protocol in the context of coherent normalization-based calibration of a bare bone phantom.

Chapter 7: This chapter aimed at employing Monte Carlo simulations as a means of assessing a possible method of soft tissue thickness determination by using Compton scattered radiation (from the source) when employing poP as well as the HAp phantom material developed in chapter 2 in the context of an in vivo bone strontium measurement using the clinical ${ }^{125}$ I-induced K-XRF system. The aim of this chapter was to assess the compositional dependence of this method of soft tissue thickness determination and its possible suitability in the context of an in vivo bone strontium measurement.

Chapter 8: This chapter applied the new HAp phantom material in a system comparison study of portable X-ray analyzers potentially suitable for bone strontium measurements. The focus of this work was the assessment of these portable X-ray analyzers for possible future work in in vivo bone strontium and lead quantification using X-ray tube based spectrometers which would make the system much more portable than the current clinical system. This study also focused on a comparison on system performance as a function of X-ray tube target material selected as well as an assessment of performance as a function of measurement time. 


\section{References}

[1] S. P. Nielsen, "The biological role of strontium," Bone, vol. 35, no. 3, pp. 583-588, 2004.

[2] W. E. Cabrera, I. Schrooten, M. E. De Broe, and P. C. D'Haese, "Strontium and bone," Journal of Bone and Mineral Research, vol. 14, no. 5, pp. 661-668, 1999.

[3] P. J. Marie, P. Ammann, G. Boivin, and C. Rey, "Mechanisms of Action and Therapeutic Potential of Strontium in Bone," Calcified Tissue International, vol. 69, no. 3, pp. 121$129,2001$.

[4] P. J. Meunier, C. Roux, E. Seeman, S. Ortolani, J. E. Badurski, T. D. Spector, J. Cannata, A. Balogh, E.-M. Lemmel, S. P. Nielsen, R. Rizzoli, H. K. Genant, and J. Y. Reginster, "The Effects of Strontium Ranelate on the Risk of Vertebral Fracture in Women with Postmenopausal Osteoporosis," The New England Journal of Medicine, vol. 350, no. 5, pp. 459-468, 2004.

[5] J. L. Omdahl and H. F. DeLuca, "Strontium Induced Rickets: Metabolic Basis," Science, vol. 174 , no. 4012, pp. 949-951, 1971.

[6] S. Ozgür, H. Sümer, and G. Koçoğlu, "Rickets and soil strontium.," Archives of Disease in Childhood, vol. 75, no. 6, pp. 524-526, 1996.

[7] M. Cohen-Solal, "Strontium overload and toxicity: impact on renal osteodystrophy," Nephrology Dialysis Transplantation, vol. 17, no. Supp. 2, pp. 30-34, 2002.

[8] I. Schrooten, P. D’Haese, M. Elseviers, L. Lamberts, and M. De Broe, "Strontiuminduced osteomalacia: a new disease entity in patients with end stage renal failure in dialysis," Nephrology Dialysis Transplantation, vol. 13, no. 6, p. A188, 1998. 
[9] H. Moise, J. D. Adachi, D. R. Chettle, and A. Pejović-Milić, "Monitoring bone strontium levels of an osteoporotic subject due to self-administration of strontium citrate with a novel diagnostic tool, in vivo XRF: A case study," vol. 51, no. 1, pp. 93-97, 2012.

[10] H. Moise, D. R. Chettle, and A. Pejović-Milić, "Monitoring bone strontium intake in osteoporotic females self-supplementing with strontium citrate with a novel in-vivo Xray fluorescence based diagnostic tool," vol. 61, pp. 48-54, 2014.

[11] J. A. Kanis, L. J. Melton III, C. Christiansen, C. C. Johnston, and N. Khaltaev, "The Diagnosis of Osteoporosis," Journal of Bone and Mineral Research, vol. 9, no. 8, pp. 11371141, 1994.

[12] J. M. Kaufman, M. Audran, G. Bianchi, V. Braga, M. Diaz-Curiel, R. M. Francis, S. Goemaere, R. Josse, S. Palacios, J. D. Ringe, D. Felsenberg, and S. Boonen, "Efficacy and Safety of Strontium Ranelate in the Treatment of Osteoporosis in Men," Journal of Clinical Endocrinology and Metabolism, vol. 98, no. 2, pp. 592-601, 2013.

[13] S. P. Neilsen, D. Slosman, O. H. Sorensen, B. Basse-Cathalinat, P. De Cassin, C. Roux, and P. J. Meunier, "Influence of Strontium on Bone Mineral Density and Bone Mineral Content Measurements by Dual X-Ray Absorptiometry," Journal of Clinical Densitometry, vol. 2, no. 4, pp. 371-379, 1999.

[14] International Commission on Radiation Units \& Measurements, "5. X-ray Absorptiometry," Journal of the ICRU, Report 81, vol. 9, pp. 37-58, 2009.

[15] J. Sherman, "The theoretical derivation of fluorescent x-ray intensities from mixtures," Spectrochimica Acta, vol. 7, no. 5, pp. 283-306, 1955. 
[16] T. Shiraiwa and N. Fujino, "Theoretical calculation of fluorescent x-ray intensities in fluorescent x-ray spectrochemical analysis," Japanese Journal of Applied Physics, vol. 5, no. 10, pp. 886-899, 1966.

[17] J. E. Fernández, "XRF Intensity in the Frame of the Transport Theory," X-ray Spectrometry, vol. 18, no. 6, pp. 271-279, 1989.

[18] G. R. Lachance and F. Claisse, Quantitative X-ray Fluorescence Analysis: Theory and Application. Chichester: John Wiley \& Sons, 1995.

[19] D. R. Chettle, "Three decades of in vivo x-ray fluorescence of lead in bone," X-ray Spectrometry, vol. 34, no. 5, pp. 446-450, 2005.

[20] M. Zamburlini, A. Pejović-Milić, and D. R. Chettle, "Spectrometry methods for in vivo bone strontium measurements," X-ray Spectrometry, vol. 37, no. 1, pp. 42-50, 2008.

[21] D. R. Chettle, "In vivo applications of X-ray fluorescence in human subjects," Pramana-Journal of Physics, vol. 76, no. 2, pp. 249-259, 2011.

[22] J. M. O'Meara, D. R. Chettle, F. E. McNeill, and C. E. Webber, "The feasibility of measuring bone uranium concentrations in vivo using source excited K x-ray fluorescence," Physics in Medicine and Biology, vol. 42, no. 6, pp. 1109-1120, 1997.

[23] J. M. O’Meara, D. R. Chettle, F. E. McNeill, and C. E. Webber, "In Vivo X-ray Fluorescence (XRF) Measurement of Uranium in Bone," Applied Radiation 83 Isotopes, vol. 49, no. 5-6, pp. 713-715, 1998.

[24] L. H. Nie, S. Sanchez, K. Newton, L. Grodzins, R. O. Cleveland, and M. G. Weisskopf, "In vivo quantification of lead in bone with a portable x-ray fluorescence system- 
methodology and feasibility," Physics in Medicine and Biology, vol. 56, no. 3, pp. N39N51, 2011.

[25] D. E. B. Fleming, M. R. Gherase, and K. M. Alexander, "A miniature X-ray tube approach to measuring lead in bone using L-XRF," X-ray Spectrometry, vol. 40, no. 5, pp. 343-347, 2011.

[26] A. Pejović-Milić, I. M. Stronach, J. Gyorffy, C. E. Webber, and D. R. Chettle, "Quantification of bone strontium levels in humans by in vivo x-ray fluorescence," Medical Physics, vol. 31, no. 3, pp. 528-538, 2004.

[27] H. Smith, ed., ICRP Publication 70, Basic Anatomical and Physiological Data for use in Radiological Protection: The Skeleton. Oxford: Pergamon, 1995.

[28] L. Ahlgren, K. Lidén, S. Mattsson, and S. Tejning, "X-ray fluorescence analysis of lead in human skeleton in vivo," Scandinavian Journal of Work 83 Environmental Health, vol. 2, no. 2, pp. 82-86, 1976.

[29] L. Ahlgren and S. Mattsson, "An X-ray Fluorescence Technique for in vivo Determination of Lead Concentration in a Bone Matrix," Physics in Medicine and Biology, vol. 24, no. 1, pp. 136-145, 1979.

[30] L. Wielopolski, D. N. Slatkin, D. Vartsky, K. J. Ellis, and S. H. Cohn, "Feasibility study for the in vivo measurement of lead in bone using L-X-ray fluorescence," IEEE Transactions on Nuclear Science, vol. NS-28, no. 1, pp. 114-116, 1981.

[31] L. Wielopolski, J. F. Rosen, D. N. Slatkin, D. Vartsky, K. J. Ellis, and S. H. Cohn, "Feasibility of noninvasive analysis of lead in human tibia by soft x-ray fluorescence," Medical Physics, vol. 10, no. 2, pp. 248-251, 1983. 
[32] L. Wielopolski, D. Vartsky, S. Yasumura, and S. H. Cohn, "Application of XRF to Measure Strontium in Human Bone In Vivo," Advances in X-ray Analysis, vol. 26, pp. $415-421,1983$.

[33] R. E. Snyder and D. C. Secord, "The in situ measurement of strontium content in bone using x-ray fluorescence analysis," Physics in Medicine and Biology, vol. 27, no. 4, pp. 515-529, 1982.

[34] L. Wielopolski, J. F. Rosen, D. N. Slatkin, R. Zhang, J. A. Kalef-Ezra, J. C. Rothman, M. Maryanski, and S. T. Jenks, "In vivo mesurement of cortical bone lead using polarized x rays," Medical Physics, vol. 16, no. 4, pp. 521-528, 1989.

[35] E. E. Laird, D. R. Chettle, and M. C. Scott, "The factors affecting in vivo x-ray fluorescence measurements of lead in bone," Nuclear Instruments and Methods, vol. 193, no. 1-2, pp. 377-382, 1982.

[36] L. J. Somervaille, D. R. Chettle, and M. C. Scott, "In vivo measurement of lead in bone using x-ray fluorescence," Physics in Medicine and Biology, vol. 30, no. 9, pp. 929-943, 1985.

[37] D. R. Chettle, M. C. Scott, and L. J. Somervaille, "Lead in Bone: Sampling and Quantitation Using K X-rays Excited by ${ }^{109} \mathrm{Cd}$," Environmental Health Perspectives, vol. 91, pp. 49-55, 1991.

[38] A. C. Todd, "Coherent scattering and matrix correction in bone-lead measurements," Physics in Medicine and Biology, vol. 45, no. 7, pp. 1953-1963, 2000.

[39] L. J. Somervaille, U. Nilsson, D. R. Chettle, I. Tell, M. C. Scott, A. Schütz, S. Mattsson, and S. Skerfving, "In vivo measurements of bone lead-a comparison of two x-ray fluo- 
rescence techniques used at three different bone sites," Physics in Medicine and Biology, vol. 34, no. 12 , pp. 1833-1845, 1989.

[40] J. A. Hoppin, A. C. A. Aro, P. L. Williams, H. Hu, and P. B. Ryan, "Validation of K-XRF Bone Lead Measurement in Young Adults," Environmental Health Perspectives, vol. 103, no. 1, pp. 78-83, 1995.

[41] A. Aro, C. Amarasiriwardena, M.-L. Lee, R. Kim, and H. Hu, "Validation of K x-ray fluorescence bone lead measurements by inductively coupled plasma mass spectrometry in cadaver legs," Medical Physics, vol. 27, no. 1, pp. 119-123, 2000.

[42] A. C. Todd, E. L. Moshier, S. Carroll, and S. W. Casteel, "Validation of X-Ray Fluorescence-Measured Swine Femur Lead Against Atomic Absorption Spectrometry," Environmental Health Perspectives, vol. 109, no. 11, pp. 1115-1119, 2001.

[43] A. C. Todd, P. J. Parsons, S. Carroll, C. Geraghty, F. A. Khan, S. Tang, and E. L. Moshier, "Measurements of lead in human tibiae. A comparison between K-shell x-ray fluorescence and electrothermal atomic absorption spectrometry," Physics in Medicine and Biology, vol. 47, no. 4, pp. 673-687, 2002.

[44] D. J. Bellis, A. C. Todd, and P. J. Parsons, "An interlaboratory comparison of bone lead measurements via $\mathrm{K}$-shell $\mathrm{X}$-ray fluorescence spectrometry: validation against inductively coupled plasma mass spectrometry," Journal of Analytical Atomic Spectrometry, vol. 27 , no. 4 , pp. 595-603, 2012.

[45] M. Zamburlini, A. Pejović-Milić, and D. R. Chettle, "Evaluation of geometries appropriate for ${ }^{125} \mathrm{I}$ in vivo bone strontium X-ray fluorescence measurement," Journal of Radioanalytical \&3 Nuclear Chemistry, vol. 269, no. 3, pp. 625-629, 2006. 
[46] M. Zamburlini, A. Pejović-Milić, D. R. Chettle, C. E. Webber, and J. Gyorffy, "In vivo study of an x-ray fluorescence system to detect bone strontium non-invasively," Physics in Medicine and Biology, vol. 52, no. 8, pp. 2107-2122, 2007.

[47] M. Zamburlini, A. Pejović-Milić, and D. R. Chettle, "Coherent normalization of finger strontium XRF measurements: feasibility and limitations," Physics in Medicine and Biology, vol. 53, no. 15, pp. N307-N313, 2008.

[48] C. M. Heirwegh, D. R. Chettle, and A. Pejović-Milić, "Ex vivo evaluation of a coherent normalization procedure to quantify in vivo finger strontium XRS measurements," Medical Physics, vol. 39, no. 2, pp. 832-841, 2012.

[49] A. C. Todd, "L-shell x-ray fluorescence measurements of lead in bone: system development," Physics in Medicine and Biology, vol. 47, no. 3, pp. 507-522, 2002.

[50] A. C. Todd, S. Carroll, C. Geraghty, F. A. Khan, E. L. Moshier, S. Tang, and P. J. Parsons, "L-shell x-ray fluorescence measurements of lead in bone: accuracy and precision," Physics in Medicine and Biology, vol. 47, no. 8, pp. 1399-1419, 2002.

[51] J. M. O'Meara, J. Börjesson, D. R. Chettle, and S. Mattsson, "Normalisation with coherent scatter signal: improvements in the calibration protocol of the ${ }^{57} \mathrm{Co}$-based in vivo XRF bone-Pb measurement," Applied Radiation 83 Isotopes, vol. 54, no. 2, pp. 319$325,2001$.

[52] M. Zamburlini, S. H. Byun, A. Pejović-Milić, W. V. Prestwich, and D. R. Chettle, "Evaluation of MCNP5 and EGS4 for the simulation of in vivo strontium XRF measurements," X-ray Spectrometry, vol. 36, no. 2, pp. 76-81, 2007. 
[53] A. C. Todd, "Contamination of in vivo bone-lead measurements," Physics in Medicine and Biology, vol. 45, no. 1, pp. 229-240, 2000. 
CHAPTER

TWO

\section{A PROPOSED MATRIX REFERENCE MATERIAL FOR X-RAY FLUORESCENCE SYSTEMS OF BONE METAL QUANTIFICATION}

Published in, and adapted (to Canadian English) with permission from: E. Da Silva, B. Kirkham, D. V. Heyd and A. Pejović-Milić, "Pure Hydroxyapatite Phantoms for the Calibration of in Vivo X-ray Fluorescence Systems of Bone Lead and Strontium Quantification," Analytical Chemistry, vol. 85, no. 19, pp. 9189-9195, 2013. http://dx.doi.org/10.1021/ac401877dDOI: 10.1021/ac401877d. Copyright (C) 2013 American Chemical Society. ${ }^{\dagger}$

\footnotetext{
${ }^{\dagger}$ E. Da Silva designed and carried out the experiments, performed the data analysis and wrote this manuscript/chapter. B. Kirkham provided assistance in the replication of the experiments herein, as a confirmatory step, and aided with the development of the curve fitting algorithm used for the data extraction necessary to produce Figure 2.5. B. Kirkham read the manuscript/chapter and provided critical feedback. D. V. Heyd provided advice throughout the course of this work and assessed the manuscript/chapter critically. A. Pejović-Milić identified the need for the clean phantom material as a means of further developing the in vivo bone strontium system, financed this project, provided critical feedback as to its contents and the experiments and assessed the manuscript/chapter critically.
} 


\section{$2.1 \quad$ Abstract}

Plaster of Paris (poP, $\mathrm{CaSO}_{4} \cdot \frac{1}{2} \mathrm{H}_{2} \mathrm{O}$ ) is the standard phantom material used for the calibration of in vivo X-ray fluorescence (IVXRF)-based systems of bone metal quantification (i.e bone strontium and lead). Calibration of IVXRF systems of bone metal quantification employs the use of a coherent normalization procedure which requires the application of a coherent correction factor $(\mathrm{CCF})$ to the data, calculated as the ratio of the relativistic form factors of the phantom material and bone mineral. Various issues have been raised as to the suitability of poP for the calibration of IVXRF systems of bone metal quantification which include its chemical purity and its chemical difference from bone mineral (a calcium phosphate). This work describes the preparation of a chemically pure hydroxyapatite phantom material, of known composition and stoichiometry, proposed for the purpose of calibrating IVXRF systems of bone strontium and lead quantification as a replacement for poP. The issue with contamination by the analyte was resolved by preparing pure $\mathrm{Ca}(\mathrm{OH})_{2}$ by hydroxide precipitation which was found to bring strontium and lead levels to $<0.7$ and $<0.3 \mu \mathrm{g} / \mathrm{g}$ Ca, respectively. HAp phantoms were prepared from known quantities of chemical pure $\mathrm{Ca}(\mathrm{OH})_{2}, \mathrm{CaHPO}_{4} \cdot 2 \mathrm{H}_{2} \mathrm{O}$ prepared from pure $\mathrm{Ca}(\mathrm{OH})_{2}$, the analyte and a $\mathrm{HPO}_{4}^{2-}$ containing setting solution. The final crystal structure of the material was found to be similar to that of the bone mineral component of NIST SRM 1486 (bone meal) as determined by XRD.

\subsection{Introduction}

Human bone is used as a biomarker of cumulative exposure to various elements including lead and strontium. In vivo X-ray fluorescence spectrometry (IVXRF) is an analytical methodology which allows one to quantify the concentration of such elements in bone non- 
destructively and with minimal radiation dose to the subject. IVXRF-based bone metal quantification has traditionally been complicated by the complex nature of the analyte's characteristic X-ray intensity which influences the calibration protocol. By extension, a major hindrance to the calibration of IVXRF systems of bone metal quantification is the availability of suitable calibrators, otherwise and hereby referred to as phantoms, to be used for the purpose of system calibration.

The earliest IVXRF-based system of bone metal quantification is the ${ }^{57} \mathrm{Co}$ induced KIVXRF system described by Ahlgren et al. ${ }^{1}$ and Ahlgren and Mattsson ${ }^{2}$ designed for the purpose of determining absolute bone lead concentrations in the finger bone of human subjects. Calibration and reliable concentration extraction from the IVXRF spectrum were hindered by various factors, including inter-subject variations in bone geometry and bone mineral concentration (i.e., gross bone composition). ${ }^{2}$ Calibration thus required that the bone size of the subject be determined by the acquisition of a series of orthoplanar X-rays of the measurement site and phantoms developed from bone ash and silica wax to mimic both the bone size and the bone mineral concentration of the subject's bone, estimated from the scattered source radiation. ${ }^{2}$ In subsequently investigated IVXRF-based methods of bone lead and strontium quantification, because of such challenges, it was necessary to resort either to the complete absence of a calibration procedure or to a calibration procedure based on the measurement of bone specimens which had been cross validated for their bone metal concentrations by a secondary method of analysis. ${ }^{3-7}$ Such an approach resulted in limited concentration ranges included in the calibration and lacked a true blank calibrator. ${ }^{3-7}$

A major improvement to the K-IVXRF analysis of bone lead was the introduction of a ${ }^{109} \mathrm{Cd}$ source as a replacement for the ${ }^{57} \mathrm{Co}$ source. ${ }^{8}$ After this major development, Somervaille et al. ${ }^{9}$ introduced a normalization procedure to the calibration protocol of the ${ }^{109} \mathrm{Cd}-$ 
induced K-IVXRF system of bone lead quantification which has become standard to IVXRF bone lead analysis and by extension to other IVXRF bone metal analyses. It was found that the majority of the coherently scattered ${ }^{109} \mathrm{Cd} \gamma$-rays had origins from scattering events within the bone mineral. ${ }^{9-11}$ By normalizing the characteristic X-ray intensity to that of the coherently scattered source radiation intensity, it became possible to determine the quantity of lead per unit mass of bone mineral. This normalization procedure corrected the observed response for various factors, including variations in source activity, source-to-detector distance, soft tissue thickness and associated signal attenuation, variations in bone shape, size and orientation, subject bone mineral concentration, and minor subject movement during measurement. ${ }^{9-11}$

The fact that coherent scattered ${ }^{109} \mathrm{Cd} \gamma$-rays originate predominately in bone mineral allows for the introduction of calibrators consisting of plaster of Paris (poP, $\mathrm{CaSO}_{4} \cdot \frac{1}{2} \mathrm{H}_{2} \mathrm{O}$ ) doped with the analyte. Concentrations are extracted from an in vivo measurement by extrapolation after applying a pseudo-matrix correction to account for the different scattering properties between the phantom (predominately a calcium sulfate) and the bone mineral being measured (predominately a calcium phosphate). The matrix correction factor is simply the ratio of the relativistic form factors of both poP and bone mineral, assumed to be pure hydroxyapatite $\left[\mathrm{HAp}, \mathrm{Ca}_{10}\left(\mathrm{PO}_{4}\right)_{6}(\mathrm{OH})_{2}\right]$; the correction factor itself is referred to as the coherent conversion factor $(\mathrm{CCF}) .{ }^{9,11}$ The success of coherent normalization-based calibration in the context of bone lead quantification by ${ }^{109} \mathrm{Cd}$ induced K-IVXRF ${ }^{9,12-17}$ has resulted in it becoming the most utilized normalization procedure within the calibration protocol of IVXRF-based systems for quantifying bone uranium, ${ }^{18,19}$ strontium, ${ }^{20-24}$ lead via L-IVXRF ${ }^{25-28}$ and ${ }^{57}$ Co-induced K-IVXRF. ${ }^{29}$

The use of poP as the phantom material raises some concerns about its purity and 
chemical composition in comparison to the matrix being measured. In the case of bone lead analysis, contamination in the poP used for the preparation of phantoms has been insinuated as a problem due to assumptions of the purity of the material when computing the CCF. ${ }^{11,30}$ It has been proposed that the level of contamination may influence the reliability of the applied CCF given that poP used for phantom preparation is generally not pure poP and does present some contamination, which is not necessarily accounted for. ${ }^{11,30}$

The problem with contamination in poP is much more severe in the case of in vivo bone strontium analysis. ${ }^{20,30}$ Strontium, being a ubiquitous element to calcium, is generally present in calcium compounds at levels which are near those of the levels expected in human bone. This is a feature which is independent of the quoted degree of purity of calcium compounds. ${ }^{20,31}$ The fact that strontium is present in poP at high concentrations does not allow for the development of a proper calibration procedure. Strontium contamination does not allow for the preparation of a blank phantom, making the true analytical figures of merit of the system difficult to determine. ${ }^{31}$

The chemical difference between the poP, a calcium sulfate [albeit also containing other species of calcium ${ }^{11,30}$, and bone mineral, a calcium phosphate, also presents some general concerns. The application of a CCF inherently introduces some uncertainty in the quantification while the chemical difference between the two materials, in the context of ${ }^{109} \mathrm{Cd}$ induced K-IVXRF bone lead measurements, results in different high-energy tails from the Compton scattering profile for calcium, sulfur and phosphorous. ${ }^{32-35}$ As such, having a phantom material composed of a calcium sulfate and a sample of calcium phosphate results in different spectral features, which require different data analysis procedures. It is desirable to have a phantom material that mimics bone mineral (HAp) as closely as possible while also being chemically pure. This chapter describes a simple method of preparing pure HAp 
phantoms as a more suitable phantom material for bone strontium and lead quantification using IVXRF.

\subsection{Experimental}

\subsubsection{Preparation of pure calcium compounds}

All of the reagents used for the preparation of phantoms and/or the purification of calcium were assessed for purity by total reflection X-ray fluorescence spectrometry (TXRF). These reagents included calcium chloride dihydrate $\left(\mathrm{CaCl}_{2} \cdot 2 \mathrm{H}_{2} \mathrm{O}, 99.0 \%+\right.$, Sigma-Aldrich, St. Louis, MO, USA), calcium hydrogen phosphate dihydrate $\left(\mathrm{CaHPO}_{4} \cdot 2 \mathrm{H}_{2} \mathrm{O}\right.$, USP grade, Amresco, Solon, OH, USA), calcium hydroxide $\left[\mathrm{Ca}(\mathrm{OH})_{2}\right.$, USP grade, Amresco, Solon, OH, USA], sodium hydroxide ( $\mathrm{NaOH}$, ACS grade, BMD, West Chester, PA, USA), sodium hydrogen phosphate anhydrous $\left(\mathrm{Na}_{2} \mathrm{HPO}_{4}\right.$, ACS grade, Amresco, Solon, OH, USA), sodium phosphate monobasic monohydrate $\left(\mathrm{NaH}_{2} \mathrm{PO}_{4} \cdot \mathrm{H}_{2} \mathrm{O}\right.$, ACS grade, BMD, West Chester, PA, USA), metal grade $\mathrm{HNO}_{3}$ (69.0-70.0\%; EMD Millipore, VWR Scientific, Mississauga, ON, Canada) and $18.2 \mathrm{M} \Omega \cdot \mathrm{cm}$ water drawn from a milli- $\mathrm{Q}^{\mathrm{TM}}$ system.

Low strontium $\mathrm{Ca}(\mathrm{OH})_{2}$ was prepared via a method similar to that described by Patti and Hernandez. ${ }^{36}$ A $2 \mathrm{~mol} / \mathrm{dm}^{3}$ aqueous solution of $\mathrm{Ca}^{2+}$ was prepared from $\mathrm{CaCl}_{2} \cdot 2 \mathrm{H}_{2} \mathrm{O}$. An aqueous solution of $\mathrm{NaOH}$, made to the appropriate concentration, was then added to the $\mathrm{Ca}^{2+}$ solution to precipitate $\mathrm{Ca}(\mathrm{OH})_{2}$. The solutions were mixed such that the final total calcium concentration in the solution was $1 \mathrm{~mol} / \mathrm{dm}^{3}$. The precipitate was allowed to age in the mother liqueur for a period of $2 \mathrm{~h}$ prior to recovery by vacuum-assisted filtration over an ashless Watman filter paper (\#512) with several washings of water. The $\mathrm{Ca}(\mathrm{OH})_{2}$ was dried at $110^{\circ} \mathrm{C}$ in a conventional gravity drying oven for a period of $6 \mathrm{~h}$. The dried 
$\mathrm{Ca}(\mathrm{OH})_{2}$ was milled to a fine powder in a tungsten carbide ball mill at a frequency of $30 \mathrm{~Hz}$ for a total milling time of 20 min prior to use. The $\mathrm{Ca}(\mathrm{OH})_{2}$ was assessed for purity by TXRF and energy dispersive X-ray fluorescence spectrometry (EDXRF) and the crystal phase confirmed by powder X-ray diffraction spectrometry (XRD).

Low strontium $\mathrm{CaHPO}_{4} \cdot 2 \mathrm{H}_{2} \mathrm{O}$ was prepared from the low strontium $\mathrm{Ca}(\mathrm{OH})_{2}$. A slurry was prepared from a suitable mass of $\mathrm{Ca}(\mathrm{OH})_{2}$ in water. The $\mathrm{Ca}(\mathrm{OH})_{2}$ was dissolved by the slow drop-wise addition of a $1 \mathrm{~mol} / \mathrm{dm}^{3}$ aqueous solution of $\mathrm{HNO}_{3}$. The aqueous solution was brought to a $\mathrm{Ca}^{2+}$ concentration of $0.14 \mathrm{~mol} / \mathrm{dm}^{3}$ and adjusted to a $\mathrm{pH}$ of 6.9 by the dropwise addition of a $0.05 \mathrm{~mol} / \mathrm{dm}^{3}$ aqueous solution of $\mathrm{NaOH}$ (if required). A second aqueous solution containing $0.030 \mathrm{~mol} / \mathrm{dm}^{3} \mathrm{Na}_{2} \mathrm{HPO}_{4}$ and $0.008 \mathrm{~mol} / \mathrm{dm}^{3} \mathrm{NaH}_{2} \mathrm{PO}_{4} \cdot \mathrm{H}_{2} \mathrm{O}$ was prepared. The solutions were prepared such that the the mole ratio between the calcium ion and both phosphoric acid anions combined was 1:1. The solution containing the phosphoric acid anions was quickly added to the calcium-containing solution, and the solution stirred vigorously for a period of $2 \mathrm{~h}$. The $\mathrm{CaHPO}_{4} \cdot 2 \mathrm{H}_{2} \mathrm{O}$ was then recovered by vacuum-assisted filtration over an ashless Watman filter paper (\#512) with several washings of water. The $\mathrm{CaHPO}_{4} \cdot 2 \mathrm{H}_{2} \mathrm{O}$ was dried at $110^{\circ} \mathrm{C}$ for a period of $6 \mathrm{~h}$ prior to characterization by TXRF and XRD.

\subsubsection{Preparation of hydroxyapatite phantoms}

Phantoms were prepared by mixing a suitable amount of dry $\mathrm{CaHPO}_{4} \cdot 2 \mathrm{H}_{2} \mathrm{O}$ and $\mathrm{Ca}(\mathrm{OH})_{2}$ in order to achieve a $1.67 \mathrm{Ca} / \mathrm{P}$ mole ratio; the $\mathrm{Ca} / \mathrm{P}$ mole ratio of $\mathrm{HAp}$. The powders were weighed to the nearest $0.01 \mathrm{mg}$ on an analytical balance calibrated against a $200.0000 \mathrm{~g}$ internal calibration mass (GR-202, A\&D Company Ltd., Tokyo, Japan). The powders were dry mixed by rotation in an acid washed polypropylene container in which the powders did 
not occupy more than $10 \%$ of the total volume. The phantoms were set by adding them to a $1 \mathrm{~mol} / \mathrm{dm}^{3}$ solution of $\mathrm{NaHPO}_{4}$ at a powder-to-liquid mass ratio of $2: 1$, followed by thorough mixing for a period of ca. 1 min and transfer of the paste to suitable molds. The molds used for the preparation of phantoms in this study consisted of Mylar XRF sample cups with a $10 \mathrm{~mm}$ diameter aperture and a height of $25.1 \mathrm{~mm}$ (Chemplex Industries, Palm City, FL, USA) sealed at one end with $4 \mu \mathrm{m}$ thick Prolene (Chemplex Industries, Palm City, FL, USA). The phantoms were allowed to set for $24 \mathrm{~h}$ at $100 \%$ humidity, were unmoulded, and were allowed to cure for an additional $24 \mathrm{~h}$ at $100 \%$ humidity. The phantoms were set under ambient conditions for 7 days until they reached constant weight. After a further 7 days stored under ambient conditions, the phantoms were dried in a drying oven at $105^{\circ} \mathrm{C}$ for $24 \mathrm{~h}$, resulting in the final phantom. The crystal phase of the phantom material was assessed by XRD and compared to the crystal phase of bone mineral against NIST bone meal (SRM 1486; National Institute of Standards and Technology, Gaithersburg, MD, USA). The density of the phantom material was determined via Archimedes' method in water.

The addition of the analyte was performed gravimetrically by adding, to the nearest $0.01 \mathrm{mg}$, a suitable amount of a NIST traceable $1000 \mathrm{ppm}$ inductively coupled plasma atomic emission spectrometry standard solution of the analyte of interest (ULTRAScientific, N. Kingstown, RI, USA). The analyte solution was added to the $1 \mathrm{~mol} / \mathrm{dm}^{3} \mathrm{NaHPO}_{4}$ setting solution, which resulted in the formation of a fine and well-dispersed precipitate. The powders were added immediately to the analyte-containing setting solution and the phantom prepared as described previously. Standard curves were prepared and measured by EDXRF. 


\subsubsection{Total reflection X-ray fluorescence spectrometry}

High-purity quartz reflectors were used as the sample carriers (Bruker-AXS, Madison, WI, USA). The reflectors were cleaned by placing them into a $2 \% \mathrm{RBS}^{\mathrm{TM}} 50$ (Sigma-Aldrich, Oakville, ON, Canada) solution prepared with milli-Q water and microwaving at full power for a period of $10 \mathrm{~min}$. The reflectors were removed from the $2 \% \mathrm{RBS}^{\mathrm{TM}} 50$ solution and thoroughly rinsed with water. The reflectors were rinsed in acetone, allowed to dry, and the $\mathrm{RBS}^{\mathrm{TM}} 50$ wash repeated with a $1 \% \mathrm{RBS}^{\mathrm{TM}} 50$ solution followed by rinsing in water. The reflectors were then treated, for a period of $3 \mathrm{~h}$, in a $10 \% \mathrm{HNO}_{3}$ solution. The $\mathrm{HNO}_{3}$ bath was maintained at $80^{\circ} \mathrm{C}$ using a conventional hot plate during this cleaning phase. After rinsing with water, the reflectors were microwaved for a further $10 \mathrm{~min}$ in water and dried in a drying oven at $85^{\circ} \mathrm{C}$ for $45 \mathrm{~min}$. All reflectors were checked for contamination at this stage by collecting a spectrum for $3600 \mathrm{~s}$ live time.

TXRF measurements were performed on an S2 PicoFox ${ }^{\top M}$ spectrometer (Bruker-AXS, Madison, WI, USA). The source photons consisted of monochromatic $17.5 \mathrm{keV}$ X-rays produced from a molybdenum target X-ray tube operating at $50 \mathrm{kV}$ and $600 \mu \mathrm{A}$. The X-ray tube was focused such that the spot size on the sample was approximately $(50 \times 50) \mu \mathrm{m}^{2}$. Photon detection was performed using a silicon drift detector (SDD) with a total area of $30 \mathrm{~mm}^{2}$ positioned approximately $2 \mathrm{~mm}$ from the sample carrier surface. Signal processing was performed on a 4096 channel 12 bit analogue-to-digital converter (ADC). The detection system had an energy resolution of $155 \mathrm{eV}$, as measured through the Mn K $\alpha$ line at ca. 10 kcps. Prior to all analyses, the detector gain was checked and adjusted using a $1 \mu \mathrm{g}$ arsenic standard (Bruker-AXS, Madison, WI, USA). The sensitivity of the system for all elements was determined using a $1 \mathrm{ng} \mathrm{Ni}$ standard (Bruker-AXS, Madison, WI, USA). The sensitivity for $\mathrm{Ni}$ was then used as a means of calculating the theoretical sensitivities for all elements and for 
the relevant X-ray series. These sensitivity factors were used for the calculation of the total mass of a given element present within the spot size of the instrument. The quantification method was checked using a $1 \mu \mathrm{L}$ deposition of a $1 \mu \mathrm{g} / \mathrm{mL}$ multielemental standard (Bernd Kraft GmbH, Germany).

Quantification was performed by digesting ca. $50 \mathrm{mg}$ of sample in $250 \mu \mathrm{L}$ of $\mathrm{HNO}_{3}$ for a period of $1 \mathrm{~h}$. The solutions were brought to a volume of $1 \mathrm{~mL}$ with water and $1 \mu \mathrm{L}$ of the digest deposited and dried onto the surface of the quartz reflector. Measurements were performed for a period of $3600 \mathrm{sec}$ live time. Quantification was performed relative to the mass of calcium in the compounds and was performed with the accompanying SPECTRA software package. The spectra were fit using a Bayes fitting procedure and the relative quantification performed using the sensitivity factors calculated from the Ni standard. The method was validated against NIST bone ash (SRM 1400; National Institute of Standards and Technology, Gaithersburg, MD, USA).

\subsubsection{Energy dispersive X-ray fluorescence spectrometry}

All EDXRF measurements were performed on an S2 Ranger ${ }^{T M}$ spectrometer equipped with a $\mathrm{Pd}$ anode X-ray tube and an SDD detection system positioned with an incident angle of $45^{\circ}$ and a take-off angle of $45^{\circ}$ (Bruker-AXS, Madison, WI, USA). The X-ray tube was operated with a potential of $40 \mathrm{kV}$ and current of $250 \mu \mathrm{A}$ and the distribution hardened using a $500 \mu \mathrm{m}$ Al filter. Measurements were made for $1200 \mathrm{~s}$ live time. Total integrated peak areas of the characteristic X-rays of interest were determined using an in-house trust-region reflective least-squares curve-fitting algorithm. 
Table 2.1: Validation of the TXRF method used for the quantification of contaminants in calcium compounds using NIST bone ash (SRM 1400). ${ }^{\S}$

\begin{tabular}{|c|c|c|c|c|c|}
\hline & \multicolumn{2}{|c|}{ certified } & \multirow{2}{*}{$\begin{array}{c}\text { determined } \\
\mu \mathrm{g} / \mathrm{g} \mathrm{Ca}\end{array}$} & \multirow[b]{2}{*}{ recovery $(\%)$} & \multirow[b]{2}{*}{$p$} \\
\hline & $\mu \mathrm{g} / \mathrm{g}$ & $\mu \mathrm{g} / \mathrm{g} \mathrm{Ca}$ & & & \\
\hline $\mathrm{Fe}$ & $660 \pm 27$ & $1729 \pm 71$ & $1601 \pm 335$ & 93 & 0.32 \\
\hline $\mathrm{Zn}$ & $181 \pm 3$ & $474 \pm 8$ & $630 \pm 43$ & 133 & 0.04 \\
\hline $\mathrm{Sr}$ & $249 \pm 7$ & $652 \pm 18$ & $695 \pm 32$ & 107 & 0.20 \\
\hline $\mathrm{Pb}$ & $9.07 \pm 0.12$ & $23.8 \pm 0.3$ & $26 \pm 1$ & 111 & 0.11 \\
\hline
\end{tabular}

\subsubsection{Powder X-ray diffraction spectrometry}

The crystal phase of the prepared $\mathrm{Ca}(\mathrm{OH})_{2}, \mathrm{CaHPO}_{4} \cdot 2 \mathrm{H}_{2} \mathrm{O}$, phantoms and NIST bone meal were assessed by powder X-ray diffraction spectrometry. The materials were finely ground prior to analysis in a tungsten carbide ball mill. The measurements were made using a Co X-ray source $(\lambda=1.79021 \AA)$ operating at a potential of $40 \mathrm{kV}$ and a current of $40 \mathrm{~mA}$ (Rigaku Geigerflex, Danvers, MA, USA). The diffractograms were collected over the range of 5.00 to $90.00^{\circ} 2 \theta$ at a sampling interval of $0.05^{\circ}$ and scan speed of $4^{\circ} / \mathrm{min}$.

\subsection{Results and discussion}

Commercially available calcium compounds used for preparing phantoms were assessed for purity by TXRF after the method was validated against a suitable standard reference material (Table 2.1). All of the calcium compounds showed contamination with various transition metals as well as lead, strontium, and in the case of the calcium chloride dihydrate, bromine (Table 2.2). 
Table 2.2: Contamination levels in the calcium compounds purchased for the preparation of phantoms. ${ }^{\S}$

\begin{tabular}{lcccc}
\hline \hline & \multicolumn{3}{c}{ commerical compounds } & purified $^{*}$ \\
\cline { 2 - 5 } & $\mathrm{Ca}(\mathrm{OH})_{2}$ & $\mathrm{CaHPO}_{4} \cdot 2 \mathrm{H}_{2} \mathrm{O}$ & $\mathrm{CaCl}_{2} \cdot 2 \mathrm{H}_{2} \mathrm{O}$ & $\mathrm{Ca}(\mathrm{OH})_{2}{ }^{\dagger} / \mathrm{CaHPO}_{4} \cdot 2 \mathrm{H}_{2} \mathrm{O}^{\ddagger}$ \\
\hline $\mathrm{Ti}$ & $63 \pm 5$ & $63 \pm 8$ & - & - \\
$\mathrm{V}$ & - & $11 \pm 5$ & - & - \\
$\mathrm{Cr}$ & $40 \pm 4$ & $30 \pm 3$ & - & - \\
$\mathrm{Mn}$ & $52 \pm 3$ & $37 \pm 4$ & - & - \\
$\mathrm{Fe}$ & $741 \pm 79$ & $1230 \pm 27$ & $75 \pm 11$ & - \\
$\mathrm{Cu}$ & $44 \pm 4$ & - & - & - \\
$\mathrm{Zn}$ & $35 \pm 2$ & $51 \pm 7$ & $24 \pm 6$ & - \\
$\mathrm{Br}$ & - & - & $480 \pm 134$ & $<0.7$ \\
$\mathrm{Sr}$ & $442 \pm 20$ & $286 \pm 6$ & $773 \pm 241$ & $<0.3$ \\
$\mathrm{~Pb}$ & $6 \pm 1$ & $9.8 \pm 0.3$ & $21 \pm 6$ & - \\
\hline \hline
\end{tabular}

${ }^{8}$ In all cases, calcium compounds were contaminated with both strontium and lead, the analytes of interest, as well as various transition metals and halides. Elements either not listed or accompanied by $(-)$ indicates that the element was present at/or below the limit of detection of the spectrometer. Limits of detection are listed for strontium and lead

${ }^{*}$ TXRF limits of detection $(3 \sigma)$, ${ }^{\dagger}$ Prepared from the $\mathrm{CaCl}_{2} \cdot 2 \mathrm{H}_{2} \mathrm{O}$, ${ }^{\ddagger}$ Prepared from the purified $\mathrm{Ca}(\mathrm{OH})_{2}$ 
One of the major problems associated with the use of poP as the phantom material for IVXRF-based methods of bone metal quantification is that of purity. Two major sources of contamination have been identified: contamination of the whole material by the analyte and other metals and contamination of the material with other chemical species of calcium. ${ }^{11,20,30}$ Such contamination makes it difficult to accurately calculate the CCF or to properly determine the analytical figures of merit of IVXRF systems given the inability to produce a true, well-characterized blank phantom. ${ }^{11,30,31}$ The contamination of calcium compounds with strontium is far more severe than contamination from lead (Table 2.2). ${ }^{20,30}$ Pure calcium compounds are required in order to have complete control over the composition of the proposed HAp phantoms.

The purification of calcium from strontium is a known challenge given the chemical similarity between the two elements. In the case in which the concentration of calcium is far greater than that of strontium, the calcium must be removed from solution, given the difficulty in removing very small masses of strontium reliably. The selective precipitation of calcium from a strontium-containing solution with 8-hydroxyquinline has been shown to be quite successful at greatly reducing the strontium content of calcium compounds. ${ }^{37,38}$ However, the process is time consuming, expensive, and requires the use of large quantities of solvent and acid for the preparation of relatively small amounts of pure calcium. That method of purification is not particularly well-suited to the preparation of a set of phantoms that require large masses of calcium compounds.

The separation of calcium from strontium has been shown to be possible by hydroxide precipitation of calcium from a strontium containing solution. ${ }^{36,39,40}$ This method of separation is successful due to the differential solubility of calcium and strontium hydroxide. ${ }^{36}$ The method is quite simple, requiring only that an aqueous $\mathrm{Ca}^{2+}$ solution be treated with 


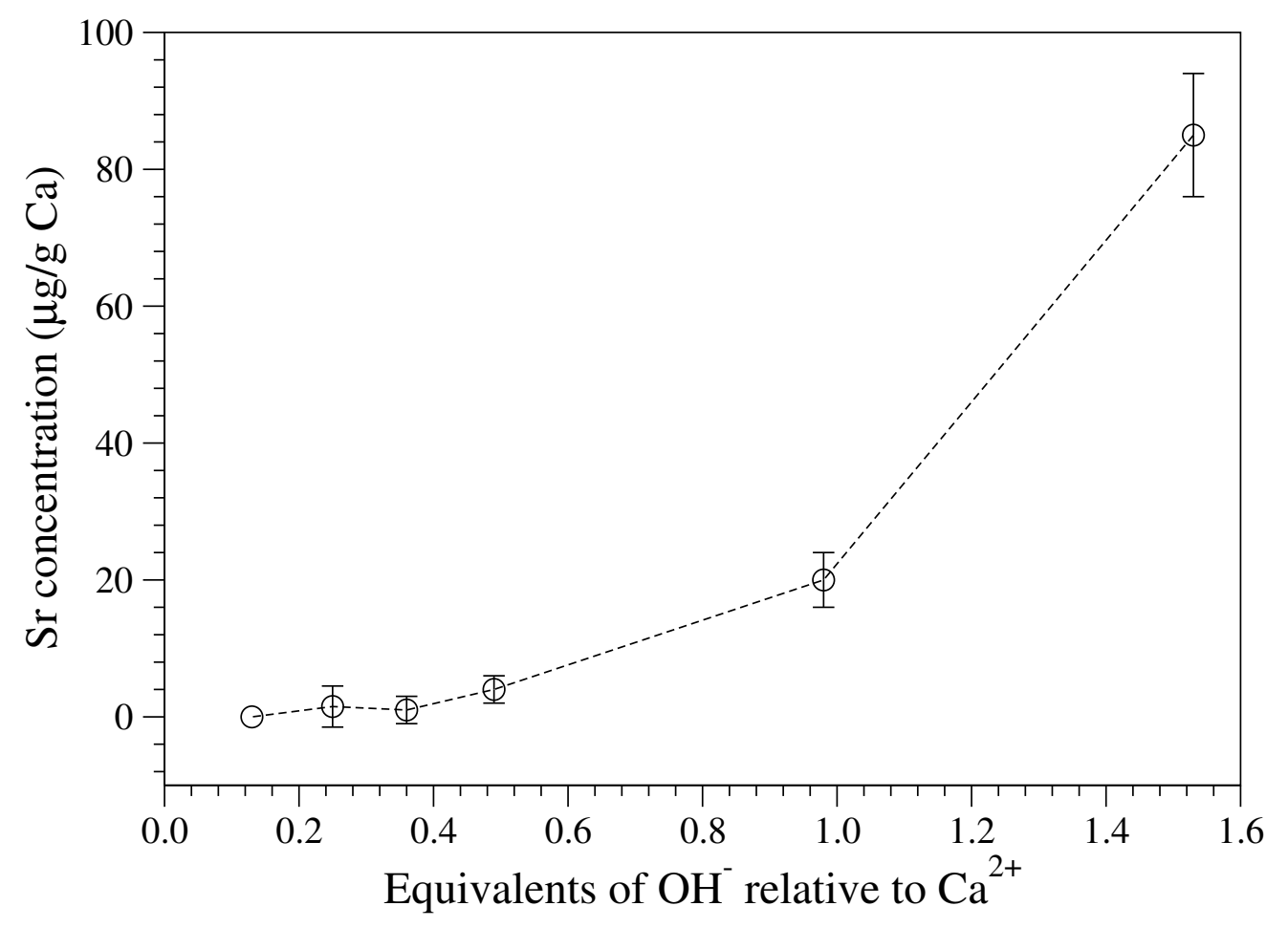

Figure 2.1: The efficiency of calcium hydroxide precipitation within a calcium chloride solution as a method for the separation of strontium from a calcium as a function of the number of equivalents of $\mathrm{OH}^{-}$relative to $\mathrm{Ca}^{2+}$ used for the precipitation reaction. 
$\mathrm{OH}^{-}$to precipitate $\mathrm{Ca}(\mathrm{OH})_{2}$. The separation of the two elements by this route is sensitive to the number of equivalents of $\mathrm{OH}^{-}$used for the precipitation, with a higher efficiency of purification being achieved by using only a small number of equivalents of $\mathrm{OH}^{-}$resulting in an excess of free $\mathrm{Ca}^{2+}$ in the solution (Figure 2.1). This observation may be due to the higher probability of coprecipitation of strontium when higher numbers of equivalents are used. In order to maximize the yield of high purity calcium, it was found that when using a calcium concentration of $1 \mathrm{~mol} / \mathrm{dm}^{3}$, the addition of 0.5 equivalents of $\mathrm{OH}^{-}$produces $\mathrm{Ca}(\mathrm{OH})_{2}$ with a strontium concentration of $<0.7 \mu \mathrm{g} / \mathrm{g} \mathrm{Ca}(p=0.05)$ (Table 2.2), which is below the limit of detection of the current IVXRF system of bone strontium quantification. ${ }^{20,21,31}$ A striking feature of this method of separation is the high efficiency for not only the removal of strontium but all other elements which were originally present in the $\mathrm{CaCl}_{2} \cdot 2 \mathrm{H}_{2} \mathrm{O}$ (Table 2.2), thus producing $\mathrm{Ca}(\mathrm{OH})_{2}$ of high purity (Figure 2.2).

The $\mathrm{Ca}(\mathrm{OH})_{2}$ produced by this method was found to be free of all metals and was used for the purpose of preparing phantoms after using the compound to prepare metal-free $\mathrm{CaHPO}_{4} \cdot 2 \mathrm{H}_{2} \mathrm{O}$ (Figure 2.3).

The preparation of phantoms for IVXRF calibration requires that the phantoms be prepared in various shapes and sizes. The use of poP for the purpose of phantom preparation was thus ideal as, being a plaster, it can be molded and shaped to virtually any geometry. The preparation of HAp calibrators was thus accomplished by preparing an HAp cement which can similarly be molded into a phantom with the same geometric flexibility. The issue of contamination by other unknown chemical species of calcium was resolved by the preparation of the calcium salts de novo where no sign of contamination was seen from other calcium species in the prepared compounds (Figure 2.3). The cement was prepared by mixing suitable quantities of $\mathrm{CaHPO}_{4} \cdot 2 \mathrm{H}_{2} \mathrm{O}$ and $\mathrm{Ca}(\mathrm{OH})_{2}$, as to achieve a $\mathrm{Ca} / \mathrm{P}$ mole ration of 


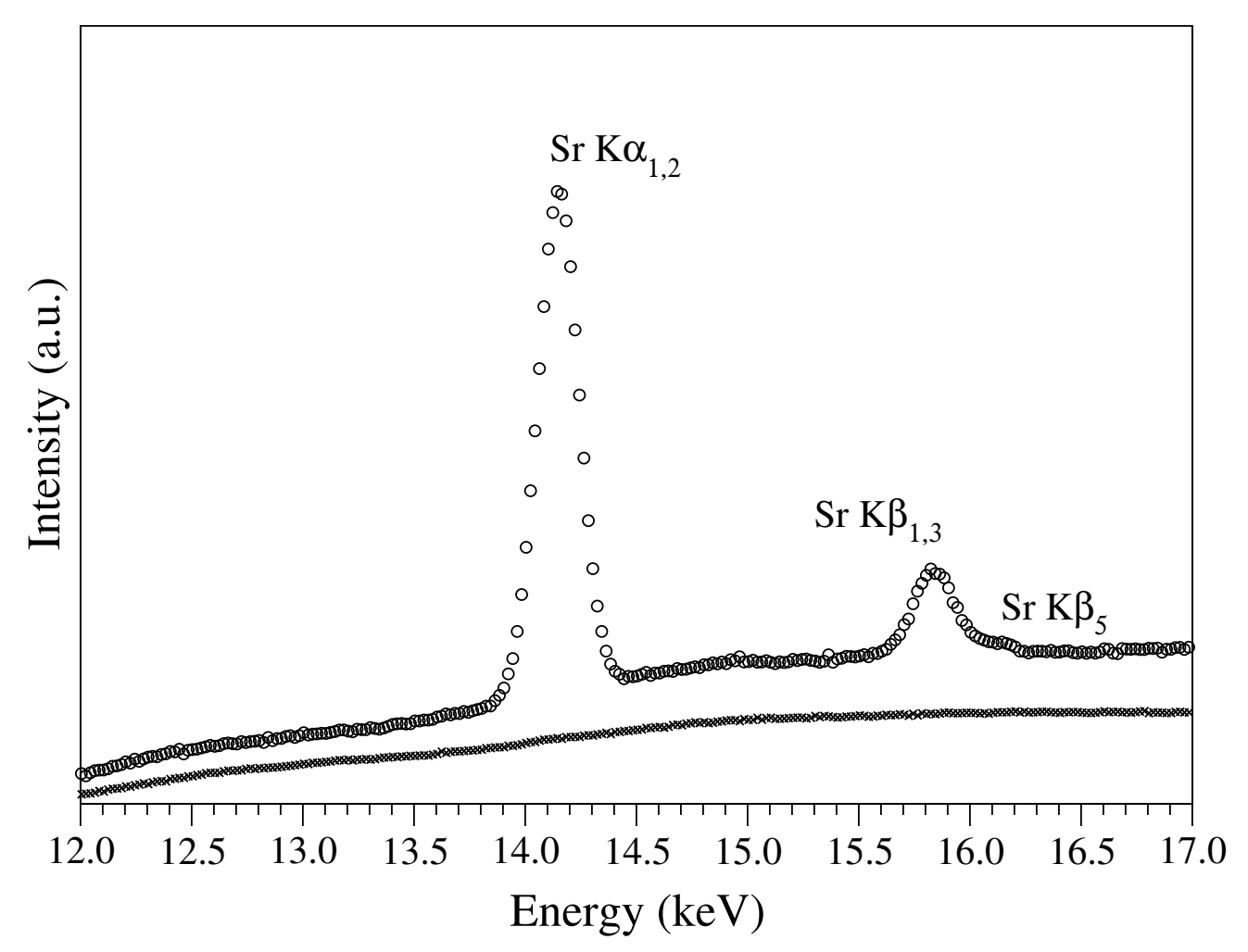

Figure 2.2: An EDXRF spectrum of commercially available $\mathrm{Ca}(\mathrm{OH})_{2}$ (upper spectrum) and the purified $\mathrm{Ca}(\mathrm{OH})_{2}$ (lower spectrum). The purified $\mathrm{Ca}(\mathrm{OH})_{2}$ shows strontium levels below the limit of detection $(3 \sigma)$ of the EDXRF system. 

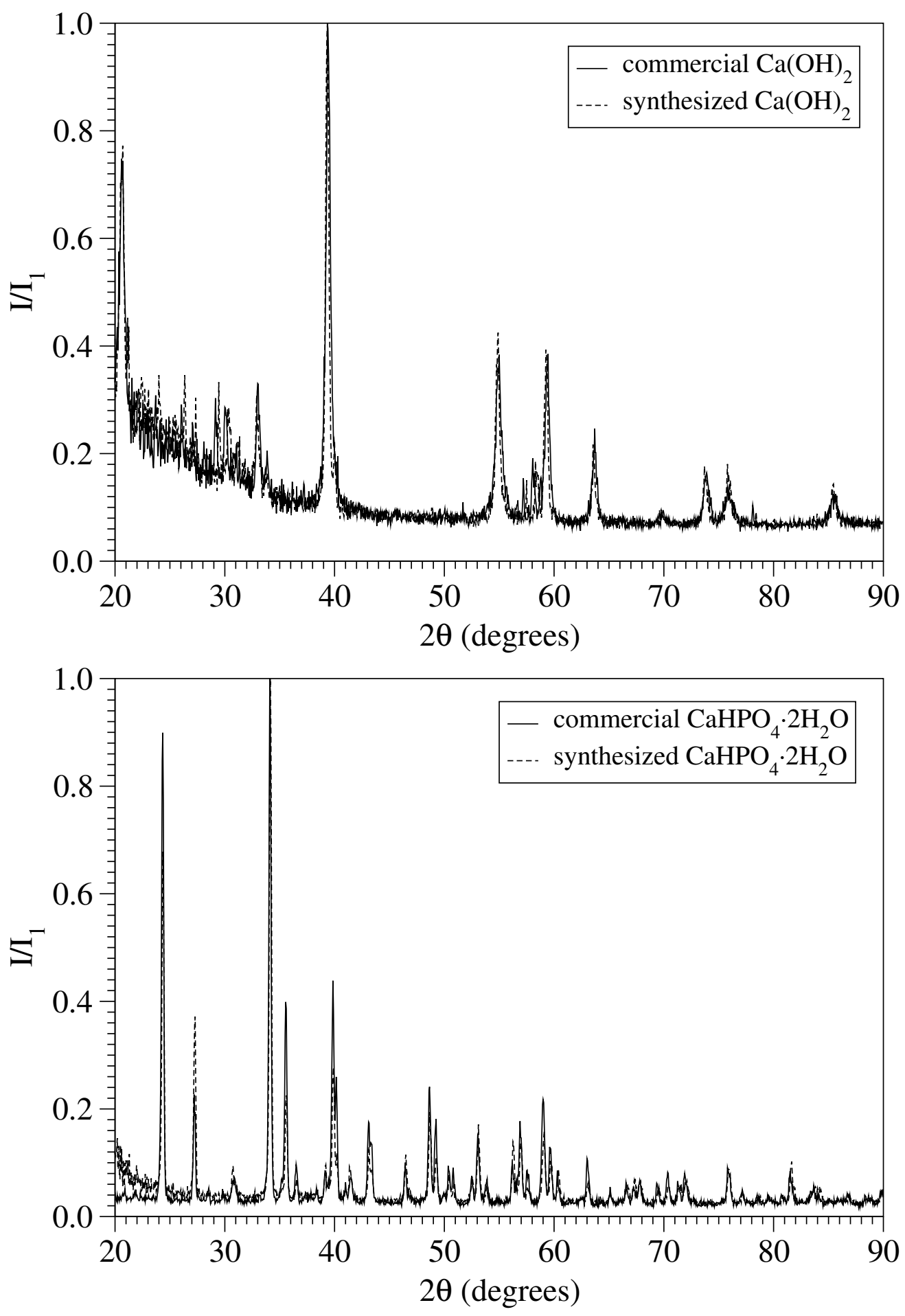

Figure 2.3: X-ray diffractograms of the prepared $\mathrm{Ca}(\mathrm{OH})_{2}$ and $\mathrm{CaHPO}_{4} \cdot 2 \mathrm{H}_{2} \mathrm{O}$ in comparison to commercially available materials. 
1.67 which is that of HAp. By the addition of a setting solution which contains the $\mathrm{HPO}_{4}^{2-}$ ion, the following reaction proceeds: ${ }^{41}$

$$
6 \mathrm{CaHPO}_{4} \cdot 2 \mathrm{H}_{2} \mathrm{O}(s)+4 \mathrm{Ca}(\mathrm{OH})_{2}(s) \stackrel{\mathrm{HPO}_{4}^{2-}(a q)}{\longrightarrow} \mathrm{Ca}_{10}\left(\mathrm{PO}_{4}\right)_{6}(\mathrm{OH})_{2}(s)+18 \mathrm{H}_{2} \mathrm{O}(\ell)
$$

producing a solid phantom composed of HAp and water. The phantoms did require setting in a humid environment, as to avoid cracking, and required on the order of 7 days to reach a constant mass once unmolded and stored at ambient. Drying of the phantom, after the complete curing phase, revealed no greater than $3 \% \mathrm{w} / w$ water content and the final phantoms had densities of $(2.0 \pm 0.6) \mathrm{g} / \mathrm{cm}^{3}$. The crystal structure of the phantom showed similarity to that of bone mineral, although a fraction of unreacted $\mathrm{CaHPO}_{4} \cdot 2 \mathrm{H}_{2} \mathrm{O}$ remained (Figure 2.4). The fraction of unreacted $\mathrm{CaHPO}_{4} \cdot 2 \mathrm{H}_{2} \mathrm{O}$ can be determined by mass difference given that, at least in the case of the phantoms prepared here, $\mathrm{Ca}(\mathrm{OH})_{2}$ was always the limiting reagent.

The analyte was integrated into the phantom material by its addition to the setting solution. Given that both analytes are introduced as the divalent ion, the addition of the analyte to the setting solution does result in the formation of a fine precipitate of the analytes' phosphate, which presumably results in integration into the HAp lattice by substitution for $\mathrm{CaHPO}_{4} \cdot 2 \mathrm{H}_{2} \mathrm{O}$ in the overall reaction. The integration of the analyte allowed for the preparation of standard curves, which showed the expected linearity and intercepts equivalent to 0 (Figure 2.5). The material thus acts a suitable calibration material in the context of $\mathrm{XRF}$ analysis and given its moldable nature by extension to IVXRF applications, allowing for the production of a true blank as well as a overall chemical composition equivalent to HAp. Although the focus of this work was the development of a calibration material for IVXRF 

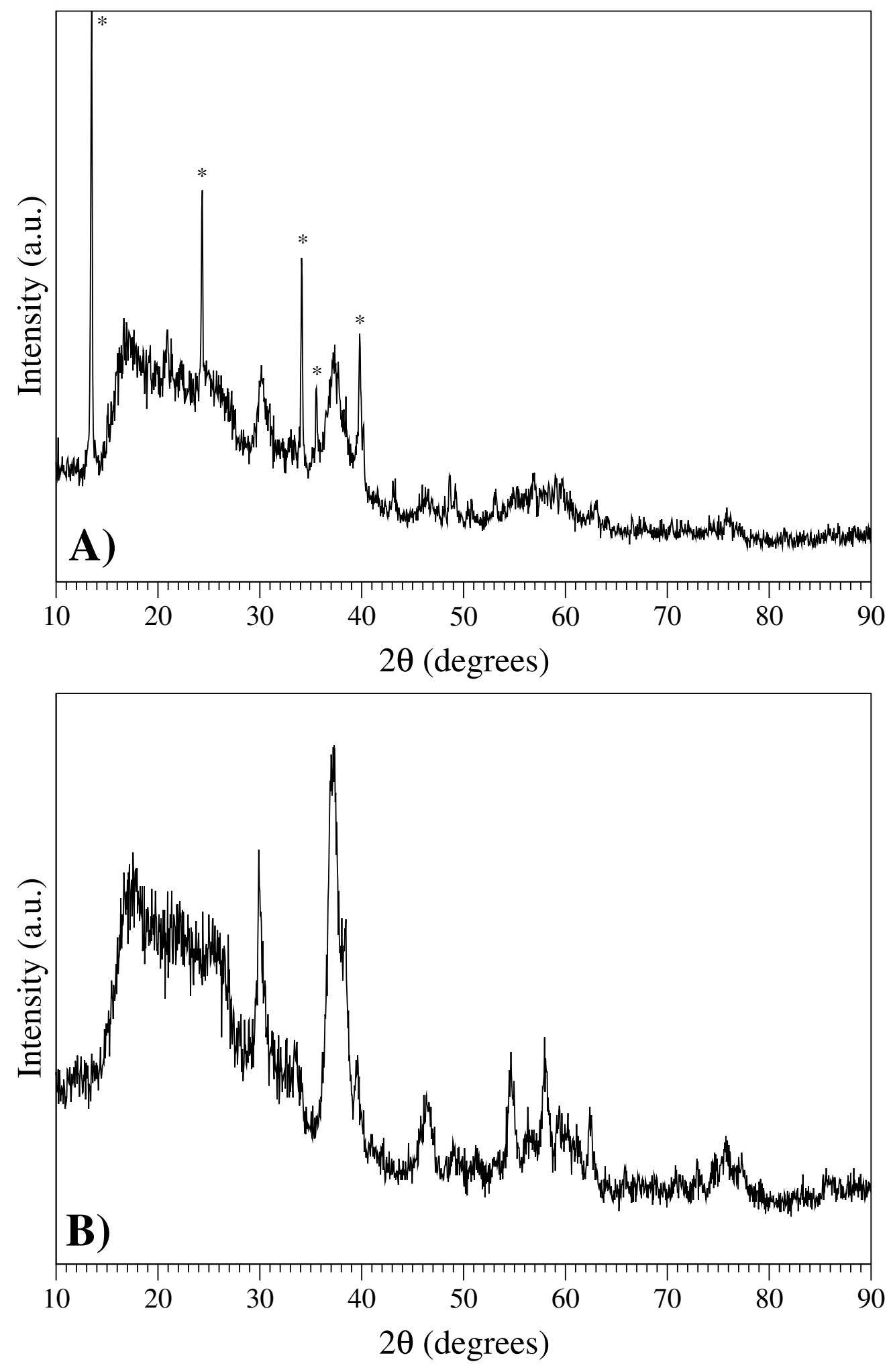

Figure 2.4: X-ray diffractograms of (A) the HAp phantom and (B) NIST bone meal. The phantom material shows a crystal structure indicating the production of HAp similar to bone mineral. The $*$ indicates reflections from unreacted $\mathrm{CaHPO}_{4} \cdot 2 \mathrm{H}_{2} \mathrm{O}$ 
analysis, the proposed calibration material can potentially be extended as a calibrator to other analytical methodologies which currently lack sufficient calibrators. ${ }^{42}$

\subsection{Conclusions}

This work describes the preparation of a pure HAp phantom material proposed here as a material for the purpose of calibrating IVXRF systems of bone strontium and lead quantification as a replacement for poP. The issue with contamination by the analyte was resolved by preparing pure $\mathrm{Ca}(\mathrm{OH})_{2}$ by hydroxide precipitation, which was found to bring strontium and lead levels to $<0.7$ and $<0.3 \mu \mathrm{g} / \mathrm{g} \mathrm{Ca}$, respectively. The pure $\mathrm{Ca}(\mathrm{OH})_{2}$ was then used for the preparation of analyte free $\mathrm{CaHPO}_{4} \cdot 2 \mathrm{H}_{2} \mathrm{O}$ for the purpose of producing HAp. HAp phantoms were then prepared from the $\mathrm{Ca}(\mathrm{OH})_{2}$ and $\mathrm{CaHPO}_{4} \cdot 2 \mathrm{H}_{2} \mathrm{O}$ with the addition of a $\mathrm{HPO}_{4}^{2-}$ containing setting solution to which the analyte was added. The final crystal structure of the material was found to be similar that of bone mineral (NIST SRM 1486). The phantom material described in this work were free of the analyte and are of known composition and thus proposed as a replacement for poP in the context of IVXRF calibration. The purification protocol was found to free the calcium of all metals in comparison to the metal content found in the reagent. This may allow for the use of this phantom material as calibrators for other elements for both in vivo and ex vivo XRF applications and for general calcified tissue analysis.

\subsection{Acknowledgements}

The authors acknowledge the Natural Science and Engineering Research Council of Canada (NSERC) for the financial support of this work through an Alexander Graham Bell Cana- 

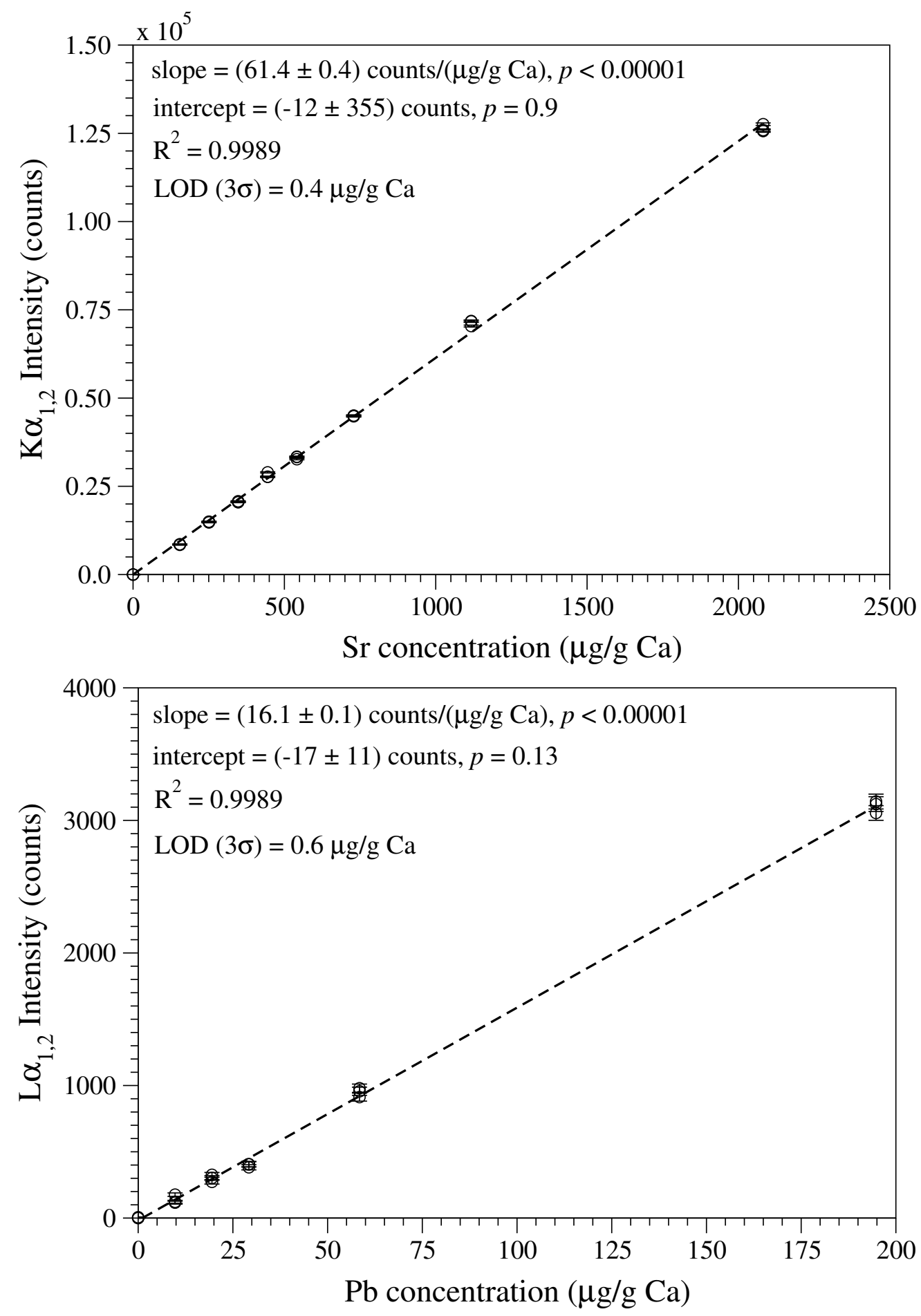

Figure 2.5: Calibration curves for strontium and lead prepared using HAp phantoms doped with the respective elements. 
dian Graduate Scholarship (EDS), a Discovery Grant (APM) and multiple Research Tools and Instruments (RTI) grants (APM). Arthur Worthington (Department of Physics), Sylvia O'Sullivan (Department of Chemistry \& Biology) and Gabriella Tesfay (Department of Chemistry \& Biology) are also acknowledged for lending their technical support throughout the course of this work. 


\section{References}

[1] L. Ahlgren, K. Lidén, S. Mattsson, and S. Tejning, "X-ray fluorescence analysis of lead in human skeleton in vivo," Scandinavian Journal of Work \& Environmental Health, vol. 2, no. 2, pp. 82-86, 1976.

[2] L. Ahlgren and S. Mattsson, "An X-ray Fluorescence Technique for in vivo Determination of Lead Concentration in a Bone Matrix," Physics in Medicine and Biology, vol. 24, no. 1, pp. 136-145, 1979.

[3] L. Wielopolski, D. N. Slatkin, D. Vartsky, K. J. Ellis, and S. H. Cohn, "Feasibility study for the in vivo measurement of lead in bone using L-X-ray fluorescence," IEEE Transactions on Nuclear Science, vol. NS-28, no. 1, pp. 114-116, 1981.

[4] L. Wielopolski, J. F. Rosen, D. N. Slatkin, D. Vartsky, K. J. Ellis, and S. H. Cohn, "Feasibility of noninvasive analysis of lead in human tibia by soft x-ray fluorescence," Medical Physics, vol. 10, no. 2, pp. 248-251, 1983.

[5] L. Wielopolski, D. Vartsky, S. Yasumura, and S. H. Cohn, "Application of XRF to Measure Strontium in Human Bone In Vivo," Advances in X-ray Analysis, vol. 26, pp. 415-421, 1983.

[6] R. E. Snyder and D. C. Secord, "The in situ measurement of strontium content in bone using x-ray fluorescence analysis," Physics in Medicine and Biology, vol. 27, no. 4, pp. 515-529, 1982.

[7] L. Wielopolski, J. F. Rosen, D. N. Slatkin, R. Zhang, J. A. Kalef-Ezra, J. C. Rothman, M. Maryanski, and S. T. Jenks, "In vivo mesurement of cortical bone lead using polarized x rays," Medical Physics, vol. 16, no. 4, pp. 521-528, 1989. 
[8] E. E. Laird, D. R. Chettle, and M. C. Scott, "The factors affecting in vivo x-ray fluorescence measurements of lead in bone," Nuclear Instruments and Methods, vol. 193, no. 1-2, pp. 377-382, 1982.

[9] L. J. Somervaille, D. R. Chettle, and M. C. Scott, "In vivo measurement of lead in bone using x-ray fluorescence," Physics in Medicine and Biology, vol. 30, no. 9, pp. 929-943, 1985.

[10] D. R. Chettle, M. C. Scott, and L. J. Somervaille, "Lead in Bone: Sampling and Quantitation Using K X-rays Excited by ${ }^{109}$ Cd," Environmental Health Perspectives, vol. 91, pp. 49-55, 1991.

[11] A. C. Todd, "Coherent scattering and matrix correction in bone-lead measurements," Physics in Medicine and Biology, vol. 45, no. 7, pp. 1953-1963, 2000.

[12] L. J. Somervaille, U. Nilsson, D. R. Chettle, I. Tell, M. C. Scott, A. Schütz, S. Mattsson, and S. Skerfving, "in vivo measurements of bone lead - a comparison of two x-ray fluorescence techniques used at three different bone sites," Physics in Medicine and Biology, vol. 34, no. 12, pp. 1833-1845, 1989.

[13] J. A. Hoppin, A. C. A. Aro, P. L. Williams, H. Hu, and P. B. Ryan, "Validation of K-XRF Bone Lead Measurement in Young Adults," Environmental Health Perspectives, vol. 103, no. 1, pp. 78-83, 1995.

[14] A. Aro, C. Amarasiriwardena, M.-L. Lee, R. Kim, and H. Hu, "Validation of K x-ray fluorescence bone lead measurements by inductively coupled plasma mass spectrometry in cadaver legs," Medical Physics, vol. 27, no. 1, pp. 119-123, 2000. 
[15] A. C. Todd, E. L. Moshier, S. Carroll, and S. W. Casteel, "Validation of X-Ray Fluorescence-Measured Swine Femur Lead Against Atomic Absorption Spectrometry," Environmental Health Perspectives, vol. 109, no. 11, pp. 1115-1119, 2001.

[16] A. C. Todd, P. J. Parsons, S. Carroll, C. Geraghty, F. A. Khan, S. Tang, and E. L. Moshier, "Measurements of lead in human tibiae. A comparison between K-shell x-ray fluorescence and electrothermal atomic absorption spectrometry," Physics in Medicine and Biology, vol. 47, no. 4, pp. 673-687, 2002.

[17] D. J. Bellis, A. C. Todd, and P. J. Parsons, "An interlaboratory comparison of bone lead measurements via K-shell X-ray fluorescence spectrometry: validation against inductively coupled plasma mass spectrometry," Journal of Analytical Atomic Spectrometry, vol. 27, no. 4, pp. 595-603, 2012.

[18] J. M. O'Meara, D. R. Chettle, F. E. McNeill, and C. E. Webber, "The feasibility of measuring bone uranium concentrations in vivo using source excited K x-ray fluorescence," Physics in Medicine and Biology, vol. 42, no. 6, pp. 1109-1120, 1997.

[19] J. M. O’Meara, D. R. Chettle, F. E. McNeill, and C. E. Webber, "In Vivo X-ray Fluorescence (XRF) Measurement of Uranium in Bone," Applied Radiation $\& 3$ Isotopes, vol. 49, no. 5-6, pp. 713-715, 1998.

[20] A. Pejović-Milić, I. M. Stronach, J. Gyorffy, C. E. Webber, and D. R. Chettle, "Quantification of bone strontium levels in humans by in vivo x-ray fluorescence," Medical Physics, vol. 31, no. 3, pp. 528-538, 2004.

[21] M. Zamburlini, A. Pejović-Milić, and D. R. Chettle, "Evaluation of geometries appropriate for ${ }^{125} \mathrm{I}$ in vivo bone strontium X-ray fluorescence measurement," Journal of Radioanalytical \&3 Nuclear Chemistry, vol. 269, no. 3, pp. 625-629, 2006. 
[22] M. Zamburlini, A. Pejović-Milić, D. R. Chettle, C. E. Webber, and J. Gyorffy, "In vivo study of an x-ray fluorescence system to detect bone strontium non-invasively," Physics in Medicine and Biology, vol. 52, no. 8, pp. 2107-2122, 2007.

[23] M. Zamburlini, A. Pejović-Milić, and D. R. Chettle, "Coherent normalization of finger strontium XRF measurements: feasibility and limitations," Physics in Medicine and Biology, vol. 53, no. 15, pp. N307-N313, 2008.

[24] C. M. Heirwegh, D. R. Chettle, and A. Pejović-Milić, "Ex vivo evaluation of a coherent normalization procedure to quantify in vivo finger strontium XRS measurements," Medical Physics, vol. 39, no. 2, pp. 832-841, 2012.

[25] A. C. Todd, "L-shell x-ray fluorescence measurements of lead in bone: system development," Physics in Medicine and Biology, vol. 47, no. 3, pp. 507-522, 2002.

[26] A. C. Todd, S. Carroll, C. Geraghty, F. A. Khan, E. L. Moshier, S. Tang, and P. J. Parsons, "L-shell x-ray fluorescence measurements of lead in bone: accuracy and precision," Physics in Medicine and Biology, vol. 47, no. 8, pp. 1399-1419, 2002.

[27] D. E. B. Fleming, M. R. Gherase, and K. M. Alexander, "A miniature X-ray tube approach to measuring lead in bone using L-XRF," X-ray Spectrometry, vol. 40, no. 5, pp. 343-347, 2011.

[28] L. H. Nie, S. Sanchez, K. Newton, L. Grodzins, R. O. Cleveland, and M. G. Weisskopf, "In vivo quantification of lead in bone with a portable x-ray fluorescence systemmethodology and feasibility," Physics in Medicine and Biology, vol. 56, no. 3, pp. N39N51, 2011. 
[29] J. M. O'Meara, J. Börjesson, D. R. Chettle, and S. Mattsson, "Normalisation with coherent scatter signal: improvements in the calibration protocol of the ${ }^{57} \mathrm{Co}$-based in vivo XRF bone-Pb measurement," Applied Radiation $\&$ Isotopes, vol. 54, no. 2, pp. 319$325,2001$.

[30] A. C. Todd, "Contamination of in vivo bone-lead measurements," Physics in Medicine and Biology, vol. 45, no. 1, pp. 229-240, 2000.

[31] M. Zamburlini, A. Pejović-Milić, and D. R. Chettle, "Spectrometry methods for in vivo bone strontium measurements," X-ray Spectrometry, vol. 37, no. 1, pp. 42-50, 2008.

[32] D. R. Chettle, M. C. Scott, and L. J. Somervaille, "Improvements in the precision of in vivo bone lead measurements," Physics in Medicine and Biology, vol. 34, no. 9, pp. 1295-1300, 1989.

[33] D. R. Chettle, "Photoelectric bremsstrahlung - analytical possibilities," Physics in Medicine and Biology, vol. 35, no. 2, pp. 259-264, 1990.

[34] G. Harding, "Comments on the article 'Photoelectric bremsstrahlung - analytical possibilities?,", Physics in Medicine and Biology, vol. 40, no. 3, pp. 471-476, 1995.

[35] H. Nie, D. R. Chettle, F. E. McNeill, and J. M. O'Meara, "An investigation of the ${ }^{109} \mathrm{Cd} \gamma$-ray induced K-x-ray fluorescence (XRF) bone-lead measurement calibration procedure," Physics in Medicine and Biology, vol. 49, no. 19, pp. N325-N334, 2004.

[36] F. Patti and J. A. Hernandez, "Nouvelle methode de separation calcium-strontium appliquee a la preparation d'un sel de calcium de tres faible teneur en strontium," Analytica Chimica Acta, vol. 55, no. 2, pp. 325-332, 1971. 
[37] T. C. Rains, H. E. Zittel, and M. Ferguson, "Flame Spectrophotometric Determination of Micro Concentrations of Strontium in Calcareous Material," Analytical Chemistry, vol. 34, no. 7, pp. 778-781, 1962.

[38] E. Da Silva, A. Pejović-Milić, and D. V. Heyd, "The use of teeth as the site for the in vivo or ex vivo quantification of skeletal strontium by energy-dispersive X-ray fluorescence spectrometry: A feasibility study," Journal of Analytical Atomic Spectrometry, vol. 23, no. 4, pp. 527-534, 2008.

[39] Q. Chen, X. Hou, Y. Yu, H. Dahlgaard, and S. P. Nielsen, "Separation of Sr from Ca, $\mathrm{Ba}$ and $\mathrm{Ra}$ by means of $\mathrm{Ca}(\mathrm{OH})_{2}$ and $\mathrm{Ba}(\mathrm{Ra}) \mathrm{Cl}_{2}$ or $\mathrm{Ba}(\mathrm{Ra}) \mathrm{SO}_{4}$ for the determination of radiostrontium," Analytica Chimica Acta, vol. 466, no. 1, pp. 109-116, 2002.

[40] L. Popov, X. Hou, S. P. Nielsen, Y. Yu, R. Djingova, and I. Kuleff, "Determination of radiostrontium in environmental samples using sodium hydroxide for separation of strontium from calcium," Journal of Radioanalytical \& Nuclear Chemistry, vol. 269, no. 1, pp. 161-173, 2006.

[41] S. Takagi, L. C. Chow, and K. Ishikawa, "Formation of hydroxyapatite in new calcium phosphate cements," Biomaterials, vol. 19, no. 17, pp. 1593-1599, 1998.

[42] D. Hare, C. Austin, P. Doble, and M. Arora, "Elemental bio-imaging of trace elements in teeth using laser ablation-inductively coupled plasma-mass spectrometry," J. Dent., vol. 39, no. 5, pp. 397-403, 2011. 
CHAPTER

THREE

\section{THE PREPARATION OF STRONTIUM-SUBSTITUTED HYDROXYAPATITE BONE PHANTOMS WITH HIGH STRONTIUM CONCENTRATIONS}

Published in, and adapted and adapted (to Canadian English) with permission from: E. Da Silva, D.V. Heyd, B. Rizvi and A. Pejović-Milić, "The preparation of strontium-substituted hydroxyapatite bone phantoms with high strontium concentrations," Biomedical Physics $\& 3$ Engineering Express, vol. 2, 015006. http://dx.doi.org/10.1021/ac401877dDOI: 10.1021/ac401877d. Copyright (C) 2016 IOP Publishing Ltd. ${ }^{\dagger}$

${ }^{\dagger}$ E. Da Silva designed and carried out the experiments, performed the data analysis and wrote this manuscript/chapter. D. V. Heyd provided advice throughout the course of this work, assessed the results and the primary author's interpretations and assessed the manuscript/chapter critically. B. Rizvi aided with the preparation of the phantoms used and assessed in this work and read the manuscript/chapter critically. A. Pejović-Milić identified the need for a new general of phantoms for the purpose of further developing the in vivo strontium system, financed this project, provided feedback as to its contents and assessed the manuscript/chapter critically. 


\subsection{Abstract}

The current in vivo X-ray fluorescence spectrometry (IVXRF)-based method of bone strontium quantification is dependent on calibration against plaster of Paris [poP; $\mathrm{CaSO}_{4} \cdot \frac{1}{2} \mathrm{H}_{2} \mathrm{O}$ ] calibrators/phantoms. Issues with the dissimilarity of the poP in comparison to bone mineral and the known issue with high levels of strontium contamination in commercial poP materials has led to the development of a strontium-free hydroxyapatite bone mineral phantom material. The analyte is introduced into this material by doping of a high concentration $\mathrm{HPO}_{4}{ }^{2-}$ setting solution. This phantom material is not particularly well suited for the preparation of strontium containing bone phantoms which are high in strontium concentration (in the mol \% concentration range) and thus when the $(\mathrm{Ca}+\mathrm{Sr}) / \mathrm{P}$ mole ratio is to be kept at 1.67; that of hydroxyapatite. This work thus evaluates the feasibility of preparing high concentration strontium-substituted hydroxyapatite phantoms using a $\mathrm{CaHPO}_{4} \cdot 2 \mathrm{H}_{2} \mathrm{O} / \mathrm{Ca}(\mathrm{OH})_{2} / \mathrm{Sr}(\mathrm{OH})_{2} \cdot 8 \mathrm{H}_{2} \mathrm{O}$ cement mixture. It was found that a strontium-substituted HAp phantom material can be prepared by mixing suitable quantities of $\mathrm{CaHPO}_{4} \cdot 2 \mathrm{H}_{2} \mathrm{O}, \mathrm{Ca}(\mathrm{OH})_{2}$ and $\mathrm{Sr}(\mathrm{OH})_{2} \cdot 8 \mathrm{H}_{2} \mathrm{O}$ to a $(\mathrm{Ca}+\mathrm{Sr}) / \mathrm{P}$ mole ratio of 1.67. Setting of the phantom using a $1 \mathrm{M} \mathrm{HPO}_{4}{ }^{2-}$ setting solution (to increase phosphate concentration) produced a phantom composed of $\left(\mathrm{Ca}_{1-\mathrm{x}} \mathrm{Sr}_{\mathrm{x}}\right)_{5}\left(\mathrm{PO}_{4}\right)_{3} \mathrm{OH}$ of known strontium concentration. The final phantom material was found to be a strontium-substituted product (through X-ray diffraction and Raman spectroscopy measurements) to the degree of substitution expected. This work thus describes the preparation of a bone phantom material which can be used for the calibration of IVXRF systems of bone strontium quantification, as well as for other modalities (i.e. dual energy X-ray absorptiometry and quantitative ultrasound) in the case that bone strontium concentrations are expected to be high such as in the case of individuals taking strontium salts for the treatment/prevention of osteoporosis. 


\subsection{Introduction}

In vivo X-ray fluorescence spectrometry (IVXRF) has been applied to the quantification of various elements in bone tissues as it offers a non-destructive method for the quantification of various elements in bone which allows for long term monitoring and with modest radiation dose to the subjects. ${ }^{1-7}$

The calibration of IVXRF systems for bone metal quantification can be quite complicated as various factors, such as the inter-subject variations in bone geometry, bone mineral concentration and overlaying soft-tissue thickness, can influence the analytical signal (the characteristic X-ray intensity of interest). ${ }^{8,9}$ As a result, a coherent normalization procedure is generally employed and has been shown to correct for such influence. ${ }^{10}$ The procedure being dependent on the assumption that bone mineral is composed of hydroxyapatite [HAp; $\left.\mathrm{Ca}_{10}\left(\mathrm{PO}_{4}\right)_{6}(\mathrm{OH})_{2}\right]$ and concentrations determined on a mass of analyte per unit mass of bone mineral basis. ${ }^{10}$ The success of the coherent normalization procedure developed in the context of a ${ }^{109} \mathrm{Cd}$-induced $\mathrm{K}-\mathrm{XRF}$ bone lead measurement ${ }^{10-16}$ has thus led to its application, in whole or in part, to other IVXRF systems of bone metal quantification, either by use of the coherent normalization procedure as a whole, or, the use of plaster of Paris [poP; $\left.\mathrm{CaSO}_{4} \cdot \frac{1}{2} \mathrm{H}_{2} \mathrm{O}\right]$ as a surrogate for bone mineral in the calibration. ${ }^{4-7,17-24}$

Several concerns have arisen as to the use of poP as a phantom material for IVXRF systems of bone metal quantification, namely, its chemical dissimilarity to bone mineral, the need to apply a coherent conversion factor $(\mathrm{CCF})$ to the calibration procedure to account for the different scattering properties of poP versus HAp and various issues with contamination by the analyte. ${ }^{2,17,25,26}$ In the case of a bone strontium measurement, commercial poP has been shown to contain rather large levels of strontium contamination, resulting in the inability to produce a true blank phantom and difficulty in determining analytical figures of 
merit. ${ }^{2,17}$ In response to these concerns, a new HAp phantom material, which is chemically pure and similar to bone mineral, has been proposed to provide a means of preparing bone mineral-like phantoms as a substitute for poP and removing the concerns which arise from poP's use as a phantom material in IVXRF calibration. ${ }^{27}$.

The HAp phantom material proposed by Da Silva et al. (2013) ${ }^{27}$ is based on the formation of $\mathrm{HAp}$ through a $\mathrm{CaHPO}_{4} \cdot 2 \mathrm{H}_{2} \mathrm{O} / \mathrm{Ca}(\mathrm{OH})_{2}$ calcium phosphate cement $(\mathrm{CPC})$ system. Phantoms are prepared using a mixture of purified $\mathrm{CaHPO}_{4} \cdot 2 \mathrm{H}_{2} \mathrm{O}$ and $\mathrm{Ca}(\mathrm{OH})_{2}$ such that a $1.67 \mathrm{Ca} / \mathrm{P}$ mole ratio (that of $\mathrm{HAp}$ ) is achieved and the mixture set using a setting solution aimed at ensuring a high concentration of free phosphate. ${ }^{27}$ The analyte is introduced by doping the setting liquid with a certified standard solution containing the analyte, which is a similar approach to the production of poP phantoms. Da Silva et al. (2013) ${ }^{27}$ have shown that this approach allows for the preparation of analyte free phantoms (blanks), in particular, phantoms clean of strontium, and also that it is possible to prepare standard curves when the analyte is introduced in this fashion.

The case of strontium in bone presents a certain analytical challenge particularly in the context of preparing phantoms. In the case of most other metals (e.g. lead), the expected concentrations in bone tissue are in the part-per-million concentration range ${ }^{1,3}$ which lends the phantom preparation to a simple doping procedure in the context of adding the analyte. Strontium is however a ubiquitous element to calcium and is naturally present in human bone in the part-per-million range. Strontium compounds are used as a treatment for osteoporosis and thus it is expected that in some populations the bone strontium concentration may reach the mol-percentage concentration range. ${ }^{28}$ This is evident from the concerns already raised in the context of dual energy X-ray absorptiometry measurements. ${ }^{29,30}$ As a result, the addition of strontium to an IVXRF phantom through doping, whether poP or the HAp phantoms, ${ }^{27}$ 
is not a feasible route as it is necessary to keep the $(\mathrm{Ca}+\mathrm{Sr}) / \mathrm{P}$ mole ratio at 1.67.

This work thus evaluates the feasibility of preparing HAp bone phantoms which are high in strontium concentration and which are maintained at a $(\mathrm{Ca}+\mathrm{Sr}) / \mathrm{P}$ mole ratio of 1.67 and thus preparing a strontium-substituted HAp phantom material $\left[\left(\mathrm{Ca}_{1-\mathrm{x}} \mathrm{Sr}_{\mathrm{x}}\right)_{5}\left(\mathrm{PO}_{4}\right)_{3} \mathrm{OH}\right]$. This is of particular importance in the case phantoms are to be prepared with strontium concentrations in the mole-percentage concentration range, and thus, the addition of the analyte may introduce a non-trivial deviation from the $1.67(\mathrm{Ca}+\mathrm{Sr}) / \mathrm{P}$ mole ratio. The procedure evaluated in this work being based on a $\mathrm{CaHPO}_{4} \cdot 2 \mathrm{H}_{2} \mathrm{O} / \mathrm{Ca}(\mathrm{OH})_{2} / \mathrm{Sr}(\mathrm{OH})_{2} \cdot 8 \mathrm{H}_{2} \mathrm{O}$ system whereby the analyte is introduced as a heavy hydroxide hydrate to reduce analytical uncertainty in computed phantom concentrations. This work thus evaluates the feasibility of preparing phantoms by this route, in which the final product is a substituted strontiumhydroxyapatite. It also provides an assessment of the reaction (given the varying solubilities of the two hydroxides) for any possible contamination issues that are of analytical importance to calibration protocol of bone strontium analysis.

\subsection{Materials and methods}

\subsubsection{Phantom preparation}

Phantoms were prepared using the method described by Da Silva et al. (2013) ${ }^{27}$ with a modification to allow for the introduction of strontium by the addition of $\mathrm{Sr}(\mathrm{OH})_{2} \cdot 8 \mathrm{H}_{2} \mathrm{O}$ in lieu of the certified standard solution. Phantoms were prepared by mixing a suitable quantity of dry $\mathrm{CaHPO}_{4} \cdot 2 \mathrm{H}_{2} \mathrm{O}$ (USP grade, Amresco, Solon, OH, USA) with dry $\mathrm{Ca}(\mathrm{OH})_{2}$ (USP grade, Amresco, Solon, OH, USA) and/or dry $\mathrm{Sr}(\mathrm{OH})_{2} \cdot 8 \mathrm{H}_{2} \mathrm{O}(99 \%$ metals basis, Alfa Aesar, Ward Hill, MA, USA). The $\operatorname{Sr}(\mathrm{OH})_{2} \cdot 8 \mathrm{H}_{2} \mathrm{O}$ was ground into a fine powder using a 
tungsten carbide ball mill prior to use. The mixtures were prepared such that the $(\mathrm{Ca}+$ $\mathrm{Sr}) / \mathrm{P}$ mole ratio was maintained at 1.67 (that of HAp) such that the final product would have a stoichiometry of the formula $\left(\mathrm{Ca}_{1-\mathrm{x}} \mathrm{Sr}_{\mathrm{x}}\right)_{5}\left(\mathrm{PO}_{4}\right)_{3} \mathrm{OH}$. All powders were weighed to the nearest $0.01 \mathrm{mg}$ on an analytical balance calibrated against a $200.0000 \mathrm{~g}$ internal calibration mass (GR-202, A\&D Company Ltd., Tokyo, Japan).

To the powdered mixture was added a setting solution, at a powder:liquid ratio of 2:1, of either $1 \mathrm{M} \mathrm{NaOH}$ (ACS grade, BMD, West Chester, PA, USA) or $1 \mathrm{M} \mathrm{Na}_{2} \mathrm{HPO}_{4}(\mathrm{ACS}$ grade, Amresco, Solon, OH, USA) made in $18.2 \mathrm{M} \Omega \cdot \mathrm{cm}$ water drawn from a milliQ ${ }^{\mathrm{TM}}$ system. The phantom mixtures were mixed and allowed to set as per Da Silva et al. (2013) ${ }^{27}$.

\subsubsection{Powder X-ray diffraction spectrometry}

The phantoms were finely ground in a tungsten carbide ball mill prior to analysis and loaded into an aluminium sample holder for XRD analysis. The measurements were made using a Co X-ray source $(\lambda=1.79021 \AA)$ operating at a potential of $40 \mathrm{kV}$ and a current of $40 \mathrm{~mA}$ (Rigaku Geigerflex, Danvers, MA, USA) with a sampling interval of $0.05^{\circ}$ and scan speed of $4^{\circ} / \min$.

\subsubsection{Raman spectroscopy}

Raman measurements were made on a Renishaw confocal Raman microscopy (Renishaw Ramascope 2000, Gloucestershire, UK) equipped with an energy dispersive CCD detector (resolution better than $2.5 \mathrm{~cm}^{-1}$ ) and a $782 \mathrm{~nm}$ laser. Measurements were made using a $20 \times$ objective on finely ground samples mounted on optically flat quartz sample carriers. 


\subsection{Results and discussion}

The preparation of the HAp phantoms is based on the solubility properties of calcium phosphates as well as the common ion effect. ${ }^{31-34}$ Within a $\mathrm{pH}$ range of 4.5 to 14 , HAp is the least soluble of all calcium phosphate compounds. ${ }^{31,34}$ As a result most calcium phosphates will tend to dissolve and precipitate as HAp. ${ }^{31,34}$ The setting mechanism for CPC systems has been proposed to be similar to that of poP. ${ }^{32}$ The precipitated phase tends to grow in clusters and the cluster mass tends to set via entanglement. $31,32,35$ The rate at which this conversion to HAp occurs is rather slow and the phosphate ion concentration in the setting solution becomes critical in the formation of an HAp product through the common ion effect. ${ }^{32-34}$ The rate of formation has a direct impact in the overall physical qualities of the phantoms, in particular, the material strength.

As with poP, the CPC system used to prepare phantoms ${ }^{27}$ takes advantage of the common ion effect in order to increase the rate of formation of HAp and thus improve its physical properties. When considering the setting behaviour of poP, potassium salts, namely $\mathrm{K}_{2} \mathrm{SO}_{4}$, are often used as setting accelerants. ${ }^{35}$ Commercial poP is often employed as a phantom material in the context of IVXRF measurements; the unknown proportion of these accelerants being a known form of contamination in the final phantoms. ${ }^{26}$ Given that current IVXRF calibration protocols require the application of a $\mathrm{CCF}$ - that is material dependent - preparing phantoms with commercial poP in which the concentration of these accelerants (and other additives) are unknown may result in added uncertainty to the measurement. ${ }^{10,26}$ Removing these accelerants to produce phantoms from pure $\mathrm{CaSO}_{4} \cdot \frac{1}{2} \mathrm{H}_{2} \mathrm{O}$ would result in brittle phantoms, or phantoms which take significant time to set. Thus, one of the major motives for moving towards an HAp-based phantom which can be prepared using a CPC system is the control over the final composition of the phantom, which, by its nature as an HAp, may 
allow for the complete removal of the CCF from the calibration protocol. ${ }^{27}$

In the case of HAp cements, a high free phosphate ion concentration is required in the system in order to ensure a rapid setting time which ultimately improves the physical qualities of the final phantom. ${ }^{32-34}$ This has been shown to be achievable by either including an anion of phosphoric acid ${ }^{27,34}$ or free hydroxyl ions ${ }^{34}$ to the setting solution. In the case of a $\mathrm{CaHPO}_{4} \cdot 2 \mathrm{H}_{2} \mathrm{O}$ based HAp cement, the hydroxyl ion can increase the overall free phosphate ion concentration in the system by increasing the solubility of $\mathrm{CaHPO}_{4} \cdot 2 \mathrm{H}_{2} \mathrm{O}$, thereby inducing the so-called "common ion" effect. ${ }^{34}$ The use of this type of CPC system for the preparation of HAp phantoms, more specifically, by increasing the phosphate concentration using an anion of phosphoric acid in the setting solution, was found to be successful when the analyte was added directly to the phosphate-containing setting solution. ${ }^{27}$ This method can only be used when small volumes of a certified standard solution of the analyte are used as not to change the phosphate concentration of the setting solution drastically. ${ }^{27}$ Addition of a large volume of a certified analyte solution would decrease the rate of formation by requiring a lower volume of phosphate containing solution be added, thereby reducing the effective phosphate ion concentration. It would also result in a stoichiometry which would deviate from the intended $(\mathrm{Ca}+\mathrm{Sr}) / \mathrm{P}$ ratio of 1.67 ; thereby, the addition of the analyte by through the addition of a strontium salt to the CPC powder mixture was investigated. More specifically, addition of strontium as its hydroxide was investigated.

With regards to a $\mathrm{CaHPO}_{4} \cdot 2 \mathrm{H}_{2} \mathrm{O} \mathrm{CPC}$ system, the reaction does require that all reagents be present in their respective proportions for the formation of HAp to occur. Considering $\mathrm{CaHPO}_{4} \cdot 2 \mathrm{H}_{2} \mathrm{O}$ alone,

$$
\mathrm{CaHPO}_{4} \cdot 2 \mathrm{H}_{2} \mathrm{O}(s) \rightleftharpoons \mathrm{Ca}^{2+}(a q)+\mathrm{HPO}_{4}^{2-}(a q)+2 \mathrm{H}_{2} \mathrm{O}(\ell)
$$


the solubility of $\mathrm{CaHPO}_{4} \cdot 2 \mathrm{H}_{2} \mathrm{O}$ is $0.02 \mathrm{~g} / 100 \mathrm{~g} \mathrm{H} \mathrm{H}_{2} \mathrm{O}\left(\right.$ at $25^{\circ} \mathrm{C}$ ) ${ }^{36}$ which makes it a rather insoluble calcium phosphate (Scheme 3.1). Adding $\mathrm{HPO}_{4}{ }^{2-}$ ion shifts the equilibrium towards formation of $\mathrm{CaHPO}_{4} \cdot 2 \mathrm{H}_{2} \mathrm{O}$, but does not result in the formation of HAp (Figure 3.1). Although it has been reported that both $\mathrm{CaHPO}_{4}$ and $\mathrm{CaHPO}_{4} \cdot 2 \mathrm{H}_{2} \mathrm{O}$ systems in solution will hydrolyse to $\mathrm{HAp},{ }^{37,38}$ in this study in which the powder-to-liquid ratio is $2: 1$, the system was prone to losing water rather rapidly, but no HAp was formed (3.1). The use of a setting solution with a high concentration of $\mathrm{OH}^{-}$ion resulted in an increase in the system's $\mathrm{pH}$, and perhaps an increase in the solubility of $\mathrm{CaHPO}_{4} \cdot 2 \mathrm{H}_{2} \mathrm{O}$, but did not change the reactant, $\mathrm{CaHPO}_{4} \cdot 2 \mathrm{H}_{2} \mathrm{O}$ (Figure 3.1).

For the $\mathrm{CaHPO}_{4} \cdot 2 \mathrm{H}_{2} \mathrm{O} / \mathrm{Ca}(\mathrm{OH})_{2} / \mathrm{Sr}(\mathrm{OH})_{2} \cdot 8 \mathrm{H}_{2} \mathrm{O}$ CPC system, the presence of $\mathrm{Ca}(\mathrm{OH})_{2}$ and/or $\mathrm{Sr}(\mathrm{OH})_{2} \cdot 8 \mathrm{H}_{2} \mathrm{O}$ did more than just increasing the $(\mathrm{Ca}+\mathrm{Sr}) / \mathrm{P}$ mole ratio to that of 1.67 as previously suggested. ${ }^{34}$ Such a mixture is desirable as a means of introducing the analyte into the phantom as it allows for maintaining the total $(\mathrm{Ca}+\mathrm{Sr}) / \mathrm{P}$ ratio at 1.67. The results of the $\mathrm{CaHPO}_{4} \cdot 2 \mathrm{H}_{2} \mathrm{O}$ reaction with the setting liquids alone suggests that the presence of all reactants need to be present in this calcium phosphate cement system in order for HAp to be produced (Figure 3.1).

In the case of a saturated solution of $\mathrm{Ca}(\mathrm{OH})_{2}$, which has a solubility of $0.160 \mathrm{~g} / 100 \mathrm{~g}$ $\mathrm{H}_{2} \mathrm{O}\left(\right.$ at $\left.20^{\circ} \mathrm{C}\right),{ }^{36}$ the equilibrium and reaction in Scheme 3.2 would be expected to occur.

$$
\mathrm{Ca}(\mathrm{OH})_{2}(s) \rightleftharpoons \mathrm{Ca}^{2+}(a q)+2 \mathrm{OH}^{-}(a q) \stackrel{\mathrm{CO}_{2}(g)}{\longrightarrow} \mathrm{CaCO}_{3}(s)+2 \mathrm{H}_{2} \mathrm{O}(\ell)
$$

Here, an interfering reaction when the phantom mixture is produced at ambient is expected due to integration of ambient $\mathrm{CO}_{2}$ from the air. In this case $\mathrm{CaCO}_{3}$ would form as a phantom contaminant given the $\mathrm{pH}$ of the solution. In the case that a $\mathrm{OH}^{-}$containing setting solution is used, the common ion effect would dictate a push towards the formation 


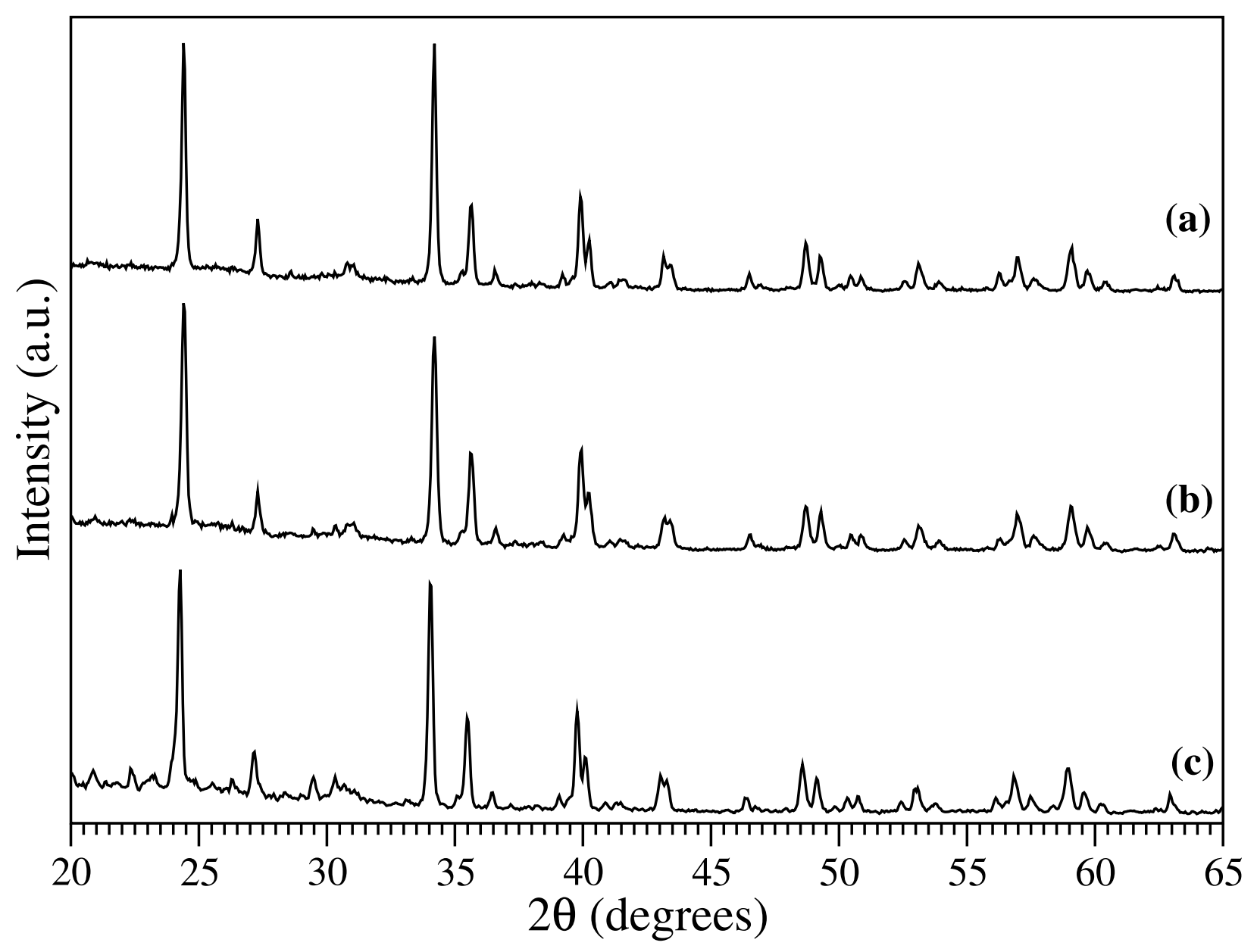

Figure 3.1: Powder X-ray diffraction spectra of $\mathrm{CaHPO}_{4} \cdot 2 \mathrm{H}_{2} \mathrm{O}$ : (a) after mixing with a $1 \mathrm{M} \mathrm{NaOH}$ setting solution at a powder-to-liquid ratio of 2:1 and allowing to set; (b) after mixing with a $1 \mathrm{M} \mathrm{Na}_{2} \mathrm{HPO}_{4}$ setting solution at a powder-to-liquid ratio of 2:1 and allowing to set; and (c) prior to the addition of a setting solution. The addition of either setting solution did not result in the formation of an apatitic product after the setting period. No contamination is apparent in (a) or (b). The difference in the diffraction pattern observed for the unreacted $\mathrm{CaHPO}_{4} \cdot 2 \mathrm{H}_{2} \mathrm{O}$ in the region of $2 \theta<32^{\circ}$ may be due to a difference in the particle size of the powders after the sample preparation as well as minor $\mathrm{pH}$ dependant structure changes. 
of $\mathrm{Ca}(\mathrm{OH})_{2}$ in this system. The production of $\mathrm{CaCO}_{3}$ would then be expected to be rather low, but, is present at low quantities when this setting solution is used (Figure 3.2). In the case of using a $\mathrm{HPO}_{4}{ }^{2-}$ containing setting solution traces of $\mathrm{Ca}_{10}\left(\mathrm{PO}_{4}\right)_{6}(\mathrm{OH})_{2}$ are observed but no $\mathrm{CaCO}_{3}$ (Figure 3.2).

The reaction of the setting solutions with $\mathrm{Sr}(\mathrm{OH})_{2} \cdot 8 \mathrm{H}_{2} \mathrm{O}$ was found to be rather different from that of the $\mathrm{Ca}(\mathrm{OH})_{2}$. The solubility of $\mathrm{Sr}(\mathrm{OH})_{2} \cdot 8 \mathrm{H}_{2} \mathrm{O}$ is $1.77 \mathrm{~g} / 100 \mathrm{~g} \mathrm{H}{ }_{2} \mathrm{O}\left(\text { at } 20^{\circ} \mathrm{C}\right)^{39}$ which is markedly greater than that of either $\mathrm{Ca}(\mathrm{OH})_{2}$ or $\mathrm{CaHPO}_{4} \cdot 2 \mathrm{H}_{2} \mathrm{O}$. In this case, a similar equilibrium and interfering reaction is expected to occur as to that of $\mathrm{Ca}(\mathrm{OH})_{2}$ (Scheme 3.3).

$$
\mathrm{Sr}(\mathrm{OH})_{2} \cdot 8 \mathrm{H}_{2} \mathrm{O}(s) \rightleftharpoons \mathrm{Sr}^{2+}(a q)+2 \mathrm{OH}^{-}(a q)+8 \mathrm{H}_{2} \mathrm{O}(\ell) \stackrel{\mathrm{CO}_{2}(g)}{\longrightarrow} \mathrm{SrCO}_{3}(s)
$$

When the $\mathrm{Sr}(\mathrm{OH})_{2} \cdot 8 \mathrm{H}_{2} \mathrm{O}$ is mixed with either of the setting solutions, the final product in both cases was nearly pure $\mathrm{SrCO}_{3}$ (Figure 3.3). This is an expected result as with this degree of solubility, the $\mathrm{CO}_{2}$ integrated into the mixture with mixing is likely to react to form $\mathrm{SrCO}_{3}$ in a more complete fashion. In the presence of the $\mathrm{HPO}_{4}{ }^{2-}$ ion, $\mathrm{Sr}_{10}\left(\mathrm{PO}_{4}\right)_{6}(\mathrm{OH})_{2}$ did begin to form in small quantities (Figure 3.3).

The high $\mathrm{pH}$ of the $\mathrm{OH}^{-}$containing setting solution seems to aid in the formation of carbonates in the final phantom. For this reason, a $\mathrm{HPO}_{4}{ }^{2-}$ ion containing setting solution was selected for phantom preparation as the formation of carbonates does not seem to be of concern. Although each component of the CPC system was investigated independently, as a system, the reaction does proceed to the formation of strontium-substituted HAp (Figure 3.4). The product which was formed in the final $\mathrm{CaHPO}_{4} \cdot 2 \mathrm{H}_{2} \mathrm{O} / \mathrm{Ca}(\mathrm{OH})_{2} / \mathrm{Sr}(\mathrm{OH})_{2} \cdot 8 \mathrm{H}_{2} \mathrm{O}$ cement system when mixed with a $\mathrm{HPO}_{4}{ }^{2-}$ setting solution was a strontium-substituted ap- 


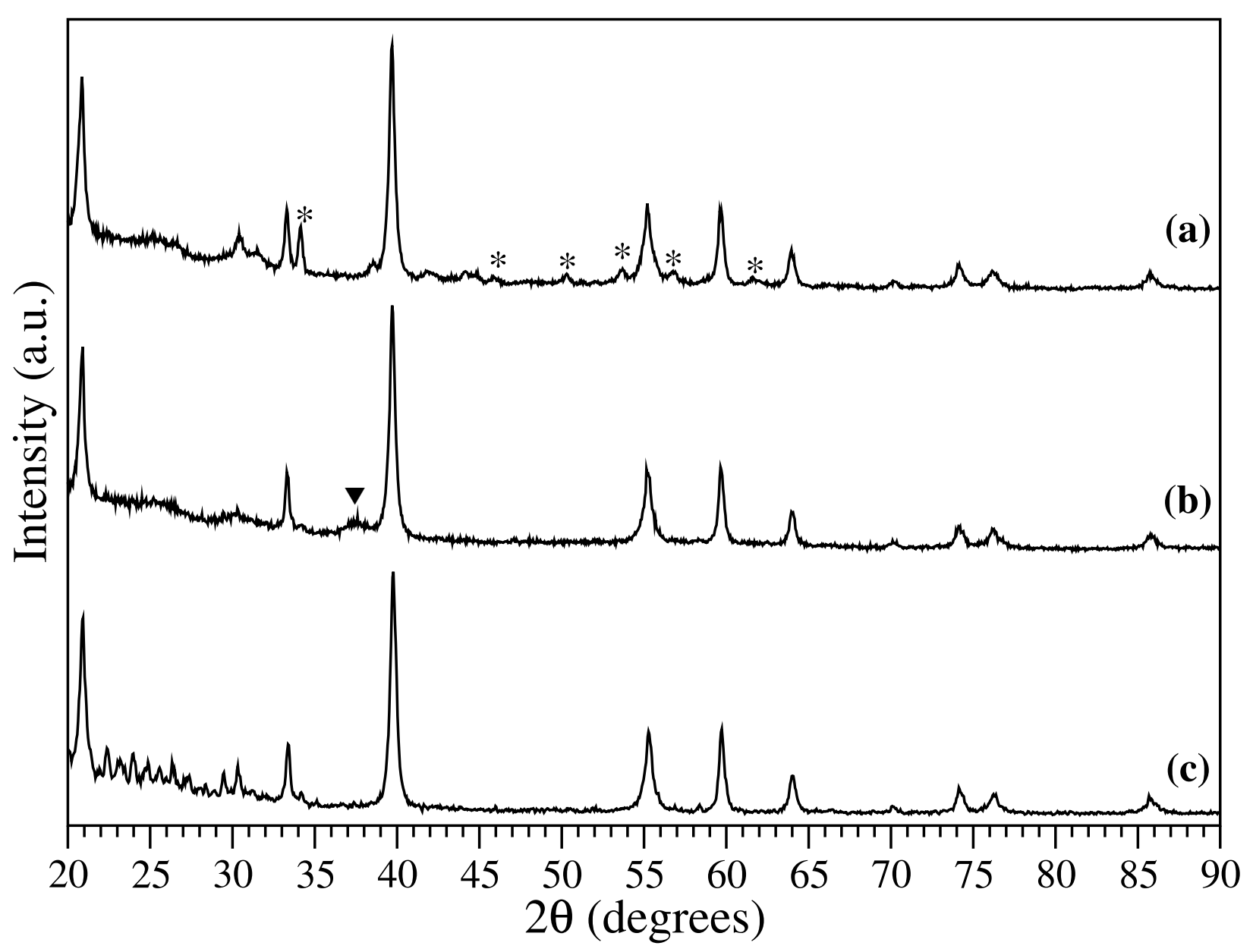

Figure 3.2: Powder X-ray diffraction spectra of $\mathrm{Ca}(\mathrm{OH})_{2}$ : (a) after mixing with a $1 \mathrm{M}$ $\mathrm{NaOH}$ setting solution (b) after mixing with a $1 \mathrm{M} \mathrm{Na}_{2} \mathrm{HPO}_{4}$ setting solution (c) prior to the addition of a setting solution. In all cases the final product consisted mostly of $\mathrm{Ca}(\mathrm{OH})_{2}$. Setting in the presence of a $1 \mathrm{M} \mathrm{NaOH}$ resulted in the formation of some $\mathrm{CaCO}_{3}$. Setting in the presence of a $1 \mathrm{M} \mathrm{Na}_{2} \mathrm{HPO}_{4}$ solution resulted in the formation of some $\mathrm{Ca}_{10}\left(\mathrm{PO}_{4}\right)_{6}(\mathrm{OH})_{2}$ but no carbonate. $(*)$ indicates $\mathrm{CaCO}_{3}$ reflections and $(\boldsymbol{\nabla})$ indicates $\mathrm{Ca}_{10}\left(\mathrm{PO}_{4}\right)_{6}(\mathrm{OH})_{2}$ reflections. The difference in the diffraction pattern observed for the unreacted $\mathrm{CaHPO}_{4} \cdot 2 \mathrm{H}_{2} \mathrm{O}$ in the region of $2 \theta<32^{\circ}$ may be due to a difference in the particle size of the powders after the sample preparation as well as minor $\mathrm{pH}$ dependant changes. 


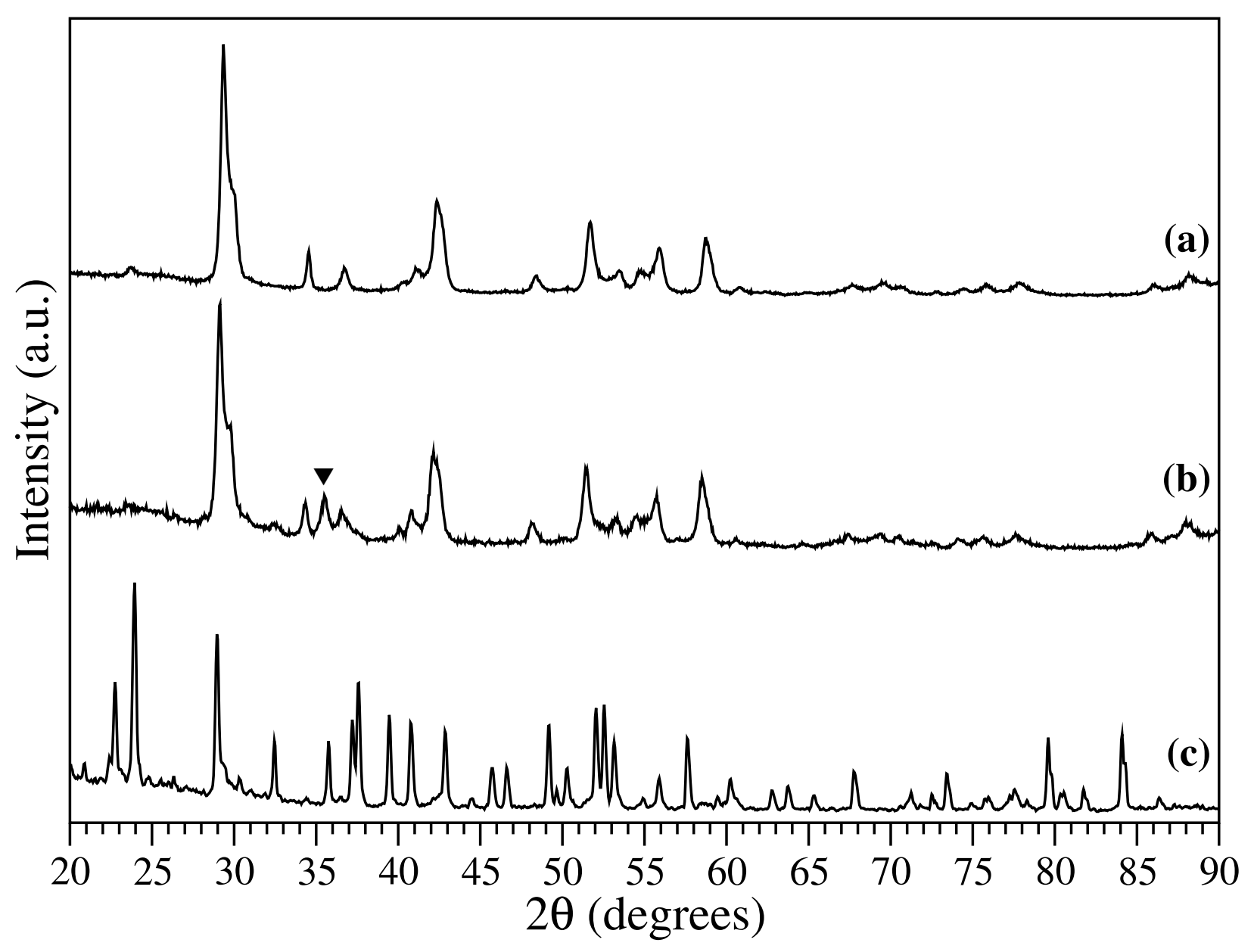

Figure 3.3: Powder X-ray diffraction spectra of $\mathrm{Sr}(\mathrm{OH})_{2} \cdot 8 \mathrm{H}_{2} \mathrm{O}$ : (a) after mixing with a $1 \mathrm{M} \mathrm{NaOH}$ setting solution (b) after mixing with a $1 \mathrm{M} \mathrm{Na}_{2} \mathrm{HPO}_{4}$ setting solution (c) prior to the addition of a setting solution. After setting in the presence of either setting solution, the final product was nearly completely $\mathrm{SrCO}_{3}$ when prepared at ambient due to the incorporation of $\mathrm{CO}_{2}$ from air. Curing in the presence of a $1 \mathrm{M} \mathrm{Na}_{2} \mathrm{HPO}_{4}$ setting solution resulted in small quantities of $\mathrm{Sr}_{10}\left(\mathrm{PO}_{4}\right)_{6}(\mathrm{OH})_{2}$ marked by $(\boldsymbol{\nabla}){ }^{40}$ 


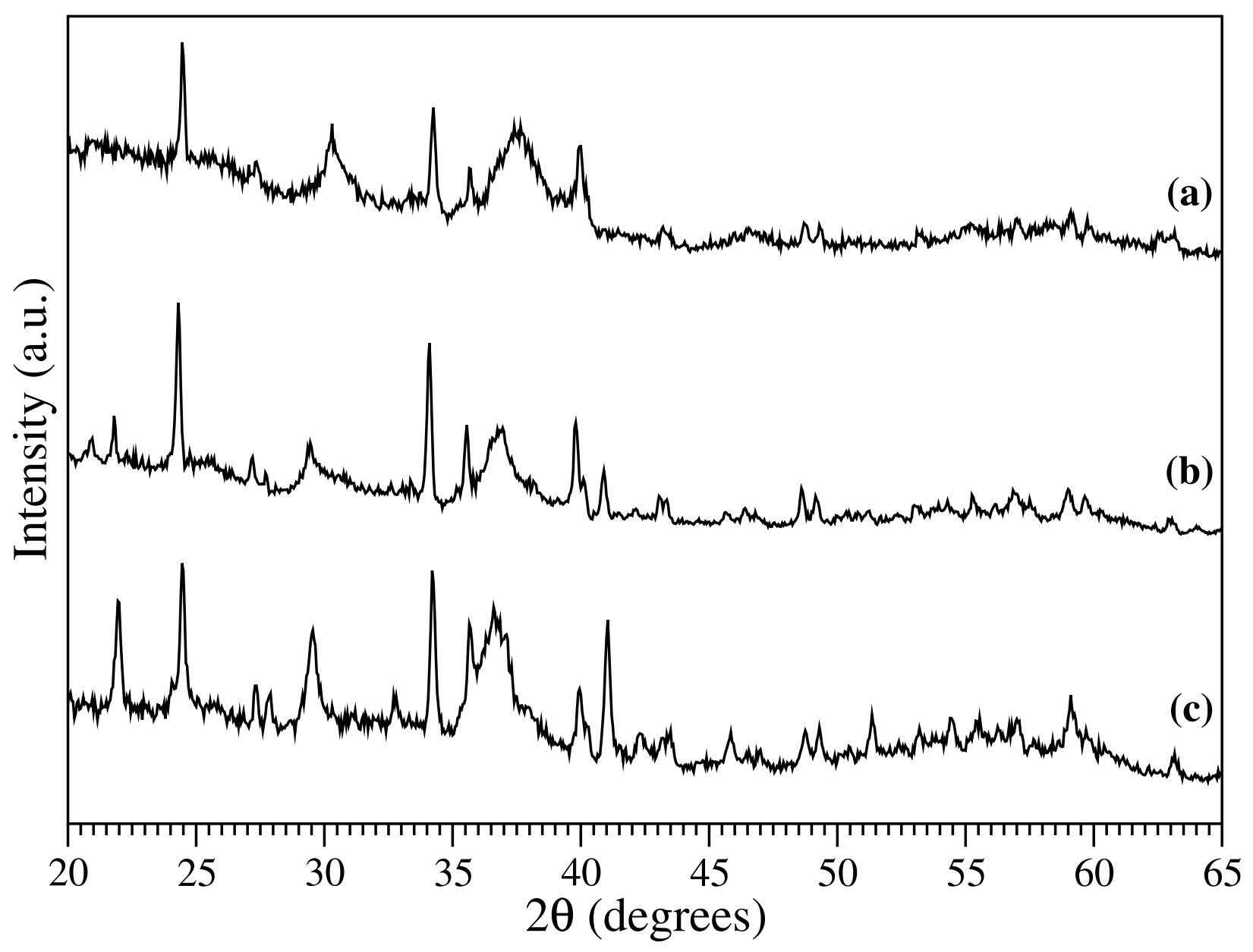

Figure 3.4: Powder X-ray diffraction spectra of apatite products formed with the aid of a phosphate setting solution for: (a) $0 \% \mathrm{~mol} / \mathrm{mol}$ strontium (b) $33.5 \% \mathrm{~mol} / \mathrm{mol}$ strontium and (c) $67 \% \mathrm{~mol} / \mathrm{mol}$ strontium. In all cases an apatitic product was formed.

atite with some minor contributions from the unreacted reagents but no apparent carbonate contamination for various strontium concentrations (Figure 3.4).

There are marked differences in the solubilities of each of the components in the CPC system; however, the final product does not seem to be hindered by this fact. Although one might presume that the $\mathrm{Sr}(\mathrm{OH})_{2} \cdot 8 \mathrm{H}_{2} \mathrm{O}$, given its greater solubility in comparison to $\mathrm{Ca}(\mathrm{OH})_{2}$, would react first forming a phantom which has crystalites of various degrees of strontium substitution and eventually of only calcium hydroxyapatite, this does not seem to be the case. Raman spectroscopy was performed on high strontium phantoms of different 


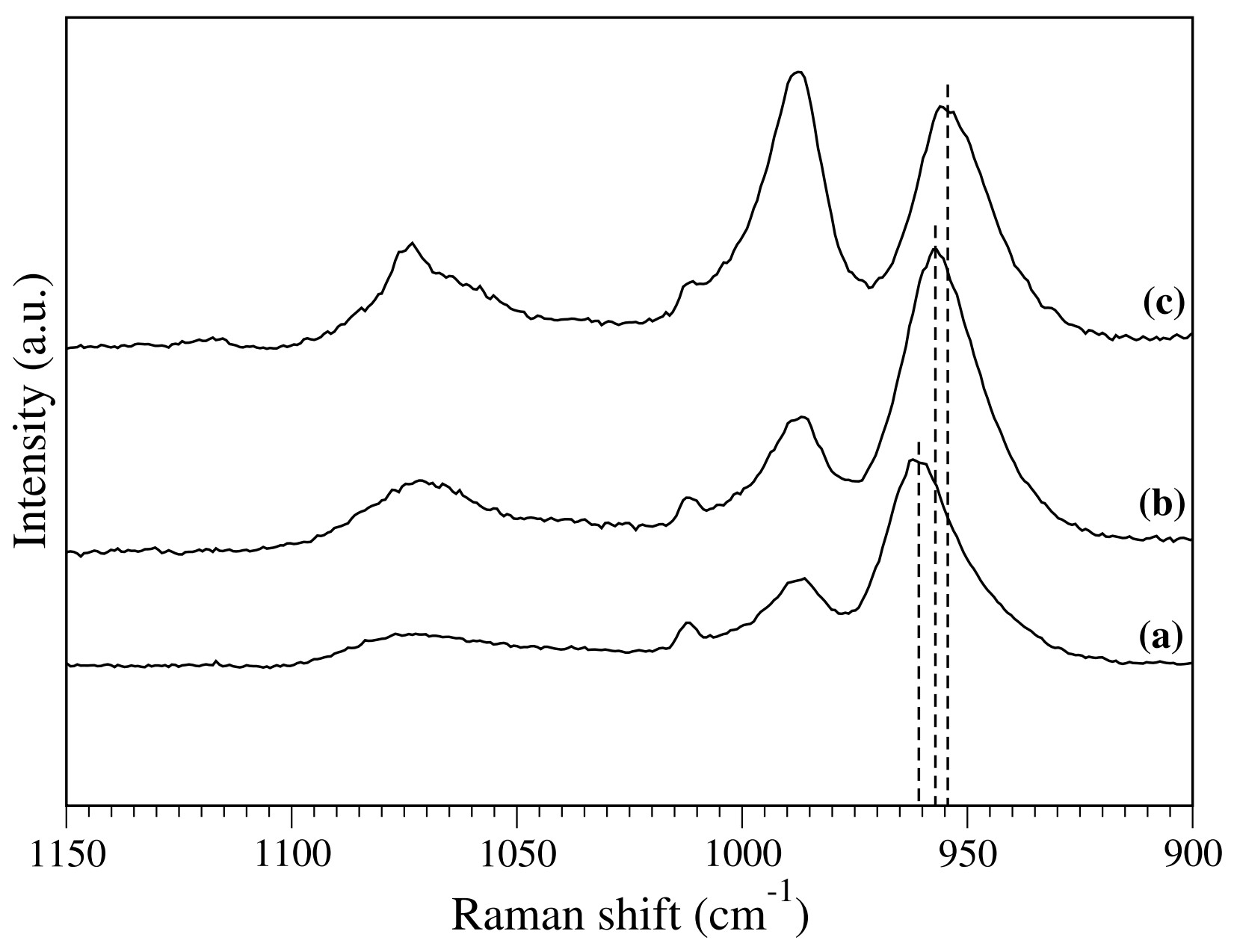

Figure 3.5: Raman spectra of the strontium-substituted HAps with a focus on the $\mathrm{PO}_{4} \nu_{1}$ band and its change in position with respect to the degree of strontium-substitution in the HAp lattice: (a) $0 \mathrm{~mol} / \mathrm{mol} \%$ strontium (b) $33.5 \mathrm{~mol} / \mathrm{mol} \%$ strontium and (c) $67 \mathrm{~mol} / \mathrm{mol} \%$ strontium.

degrees of substitution of the $\mathrm{Ca}(\mathrm{OH})_{2}$ by $\mathrm{Sr}(\mathrm{OH})_{2} \cdot 8 \mathrm{H}_{2} \mathrm{O}$ (Figure 3.5).

The degree of substitution was evaluated using Raman spectroscopy by monitoring the shift in the $\mathrm{HAp}^{\mathrm{PO}_{4}} \nu_{1}$ band at about $960 \mathrm{~cm}^{-1} .{ }^{41}$ Figure 3.5 shows that the trend in the $\mathrm{PO}_{4} \nu_{1}$ band is consistent with increase strontium substitution into the HAp lattice. ${ }^{41}$ This is shown quantitatively in Figure 3.6. The Raman analysis thus indicates that although there are varying solubilities between the reactants, the setting does in fact result in a strontium substituted product in the expected fashion. 


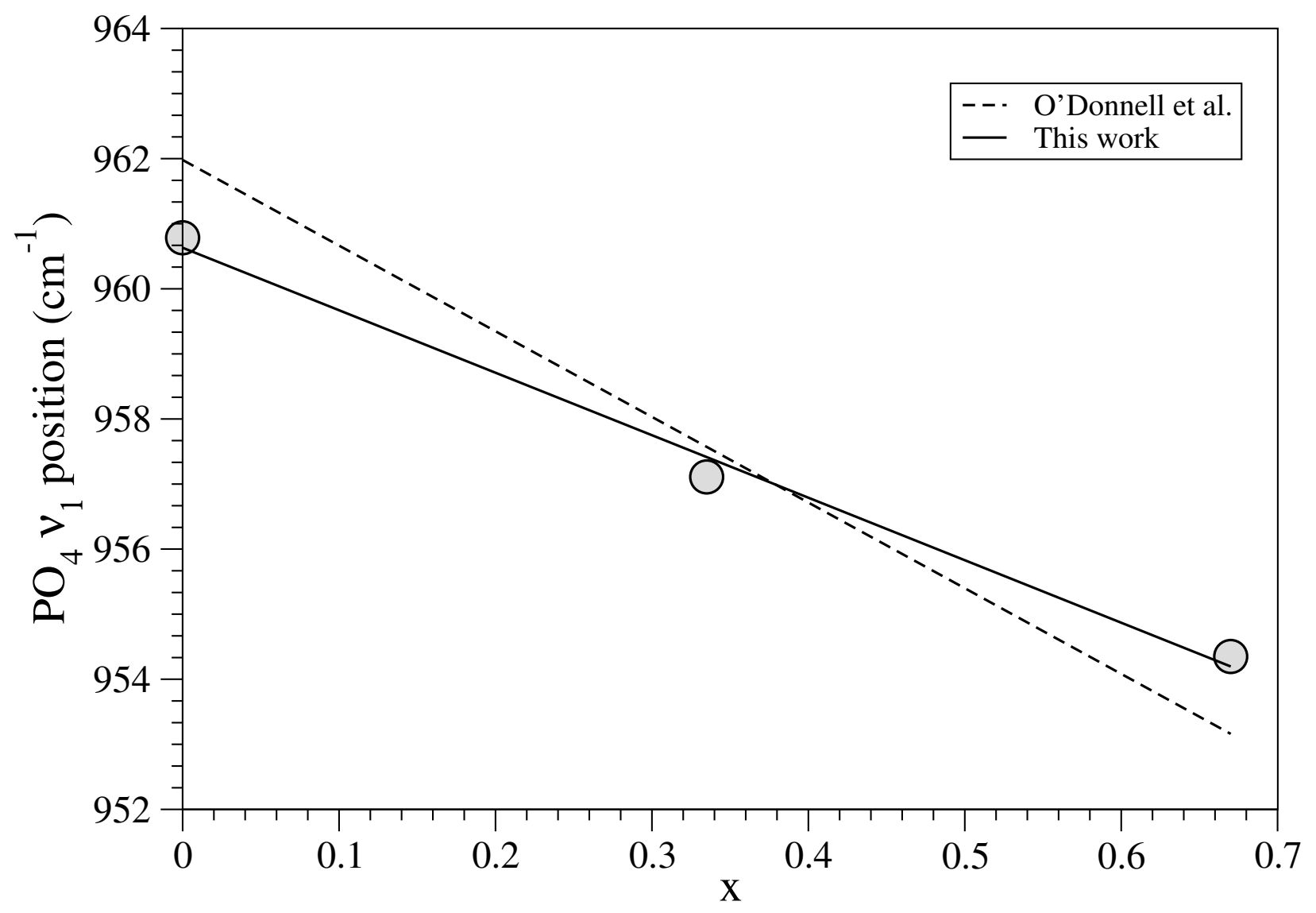

Figure 3.6: Raman analysis of the $\mathrm{PO}_{4} \nu_{1}$ band position as a function of degree of strontium substitution, $x$. The analysis indicates that strontium is in fact substituting into the HAp lattice as a strontium-substituted HAp.

It is thus possible to introduce high levels of strontium into HAp phantoms by the incorporation of the $\mathrm{Sr}(\mathrm{OH})_{2} \cdot 8 \mathrm{H}_{2} \mathrm{O}$, thereby producing biological relevant bone mineral phantoms with well-controlled high strontium concentrations. This study also demonstrates that the strontium, and by extension potentially lead and other divalent metals, does in fact integrate directly into the HAp lattice, as it is known to do in bone. 


\subsection{Conclusions}

This work assessed the feasibility of preparing strontium-substituted HAp bone phantoms with inherently high concentrations of strontium for the purpose of calibration of IVXRF systems of bone strontium quantification. These phantoms to be used in cases in which strontium concentrations are sufficiently high that doping of the setting solution in the phantom preparation protocol previously reported ${ }^{27}$ becomes impractical and in which the $(\mathrm{Ca}$ $+\mathrm{Sr}) / \mathrm{P}$ ratio would deviate from 1.67. Phantoms were prepared using a $\mathrm{CaHPO}_{4} \cdot 2 \mathrm{H}_{2} \mathrm{O} /$ $\mathrm{Ca}(\mathrm{OH})_{2} / \mathrm{Sr}(\mathrm{OH})_{2} \cdot 8 \mathrm{H}_{2} \mathrm{O}$ CPC system with setting using a $1 \mathrm{M}$ setting solution of $\mathrm{Na}_{2} \mathrm{HPO}_{4}$.

The preparation being based on the substitution of the $\mathrm{Ca}(\mathrm{OH})_{2}$ with a suitable quantity of $\mathrm{Sr}(\mathrm{OH})_{2} \cdot 8 \mathrm{H}_{2} \mathrm{O}$ to achieve a total $(\mathrm{Ca}+\mathrm{Sr}) / \mathrm{P}$ mole ration of 1.67 while reducing weighing error by introducing the analyte as a heavy hydroxide hydrate. As a means of assessing the feasibility of the phantom preparation each individual component was assessed by preparation of cements using both a $1 \mathrm{M}$ setting solution of $\mathrm{Na}_{2} \mathrm{HPO}_{4}$ and a $1 \mathrm{M}$ setting solution of $\mathrm{NaOH}$, the latter an alternative method of increasing phosphate content in the phantom mixture by increasing the solubility of $\mathrm{CaHPO}_{4} \cdot 2 \mathrm{H}_{2} \mathrm{O}$. It was found that the $\mathrm{CaHPO}_{4} \cdot 2 \mathrm{H}_{2} \mathrm{O} / \mathrm{Ca}(\mathrm{OH})_{2} / \mathrm{Sr}(\mathrm{OH})_{2} \cdot 8 \mathrm{H}_{2} \mathrm{O}$ CPC system forms a strontium substituted HAp phantom as assessed by X-ray diffraction spectrometry and Raman spectroscopy. The use of a $1 \mathrm{M}$ setting solution of $\mathrm{NaOH}$ was found to tend to increase the rate of carbonate formation by reaction with ambient $\mathrm{CO}_{2}$ and the $\mathrm{Ca}(\mathrm{OH})_{2}$ fraction which is a reason for the selection of the $\mathrm{Na}_{2} \mathrm{HPO}_{4}$ setting solution which which did not present this feature. Although given the greater solubility of $\mathrm{Sr}(\mathrm{OH})_{2} \cdot 8 \mathrm{H}_{2} \mathrm{O}$ versus $\mathrm{Ca}(\mathrm{OH})_{2}$, no adverse effect was observed with regards to the formation of a strontium-substituted HAp with the predicted degree of strontium substitution. This work thus describes a method for the preparation of strontium-substituted HAp bone phantoms for use in the calibration of IVXRF systems of 
bone strontium quantification with extension to other methods including dual-energy X-ray absorptiometry. ${ }^{29,30}$

\subsection{Acknowledgements}

The authors acknowledge the Natural Science and Engineering Research Council of Canada (NSERC) for financial support of this work through an Alexander Graham Bell Canadian Graduate Scholarship (CGS to EDS) and a Discovery Grant (APM). Ryerson University is also acknowledged for their financial support in the form of various graduate scholarships to EDS and BR and for research support to APM. Danny Jang (Department of Physics) is acknowledged for providing some assistance throughout the course of this work. Dr. Dérick Rousseau (Department of Chemistry \& Biology) is also gratefully acknowledged for lending access to the Raman spectrometer as is Sylvia O'Sullivan and Shawn McFadden (Department of Chemistry \& Biology) for their technical assistance. 


\section{References}

[1] D. R. Chettle, "Three decades of in vivo x-ray fluorescence of lead in bone," X-ray Spectrometry, vol. 34, no. 5, pp. 446-450, 2005.

[2] M. Zamburlini, A. Pejović-Milić, and D. R. Chettle, "Spectrometry methods for in vivo bone strontium measurements," X-ray Spectrometry, vol. 37, no. 1, pp. 42-50, 2008.

[3] D. R. Chettle, "In vivo applications of X-ray fluorescence in human subjects," Pramana-Journal of Physics, vol. 76, no. 2, pp. 249-259, 2011.

[4] J. M. O'Meara, D. R. Chettle, F. E. McNeill, and C. E. Webber, "The feasibility of measuring bone uranium concentrations in vivo using source excited K x-ray fluorescence," Physics in Medicine and Biology, vol. 42, no. 6, pp. 1109-1120, 1997.

[5] J. M. O'Meara, D. R. Chettle, F. E. McNeill, and C. E. Webber, "In Vivo X-ray Fluorescence (XRF) Measurement of Uranium in Bone," Applied Radiation $E$ Isotopes, vol. 49, no. 5-6, pp. 713-715, 1998.

[6] D. E. B. Fleming, M. R. Gherase, and K. M. Alexander, "A miniature X-ray tube approach to measuring lead in bone using L-XRF," X-ray Spectrometry, vol. 40, no. 5, pp. 343-347, 2011.

[7] L. H. Nie, S. Sanchez, K. Newton, L. Grodzins, R. O. Cleveland, and M. G. Weisskopf, "In vivo quantification of lead in bone with a portable x-ray fluorescence systemmethodology and feasibility," Physics in Medicine and Biology, vol. 56, no. 3, pp. N39N51, 2011.

[8] L. Ahlgren, K. Lidén, S. Mattsson, and S. Tejning, "X-ray fluorescence analysis of lead 
in human skeleton in vivo," Scandinavian Journal of Work \& Environmental Health, vol. 2, no. 2, pp. 82-86, 1976.

[9] L. Ahlgren and S. Mattsson, "An X-ray Fluorescence Technique for in vivo Determination of Lead Concentration in a Bone Matrix," Physics in Medicine and Biology, vol. 24, no. 1, pp. 136-145, 1979 .

[10] L. J. Somervaille, D. R. Chettle, and M. C. Scott, "In vivo measurement of lead in bone using x-ray fluorescence," Physics in Medicine and Biology, vol. 30, no. 9, pp. 929-943, 1985.

[11] L. J. Somervaille, U. Nilsson, D. R. Chettle, I. Tell, M. C. Scott, A. Schütz, S. Mattsson, and S. Skerfving, "in vivo measurements of bone lead - a comparison of two x-ray fluorescence techniques used at three different bone sites," Physics in Medicine and Biology, vol. 34 , no. 12 , pp. 1833-1845, 1989.

[12] J. A. Hoppin, A. C. A. Aro, P. L. Williams, H. Hu, and P. B. Ryan, "Validation of K-XRF Bone Lead Measurement in Young Adults," Environmental Health Perspectives, vol. 103, no. 1, pp. 78-83, 1995.

[13] A. Aro, C. Amarasiriwardena, M.-L. Lee, R. Kim, and H. Hu, "Validation of K x-ray fluorescence bone lead measurements by inductively coupled plasma mass spectrometry in cadaver legs," Medical Physics, vol. 27, no. 1, pp. 119-123, 2000.

[14] A. C. Todd, E. L. Moshier, S. Carroll, and S. W. Casteel, "Validation of X-Ray Fluorescence-Measured Swine Femur Lead Against Atomic Absorption Spectrometry," Environmental Health Perspectives, vol. 109, no. 11, pp. 1115-1119, 2001. 
[15] A. C. Todd, P. J. Parsons, S. Carroll, C. Geraghty, F. A. Khan, S. Tang, and E. L. Moshier, "Measurements of lead in human tibiae. A comparison between K-shell x-ray fluorescence and electrothermal atomic absorption spectrometry," Physics in Medicine and Biology, vol. 47, no. 4, pp. 673-687, 2002.

[16] D. J. Bellis, A. C. Todd, and P. J. Parsons, "An interlaboratory comparison of bone lead measurements via K-shell X-ray fluorescence spectrometry: validation against inductively coupled plasma mass spectrometry," Journal of Analytical Atomic Spectrometry, vol. 27 , no. 4, pp. 595-603, 2012.

[17] A. Pejović-Milić, I. M. Stronach, J. Gyorffy, C. E. Webber, and D. R. Chettle, "Quantification of bone strontium levels in humans by in vivo x-ray fluorescence," Medical Physics, vol. 31, no. 3, pp. 528-538, 2004.

[18] M. Zamburlini, A. Pejović-Milić, and D. R. Chettle, "Evaluation of geometries appropriate for ${ }^{125} \mathrm{I}$ in vivo bone strontium X-ray fluorescence measurement," Journal of Radioanalytical \&3 Nuclear Chemistry, vol. 269, no. 3, pp. 625-629, 2006.

[19] M. Zamburlini, A. Pejović-Milić, D. R. Chettle, C. E. Webber, and J. Gyorffy, "In vivo study of an x-ray fluorescence system to detect bone strontium non-invasively," Physics in Medicine and Biology, vol. 52, no. 8, pp. 2107-2122, 2007.

[20] M. Zamburlini, A. Pejović-Milić, and D. R. Chettle, "Coherent normalization of finger strontium XRF measurements: feasibility and limitations," Physics in Medicine and Biology, vol. 53, no. 15, pp. N307-N313, 2008.

[21] C. M. Heirwegh, D. R. Chettle, and A. Pejović-Milić, "Ex vivo evaluation of a coherent normalization procedure to quantify in vivo finger strontium XRS measurements," Medical Physics, vol. 39, no. 2, pp. 832-841, 2012. 
[22] A. C. Todd, "L-shell x-ray fluorescence measurements of lead in bone: system development," Physics in Medicine and Biology, vol. 47, no. 3, pp. 507-522, 2002.

[23] A. C. Todd, S. Carroll, C. Geraghty, F. A. Khan, E. L. Moshier, S. Tang, and P. J. Parsons, "L-shell x-ray fluorescence measurements of lead in bone: accuracy and precision," Physics in Medicine and Biology, vol. 47, no. 8, pp. 1399-1419, 2002.

[24] J. M. O'Meara, J. Börjesson, D. R. Chettle, and S. Mattsson, "Normalisation with coherent scatter signal: improvements in the calibration protocol of the ${ }^{57} \mathrm{Co}$-based in vivo XRF bone-Pb measurement," Applied Radiation $\&$ Isotopes, vol. 54, no. 2, pp. 319$325,2001$.

[25] A. C. Todd, "Contamination of in vivo bone-lead measurements," Physics in Medicine and Biology, vol. 45, no. 1, pp. 229-240, 2000.

[26] A. C. Todd, "Coherent scattering and matrix correction in bone-lead measurements," Physics in Medicine and Biology, vol. 45, no. 7, pp. 1953-1963, 2000.

[27] E. Da Silva, B. Kirkham, D. V. Heyd, and A. Pejović-Milić, "Pure Hydroxyapatite Phantoms for the Calibration of in Vivo X-ray Fluorescence Systems of Bone Lead and Strontium Quantification," Analytical Chemistry, vol. 85, no. 19, pp. 9189-9195, 2013.

[28] S. P. Nielsen, "The biological role of strontium," Bone, vol. 35, no. 3, pp. 583-588, 2004.

[29] J. Christoffersen, M. R. Christoffersen, N. Kolthoff, and O. Bäarenholdt, "Effects of Strontium Ions on Growth and Dissolution of Hydroxyapatite and on Bone Mineral Detection," Bone, vol. 20, no. 1, pp. 47-54, 1997.

[30] S. P. Nielsen, D. Slosman, O. H. Sørensen, B. Basse-Cathalinat, P. De Cassin, C. Roux, and P. J. Meunier, "Influence of Strontium on Bone Mineral Density and Bone Mineral 
Content Measurements by Dual X-Ray Absorptiometry," Journal of Clinical Densitometry, vol. 2, no. 4, pp. 371-379, 1999.

[31] P. W. Brown, N. Hocker, and S. Hoyle, "Variations in Solution Chemistry During the Low-Temperature Formation of Hydroxyapatite," Journal of the American Ceramics Society, vol. 74, no. 8, pp. 1848-1854, 1991.

[32] E. Fernández, M. G. Boltong, M. P. Ginebra, O. Bermúdez, F. C. M. Driessens, and J. A. Planell, "Common Ion Effect on Some Calcium Phosphate Cements," Clinical Materials, vol. 16, no. 2, pp. 99-103, 1994.

[33] L. C. Chow, M. Markovic, and S. Takagi, "Formation of Hydroxyapatite in Cement Systems: Effects of Phosphate," Phosphorous, Sulfur and Silicon, vol. 144-146, no. 1, pp. 129-132, 1999.

[34] S. Takagi, L. C. Chow, and K. Ishikawa, "Formation of hydroxyapatite in new calcium phosphate cements," Biomaterials, vol. 19, no. 17, pp. 1593-1599, 1998.

[35] K. D. Jørgensen and A. S. Posner, "Study of the Setting of Plaster," Clinical Materials, vol. 38 , no. 3 , pp. 491-499, 1956.

[36] W. H. Haynes, ed., CRC Handbook of Chemistry 83 Physics. CRC Press, 95 ed., 2014.

[37] K. Ishikawa and E. D. Eanes, "The Hydrolysis of Anhydrous Dicalcium Phosphate into Hydroxyapatite," Journal of Dental Research, vol. 38, no. 3, pp. 491-499, 1993.

[38] M. T. Fulmer and P. W. Brown, "Hydrolysis of dicalcium phosphate dihydrate to hydroxyapatite," Journal of Materials Science: Materials in Medicine, vol. 9, no. 4, pp. 197202, 1998. 
[39] R. C. Ropp, Encyclopedia of the Alkaline Earth Compounds. Elsevier, 2013.

[40] R. C. Ropp, M. A. Aia, C. W. W. Hoffman, T. J. Veleker, and R. W. Mooney, "X-Ray Powder Diffraction Patterns of Strontium Phosphates," Analytical Chemistry, vol. 31, no. 7, pp. 1163-1166, 1959.

[41] M. D. O'Donnell, Y. Fredholm, A. de Rouffignac, and R. G. Hill, "Structural analysis of a series of strontium-substituted apatites," Acta Biomaterialia, vol. 4, no. 5, pp. 14551464, 2008. 
CHAPTER

FOUR

\section{APPLICATION OF THE BLANK HYDROXYAPATITE PHANTOM TO ASSESS SPECTRAL BACKGROUND IN THE CONTEXT OF AN IN VIVO XRF BONE STRONTIUM MEASUREMENT}

Working paper for publication: E. Da Silva, H. Moise, D. R. Chettle and A. Pejović-Milić, "Assessing spectral background interference in the in vivo bone strontium system using a blank phantom." $†$

${ }^{\dagger}$ E. Da Silva designed and carried out the experiments, performed the data analysis and wrote this manuscript/chapter. M. Moise and D. R. Chettle made similar observations to be included in future drafts of this work (see Figure 4.2) with regards to a direct seed measurement, but on the clinical system (not included in this draft). A. Pejović-Milić financed this project, provided critical feedback as to its contents and the experiments, assessed the manuscript/chapter critically and brought both research groups together. 


\subsection{Abstract}

Analytical blanks are routinely used in spectrochemical analysis as a means of assessing spectral background, the presence of spectral interferences and for the determination of analytical figures of merit. In the context of an in vivo X-ray fluorescence spectrometry (XRF)-based bone strontium determination, a true blank measurement has not been possible to date given the lack of a suitable blank phantom. The absence of a suitable blank being due to the fact that calcium compounds (including plaster of Paris typically used to make bone phantoms) are heavily contaminated with the analyte strontium. In this work, we investigate the need for the blank hydroxyaptite phantom recently developed for the purpose of XRF-based bone strontium quantification. ${ }^{1}$ It was found that the ${ }^{125} \mathrm{I}$ brachytherapy seed excitation source used in the clinical system emits a spectrum containing the zirconium K-series $\left(\mathrm{K} \alpha_{1,2}=15.73 \mathrm{keV}, \mathrm{K} \beta_{1,3}=17.66 \mathrm{keV}\right)$, which overlaps with the strontium K-series $\left(\mathrm{K} \alpha_{1,2}\right.$ $=14.13 \mathrm{keV}, \mathrm{K} \beta_{1,3}=15.83 \mathrm{keV}$ ) and thus presents a possible source of spectral interference. The presence of zirconium on/in the seeds was confirmed after their decay and qualitative assessment using a portable X-ray analyzer. Monte Carlo simulations demonstrated that in the $180^{\circ}$ backscatter geometry, used for clinical bone strontium measurements, the most probable scattering interaction into the detector is Compton scattering of the zirconium $\mathrm{K}$ $\mathrm{X}$-rays; thus, presenting a possible spectral interference beneath both the strontium $\mathrm{K} \alpha_{1,2}$ and $\mathrm{K} \beta_{1,3}$ lines. A blank measurement using a blank hydroxyaptite phantom and silicon drift detector (SDD)-based detection system in an off-centre backscatter geometry showed the presence of rubidium and possible strontium (believe to be system contamination) and Compton scattered zirconium photons. This work thus demonstrates the need for a blank measurement in the context of an in vivo XRF-based bone strontium measurement as a means of quantifying these interferences further and implementing them in future system 
developments as well as refinements to the overall calibration protocol.

\subsection{Introduction}

Spectrochemical methods of quantitative analysis generally include an analytical blank measurement as part of their calibration protocols. Analytical blank measurements serve various important functions. For wet chemical methods, in which a sample is to be digested and samples and calibrators prepared as solutions, an analytical blank will generally be composed of all of the reagents used to prepare the samples and calibrators with the exception of any added analyte. A measurement of an analytical blank then provides a measure of any signal which may arise due to contamination from the analyte as well as provide an assessment of any spectral interferences which may hinder the ability to measure the given analyte-produced signal reliably. Analytical blank measurements thus allow the analyst to devise background subtraction methods in the case any inherent contamination is present to the system and/or reagents or if sufficiently minor spectral interferences are present. Aside from simple background and spectral interference assessments, one of the more important applications of an analytical blank measurement is to assess the statistical distribution of the spectral background and associated system noise without the inclusion of any signal from the analyte. This allows one to properly compute analytical figures of merit for the system (i.e. the signal-to-noise ratio, limit of detection and limit of quantification) - a critical component of any calibration procedure. Although not a wet chemical method, for in vivo methods of bone metal quantification, blanks are employed for the determination of the minimum detectable limit (MDL) which is an analogous parameter to the limit of detection for the same reasons as for wet chemical methods.

For solid state, in situ, methods of quantitative metals analysis, such as X-ray fluores- 
cence spectrometry (XRF), it is desirable to make an analytical blank measurement as a means of assessing for any spectral interferences as well as for any contamination that may arise from any sample preparation pretreatments. Sample pretreatment as a source of contamination is not relevant for the case of in vivo XRF (IVXRF) measurements which are in situ measurements void of a sample preparation.

The determination of true background noise is however more complicated for in situ methods, such as XRF, in comparison to wet chemical methods of metals analysis, as wet chemical methods generally present the analyte in solution at low concentrations, whereby, XRF measurements are routinely used to assess total sample composition, or, as is the case of an in vivo bone metal measurement a single element with assumptions about total sample composition. By the measurements very nature it becomes difficult, if, at all possible, to produce true analytical blanks for many cases of XRF calibration.

From a practical viewpoint, XRF, in its most general sense and not only considering the in vivo case, is a method in which a blank calibrator is not available for assessment of spectral background. Given that XRF is used to quantify the total composition of samples, thereby, as a requirement for calibration procedure all analyte lines are present, ${ }^{2-4}$ and thereby, blanks are often not available, estimates of the background are often performed using background information adjacent to the analytical peak of interest, while, spectral interferences from system components can be estimated using selected pure materials which act as scatterers (i.e. graphite). ${ }^{5}$

IVXRF bone metal measurements offer a scenario in which a blank can be produced (see Chapter 2). Given that the analyte, say, strontium, is only present in small concentrations (at trace or minor levels) then it is possible to produce a blank in which the matrix (bone mineral) is free of the analyte, although, in the case of strontium, such a material has 
traditionally been unavailable. ${ }^{1,6}$

IVXRF methods of bone lead and bone uranium quantification have been shown to be calibrated against sufficiently pure materials such that blanks are produced adequately. ${ }^{7-11}$ This is not however the case for bone strontium analyses as there has been no available analytical blank for the system until this work. ${ }^{1,12}$ The lack of a blank being due to endogenous contamination of the plaster of Paris (poP) used for the preparation of phantoms with the analyte strontium. ${ }^{12,13}$

One of the most important functions of an analytical blank is its critical role in the determination of the minimum detectable limit (MDL) of the system/method. Determination of the MDL inherently involves assessing sources of noise in the analytical/spectral region associated with the signal produced by the analyte. In the case of an IVXRF bone strontium determination, if one ignores any other sources of background/interference, background and associated noise would include electronic noise as well as the background due to Compton scattering of source photons into the energy region of the strontium K-series. In reality however, sources of background may include spectral interference from other overlapping characteristic X-rays, which could influence the data reduction (curve fitting) procedures used to extract the analytical signal (integrated peak areas) as well as the MDL. If these spectral interferences - notably peak overlaps - are severe enough, they may not be perfectly visible on any collected spectrum. In this case, the blank serves the function of assessing sources of noise and possible exogenous analyte contamination from the system, that will influence the MDL as well as the determined analytical signal in any given spectrum collected for analysis, if spectral interferences are present.

The current IVXRF system of bone strontium measurement uses phantoms which are heavily contaminated with strontium. ${ }^{12,13}$ The current "blank" (i.e. the $0 \mathrm{ppm}$ phantom) is 
simply a poP phantom with no additionally added strontium but which contains an inherently large amount of the strontium due to endogenous contamination. ${ }^{12,13}$

In this case, by use of a heavily contaminated blank phantom possible spectral interferences cannot be assessed as even the "blank" phantom produces a significant amount of analytical signal. From the point of view of an MDL determination, then, this is not an ideal scenario. Firstly, the presence of analytical signal in the lowest concentration phantom does not allow for the determination of a true background which may influence the spectral analysis of collected spectra (i.e. if a spectral overlap is present due to system contamination). Secondly, determination of the MDL requires an estimate of $\sigma_{0}$, which is the standard deviation of the signal produced at the energy region of the analyte due to background. In the case in which the analyte's signal is present, $\sigma_{0}$ would not truly account for background variation alone, as the determined $\sigma_{0}$ would likely be over shadowed by counting statistics from the observed analytical signal. With current determined MDLs being well below the average inherent bone strontium content in humans, one could however argue that in the case of a bone strontium measurement, it would be impossible to have a measurement take place such that the bone strontium concentration would ever be below the MDL. ${ }^{12,13}$ The more important application of the analytical blank would thus be to assess spectral interferences which may result in biases in the determined analytical peak areas used for quantitative purposes. For this reason, the influence of having a true blank available on the MDL was not further investigated in this work and is a point for future investigation. Instead this work focused on the necessity and importance of the blank developed by Da Silva et al. ${ }^{1}$ for the purpose of background and contamination assessment.

In this chapter we provide the first blank phantom measurement for bone strontium quantification and discuss possible sources of spectral interference which inherently demonstrate 
the necessity for the material which is suitable for a true blank measurement to assess for spectral interferences.

\section{$4.3 \quad$ Experimental}

\subsubsection{Blank Bone Phantom}

The blank phantom was prepared as previously described ${ }^{1}$ (Chapter 2) using the same listed reagents and methodologies. The phantom was prepared with a diameter of $10 \mathrm{~mm}$ and a height of $20 \mathrm{~mm}$. The presence of strontium in the blank bone phantom was assessed by total reflection X-ray fluorescence spectrometry (TXRF) as previously described. ${ }^{1}$

\subsubsection{Brachytherapy Seeds}

The excitation source used for the purpose of IVXRF bone strontium measurements was ${ }^{125} \mathrm{I}$ in the form of brachytherapy seeds. This type of excitation source is what is typically used as the excitation source for said measurements. ${ }^{14-16}$ The seeds used in this study were Advantage ${ }^{125}$ I interstitial brachytherapy seeds (Model No. IAI-125A; IsoAid, Port Richey, FL, USA). Each seed consisted of a laser welded titanium capsule which contained ${ }^{125} \mathrm{I}$ chemically affixed onto a silver rod. In the context of the actual application of these seeds, prostate brachytherapy, the silver rod acts as an X-ray marker. Each seed had a total length of $4.5 \mathrm{~mm}$, a thickness of $0.8 \mathrm{~mm}$ and a titanium wall thickness of $0.5 \mathrm{~mm}$.

The batch of brachytherapy seeds consisted of three seeds in total. The weighted average activity per seed was determined by the manufacturer to be $0.638 \mathrm{mCi}$ (range of $0.632-$ $0.644 \mathrm{mCi}$ ) and the total activity of all three seeds was $1.91 \mathrm{mCi}$. The emission spectrum assumed for these seeds in the simulation work was that as determined by Zamburlini et al 
$(2007) \cdot{ }^{6,17}$

\subsubsection{Qualitative elemental analysis of brachytherapy seeds}

The seeds were assessed for their overall composition, on a qualitative level by XRF. This measurement was performed as to assess the composition of the seeds without fear of exciting surrounding features of the silicon drift detector-based in vivo XRF unit. The seeds were allowed to decay for a period of 430 days prior to the measurement which amounts to 7.24 half-lives of ${ }^{125} \mathrm{I}\left(t_{1 / 2}=59.4\right.$ days $)$. The total activity at the time of the measurement for all three seeds was calculated to be $12.6 \mu \mathrm{Ci}$.

The XRF measurement was performed using a portable X-ray spectrometer (Tracer-III SD, Bruker-AXS, Madison, WI, USA). The spectrometer was equipped with a miniaturized rhodium target $\mathrm{X}$-ray tube operating at $40 \mathrm{kVp}$ and $30 \mu \mathrm{A}$. The primary beam was hardened for this measurement using a multilayer filter composed of $12 \mathrm{mil} \mathrm{Al}+1 \mathrm{mil} \mathrm{Ti}+1 \mathrm{mil}$ $\mathrm{Cu}$ as to improve the background at the zirconium K-series energy region. Photon detection was achieved using a $10 \mathrm{~mm}^{2}$ XFlash@) silicon drift detector system (Bruker-AXS, Madison, WI, USA). The resolution of the detector was quoted by the manufacturer as being on the order of $145 \mathrm{eV}$.

The measurement was made by placing the seeds directly onto the measurement window and a 300 s real time measurement acquired. Although the seeds were still relatively active, the measurement did not exceed a dead time of $2.1 \%$ (total raw count rate of $8947 \mathrm{cps}$ ). The system is routinely monitored for contamination using a series of standard alloys and glasses. No inherent zirconium contamination is known of this system as a whole, as determined routinely using various scatterers. 


\subsubsection{Direct Source and Blank Phantom Measurement}

The direct seed measurement and the blank phantom measurement was performed on the SDD detector-based detection system which was selected due to availability. This system was a test system for the first blank measurement and is not currently the clinical IVXRF bone strontium system which was selected for the simulation study. The clinical system being based on a $\mathrm{Si}(\mathrm{Li})$ detection system and a true $180^{\circ}$ backscatter geometry as described elsewhere. ${ }^{6,15,16}$ The detector used for our measurements, due to availability for a preliminary assessment, was an $80 \mathrm{~mm}^{2}$ active area Vitus H80 single-element SDD detector with an associated AXAS-A module (KETEK GmBH, Munich, Germany). A tungsten collimator was place at the head of the detector, which reduced the total area of the detector and acted as a mount for the tungsten collimator used to house the brachytherapy seeds. This collimator was placed off centre as shown by Sibai $(2011)^{18}$ which produces a backscatter geometry with scattering angles slightly less than $180^{\circ}$. This arrangement was used as given the small size of the detector, placing the collimator in a fashion as to ensure a true $180^{\circ}$ backscatter geometry would result in covering of the majority of the active area of the detector.

The direct seed measurement was made by placing the seed in front of the detector at a distance of $1 \mathrm{~m}$ from the detector window of the SDD detection system. The direct seed measurement was made for a $12 \mathrm{hr}$ live time period.

For the blank bone phantom measurement, the phantom was placed at a source-to-sample surface distance of $5 \mathrm{~mm}$ and a measurement was made for $20 \mathrm{~min}$ live time, simulating an in vivo human measurement. The experimental set-up is shown in Figure 4.1. At the time of the blank measurement the seeds had decayed by approximately three half-lives and only one seed was used for the purpose of the blank measurement. 


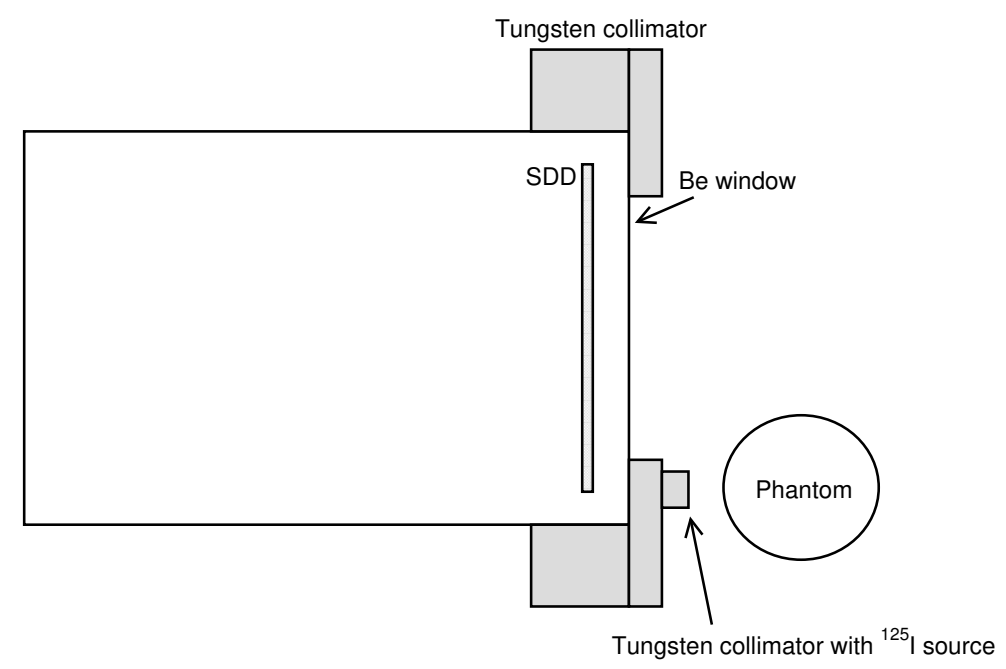

Figure 4.1: Experimental set-up for the blank phantom measurement. The drawing is not to scale.

\subsubsection{Monte Carlo Simulations}

Monte Carlo simulations were made as per Zamburlini et al. ${ }^{17}$ as to mimic a human bone strontium measurement. ${ }^{6,15,16}$ The simulations were completed using the EGS5 (Electron Gamma Shower) Monte Carlo simulation package using $10^{12}$ incidence particles. $10^{12}$ incident particles was selected as it was found that this was an optimal number to balance computation time and statistical variation at the strontium $\mathrm{K} \alpha_{1,2}$ (not greater than approximately $5 \%$ at $400 \mathrm{ppm})$. The emission spectrum used for the ${ }^{125} \mathrm{I}$ brachytherapy source was that described by Zamburlini et al. ${ }^{6}$ Simulations were carried out on a finger phantom modelled as a $9 \mathrm{~mm}$ cylinder of cortical bone tissue with a $2 \mathrm{~mm}$ shell of soft tissue which models the average geometry of a human finger adequately. ${ }^{17}$ The detector window-to-phantom surface distance was maintained at $5 \mathrm{~mm}$ for all simulations. The detector arrangement was simulated as to mimic a $\mathrm{Si}(\mathrm{Li})$ detection system, with a tungsten collimator housing the ${ }^{125} \mathrm{I}$ brachytherapy source which allows for a $180^{\circ}$ backscatter geometry to the detector relative to the sample. ${ }^{17}$ A schematic of the geometry used for the simulations is shown in Figure 
1.1 (see section 1.4, pg. 12).

The composition of cortical bone tissue used for the simulations was that described by the International Commission on Radiological Protection ICRP $^{19}$ with a mass density of $1.9 \mathrm{~g} / \mathrm{cm}^{3}$ and a composition of: $0.034 \% w / w \mathrm{H} ; 0.155 \% w / w \mathrm{C} ; 0.042 \% w / w \mathrm{~N} ; 0.435 \%$ $w / w \mathrm{O} ; 0.003 \% w / w \mathrm{Na} ; 0.002 \% w / w \mathrm{Mg} ; 0.103 \% w / w \mathrm{P} ; 0.003 \% w / w \mathrm{~S} ; 0.225 \% w / w$ Ca. The composition of the soft tissue used for the simulations was that described by the International Commission on Radiological Units ICRU ${ }^{20}$ with a mass density of $1.04 \mathrm{~g} / \mathrm{cm}^{3}$ and a composition of: $0.1 \% w / w \mathrm{H} ; 0.204 \% w / w \mathrm{C} ; 0.042 \% w / w \mathrm{~N} ; 0.645 \% w / w \mathrm{O}$; $0.002 \% w / w \mathrm{Na} ; 0.001 \% w / w \mathrm{P} ; 0.002 \% w / w \mathrm{~S} ; 0.003 \% w / w \mathrm{Cl} ; 0.001 \% w / w \mathrm{~K}$. In order to account for the inclusion of zirconium in the source, the source component of the code was normalized to $100 \%$ fluence and zirconium was added by including its emission spectrum with various relative contributions to the total fluence. The entire zirconium K-series was included in the simulation when performing this operation. Data was processed using an in-house script written in BASH and GNU Octave.

\subsection{Results and Discussion}

One possible source of spectral interference/system contamination may be the excitation source itself, which, in the context of an in vivo bone strontium measurement, consists of brachytherapy seeds. These seeds, being prepared for a therapeutic application, have not been specifically prepared for such an analytical application and may be a source of contamination to the system. Figure 4.2 shows a spectrum produced from a direct measurement of the brachytherapy seeds used as a source for the IVXRF quantification of bone strontium $6,15,16$ measured on an SDD detection system. The spectrum shows the presence of rubidium, strontium and the zirconium K-series (Figure 4.2). From this measurement it is 
Table 4.1: Characteristic X-ray energies organized by possible spectral overlap for rubidium, strontium and zirconium. ${ }^{21}$ All energies are quoted in units of $\mathrm{keV}$.

\begin{tabular}{ll|ll|ll}
\hline \hline \multicolumn{2}{c}{${ }_{37} \mathrm{Rb}$} & \multicolumn{2}{c}{${ }_{38} \mathrm{Sr}$} & \multicolumn{2}{c}{${ }_{40} \mathrm{Zr}$} \\
\hline $\mathrm{K} \alpha_{1,2}$ & 13.37 & & & \\
$\mathrm{~K} \beta_{1,3}$ & 14.96 & $\mathrm{~K} \alpha_{1,2}$ & 14.13 & & \\
$\mathrm{~K} \beta_{5}$ & 15.09 & $\mathrm{~K} \beta_{1,3}$ & 15.83 & $\mathrm{~K} \alpha_{1,2}$ & 15.73 \\
& & $\mathrm{~K} \beta_{5}$ & 15.97 & & \\
& & & & $\mathrm{~K} \beta_{1,3}$ & 17.66 \\
& & & & $\mathrm{~K} \beta_{5}$ & 17.22 \\
\hline \hline
\end{tabular}

apparent that the system is prone to possible spectral contamination from rubidium, the analyte strontium and zirconium. Provided that this is a direct measurement, it is likely that these X-rays are emanating directly from the source, but may be due to excitation of system components which necessitated a secondary assessment of the source external to the detection system. Based on the direct seed measurement, the rubidium can be of concern in the case in which it is present in large concentrations as the rubidium $\mathrm{K} \beta$ line overlaps with the high energy side of the strontium $\mathrm{K} \alpha_{1,2}$ line which is often used for the purpose of quantification (Table 4.1). Zirconium contamination may be an issue when the strontium $\mathrm{K} \beta$ line is to be used for quantitative purposes (Table 4.1). With regards to the degree of contamination, from the direct measurement, the total measured fluence of the zirconium K-series was estimated to be less than $1 \%$ of the total fluence from the source, as normalized to the full emission spectrum.

Although characteristic X-rays from elements which produced characteristic X-rays within the strontium energy region were observed during a direct seed measurement (Figure 4.2), this does not necessarily mean that their origins were from the excitation source. For this reason, the brachytherapy seeds themselves were subjected to a qualitative assessment by XRF after a sufficient time was allowed for the seeds to decay to an appropriate level of 


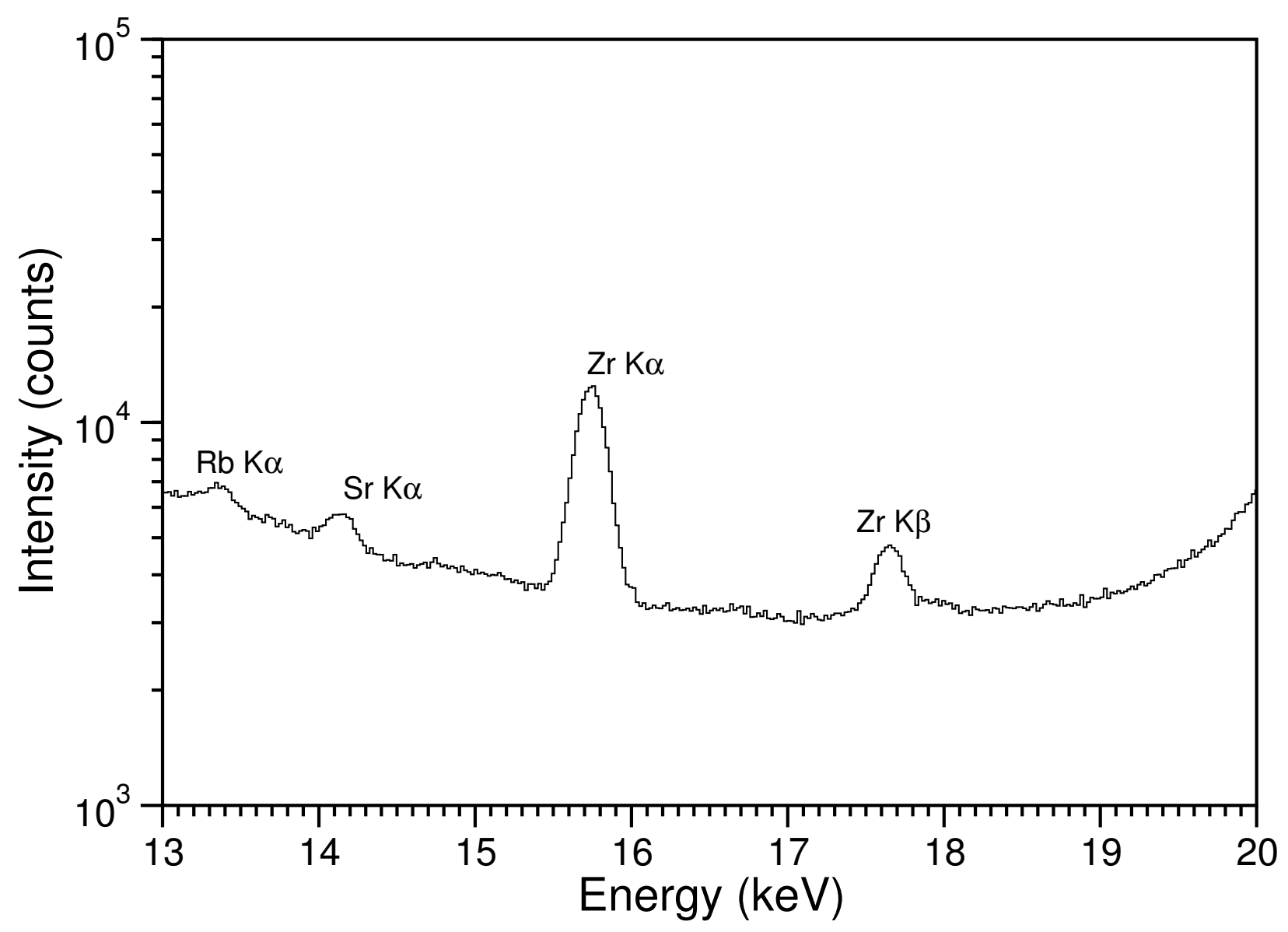

Figure 4.2: Result of a direct measurement of the brachytherapy seeds used as an excitation source for in vivo X-ray fluorescence spectrometry measurements of bone strontium (see section 4.3.4) at $1 \mathrm{~m}$ from the SDD detector window. The figure shows the energy region of analytical interest within the energy range of $13-20 \mathrm{keV}$. The direct measurement collected over a 12 hour live time period shows the presence of rubidium, strontium and zirconium characteristic X-rays presumed to be emitted from the brachytherapy seeds themselves. 
activity, in order to assess their composition. This decay was implemented as a means of ensuring that the fluence rate from the $\gamma$-radiation emitted by the brachytherapy seeds to the X-ray spectrometer's detector was not exceedingly high. The spectrum showed the expected X-ray series from the ${ }^{125} \mathrm{I}$ decay as well as the presence of zirconium (Figure 4.3). There was no evidence of rubidium or strontium in the spectrum obtained from the direct seed measurement (Figure 4.3) which would indicate that the rubidium and strontium were likely from internal components of the SDD detection system or from surrounding contamination. The qualitative assessment of the cold brachytherapy seeds thus indicates that the only spectral interference to be considered as emanating from the source is in fact zirconium and not any rubidium or strontium (Figure 4.3).

The presence of zirconium in the brachytherapy seeds in not unexpected. The main application of the seeds is for permanent implantable brachytherapy for the treatment of prostate cancer. The seed capsules are composed of titanium (Section 4.3.2); however, as a means of reducing the corrodibility of the titanium, biomedical grade titanium is often either coated with, or an alloy of, zirconium. It is thus reasonable to conclude that the brachytherapy seeds used as a source for the IVXRF system for bone strontium quantification are contaminated directly with zirconium, which presents a possible spectral interference within the analyte's energy region (Table 4.1).

The consequence to the presence of zirconium in/on the seeds is relatively clear when inspecting Table 4.1. The zirconium $\mathrm{K} \alpha_{1,2} \mathrm{X}$-ray overlaps directly with the $\mathrm{K} \beta_{1,3}$ of strontium. In this case then, it is possible that if the strontium $\mathrm{K} \alpha_{1,2} / \mathrm{K} \beta_{1,3}$ ratio is to be used as an analytical measure ${ }^{6}$ then the ratio would tend to be skewed if zirconium is present. If this were to occur however, the contribution to the spectrum from zirconium would be due to scattering back into the detector and not from a direct measurement contribution as 


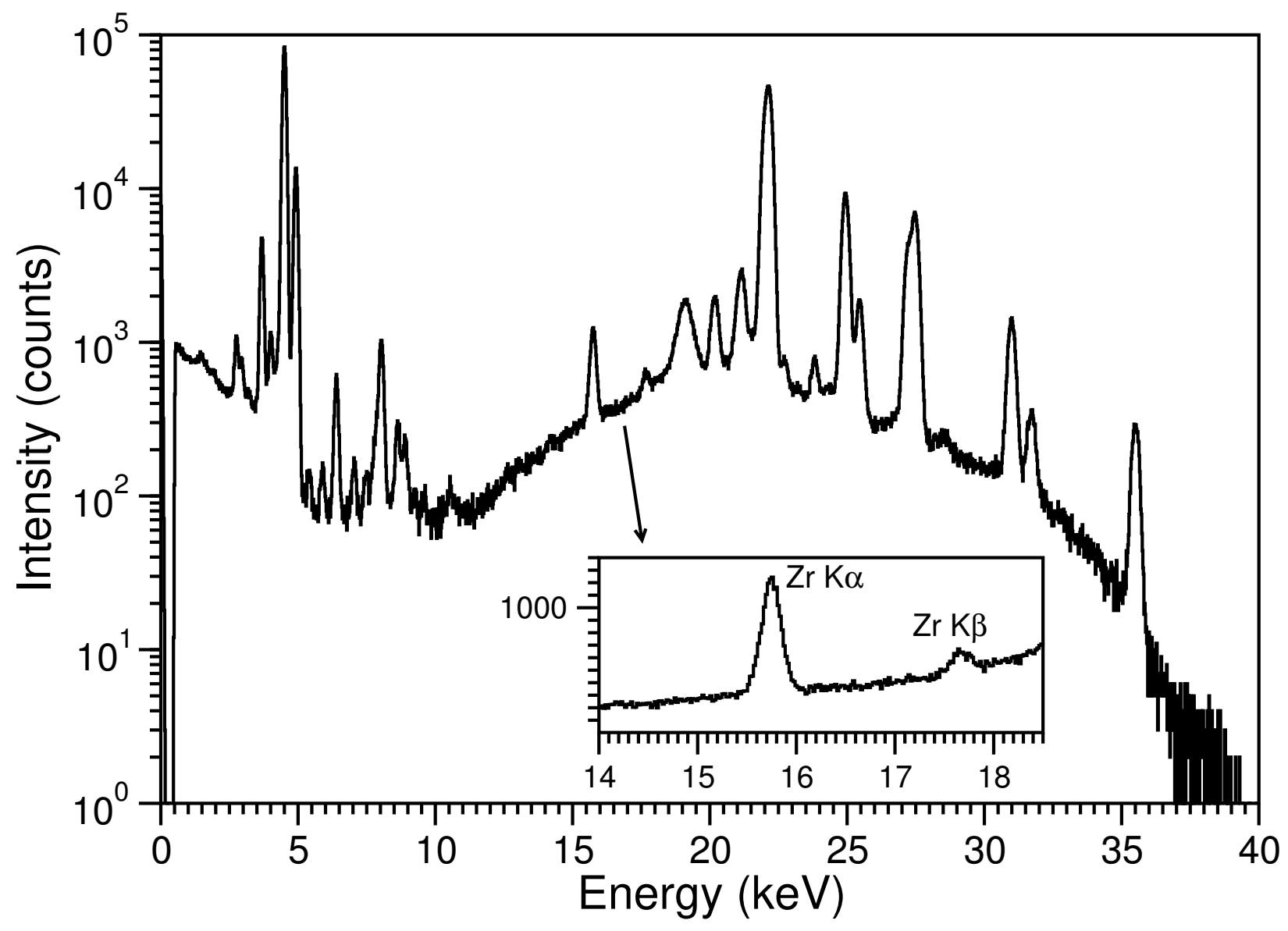

Figure 4.3: Qualitative X-ray fluorescence spectrometry measurement of the three ${ }^{125} \mathrm{I}$ brachytherapy seeds used as a source for in vivo XRF bone strontium measurements $(12.6 \mu \mathrm{Ci}$ total activity at the time of measurement) made on a portable X-ray analyzer known to be void of zirconium. Measurement made of the seeds after they were allowed to sufficiently decay using a portable X-ray analyzer (see Section 4.3.3) The spectrum shows the presence of the zirconium as well as several other light elements (not of interest to this work). The higher energy lines are those of the the Rh K-series as well as the ${ }^{125} \mathrm{I} \gamma$-ray, Te, Ag characteristic $\mathrm{X}$-rays and associated Compton peaks. The inlay shows the zirconium K-series (see Table $4.1)$. 
measured in Figure 4.2.

The clinical IVXRF system for bone strontium measurements is dependant on measurements made in a $180^{\circ}$ backscatter geometry whereby the source is facing the finger used as the measurement site (or the phantom) and the detector is placed behind the seeds as sources. ${ }^{6,15,16}$ If we presume that the tungsten collimator holding the seeds is acting such that all photons are attenuated by the backing of the collimator, then, the only zirconium signal that would be observed from the seeds would be coherently and incoherently scattered zirconium X-rays scattered from the soft tissue and bone in the phantom/finger being measured. Photons in this energy region demonstrate the highest probability for coherent scatter. It would then be easy to assume that the spectral contribution of greatest proportion would be coherently scattered zirconium X-rays. From the point of view of the directional scattering probability coherent scattering is highly forward directed. As a result a further investigation was made, using simulations, to assess contributions from source contamination by zirconium in the backscatter geometry.

Monte Carlo simulations were performed on a finger phantom using the geometry described by Zambrulini et al. ${ }^{22}$ Here, the simulation was of a finger with a source with varying zirconium K-series contributions to the total source fluence to simulate cases in which the total zirconium contribution to the emission spectrum varies. A typical spectrum is shown in Figure 4.4 whereby, the phantom was void of any strontium as to assess only backscattered contributions from zirconium alone.

The results of the simulations indicate that when zirconium is present in the source, then the major contribution to the IVXRF spectrum of a finger is in fact Compton scattered zirconium photons (Figure 4.4). This results in a possible spectral interference in the context of an IVXRF bone strontium measurement. In this case, the Compton peak resulting from 


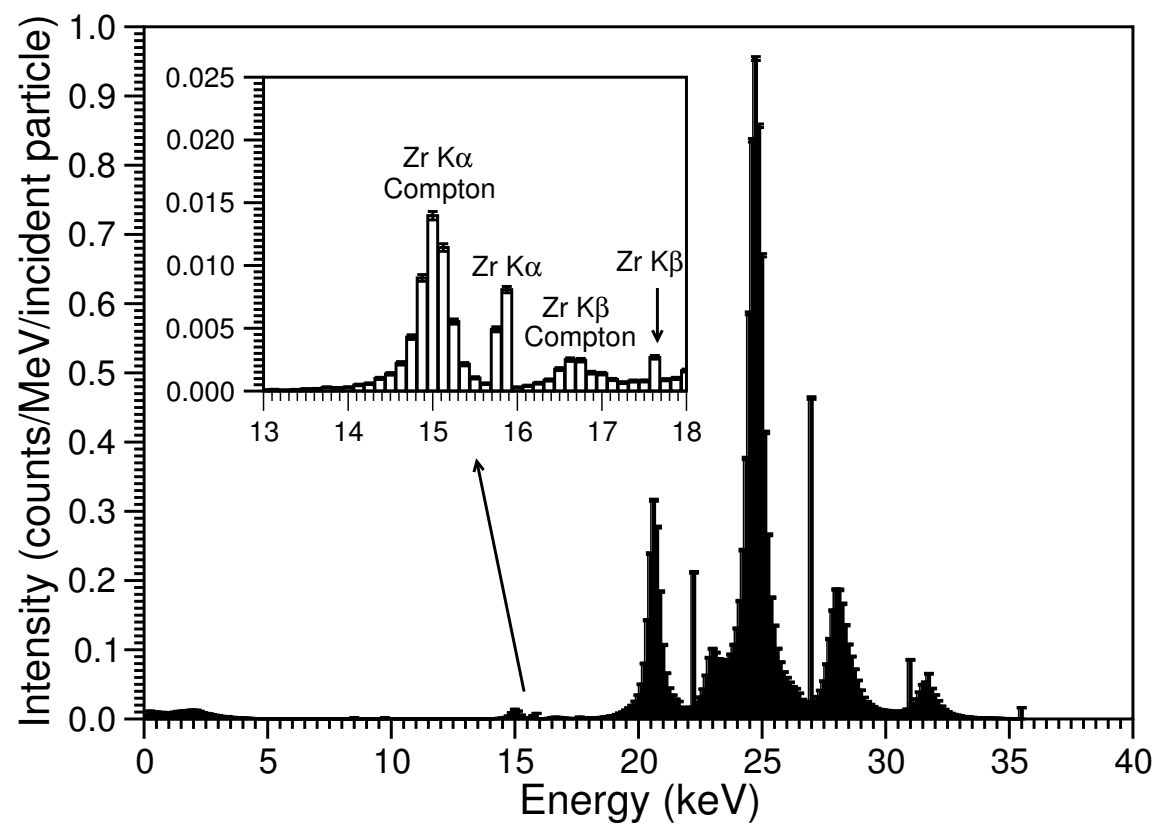

Figure 4.4: Result of a Monte Carlo simulation of an IVXRF bone strontium measurement in a $180^{\circ}$ backscatter geometry using an ${ }^{125}$ I excitation source with zirconium contamination of $10 \%$ of the total source fluence for illustration purposes. The simulation is of a finger phantom that does not contain any strontium.

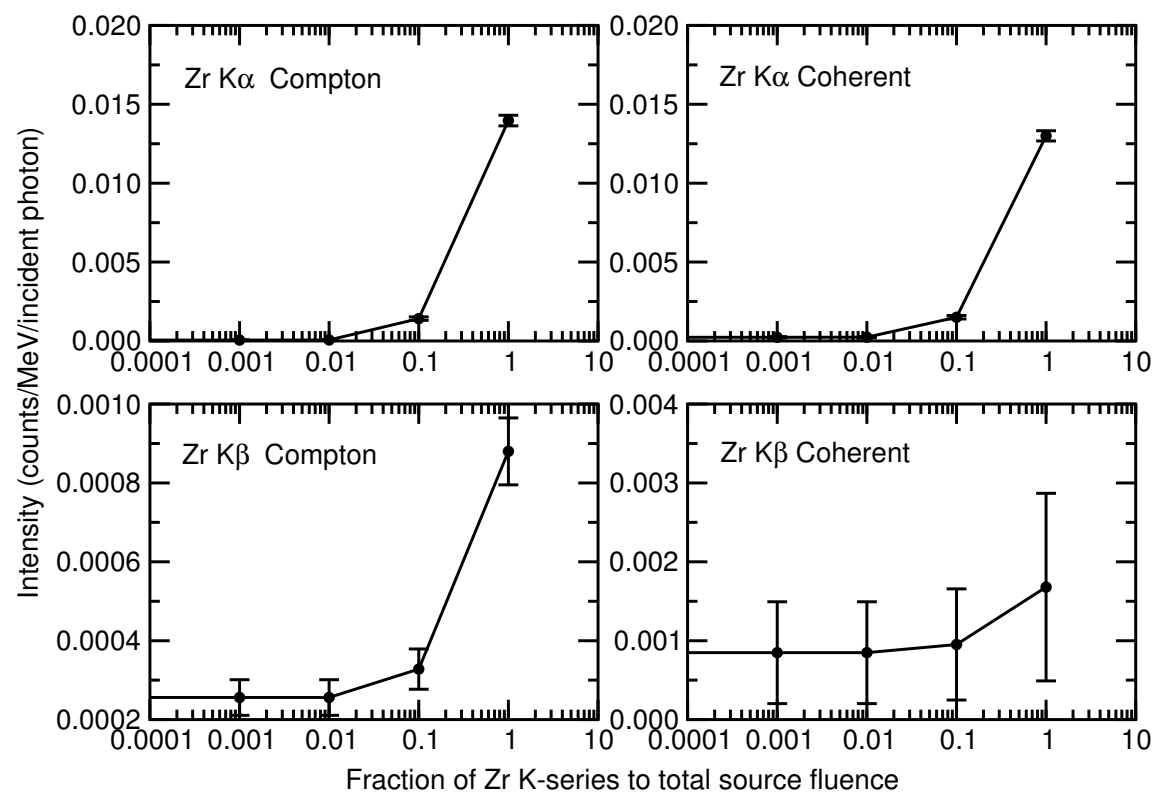

Figure 4.5: Intensities of zirconium contributions for various fractional proportions of the zirconium K-series to the total source fluence. Once below a $1 \%$ contribution, the simulations indicate that the zirconium contributions become negligible. 
the zirconium $\mathrm{K} \alpha_{1,2}$ Compton interactions, which are scattered back into the detector, are at the high energy side of the strontium $\mathrm{K} \alpha_{1,2}$ energy region, while zirconium $\mathrm{K} \alpha_{1,2}$ coherent contributions overlap directly with the strontium $\mathrm{K} \beta$ line (Table 4.1). This would give the impression of a large contribution from the rubidium $\mathrm{K} \beta$ if one were to simply observe a clear rubidium $\mathrm{K} \alpha_{1,2}$ line in a measured spectrum (Figure 4.2) and would result in an inherent overestimation of the strontium $\mathrm{K} \beta$ line. As was observed from the direct measurement (Figure 4.2), rubidium is a contaminant in IVXRF bone strontium spectra. Thus, if a measurement demonstrates this contamination from rubidium, the contribution from the zirconium Compton scattered photons may seem to be emanating from rubidium as the $\mathrm{K} \beta$ line. Moise has evaluated fitting routines to try to take into account this phenomenon, that is, trying to fit the rubidium $\mathrm{K} \beta$ line based on the presence of rubidium contamination seem through the presence of the rubidium $\mathrm{K} \alpha_{1,2}$ line. ${ }^{23}$ In this case, it may be quite probable, that any failure to make such corrections is due to the previous lack of consideration of zirconium Compton scattered photons as evident through this simulation study. If these contributions were to be unaccounted for, then, analytical curve fitting of the strontium $\mathrm{K} \alpha_{1,2}$ and $\mathrm{K} \beta_{1,3}$ lines would result in possible positive bias, if the zirconium signal contribution were sufficiently significant to produce a contribution above the uncertainty of the fitting routine. This may also have an influence on the computation of other parameters, such as the $\mathrm{K} \alpha_{1,2} / \mathrm{K} \beta_{1,3}$ ratio which has been proposed as an analytical measure in human data with mixed success experimentally. ${ }^{6,23,24}$ The effect is however suppressed greatly as the the zirconium characteristic X-ray contribution to the total source fluence decreases, which would be apparent through a reduction in the total activity of the source (Figure 4.5). It would thus be required that the contribution from the zirconium backscatter be assessed throughout measurements using a suitable blank phantom. 


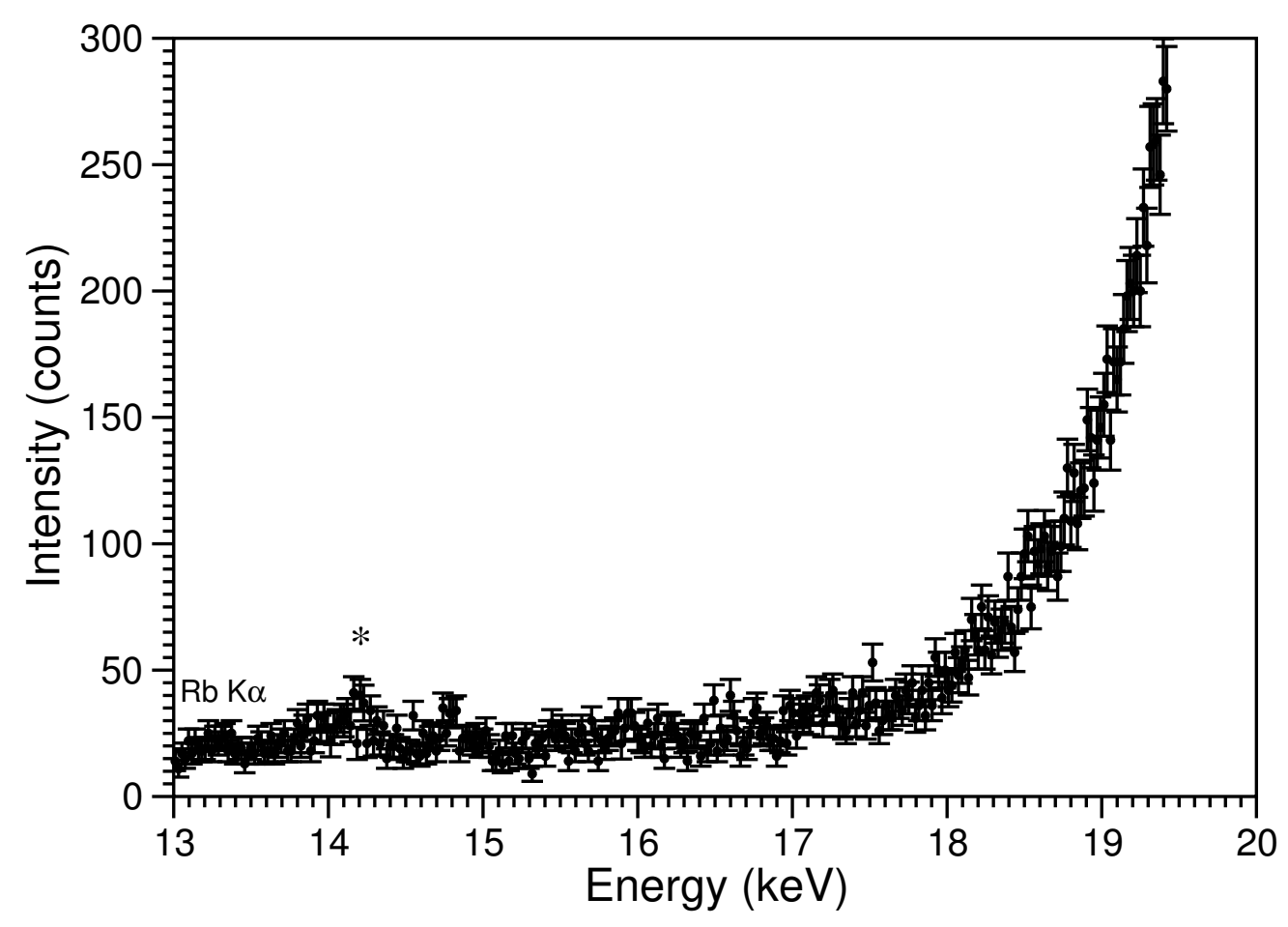

Figure 4.6: A preliminary measurement of a blank hydroxyapatite phantom made for a 20 minute live time using an SDD detection system and an off-centre source backscatter geometry. The spectrum is poor statistically due to the use of cold seeds but may indicate the presence of the dominant zirconium Compton scattered X-ray $\left(^{*}\right)$, although this peak may be due to strontium contamination that is system dependent as seen from the direct measurement of this system (Figure 4.2). Rubidium is also shown as a contaminant of the system. 


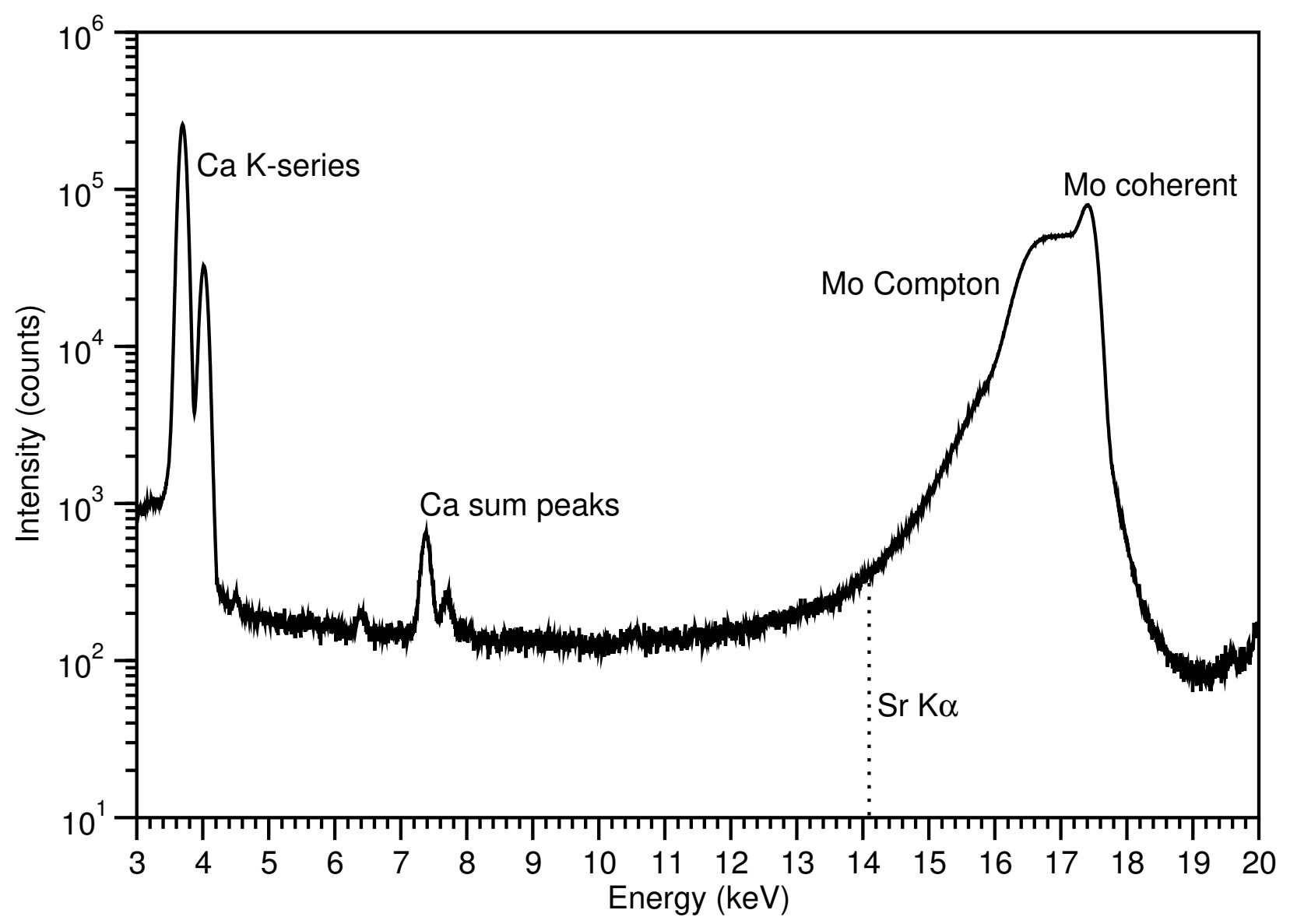

Figure 4.7: Total reflection X-ray fluorescence spectrum of the clean phantom material. There is no indication of strontium in the material at levels of less than $0.7 \mu \mathrm{g} / \mathrm{g} \mathrm{Ca}$.

Although the simulation work was performed and showed the possibility of interference from scattered zirconium X-rays when considering an in vivo bone strontium measurement using brachytherapy seeds as sources, the actual total fluence from the zirconium in the source is rather low representing less than $10 \%$ of the total fluence. The actual contribution to the spectrum being small when the total relative fluence is $1 \%$ or less (Figure 4.5) and this type of backscatter may, or may not, be a true concern depending on the activity of the source which will influence the zirconium contribution and can only be evaluated with a blank phantom on a measurement-by-measurement basis, thus necessitating a blank bone phantom. 
To assess the possibility of this type of interference in a real measurement, a blank phantom was prepared as per Da Silva et al. ${ }^{1}$ which has been found to be void of strontium (concentrations less than $0.7 \mu \mathrm{g} / \mathrm{g} \mathrm{Ca}$ ) (Figure 4.7). The blank measurement is shown in Figure 4.6 as acquired on an SDD detection system using an off-centre $180^{\circ}$ backscatter source geometry. The blank measurement seems to indicate the presence of rubidium and possibly some strontium and/or zirconium Compton contributions (Figure 4.6). Although no strontium was found in the phantom as per a previous secondary analysis (Chapter 2, Figure 4.7), or rather at levels expected to be below current MDLs of in vivo systems, ${ }^{1}$ the strontium may be from exogenous system contamination as previously shown through the direct measurement (Figure 4.2). There also seems to be a small peak which would correspond in energy to the zirconium Compton for the angle used in the measurement of approximately $180^{\circ}$ with the SDD detection system. This Compton peak is very minor and buried in uncertainty, which indicates that the backscatter issue from zirconium is in fact rather minor. This measurement does however indicate, in conjunction with the simulations, that the use of an analytical blank for IVXRF systems is needed in order to investigate experimentally the possibility of spectral interferences, which may be influencing the measurements in humans. Although the problem with zirconium is source dependent, the consistent presence of both strontium and rubidium in the measured spectra throughout this work may indicate the need to move towards a new closed system for IVXRF bone strontium analysis, namely and potentially, commercially available portable X-ray analyzers, the focus of Chapter 8, or the use of other custom X-ray tube-based sources which can be design to counter these issues of spectral interferences. 


\subsection{Conclusions}

In this work, the need for the analytical blank bone phantom developed by Da Silva et al. ${ }^{1}$ is discussed in the context of assessing spectral interferences, which ultimately has an influence on the determination of analytical figures of merit for the IVXRF system of bone strontium quantification. A major observation in this work was the presence of zirconium in the ${ }^{125}$ I brachytherapy seed excitation source used for IVXRF bone strontium measurements. Monte Carlo simulations demonstrated that in the $180^{\circ}$ backscatter geometry used for IVXRF bone strontium measurements, that Compton scattered zirconium X-rays $\left(\mathrm{K} \alpha_{1,2}\right.$ $\left.=15.73 \mathrm{keV}, \mathrm{K} \beta_{1,3}=17.66 \mathrm{keV}\right)$ may in fact be the largest source of spectral interference. Given that this work also demonstrated a consistent source-independent contamination from rubidium, the presence of scattered zirconium X-rays may be responsible for the observed issues with the accounting of rubidium K X-rays within the analytical curve fitting procedure used for in vivo bone strontium measurements ${ }^{23}$ due to an inflation of the rubidium $\mathrm{K} \beta$ line by Compton scattered zirconium photons. The first true blank measurement using ${ }^{125} \mathrm{I}$ brachytherapy seeds is presented and showed the possible presence of zirconium Compton peaks in an experimentally measured blank. All measurements showed the presence of strontium and rubidium contamination which indicates room for improvement in the measurements by investigated more closed systems for measurement including those provided through the use of portable X-ray spectrometers (tube-based, custom or portable X-ray analyzers). This is the focus of Chapter 8 which evaluates the suitability of portable X-ray spectrometers for IVXRF bone strontium measurements. This work is however limited to the fact that measurements were not made on the clinical system presently used for the bone strontium IVXRF measurements, which presents a different resolution in comparison to the SDD detection system as well as source-phantom geometry. The blank measurement 
being made on relatively cold seeds, also necessitates a more thorough and statistically valid assessment of measured blank spectra prior to any firm conclusions being made as to the real effect this type of interference may have on human measurements and other analytical measures, namely, the strontium $\mathrm{K} \alpha_{1,2} / \mathrm{K} \beta_{1,3}$ ratio which has been proposed as a means of assessing strontium homogeneity in humans. ${ }^{6,23,24}$ The observations made in this work were also step-wise, requiring decay of the source and thus low count rates when producing Figure 4.6. Future work thus requires that the clinical system ${ }^{14-16}$ be used to make blank measurements as to assess the impact on true human measurements as well as correlation to the Monte Carlo simulations.

\subsection{Acknowledgements}

The authors would like to acknowledge the Natural Science and Engineering Research Council of Canada (NSERC) for their financial support of this work through an Alexander Graham Bell Canadian Graduate Scholarship and a Discovery Grant (APM). The authors acknowledge Elstan Desouza for his help in setting up the SDD detection system used in this work, which at the time of its set-up, led to the observation in Figure 4.2 and thus this investigation. Matthew Brandt is also acknowledged for his help in making the phantom measurement. 


\section{References}

[1] E. Da Silva, B. Kirkham, D. V. Heyd, and A. Pejović-Milić, "Pure Hydroxyapatite Phantoms for the Calibration of in Vivo X-ray Fluorescence Systems of Bone Lead and Strontium Quantification," Analytical Chemistry, vol. 85, no. 19, pp. 9189-9195, 2013.

[2] J. Sherman, "The theoretical derivation of fluorescent x-ray intensities from mixtures," Spectrochimica Acta, vol. 7, no. 5, pp. 283-306, 1955.

[3] T. Shiraiwa and N. Fujino, "Theoretical calculation of fluorescent x-ray intensities in fluorescent x-ray spectrochemical analysis," Japanese Journal of Applied Physics, vol. 5, no. 10, pp. 886-899, 1966.

[4] J. E. Fernández, "XRF Intensity in the Frame of the Transport Theory," X-ray Spectrometry, vol. 18, no. 6, pp. 271-279, 1989.

[5] R. M. Rousseau, "Detection limit and Estimation of Uncertainty of Analytical XRF Results," The Rigaku Journal, vol. 18, no. 2, pp. 33-47, 2001.

[6] M. Zamburlini, A. Pejović-Milić, D. R. Chettle, C. E. Webber, and J. Gyorffy, "In vivo study of an x-ray fluorescence system to detect bone strontium non-invasively," Physics in Medicine and Biology, vol. 52, no. 8, pp. 2107-2122, 2007.

[7] L. J. Somervaille, D. R. Chettle, and M. C. Scott, "In vivo measurement of lead in bone using x-ray fluorescence," Physics in Medicine and Biology, vol. 30, no. 9, pp. 929-943, 1985.

[8] J. M. O'Meara, D. R. Chettle, F. E. McNeill, and C. E. Webber, "The feasibility of measuring bone uranium concentrations in vivo using source excited K x-ray fluorescence," Physics in Medicine and Biology, vol. 42, no. 6, pp. 1109-1120, 1997. 
[9] J. M. O'Meara, D. R. Chettle, F. E. McNeill, and C. E. Webber, "In Vivo X-ray Fluorescence (XRF) Measurement of Uranium in Bone," Applied Radiation $\mathcal{F}_{3}$ Isotopes, vol. 49, no. 5-6, pp. 713-715, 1998.

[10] D. E. B. Fleming, M. R. Gherase, and K. M. Alexander, "A miniature X-ray tube approach to measuring lead in bone using L-XRF," X-ray Spectrometry, vol. 40, no. 5, pp. 343-347, 2011.

[11] L. H. Nie, S. Sanchez, K. Newton, L. Grodzins, R. O. Cleveland, and M. G. Weisskopf, "In vivo quantification of lead in bone with a portable x-ray fluorescence systemmethodology and feasibility," Physics in Medicine and Biology, vol. 56, no. 3, pp. N39N51, 2011.

[12] M. Zamburlini, A. Pejović-Milić, and D. R. Chettle, "Spectrometry methods for in vivo bone strontium measurements," X-ray Spectrometry, vol. 37, no. 1, pp. 42-50, 2008.

[13] A. Pejović-Milić, I. M. Stronach, J. Gyorffy, C. E. Webber, and D. R. Chettle, "Quantification of bone strontium levels in humans by in vivo x-ray fluorescence," Medical Physics, vol. 31, no. 3, pp. 528-538, 2004.

[14] M. Zamburlini, A. Pejović-Milić, and D. R. Chettle, "Evaluation of geometries appropriate for ${ }^{125} \mathrm{I}$ in vivo bone strontium X-ray fluorescence measurement," Journal of Radioanalytical \& Nuclear Chemistry, vol. 269, no. 3, pp. 625-629, 2006.

[15] H. Moise, J. D. Adachi, D. R. Chettle, and A. Pejović-Milić, "Monitoring bone strontium levels of an osteoporotic subject due to self-administration of strontium citrate with a novel diagnostic tool, in vivo XRF: A case study," vol. 51, no. 1, pp. 93-97, 2012. 
[16] H. Moise, D. R. Chettle, and A. Pejović-Milić, "Monitoring bone strontium intake in osteoporotic females self-supplementing with strontium citrate with a novel in-vivo Xray fluorescence based diagnostic tool," vol. 61, pp. 48-54, 2014.

[17] M. Zamburlini, S. H. Byun, A. Pejović-Milić, W. V. Prestwich, and D. R. Chettle, "Evaluation of MCNP5 and EGS4 for the simulation of in vivo strontium XRF measurements," X-ray Spectrometry, vol. 36, no. 2, pp. 76-81, 2007.

[18] M. Sibai, "Second generation of the diagnostic tool for the In vivo measuremet of strontium levels in human bone," Master's thesis, Ryerson University, Toronto, Ontario, Canada, 2011.

[19] ICRP, "Basic Anatomical \& Physiological Data for use in Radiological Proetection The Skeleton," ICRP Publication 70, Annuals of the ICRP, vol. 25, no. 2, pp. -, 1995.

[20] ICRU, "Tissue Substitutes in Radiation Dosimetry and Measurement," Report 44 of the Internatonal Commission on Radiation Units and Measurements, vol. -, no. -, pp. - , 1989.

[21] R. D. Deslattes, E. G. Kessler Jr., P. Indelicato, L. de Billy, E. Lindroth, J. Anton, J. S. Coursey, D. J. Schwab, J. Chang, R. Sukumar, K. Olsen, and R. A. Dragoset, "X-ray transition energies, http://www.nist.gov/pml/data/xraytrans/, last checked: 02.05.2016. last modified: 2014,"

[22] M. Zamburlini, A. Pejović-Milić, and D. R. Chettle, "Coherent normalization of finger strontium XRF measurements: feasibility and limitations," Physics in Medicine and Biology, vol. 53, no. 15, pp. N307-N313, 2008. 
[23] H. Moise, Energy Dispersive X-ray Fluorescence Spectrometry and Kinetic Modeling of Elemental Strontium in Bone. PhD thesis, McMaster University, Hamilton, Ontario, Canada, 2014.

[24] C. Heirwegh, "In Vivo Quantification of Bone Strontium Using X-ray Fluorescence," Master's thesis, McMaster University, Hamilton, Ontario, Canada, 2008. 
CHAPTER

FIVE

\section{SECONDARY EXCITATION OF THE LEAD L-SERIES BY THE STRONTIUM K-SERIES IN CASES OF HIGH BONE STRONTIUM CONCENTRATIONS}

Working paper/technical note for publication: Eric Da Silva, Hazra Sokoli, David E. B. Fleming and Ana Pejović-Milić, "Secondary excitation of the lead L-series by the strontium Kseries in cases of high bone strontium concentrations: A necessary consideration in the context of bone lead quantification using lead L-series?"†

${ }^{\dagger} \underline{E}$. Da Silva designed and carried out the experiments, performed the data analysis and wrote this manuscript/chapter. H. Sokoli aided with the simulations and provided validation of the Monte Carlo code alongside E. Da Silva. D. E. B. Fleming and A. Pejović-Milić provided critical feedback as to the work's contents and assessed the manuscript/chapter critically. 


\subsection{Abstract}

In vivo X-ray fluorescence (XRF)-based methods of bone metal quantification ignore the possibility of secondary excitation in their calibration protocols. Ignoring the possibility of secondary excitation of certain analytes is not generally detrimental as the analytes are present in matrices in which the analyte is either of the highest atomic number within the mixture and/or they are often present in trace quantities, furthermore the difference in energy between emitted characteristic X-rays and the K- or L-edges of other elements is typically large. In all of these case, the system is not conducive to secondary excitation by definition. One exception to this would be the case of quantifying bone lead in the presence of a high concentration of strontium when the lead L-series is to be used as the analytical signal. Strontium is not a trace, but rather a minor element, and has been well established to bias dual energy-X-ray absorptiometry (DXA) measurements given its concentration in bone reaching the mole-percentage level relative to calcium. ${ }^{1-5}$ This bias being introduced due to strontium's ability to increase the mass attenuation coefficient of the bone, reported at even fractional mole percentages of strontium in the case of DXA studies. Given the fact that it has been observed for DXA measurements that relevant bone strontium concentrations can alter the mass attenuation coefficient of bone, and the fact that the strontium K-series is just above the $\mathrm{L}_{3}$ edge for lead, secondary excitation is at least theoretically possible. If secondary excitation does occur this would require a priori knowledge of bone strontium content in order to quantify lead via its L-series. In this work, we employed Monte Carlo simulations to evaluate the possibility of secondary excitation of lead in bone matrices with high bone strontium concentration - within the $0-10 \% \mathrm{~mol} / \mathrm{mol}$ range $[\mathrm{Sr} /(\mathrm{Sr}+\mathrm{Ca})]$, using a ${ }^{125} \mathrm{I}$ source excited system currently used for in vivo bone strontium measurements. No evidence of secondary excitation was observed which indicates that lead can be freely quantified using 
its L-series without a priori knowledge of bone strontium concentrations. Unlike the case of DXA, it was found that the mass attenuation coefficient of bone changes by less than $5 \%$ within the strontium concentration range observed in humans. Coupled with the low concentration of lead to be expected in humans (much less than $1000 \mathrm{ppm}$, selected in this study as a higher upper theoretical limit), secondary excitation becomes negligible and can be ignored in the case of in vivo bone lead determinations using the lead L-series.

\subsection{Introduction}

$\mathrm{X}$-ray fluorescence spectrometry (XRF)-based analyses by definition considers various forms of fluorescence which can occur within a specimen when irradiated with a source and which may result in the emission of analyte characteristic X-rays. ${ }^{6-8}$ Fluorescence caused solely by the interaction of the primary beam, being known as primary fluorescence, is the major source of characteristic X-ray emission in specimens. ${ }^{6}$ In cases in which various elements are present within a matrix in sufficiently large concentrations, which is often the case for most matrices, characteristic X-rays emitted by one element may be of sufficiently high fluence and of sufficient energy to cause excitation of another element on its passage out of the specimen. This is known higher order, or more specifically, secondary excitation/fluorescence, that is, when a photon being emitted from an element within the specimen causes fluorescence of another, thus, fluorescence being created due to interactions not created by the primary beam fluence alone. ${ }^{6}$ In cases in which secondary excitations are probable, it is then necessary to quantify not only the analyte, but all elements which may result in secondary fluorescence-, which is the basis of the so-called Sherman equations. ${ }^{7,8}$ In order for secondary excitation to be probable, the product of the excitation probabilities, which are a function of concentration as well as proximity of the photon's energy to a K- or L-edge 
energy, must be substantial; therefore, both the exciting element and analyte need to be present a sufficiently high concentrations, and, the energy of the photon causing secondary fluorescence must be sufficiently close in energy to that of the K- or L-edge of the element begin fluoresced. The term "high concentrations" defined here as being a concentration of an element sufficiently large as to have a substantial influence on the total mass attenuation coefficient of the specimen. ${ }^{6-8}$

In the context of an in vivo XRF (IVXRF) bone metal quantification, secondary excitation has been ignored in the calibration protocols. Ignoring this effect is quite reasonable as the analytes of interest are often at low concentrations in bone (that is, their concentration and changes thereof do not affect the total mass attenuation coefficient of the specimen) and there are no other elements present in the bone sample which would fulfill the condition of secondary excitation, largely due to the fact that the emitted characteristic X-ray energy is far from either the K- or L-edge of the analyte of interest. This is the case for bone lead, strontium and uranium analysis which all use the K-series of the analyte for quantitative purposes. ${ }^{9-19}$

In the case of bone strontium, the element cannot be considered a trace element. In fact, dual energy X-ray absorptiometry (DXA) measurements are well established to be biased by bone strontium concentrations, whereby, bone strontium content results in an overestimation of the DXA determined areal bone mineral density. ${ }^{1-5}$ This overestimation being due to strontium's influence on the mass attenuation coefficient of bone and being apparent at concentrations of even a fraction of a mole percentage of strontium being present in bone. ${ }^{1,2}$ DXA is a transmission-based method of analysis, and uses higher energy X-rays than does $\mathrm{XRF}$; however, this effect would indicate that even small quantities of strontium in bone can produce a sufficiently significant change in the bone's mass attenuation coefficient as to 
present an observable change in a determined physical quantity.

Given the fact that strontium seems to be able to substantially change the total mass attenuation coefficient sufficiently such that DXA measurements are influenced through a measured bias, ${ }^{1-5}$ it would follow that at these clinically relevant levels of bone strontium the secondary excitation may be probable for certain analytes. This would be the case in the context of a bone lead measurement when the L-series is employed as the analytical signal which has gained recent and further interest given advancements in the development of field portable X-ray analyzers ${ }^{20-23}$ after some preliminary work in the area. ${ }^{24-28}$ This work thus evaluates possible secondary excitation in the context of a bone lead measurement, when the L-series is used as the analytical signal, in the presence of high strontium levels. If present, this would indicate that both strontium and lead would need to be quantified simultaneously, in order to accurately obtained bone lead determinations in the presence of high bone strontium concentrations.

\subsection{Monte Carlo Simulations}

Monte Carlo simulations were performed using the EGS5 system using code as per Zamburlini et al. ${ }^{29}$ Although portable X-ray analyzers are most often used for in vivo XRF measurements of bone lead when employing the L-series as the analytical measure, ${ }^{20-23}$ simulations were performed in this work using the validated code used for simulations that mimic a ${ }^{125} \mathrm{I}-$ induced bone strontium measurement (schematic in Figure 1.1). ${ }^{13,29-31}$ This difference was not deemed as of concern as the source spectrum from an ${ }^{125}$ I brachytherapy seed has a fluence that is most produced from the silver in the seeds, thus, mimicking the major line used for excitation in tube-based systems. ${ }^{20-23}$ The source was simulated as to emit $10^{12}$ incidence particles found to produce sufficient uncertainty in the simulated net peak 
areas of interest (less than 5\%), each particle being sampled from a source spectrum that of a ${ }^{125} \mathrm{I}$ brachytherapy source as described elsewhere. This source spectrum accounted for the emission spectrum of the ${ }^{125}$ I as well as emitted silver and tellurium X-rays due to ${ }^{125}$ I decay and excitation of the silver beads. ${ }^{13}$ To simulate a human finger bone (the phalanges) adequately, the simulations were performed a bare bone finger phantom modelled as a $9 \mathrm{~mm}$ cylinder of cortical bone tissue. ${ }^{29} \mathrm{~A}$ bare bone phantom was selected as to avoid any confounding of the results from overlaying soft tissue attenuation. The sample-to-detector window distance was maintained at $5 \mathrm{~mm}$ for all simulations in this work. The detector arrangement was simulated as to mimic a $\mathrm{Si}(\mathrm{Li})$ detection system, with a tungsten collimator housing the ${ }^{125} \mathrm{I}$ brachytherapy source which allows for a $180^{\circ}$ backscatter geometry to the detector relative to the sample. ${ }^{29}$ A schematic of the simulation geometry is shown in Figure 1.1 (see section 1.4, pg. 12).

Simulations were performed using the following composition for bone per the International Commission of Radiological Protection (ICRP) ${ }^{32}: 0.034 \% w / w \mathrm{H} ; 0.155 \% w / w \mathrm{C}$; $0.042 \% w / w \mathrm{~N} ; 0.435 \% w / w \mathrm{O} ; 0.003 \% w / w \mathrm{Na} ; 0.002 \% w / w \mathrm{Mg} ; 0.103 \% w / w \mathrm{P} ; 0.003 \%$ $w / w \mathrm{~S} ; 0.225 \% w / w$ Ca. The mass density of bone was $1.9 \mathrm{~g} / \mathrm{cm}^{3}$ and was maintained constant for all simulations. Lead was added to the bone at a concentration of 1,000 ppm at the expense of calcium. Bone strontium concentrations were varied between 0-10\% $\mathrm{mol} / \mathrm{mol}$ $[\mathrm{Sr} /(\mathrm{Sr}+\mathrm{Ca})]$ by molar substitution with calcium. All simulations were post-processed using custom computer programs written in BASH and GNU Octave.

\subsection{Results and Discussion}

Higher order fluorescence is a concern in XRF-based analyses, as if probable and present, the determined intensity of an analyte's characteristic X-ray is not only a function of the pri- 
mary beam fluence, but also a function of the concentration of other, higher atomic number elements within the sample being measured. ${ }^{6-8}$ Quantification in this case becomes complicated and requires various iterative approaches to calibration/quantification which stem from the so-called Sherman Equations. ${ }^{6}$ Aside from the introduction of higher order fluorescence into the calibration procedure and quantification methodology, if the condition of higher order fluorescence is met such that concentrations of various elements are sufficiently high as to change the mass attenuation coefficient as a function of concentration, then calibration against linear standard curves, which is customary in the context of in vivo bone metal analyses, ${ }^{9-17}$ is not possible.

Expressions for the secondary excitation term under various conditions have been well developed. ${ }^{6-8}$ In general, the effect can only occur if the product of the excitation probabilities between both elements is significant which is generally apparent only if the fluorescing element produces characteristic X-rays which are close in energy to either the K- or L-edge of the analyte of interest. ${ }^{6-8}$ Given that the excitation probability term is highly dependant on the product of both elements' weight fractions (which translates to the bulk number density of both elements), it would follow that secondary excitation can only occur if the weight fraction of each element is sufficiently large as to make a marked change in the total mass attenuation coefficient of the specimen. In the case of in vivo bone metal analyses, secondary excitation has largely been ignored as a possible factor in the calibration protocol as this condition is often not met.

One possible case in which secondary excitation may occur when considering methods of in vivo bone metal analysis, is in the case of a bone lead measurement when the lead L-series is to be used as the analytical signal and when the bone strontium content is sufficiently high. Strontium emits its most intensity K-lines at $14.1 \mathrm{keV}\left(\mathrm{K} \alpha_{1,2}\right)$ and $15.8 \mathrm{keV}\left(\mathrm{K} \beta_{1,3}\right){ }^{33}$ 
The $\mathrm{L}_{3}$ edge of lead is at $13.0 \mathrm{keV} \cdot{ }^{33}$ As such, the strontium $\mathrm{K}$-series are able to cause photoelectric emission at the $\mathrm{L}_{3}$ level of lead. Given that the most prominent lines in a bone lead spectrum are the $\mathrm{L} \alpha_{1,2}\left(\mathrm{~L}_{3} \mathrm{M}_{5} \text { and } \mathrm{L}_{3} \mathrm{M}_{4} \text { transitions, respectively }\right)^{33}$ and $\mathrm{L} \beta_{1,2}\left(\mathrm{~L}_{2} \mathrm{M}_{4}\right.$ and $\mathrm{L}_{3} \mathrm{~N}_{5}$ transitions, respectively ${ }^{33}$ ) lines, then photoelectric excitation via the strontium K-series can result in fluorescence emission from lead of relevant lines used for quantitative purposes. This would thus necessitate the need to quantify both strontium and lead together.

Figure 5.1 shows the strontium $\mathrm{K} \alpha_{1,2}$ and $\mathrm{K} \beta_{1,3}$ line intensities as a function of strontium concentration. Considering that the only change to the bone phantom being simulated here is the concentration of strontium (bone density maintained constant at $1.9 \mathrm{~g} / \mathrm{cm}^{3}$ ), whereby concentration changes occur due to a molar substitution with calcium, then the non-linearity can be attributed to the change in the strontium concentration only, and by association, a decrease in the calcium concentration. This is an expected trend but was found to be rather minor in this case. A change in the strontium concentration at the cost of removal of calcium from the system, is expected to result in slight changes to the mass attenuation coefficient of the specimen. With strontium being a higher atomic number element than calcium, the increase in the mass attenuation coefficient with strontium concentration would result in a higher degree of photon attenuation for the $\mathrm{K} \alpha_{1,2}$ and $\mathrm{K} \beta_{1,3}$ line energies of 14.1 and $15.8 \mathrm{keV}$, respectively. The non-linearity was rather minor and it is possible that in practice and experimentally, that this trend may be shadowed by the associated increased uncertainty in measurements which produce high count rates as would be expected from simple counting statistics (Figure 5.1).

Despite this minor non-linear change in the strontium $\mathrm{K} \alpha_{1,2}$ and $\mathrm{K} \beta_{1,3}$ line intensities (Figure 5.1), the lead $\mathrm{L} \alpha_{1,2}$ and $\mathrm{L} \beta_{1,3}$ lines showed a no change $(p<0.05)$ in their intensities for a bone phantom containing a constant concentration of 1,000 ppm lead (Figure 5.2), 


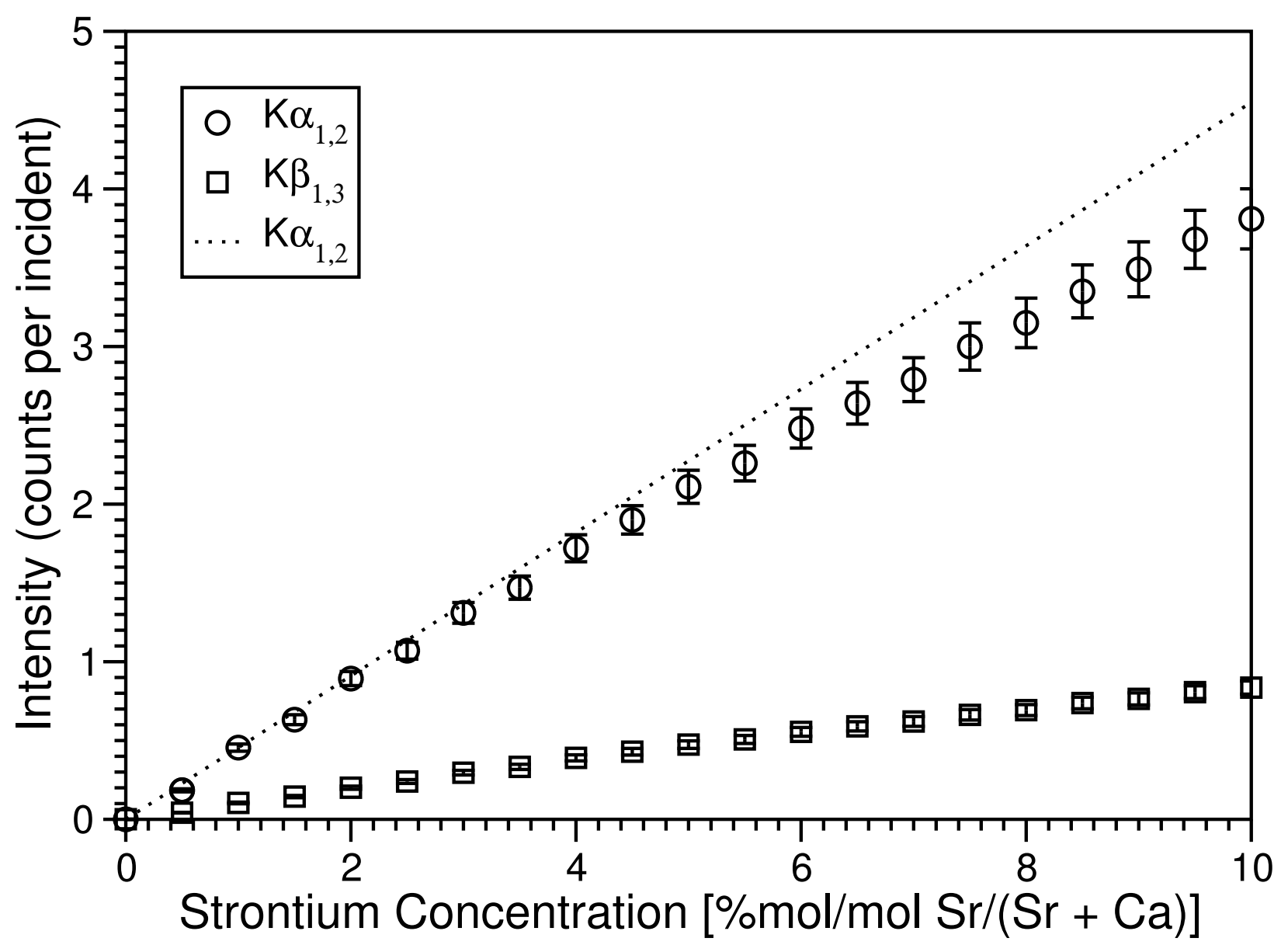

Figure 5.1: Strontium $\mathrm{K} \alpha_{1,2}$ and $\mathrm{K} \beta_{1,3}$ intensities as a function of strontium concentration and with a constant bone density of $1.9 \mathrm{~g} / \mathrm{cm}^{3}$. The strontium lines show a non-linear relationship with concentration when approaching high concentrations. The dashed line represents a linear trend based on low concentration data. Concentration of $10 \% \mathrm{~mol} / \mathrm{mol}$ $[\mathrm{Sr} /(\mathrm{Sr}+\mathrm{Ca})]$ equivalent to approximately $4.9 \% \mathrm{w} / \mathrm{w}$ and is selected here as a hypothetical extrema whereby concentrations in humans in the context of DXA studies do not generally exceed $3 \% \mathrm{~mol} / \mathrm{mol}[\mathrm{Sr} /(\mathrm{Sr}+\mathrm{Ca})]$. 


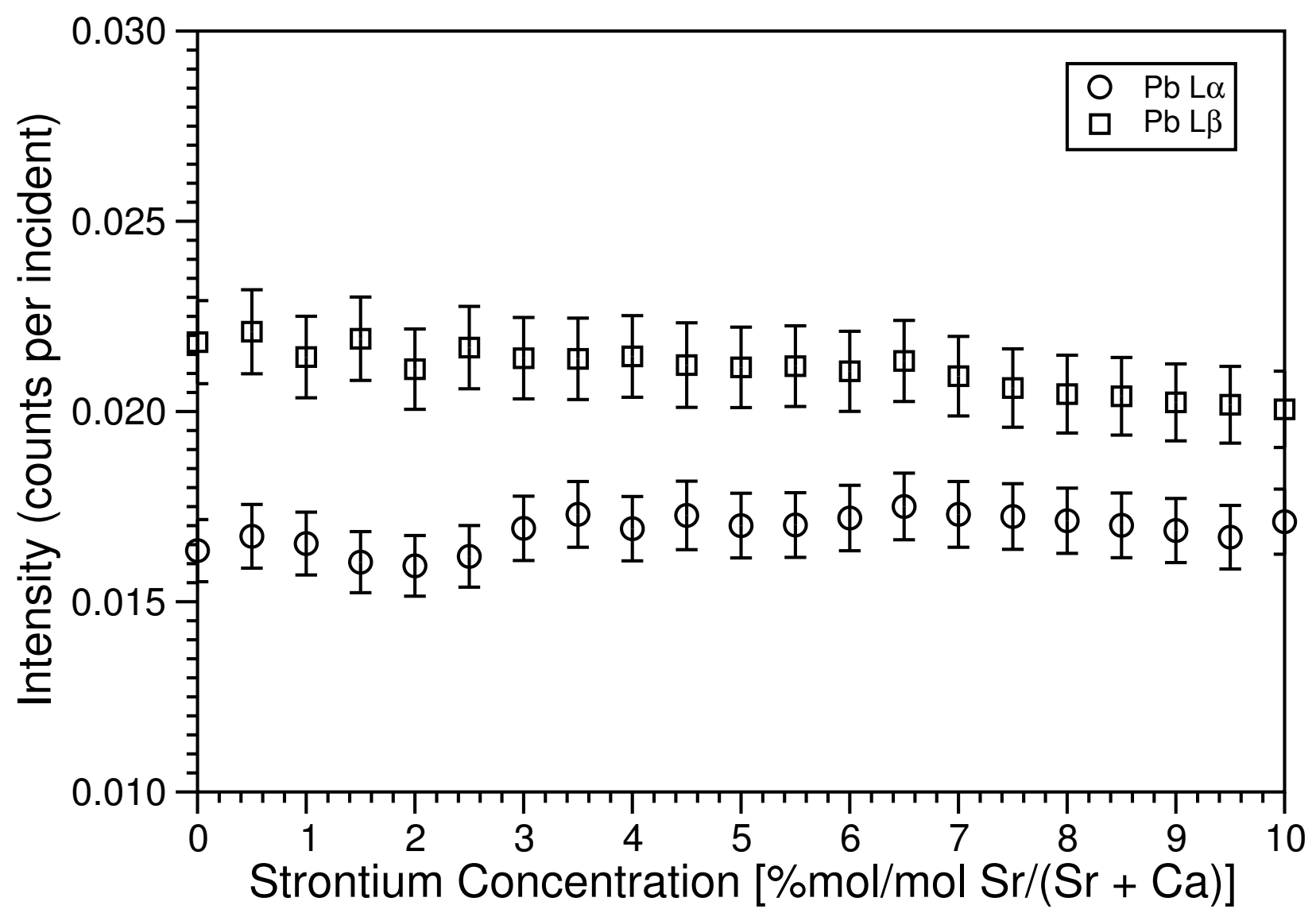

Figure 5.2: Lead $\mathrm{L} \alpha_{1,2}$ and $\mathrm{L} \beta_{1,2}$ intensities as a function of strontium concentration for a bone phantom containing $1,000 \mu \mathrm{g} / \mathrm{g}$ lead. The lead L-series intensities showed no change $(p>0.05)$ with respect to strontium content at a constant lead concentration. 
a concentration which is expected to be higher than that expected in humans in modern days. ${ }^{34}$ The absence of any change in characteristic line intensities for these lead lines, which are the analytically relevant lines, indicates the absence of any enhancement as well as no real influence with changes in the mass attenuation coefficient of the specimen. Even in cases in which the bone lead concentration is orders higher than what would be expected in a human subject, ${ }^{34}$ selected here as a hypothetical extrema to observe any possible effect given the enhancement effect's dependence on concentration, there was no observable effect as seen through the simulation. This is attributed to the fact that even at concentration of lead and strontium which far exceed the clinically relevant concentrations, no enhancement needs to be considered. This also indicates that calibration protocols may be produced without the need to account for total mass attenuation coefficient changes in the specimen at these high strontium concentrations. This observation thus indicates that calibration protocols can proceed for lead analysis in bone using the L-series without the need to account for strontium concentrations and that traditional approaches to calibration may be sufficiently suitable. ${ }^{9-17,20-23}$

The lack of enhancement of the lead $\mathrm{L} \alpha_{1,2}$ and $\mathrm{L} \beta_{1,3}$ lines can be attributed largely to the fact that even when the strontium concentration increases, the concentration of lead remains sufficiently low as to negate the probability of secondary excitation. Even if the probability of secondary excitation is high due to the proximity of the strontium X-rays to the $L_{3}$ edge of lead, the concentration of lead remains so negligible that the probability of secondary excitation vanishes. This was observed even when selecting a concentration range for strontium which is expected to far exceed the concentration in human populations as well as selecting a concentration of bone lead that is orders higher in concentration than that expected in exposed populations. 


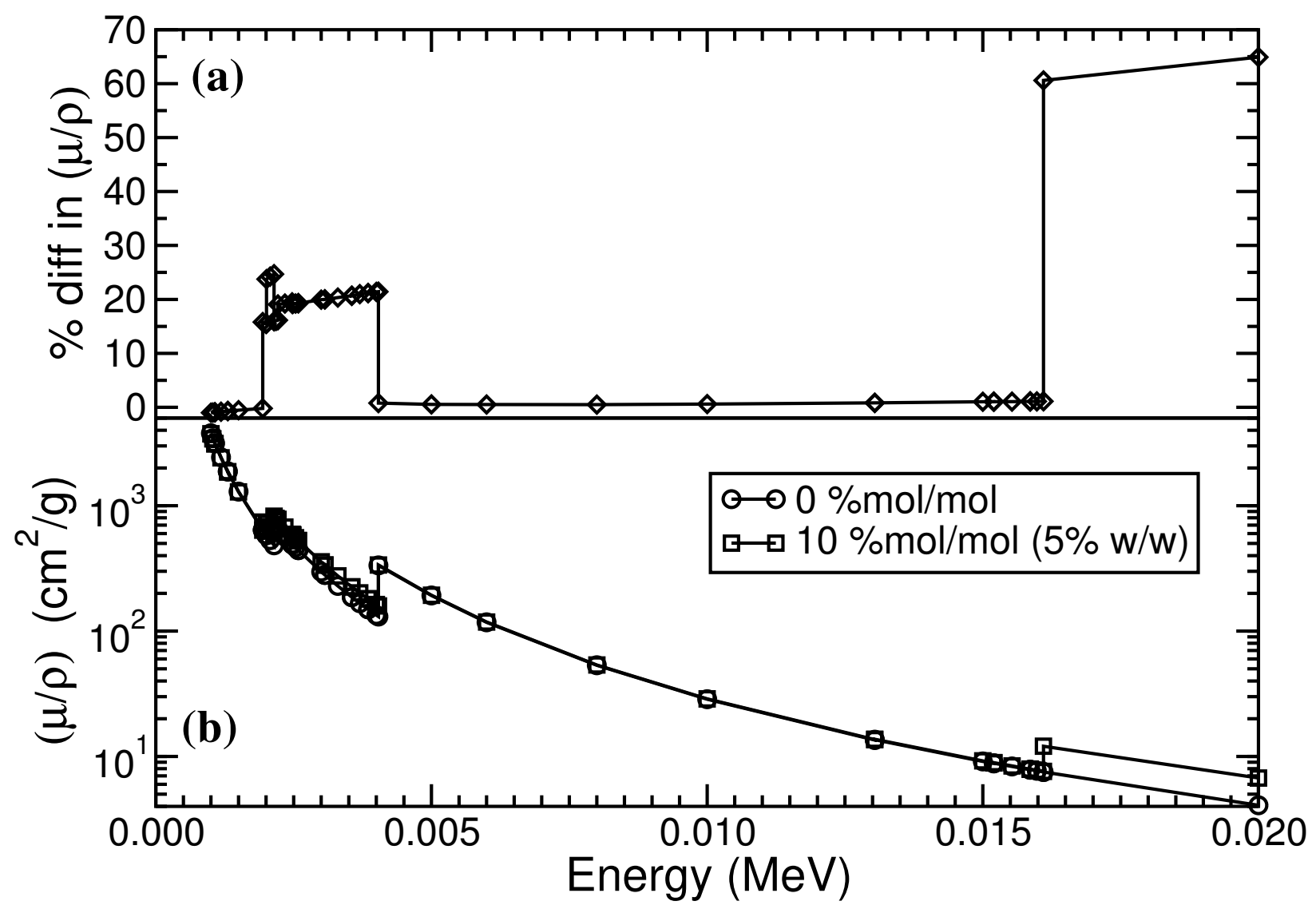

Figure 5.3: (a) Percentage differences in the mass attenuation coefficient in the energy region corresponding the lead L-series less than $5 \%$. (b) Total mass attenuation coefficient for bone with no strontium and with a a $10 \% \mathrm{~mol} / \mathrm{mol}[\mathrm{Sr} /(\mathrm{Sr}+\mathrm{Ca})]$ strontium concentration demonstrating a minimal influence in the mass attenuation coefficient as a function of strontium concentration. 
The mass attenuation coefficient changes for bone in the energy region relevant to XRF were found to be minimal, being less than $5 \%$ over an energy range relevant to XRF analysis (Figure 5.3), and for this reason, demonstrates little effect due to attenuation for either the elemental lines with varying strontium concentration. The total mass attenuation coefficient changed more substantially only for photon energies surpassing the K-edge of strontium. Although in the context of DXA measurements, even small fractional percent changes have been shown to change the mass attenuation coefficient sufficiently as to show a marked difference in determined bone mineral densities, ${ }^{1-5}$ in the case of an in vivo bone lead determination, these changes are negligible and allow for quantification without the need to resort to iterative methods. The differences in the mass attenuation coefficient which would become relevant to DXA measurements are only seen to occur at energies which are greater than the K-edge of strontium and this may be the reason why DXA, a transmission-based method, becomes more sensitivity to strontium content in bone.

\subsection{Conclusions}

In this work we assessed the possibility of secondary excitation of lead, as would be apparent in the L-series, in the case in which bone strontium concentrations are sufficiently high in the matrix being measured. This theoretical study being carried out given the known effect strontium concentration, even at fraction mole percentage levels, has on DXA-determined bone mineral densities. It was found that in cases whereby strontium concentrations reach as high in concentration as $10 \% \mathrm{~mol} / \mathrm{mol}[\mathrm{Sr} /(\mathrm{Sr}+\mathrm{Ca})]$, which corresponds to approximately $5 \% \mathrm{w} / \mathrm{w}$, that secondary excitation of lead is not of concern in the context of a bone lead measurement via the lead L-series. This study thus demonstrates that although high bone strontium concentrations seem to have an effect on the mass attenuation coefficient in the 
context of a DXA measurement, ${ }^{1-5}$ in the context of an in vivo L-XRF bone lead determination, lead can be determined irrespective of any a priori knowledge of bone strontium concentration.

\subsection{Acknowledgement}

The authors acknowledge the Natural Science and Engineering Research Council of Canada (NSERC) for financial support of this work through an Alexander Graham Bell Canadian Graduate Scholarship (EDS) and a Discovery Grant (APM). Matthew Forrest and Graham Pearson (Department of Physics, Ryerson University) are acknowledged for their technical assistance during the course of this work. 


\section{References}

[1] J. Christoffersen, M. R. Christoffersen, N. Kolthoff, and O. Bärenholdt, "Effects of strontium ion on growth and dissolution of hydroxyapatite and on bone mineral detection," Bone, vol. 20, no. 1, pp. 47-54, 1997.

[2] S. P. Neilsen, D. Slosman, O. H. Sorensen, B. Basse-Cathalinat, P. De Cassin, C. Roux, and P. J. Meunier, "Influence of Strontium on Bone Mineral Density and Bone Mineral Content Measurements by Dual X-Ray Absorptiometry," Journal of Clinical Densitometry, vol. 2, no. 4, pp. 371-379, 1999.

[3] G. M. Blake and I. Fogelman, "Effect of Bone Strontium on BMD Measurements," Journal of Clinical Densitometry, vol. 10, no. 1, pp. 34-38, 2006.

[4] G. M. Blake, E. M. Lewiecki, D. L. Kendler, and I. Fogelman, "A Review of Strontium Renelate and Its Effect of DXA Scans," Journal of Clinical Densitometry, vol. 10, no. 2, pp. 113-119, 2007.

[5] G. M. Blake and I. Fogelman, "The Correction of BMD Measurements for Bone Strontium Content," Journal of Clinical Densitometry, vol. 10, no. 3, pp. 259-265, 2007.

[6] J. Sherman, "The theoretical derivation of fluorescent x-ray intensities from mixtures," Spectrochimica Acta, vol. 7, no. 5, pp. 283-306, 1955.

[7] T. Shiraiwa and N. Fujino, "Theoretical calculation of fluorescent x-ray intensities in fluorescent x-ray spectrochemical analysis," Japanese Journal of Applied Physics, vol. 5, no. 10, pp. 886-899, 1966.

[8] J. E. Fernández, "XRF Intensity in the Frame of the Transport Theory," X-ray Spectrometry, vol. 18, no. 6, pp. 271-279, 1989. 
[9] J. M. O'Meara, D. R. Chettle, F. E. McNeill, and C. E. Webber, "The feasibility of measuring bone uranium concentrations in vivo using source excited $\mathrm{K}$ x-ray fluorescence," Physics in Medicine and Biology, vol. 42, no. 6, pp. 1109-1120, 1997.

[10] J. M. O'Meara, D. R. Chettle, F. E. McNeill, and C. E. Webber, "In Vivo X-ray Fluorescence (XRF) Measurement of Uranium in Bone," Applied Radiation $\&$ Isotopes, vol. 49, no. 5-6, pp. 713-715, 1998.

[11] A. Pejović-Milić, I. M. Stronach, J. Gyorffy, C. E. Webber, and D. R. Chettle, "Quantification of bone strontium levels in humans by in vivo x-ray fluorescence," Medical Physics, vol. 31, no. 3, pp. 528-538, 2004.

[12] M. Zamburlini, A. Pejović-Milić, and D. R. Chettle, "Evaluation of geometries appropriate for ${ }^{125}$ I in vivo bone strontium X-ray fluorescence measurement," Journal of Radioanalytical \& Nuclear Chemistry, vol. 269, no. 3, pp. 625-629, 2006.

[13] M. Zamburlini, A. Pejović-Milić, D. R. Chettle, C. E. Webber, and J. Gyorffy, "In vivo study of an x-ray fluorescence system to detect bone strontium non-invasively," Physics in Medicine and Biology, vol. 52, no. 8, pp. 2107-2122, 2007.

[14] M. Zamburlini, A. Pejović-Milić, and D. R. Chettle, "Coherent normalization of finger strontium XRF measurements: feasibility and limitations," Physics in Medicine and Biology, vol. 53, no. 15, pp. N307-N313, 2008.

[15] C. M. Heirwegh, D. R. Chettle, and A. Pejović-Milić, "Ex vivo evaluation of a coherent normalization procedure to quantify in vivo finger strontium XRS measurements," Medical Physics, vol. 39, no. 2, pp. 832-841, 2012. 
[16] J. M. O'Meara, J. Börjesson, D. R. Chettle, and S. Mattsson, "Normalisation with coherent scatter signal: improvements in the calibration protocol of the ${ }^{57} \mathrm{Co}-$ based in vivo XRF bone-Pb measurement," Applied Radiation 83 Isotopes, vol. 54, no. 2, pp. 319$325,2001$.

[17] L. J. Somervaille, D. R. Chettle, and M. C. Scott, "In vivo measurement of lead in bone using x-ray fluorescence," Physics in Medicine and Biology, vol. 30, no. 9, pp. 929-943, 1985.

[18] L. Ahlgren, K. Lidén, S. Mattsson, and S. Tejning, "X-ray fluorescence analysis of lead in human skeleton in vivo," Scandinavian Journal of Work $\&$ Environmental Health, vol. 2, no. 2, pp. 82-86, 1976.

[19] L. Ahlgren and S. Mattsson, "An X-ray Fluorescence Technique for in vivo Determination of Lead Concentration in a Bone Matrix," Physics in Medicine and Biology, vol. 24, no. 1, pp. 136-145, 1979.

[20] L. H. Nie, S. Sanchez, K. Newton, L. Grodzins, R. O. Cleveland, and M. G. Weisskopf, "In vivo quantification of lead in bone with a portable x-ray fluorescence systemmethodology and feasibility," Physics in Medicine and Biology, vol. 56, no. 3, pp. N39N51, 2011.

[21] D. E. B. Fleming, M. R. Gherase, and K. M. Alexander, "A miniature X-ray tube approach to measuring lead in bone using L-XRF," X-ray Spectrometry, vol. 40, no. 5, pp. 343-347, 2011.

[22] A. J. Specht, M. Weisskopf, and L. H. Nie, "Portable XRF Technology to Quantify Pb in Bone In Vivo," Journal of Biomarkers, vol. 2014, p. 398032, 2014. 
[23] A. J. Specht, Y. Lin, M. Weisskopf, C. Yan, H. Hu, J. Xu, and L. H. Nie, "XRFmeasured bone lead $(\mathrm{Pb})$ as a biomarker for $\mathrm{Pb}$ exposure and toxicity among children diagnosed with Pb poisoning," Biomarkers, vol. 21, no. 4, pp. 347-352, 2016.

[24] A. C. Todd, "L-shell x-ray fluorescence measurements of lead in bone: system development," Physics in Medicine and Biology, vol. 47, no. 3, pp. 507-522, 2002.

[25] A. C. Todd, S. Carroll, C. Geraghty, F. A. Khan, E. L. Moshier, S. Tang, and P. J. Parsons, "L-shell x-ray fluorescence measurements of lead in bone: accuracy and precision," Physics in Medicine and Biology, vol. 47, no. 8, pp. 1399-1419, 2002.

[26] L. Wielopolski, D. N. Slatkin, D. Vartsky, K. J. Ellis, and S. H. Cohn, "Feasibility study for the in vivo measurement of lead in bone using L-X-ray fluorescence," IEEE Transactions on Nuclear Science, vol. NS-28, no. 1, pp. 114-116, 1981.

[27] L. Wielopolski, J. F. Rosen, D. N. Slatkin, D. Vartsky, K. J. Ellis, and S. H. Cohn, "Feasibility of noninvasive analysis of lead in human tibia by soft x-ray fluorescence," Medical Physics, vol. 10, no. 2, pp. 248-251, 1983.

[28] L. Wielopolski, J. F. Rosen, D. N. Slatkin, R. Zhang, J. A. Kalef-Ezra, J. C. Rothman, M. Maryanski, and S. T. Jenks, "In vivo mesurement of cortical bone lead using polarized x rays," Medical Physics, vol. 16, no. 4, pp. 521-528, 1989.

[29] M. Zamburlini, S. H. Byun, A. Pejović-Milić, W. V. Prestwich, and D. R. Chettle, "Evaluation of MCNP5 and EGS4 for the simulation of in vivo strontium XRF measurements," X-ray Spectrometry, vol. 36, no. 2, pp. 76-81, 2007.

[30] H. Moise, J. D. Adachi, D. R. Chettle, and A. Pejović-Milić, "Monitoring bone strontium 
levels of an osteoporotic subject due to self-administration of strontium citrate with a novel diagnostic tool, in vivo XRF: A case study," vol. 51, no. 1, pp. 93-97, 2012.

[31] H. Moise, D. R. Chettle, and A. Pejović-Milić, "Monitoring bone strontium intake in osteoporotic females self-supplementing with strontium citrate with a novel in-vivo Xray fluorescence based diagnostic tool," vol. 61, pp. 48-54, 2014.

[32] ICRP, "Basic Anatomical \& Phsiological Data for use in Radiological Proetection The Skeleton," ICRP Publication 70, Annuals of the ICRP, vol. 25, no. 2, pp. -, 1995.

[33] R. D. Deslattes, E. G. Kessler Jr., P. Indelicato, L. de Billy, E. Lindroth, J. Anton, J. S. Coursey, D. J. Schwab, J. Chang, R. Sukumar, K. Olsen, and R. A. Dragoset, "X-ray transition energies." http://www.nist.gov/pml/data/xraytrans/. Last Accessed: 02-May-2016. Last Updated: 2014.

[34] D. R. Chettle, "In vivo applications of X-ray fluorescence in human subjects," Pramana-Journal of Physics, vol. 76, no. 2, pp. 249-259, 2011. 
CHAPTER SIX

\section{CALIBRATION OF THE ${ }^{125}$ I-INDUCED X-RAY FLUORESCENCE SPECTROMETRY-BASED SYSTEM OF IN VIVO BONE STRONTIUM DETERMINATIONS USING HYDROXYAPATITE AS A PHANTOM MATERIAL: A SIMULATION STUDY}

Working paper for publication: E. Da Silva and A. Pejović-Milić, "Calibration of the ${ }^{125}$ Iinduced X-ray fluorescence spectrometry-based system of in vivo bone strontium determinations using hydroxyapatite as a phantom material: A simulation study." $†$

${ }^{\dagger}$ E. Da Silva designed and carried out the experiments/simulations, performed the data analysis and wrote this manuscript/chapter. A. Pejović-Milić spearheaded this work as a part of the bone strontium program run in her lab, provided critical feedback as to its contents and assessed the manuscript/chapter critically. 


\subsection{Abstract}

The calibration of in vivo X-ray fluorescence systems of bone strontium quantification, based on ${ }^{125}$ I excitation, are dependant on a coherent normalization procedure. Application of this procedure with the use of plaster of Paris (poP) as a phantom material requires the application of a coherent conversion factor (CCF) to make the calibration functions transferable between the phantom material and human bone. In this work we evaluate, with the use of Monte Carlo simulation, the potential benefit of employing a newly developed hydroxyapatite phantom material into the calibration protocol. Simulations being performed on bare bone phantoms, as the emission spectrum in this case is equivalent to an emission spectrum of an adequately corrected measurement for soft tissue attenuation of emitted strontium signal. We report that the application of hydroxyapatite phantoms does in fact remove the need for a coherent correction factor $(\mathrm{CCF})$. The newly developed phantoms can thus be used for the calibration of in vivo bone strontium systems removing one step of the calibration protocol. Calibration is however limited to cases in which the concentration is relative to the amount of calcium in the specimen, which is, the most useful quantity in a clinical sense. Determining concentrations on a per-mass-of-material basis, that is, a concentration not normalized to the calcium content of the phantom/bone, results in large biases in estimated bone strontium content. The use of an HAp phantom material was found to remove the need for a CCF but it was also found that variations in the degree to which the phantom material truly converts to HAp has little influence on the differential coherent cross-section and thereby the calibration protocol. 


\subsection{Introduction}

The calibration of in vivo X-ray fluorescence systems (IVXRF) of bone metal quantification are heavily dependant on a coherent normalization procedure as central to the calibration protocol. ${ }^{1-9}$ The coherent normalization procedure being developed by Somervaille et al. ${ }^{1}$ in the context of a bone lead analysis using a ${ }^{109} \mathrm{Cd}$ source and later extrapolated to other IVXRF systems of bone metal quantification. ${ }^{2-8}$ The development of this method of calibration was in response to the complexity of the calibration protocol proposed by Ahlgren et al. ${ }^{10}$ and Ahlgren and Mattsson ${ }^{11}$ based on excitation using a ${ }^{57}$ Co source, which required the use of orthoplanar X-rays, estimations of bone mineral concentration/density through the scattered source radiation and the construction of custom phantoms on a per-subject basis composed of bone ash and wax.

The coherent normalization procedure developed by Somervaille and colleagues ${ }^{1}$ was found to correct for various measurement-based factors, including variations in source activity, source-to-detector distance, soft tissue thickness/signal attenuation, variations in bone shape, size and orientation, the subjects bone mineral concentration, and minor subject movement during the measurement. ${ }^{1,12,13}$ The total procedure thus allowed the analyst to determine the concentration of lead in the bone sample being measured in vivo from a single measurement, making this a great advancement in the context of in vivo bone metal analysis. It is not thus surprising that this method of calibration has extended to most other methods of bone metal quantification including those for bone uranium quantification, ${ }^{2,3}$ bone strontium quantification, ${ }^{4-8}$ bone lead quantification via L-IVXRF ${ }^{14-17}$ and ${ }^{57}$ Co-induced K-IVXRF bone lead quantification. ${ }^{9}$

Coherent normalization is based on the premise that calcium is the major coherent scatterer in bone mineral, and thus, a surrogate for bone mineral can be used for calibration. For 
this reason, plaster of Paris (poP, calcium sulphate) was selected as the calibration/phantom material given its availability. ${ }^{1,4-8,16-19}$ Several factors do however have to be met for coherent normalization to be applicable. The cadmium-109 source emits a $\gamma$-ray which is directly at the K-edge of lead; ${ }^{1,20}$, thus, any Compton interactions will result in photons with energies unable to excite lead via the K-edge. Further, the degree of attenuation of the coherently scattered photons must be minimal by the overlaying soft tissue layer and the source photons need to fully subtend to the bone. In the context of a bone strontium measurement, these conditions are not necessarily met and coherent normalization can be applied only under certain conditions and only corrects for bone size and not necessarily for overlaying soft tissue attenuation. ${ }^{7}$

Our research group has developed a novel hydroxyapatite (HAp)-based phantom material for the purpose of calibrating in vivo methods of bone metal analysis. ${ }^{21,22}$ The impetus of this development was to have available a phantom material which mimics bone mineral more closely thus potentially simplifying the calibration protocol for bone strontium measurements by removing the required coherent conversion factor $(\mathrm{CCF})$ from the protocol and thus removing one potential source of uncertainty. In this study, Monte Carlo simulations are employed to investigate the use of these phantoms ${ }^{21}$ in the context of a bone strontium quantification. This study being based on bare bone phantoms which are intended to have emission spectra that act as a surrogate for soft tissue corrected signal. Bare bone spectra were selected and soft tissue correction ignored in the calibration protocol as soft tissue attenuation corrections have not yet fully been developed for in vivo bone strontium measurements and methods proposed ${ }^{17-19}$ need to be further evaluated (the topic of Chapter 7 ). Although bare bone measurements are by their very nature not possible in the context of an in vivo bone strontium quantification, and, counter to their purpose, they are presented 
here as to evaluate the suitability of the hydroxyapatite phantom material, ${ }^{21}$ as signal from bare bone is in fact the desired corrected signal for the quantification.

\subsection{Methods}

Monte Carlo simulations were performed to assess the HAp phantom material as a suitable calibrator for the purpose of calibrating the ${ }^{125}$ I-induced IVXRF system of bone strontium quantification used for the purpose of measuring human populations as described elsewhere. ${ }^{6,23-25}$ Monte Carlo simulations were performed using the EGS5 (Electron Gamma Shower) system using bench-marked code for the ${ }^{125}$ I-induced IVXRF system of bone strontium quantification. ${ }^{23}$ The simulations were performed on bare phantoms without the addition of any overlaying soft tissue composed of various compositions including that of cortical bone ${ }^{26}$ plaster of Paris (poP) and hydroxyapatite (HAp) (Table 6.1). Cortical bone was selected as the material type as it is presumed that on average the cortical layer can be considered infinitely thick for these in vivo measurements. In order to assess compositional influence only, all phantoms were simulated to be of a diameter of $9 \mathrm{~mm}$ as to mimic the second phalanges of the finger: the measurement site for an in vivo bone strontium measurement and the system geometry is described elsewhere. ${ }^{23}$ An assumption is made as to the substension of the primary beam in all cases with relation to any IVXRF quantification methodology. In the context of this study it was assumed that the beam completely subtended around the bone, thus all photons interacted with the phantom/bone material. This is assumed to be an ideal case and was selected as a means of investigating material dependence only. No further assessment as a function of bone size was evaluated as such effects have already been established by Zamburlini et al. ${ }^{23}$

Simulations were performed using the following parameters: $10^{12}$ incident particles; in- 
Table 6.1: Materials and associated physical properties used for the Monte Carlo simulations. Data for HAp and poP taken as basic physical/chemical properties. Data for cortical bone taken from the ICRP. ${ }^{26}$

\begin{tabular}{lcccccccccc}
\hline \hline & \multicolumn{10}{c}{ Element and associated weight fraction } \\
\hline & $\mathrm{H}$ & $\mathrm{C}$ & $\mathrm{N}$ & $\mathrm{O}$ & $\mathrm{Na}$ & $\mathrm{Mg}$ & $\mathrm{P}$ & $\mathrm{S}$ & $\mathrm{Ca}$ & $\rho\left(\mathrm{g} / \mathrm{cm}^{3}\right)$ \\
Cortical bone & 0.034 & 0.155 & 0.042 & 0.435 & 0.003 & 0.002 & 0.103 & 0.003 & 0.225 & 1.9 \\
Plaster of Paris (poP) & 0.002 & - & - & 0.496 & - & - & - & 0.221 & 0.276 & 2.31 \\
Hydroxyapatite (HAp) & 0.002 & - & - & 0.414 & - & - & 0.185 & - & 0.399 & 3 \\
\hline \hline
\end{tabular}

cident particles modelled for a brachytherapy seed as per by Zamburlini et al. ${ }^{6}$; sample-todetector window distance of $5 \mathrm{~mm}$ (see Figure 1.1, section 1.4, pg. 12).

To evaluate the influence of bone mass density variations on the quantification protocol, a cortical bone phantom was used and the densities changed in the code from $1.2-3.0 \mathrm{~g} / \mathrm{cm}^{3}$. These variations in bone mass density were selected to encompass the range expected in human's as a function of various biological factors ${ }^{26}$ with an extension to cover the density of pure HAp.

The effect of various matrix compositions on the quantification was evaluated by producing calibration curves with varying strontium concentrations at the expense of a calcium substitution. Standard curves being prepared against the concentration of strontium and either the $\mathrm{K} \alpha_{1,2}$ alone, or, the $\mathrm{K} \alpha_{1,2}$ peak normalized to the intensity of the coherently scattered ${ }^{125} \mathrm{I} \gamma$-ray at $35.5 \mathrm{keV} .{ }^{7}$ From these calibration curves, recovery analyses were produced as to assess the analytical bias of the measurements when different phantom materials are used for quantification. Recovery was determined by using the intensities from cortical bone phantoms with known strontium concentrations and those determined when quantification was performed against either poP or HAp. In all cases, calibration was presumed to follow a linear model as is customary for the calibration of IVXRF bone strontium systems. ${ }^{4-8}$ For this reason, the concentrations of strontium in bone were maintained to a maximum concentration of $1000 \mu \mathrm{g} / \mathrm{g}$ phantom material as a means of ensuring that no effects on the linearity would be observed. 
Differential coherent cross-sections were computed using a custom computer program written for this purpose in GNU Octave. Elemental form factor data was taken from Hubbell and $\varnothing v e r b \varnothing^{27}$ and extrapolations made on this data in order to compute the differential coherently scattered cross-section. The computation of the differential coherent cross-section for mixtures was performed by determining the differential coherent cross-section at an elemental level and performing weighting by each element's weight fraction within the mixture. For the purpose of this study, differential coherent cross-sections were computed for various hydroxyapatite mixtures with varying degrees of reaction completeness (conversion ratios). Differential coherent cross-sections where thus calculated for mixtures of hydroxyapatite, brushite and calcium hydroxide.

\subsection{Results and Discussion}

In practice it is not possible to prepare a phantom for IVXRF purposes which matches the human bone matrix exactly for all factors including composition as well as geometry. This was a concern which was presented by Ahlgren et al. ${ }^{10}$ and Ahlgren and Mattsson ${ }^{11}$ early on in the development of IVXRF systems of bone metal quantification which necessitated the production of patient-specific phantoms. Early work by Ahlgren et al. ${ }^{10}$ and Ahlgren and Mattsson ${ }^{11}$ demonstrated that the characteristic X-ray intensity as well as the scattered Xray intensity was a function of both bone mineral density as well as composition. As shown by Somervaille et al., ${ }^{1}$ the issue of compositional difference as well as geometrical factors can be resolved when employing a coherent normalization procedure and using a surrogate for bone mineral such a poP; however a matrix correction is still required. When poP is used as a calibration/phantom material, the sulphur presents a coherent scattering profile which is different than that of phosphorous which is found in the bone matrix. As a result, 
Table 6.2: Rate of change in characteristic X-ray intensity for the strontium K-series as a function of $\rho_{b}$. Computed $p$ values are those computed using a $t$-test about the slope, intercept and correlation coefficient. Tests performed at the $95 \%$ level of confidence $(\alpha=$ $0.05)$.

\begin{tabular}{l|cc|cc|cc|c}
\hline \hline & slope & $p$ & intercept & $p$ & $r$ & $p$ & $R^{2}$ \\
\hline $\mathrm{K} \alpha_{1}$ & $-1506 \pm 201$ & 0.002 & $61631 \pm 431$ & $<0.0001$ & -0.9659 & 0.002 & 0.9330 \\
$\mathrm{~K} \alpha_{2}$ & $-160 \pm 199$ & 0.47 & $30452 \pm 424$ & $<0.0001$ & -0.3734 & 0.47 & 0.1394 \\
$\mathrm{~K} \alpha_{1,2}$ & $-1666 \pm 230$ & 0.002 & $92083 \pm 492$ & $<0.0001$ & -0.9638 & 0.002 & 0.9289 \\
\hline $\mathrm{K} \beta_{1,3}$ & $-255 \pm 171$ & 0.21 & $18429 \pm 366$ & $<0.0001$ & -0.5970 & 0.21 & 0.3564 \\
$\mathrm{~K} \beta_{5}$ & $6 \pm 55$ & 0.92 & $2404 \pm 117$ & $<0.0001$ & 0.05332 & 0.92 & 0.002843 \\
$\mathrm{~K} \beta_{1,2,5}$ & $-249 \pm 153$ & 0.18 & $20833 \pm 327$ & $<0.0001$ & 0.6595 & 0.15 & 0.4350 \\
\hline \hline
\end{tabular}

a coherent conversion factor (CCF) needs to be applied, which is simply defined as the ratio of the differential coherent cross-sections between poP and bone mineral (presumed to be HAp). ${ }^{1,13}$ Application of the CCF to poP-based calibration curves adjusts the determined poP calibration factor/sensitivity to a calibration factor/sensitivity, which is usable against hydroxyapatite/bone mineral-based signal.

Bone mass density is known to be variable depending on various factors such as sex, age and health status. The effect of variations in subject bone mass density was evaluated at the level of both the strontium characteristic X-rays and the normalizing signal - the ${ }^{125} \mathrm{I}$ coherently scattered photon. In the case of bone mass density $\left(\rho_{b}\right)$ variations which can occur in human subjects, ${ }^{26}$ a marginal influence was observed for the $\mathrm{K}$ lines for strontium (Figure $6.1 \&$ Table 6.2). Only a minor decrease in the $\mathrm{K} \alpha_{1}$ line was observed as a function of bone density, which thus, presented itself in the form of a decrease in the $\mathrm{K} \alpha_{1,2}$ line which is used for the purpose of quantification (Figure 6.1 \& Table 6.2).

For an arbitrary infinitely thick specimen, which one would presume to be the case of the cylindrical bone phantom simulated in this study, one would expect the characteristic X-ray intensities to be independent of sample mass density (or in the case of this study $\rho_{b}$ ). This is 

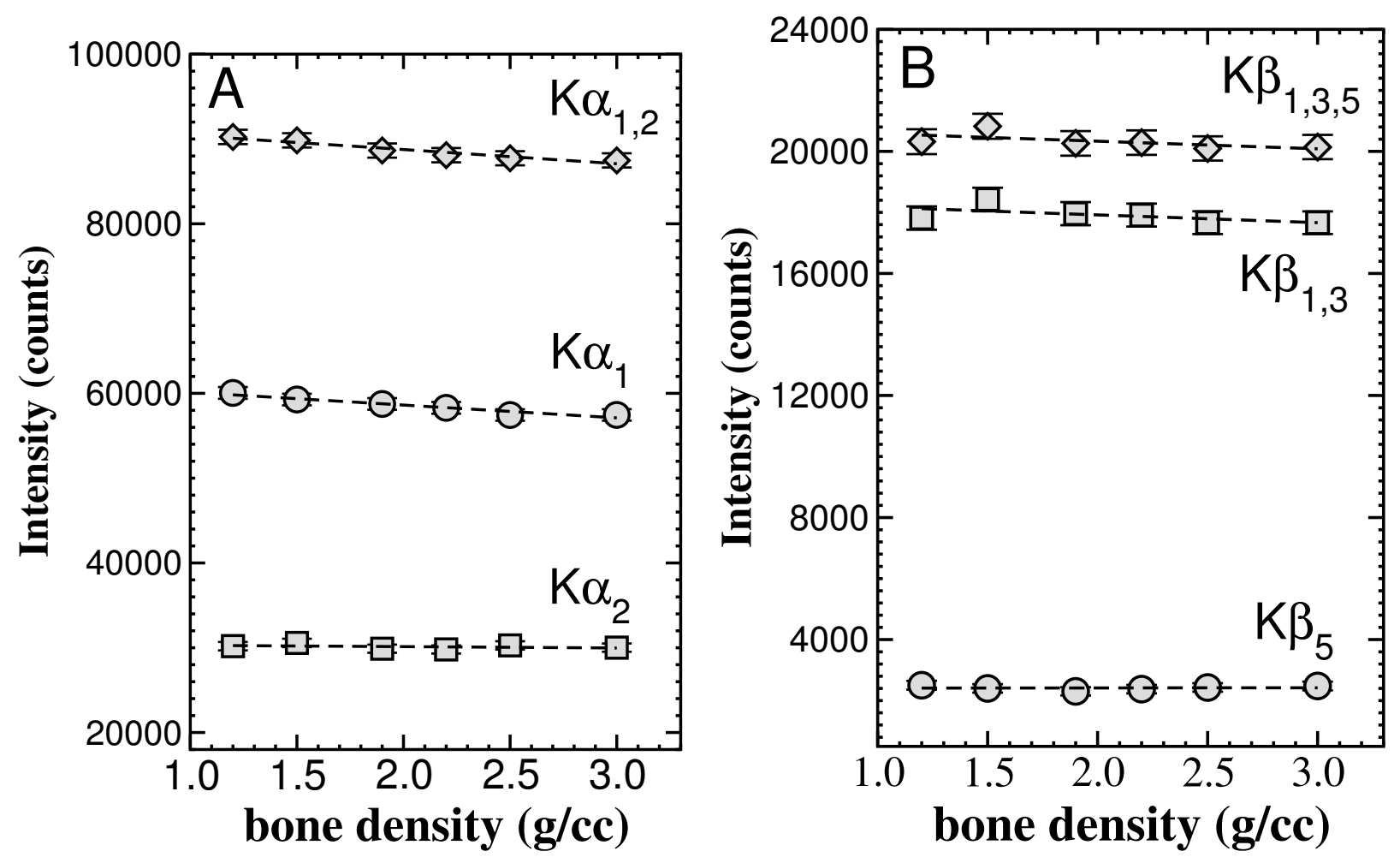

Figure 6.1: Effect of bone density $\left(\rho_{b}\right)$ variations on the observed strontium $\mathrm{K} \alpha(\mathbf{A})$ and $\mathrm{K} \beta$ (B) lines for a cortical bone phantom containing $400 \mu \mathrm{g} / \mathrm{g}$ strontium. There is only a slight decrease in intensity as a function of $\rho_{b}$ for the $\mathrm{K} \alpha_{1}$ and thus the $\mathrm{K} \alpha_{1,2}$ line (see Table $6.2)$. 
only the case when the primary beam is treated as a pencil beam, which is well established and is one of the attractive features when employing XRF for quantitative analysis as it simplified both calibration and quantification greatly. ${ }^{28-30}$ Therefore the fluorescent X-ray intensity becomes a direct function of only the total mass attenuation coefficient of the sample matrix and is density independent. ${ }^{30}$ The decrease in characteristic X-ray intensity as a function of sample mass density $\left(\rho_{b}\right)$ which was observed in this simulation study is thus contrary to the expected trend for infinitely thick specimens. The relatively minor decrease in the analytical signal was only observed for the $\mathrm{K} \alpha_{1}$ line which is the less energetic of the characteristic X-rays. This decrease in analytical signal is likely attributed to the signal emanating and being self attenuated at the edges of the cylindrical phantom/bone in which the beam substends which would not be considered necessarily infinitely thick for this X-ray energy.

The coherently scattered photon from the ${ }^{125}$ I source does however show a strong dependence in its intensity with relation to bone mass density (Figure 6.2). This can be attributed simply to the increase in the total number density of potential scattering targets for the same probed volume and thus simply a larger number of scatterers. The total coherently scattered photon intensity thus follows a trend which may result in an issue with regards to strontium quantification via coherent normalization, given that the fluorescence X-ray intensity is independent of density while the coherently scattered photon intensity is dependant on density. Quantification for strontium using the $\mathrm{K} \alpha_{1,2} \mathrm{X}$-ray relative to the coherently scattered X-ray, thus results in strong biases, given that no normalization has been made for the number of scatterers for which the coherently scattered photon intensity depends (Figure 6.3). This thus may result in the necessity to normalize more globally to the total number of scatterers versus fluorescent atoms which is one of the primary goals of employing 


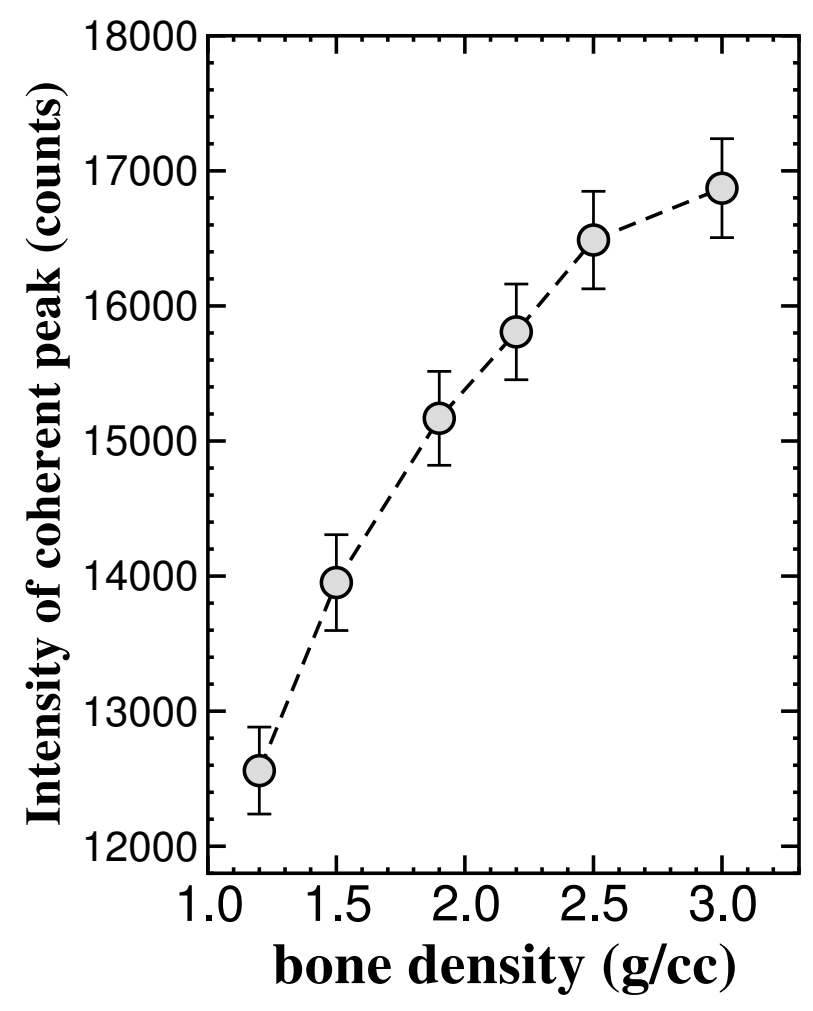

Figure 6.2: Effect of $\rho_{b}$ on the observed coherent peak intensity from the $35.5 \mathrm{keV}{ }^{125} \mathrm{I}$ source $\gamma$-ray, for a cortical bone phantom containing $400 \mu \mathrm{g} / \mathrm{g}$ strontium. The "physiological range" is between 1.5 and $2.2 \mathrm{~g} / \mathrm{cm}^{326}$ resulting in a $14 \%$ increase in intensity. The range of densities evaluated in this figure extends further from the physiological range to include the density of pure HAp. 


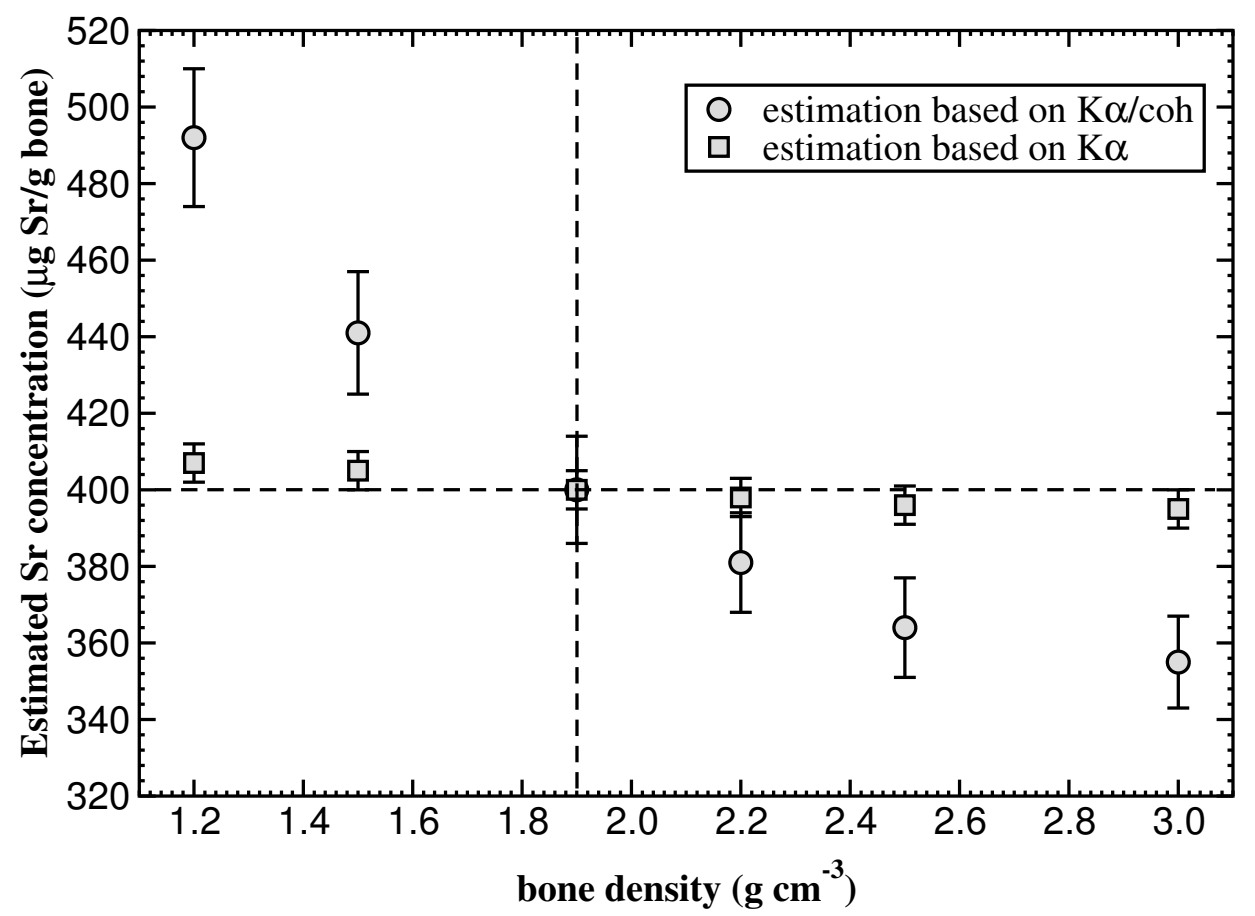

Figure 6.3: Quantification of strontium for a $400 \mu \mathrm{g} / \mathrm{g}$ cortical bone sample, using either the $\mathrm{K} \alpha_{1,2}$ line alone or the $\mathrm{K} \alpha_{1,2} /$ coh ratio against a cortical bone-based calibration curve. A larger bias is observed in the case of using the $\mathrm{K} \alpha_{1,2} /$ coh ratio as the analytical measure due to introduction of the density dependence of the coherent scattered photon. The close match in results when using the $\mathrm{K} \alpha_{1,2}$ alone is due to the match in geometry between sample and phantoms and a match in the total mass attenuation coefficients of the sample and phantoms/calibrators.

coherent normalization. ${ }^{1}$ The dependence on density alone thus becomes a potential factor in the quantitative power of the coherent normalization procedure, even when the calibration material is perfectly matched to the sample matrix as is the case for Figures $6.1-6.3$ and Table 6.2.

In the case of any sample of a given composition, the fluorescence intensity becomes a function of the total mass attenuation coefficient as previously described. ${ }^{28-30}$ Figure 6.4 shows calibration curves prepared for phantoms made of cortical bone, poP and HAp, each showing a difference in sensitivity which relates directly to the total mass attenuation coefficient of the material; calibration curves being prepared against the concentration of stron- 
tium relative to the total mass of the material and showing a large difference between the sensitivities as a function of the total matrix composition.

The end result of this variation in analytical sensitivities is a large bias in quantitative result, in both cases of either using poP or HAp as a calibrator/phantom material to quantify measured results acquired from a cortical bone specimen (Figure 6.5). The use of either poP or HAp as a calibration material thus does not allow for strontium quantification relative to the total mass of bone even in the most ideal of quantitative scenarios of same sample geometry as well as no overlaying soft tissue attenuation of the strontium characteristic Xray signal in the case of applying the strontium $\mathrm{K} \alpha_{1,2}$ alone as the analytical measure. It is thus apparent that a global matrix correction needs to be performed prior to reporting quantitative results for strontium.

Preparing calibration curves using the $\mathrm{K} \alpha_{1,2}$-to-coherent ratio, in the context of quantification of strontium relative to the total mass of bone, results in the same discrepancy in sensitivity (Figure 6.6), only introducing the density dependence previously explored (Figure $6.2)$.

Interestingly, the result of strontium quantification relative to the total mass of bone using either HAp or poP phantoms as calibrators worsens when the $\mathrm{K} \alpha$-to-coherent ratio is used as the analytical measure (Figure 6.7) with biases on the order of $126 \%$ and $35 \%$, respectively.

This simulation study thus indicates that quantification relative to the total mass of bone is not possible using either direct characteristic X-ray intensities or the $\mathrm{K} \alpha_{1,2}$-to-coherent ratio, and this observation is independent of which calibration/phantom material is used. The total mass attenuation coefficient and the density of the calibrators/phantoms must be matched to that of the patients bone in order for quantification to be achievable. In 

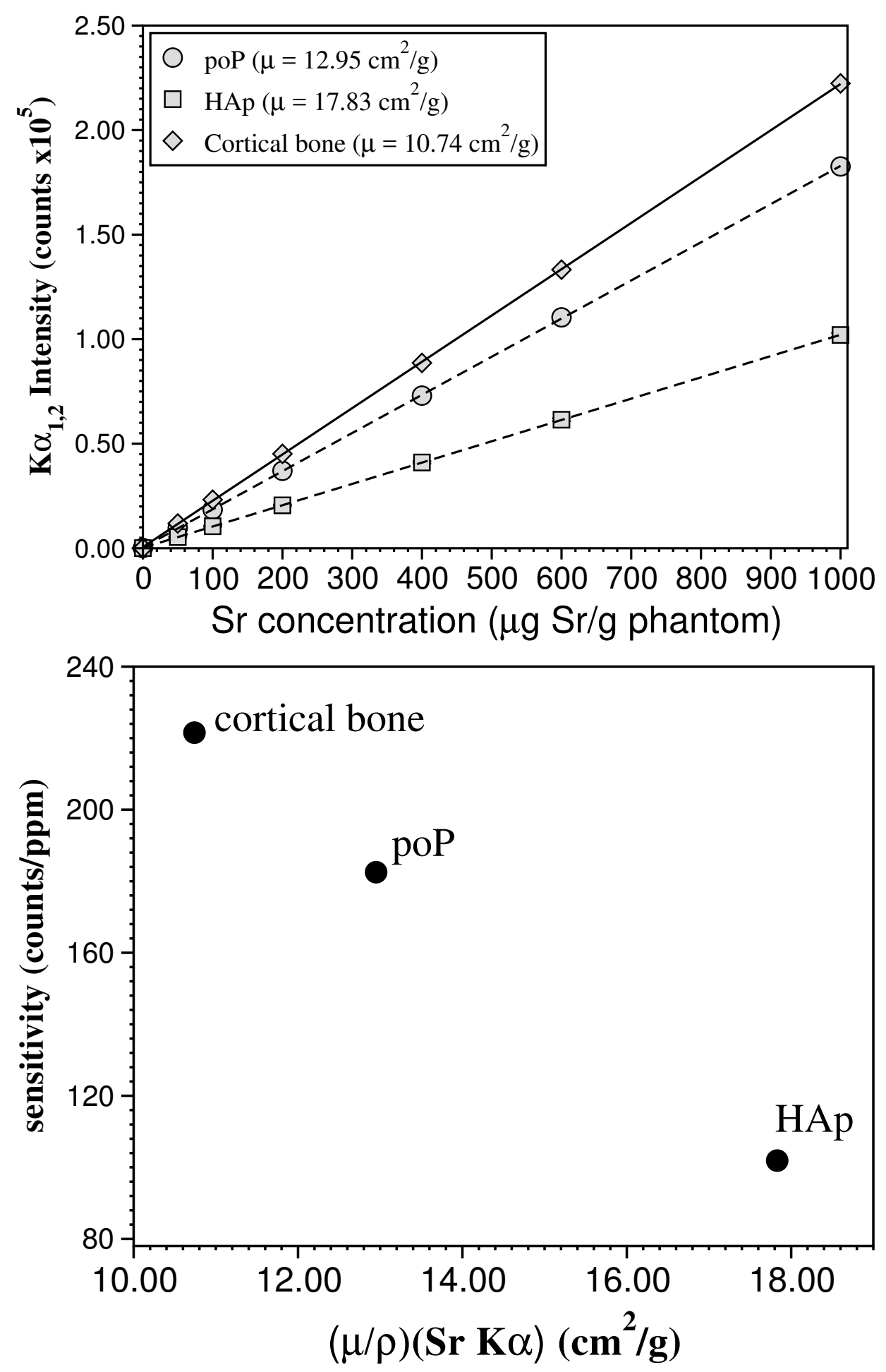

Figure 6.4: Calibration curves prepared against the strontium $\mathrm{K} \alpha_{1,2}$ line only for poP, HAp and cortical bone phantoms. The variation in sensitivity is due to variations in the total mass attenuation coefficients between the materials. 


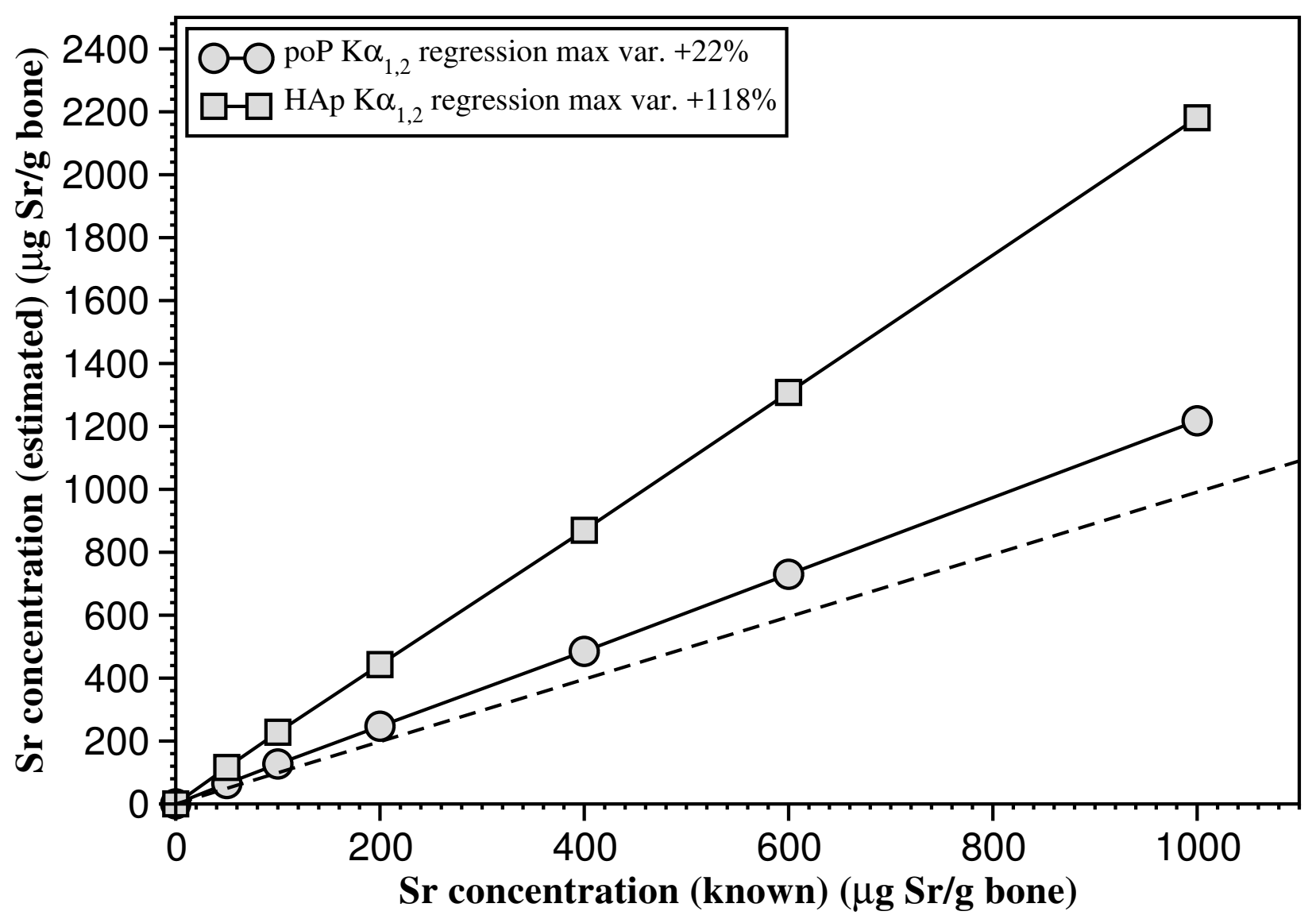

Figure 6.5: Attempts at quantifying strontium concentrations in units of mass strontium per total mass of bone using either poP and HAp calibrators/phantoms and un-normalized strontium $\mathrm{K} \alpha_{1,2}$ intensities. The quantification results in rather larger percentage deviations from known concentrations. The dashed line represents the 1:1 point. 

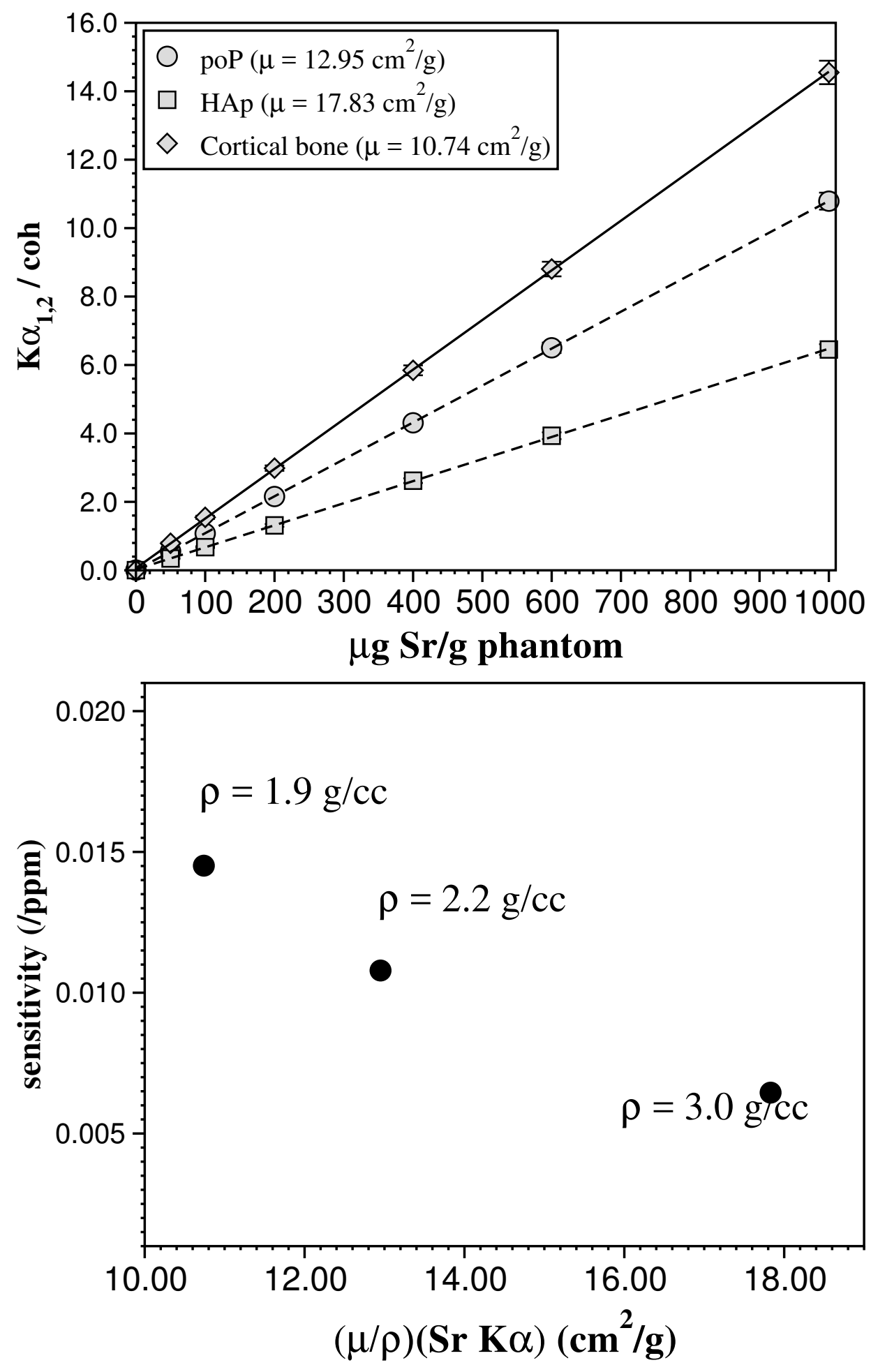

Figure 6.6: Calibration curves prepared against the strontium $\mathrm{K} \alpha_{1,2} /$ coherent ratio for poP, HAp and cortical bone phantoms. The variation in sensitivity is due to variations in the total mass attenuation coefficients between the materials but also influenced by the density effect on the coherent peak previously shown (Figure 6.2). 


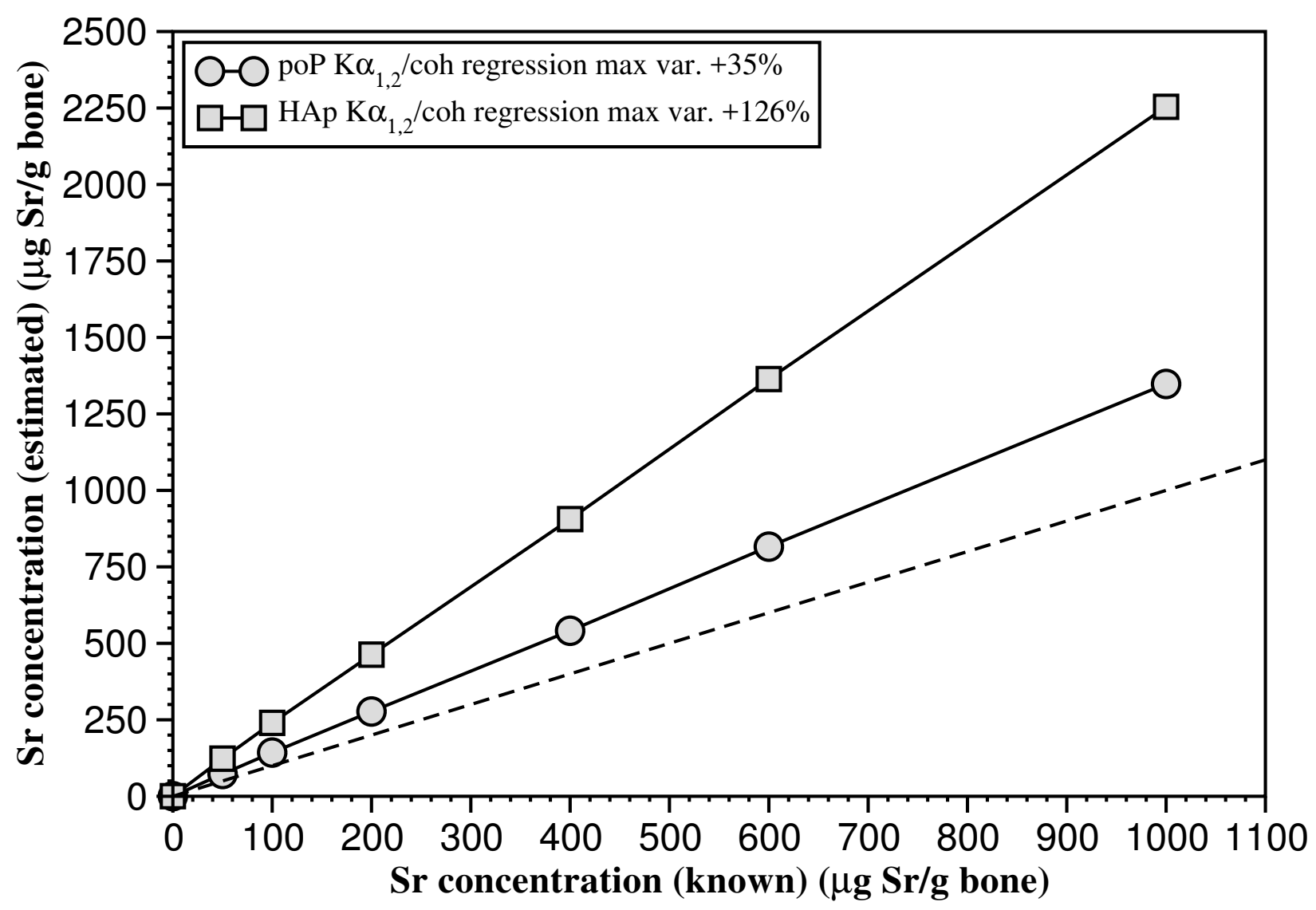

Figure 6.7: Attempts at quantifying strontium concentrations in units of mass strontium per total mass of bone using both poP and HAp phantoms and the $\mathrm{K} \alpha_{1,2}$-to-coherent ratio as the analytical measure. The quantification results in rather larger percentage deviations from known concentrations when using either of the two phantoms/calibrators. 
this case, quantification relative to the total mass of bone would thus require a method of applying a fundamental parameters approach, or, a Monte Carlo-based quantitative method to account more fully for factors such as geometry, which would require information similar to that required by the method proposed by Ahlgren et al. ${ }^{10}$ and Ahlgren and Mattsson ${ }^{11}$.

One of the features determined by Somervaille et al. ${ }^{1}$ with regards to coherent normalization in the context of an in vivo bone lead determination was that calcium is the prominent scattering element in both bone and phantom. Coherent normalization does allow for quantification relative to the amount of calcium within the sample as the coherently scattered radiation becomes a direct function of the number density of calcium atoms within the probing volume. In this case, the total mass of strontium in the phantom is normalized to the total mass of calcium, thus, normalizing for the number of scatterers. This mode of representing an analyte concentration in bone, that is, relative to the calcium content and by extension of a per mass of mineral basis, is in fact more clinically relevant than a representation on a total mass of bone basis. Analytes such as strontium and lead are bone seeking and substitute for calcium in the bone mineral phase of the tissue. As such, representation of concentrations at the level of mass of mineral and thereby calcium in of itself is a normalizing factor for inter-patient bone mineral density and bone mineral content variations.

Somervaille et al. ${ }^{1}$ have shown that the major scattering source in bone mineral are the calcium atoms, thus normalizing to the amount of calcium would account for the differences in density and likely sensitivity. The sensitivity differences being attributed to, as previously described, the differences in scattering properties between sulphur and phosphorous requiring the application of the CCF. For the strontium system investigated here, it was found via simulation that calibrations based on the strontium concentration relative to the amount of calcium (the dominate scatterer) results in excellent agreements between the HAp phantom 

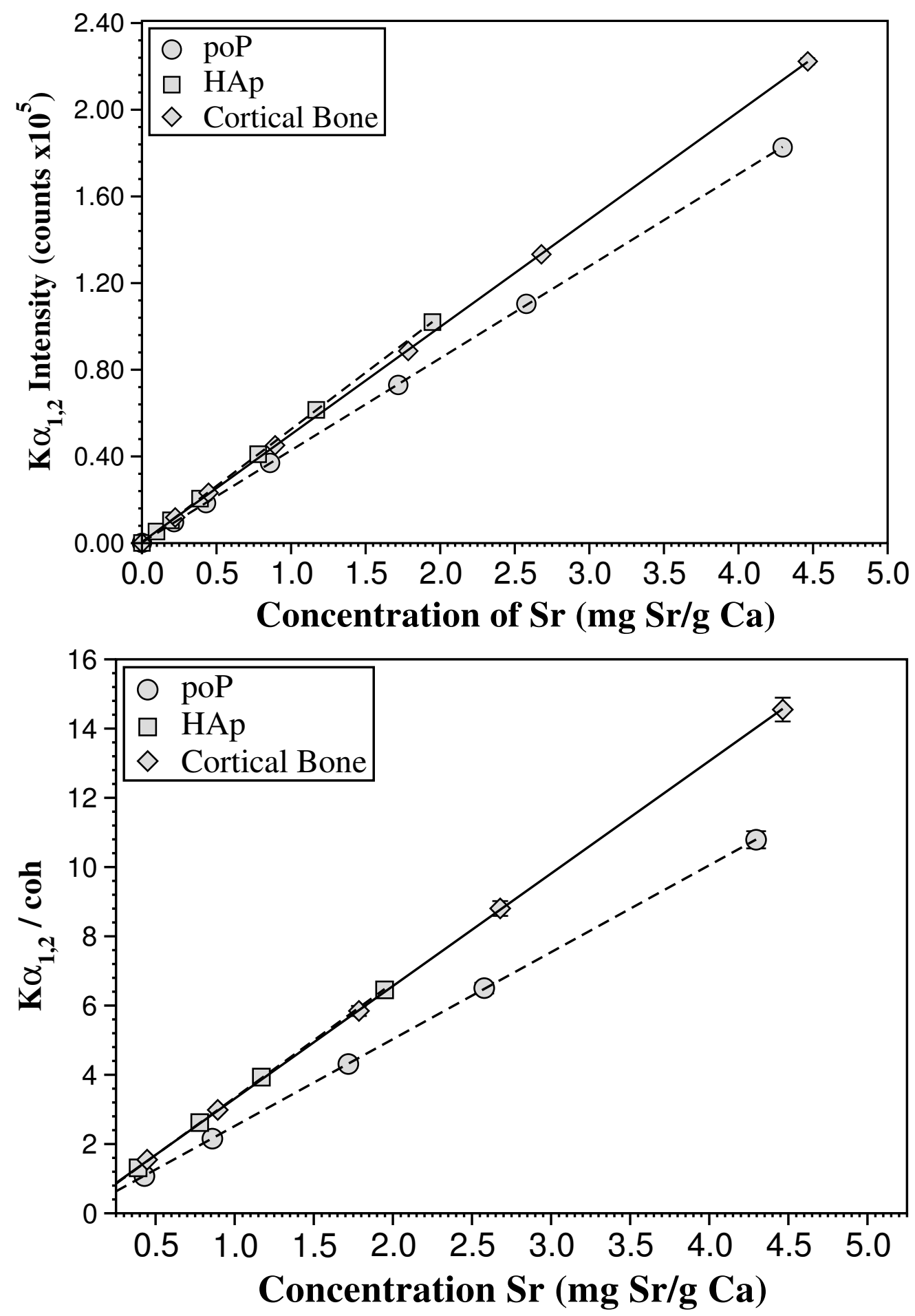

Figure 6.8: Calibration curves for poP, HAp and cortical bone expressed with concentration units normalized to mass of calcium in the specimen. There is excellent agreement between HAp and cortical bone calibration curves but not between poP and cortical bone calibration curves. 
and cortical bone, with the coherent ratio used as an analytical measure showing slightly better agreement (Figure 6.8). This demonstrates that the use of an HAp phantom material removes the need for a $\mathrm{CCF}$ by allowing for excellent agreement between the sensitivities of HAp and cortical bone curves.

Given the agreement between HAp and cortical bone sensitivities (Figure 6.8), quantification against the HAp calibration line produces quantified results for cortical bone which matched to known quantities (Figure 6.9) and with a minimal of bias. The difference in agreement when using poP as a calibrator/phantom material being due to not applying the CCF. Although Zamburlini et al. ${ }^{7}$ have shown that coherent normalization can be applied to correct for bone size variations, as well as geometric effects during the measurement, this study shows the advantage of using the HAp phantom material developed by Da Silva et al. ${ }^{21}$ in the context of an in vivo bone strontium measurement and potentially more generally as in the case of a bone lead measurement using the K-XRF system. Application of the HAp phantom material allows one to remove the need for the CCF directly which removes a large source of uncertainty in the quantification as outline previously. ${ }^{31}$

Aside from the fact that the CCF can be removed from the calibration protocol (Figure 6.9), the result shown in Figures $6.8 \& 6.9$ does carry other implications. It has been previously shown that the actual composition of poP is little known and this has impact on the true computation of the CCF in that case. ${ }^{31}$ This has been shown to bring in potentially large uncertainties into the quantification protocol when a CCF is applied for a poP-based calibration. ${ }^{31}$ Given that HAp and bone, although calcium phosphate, still do vary considerably in their composition, the fact that quantitative results are well aligned indicates that the issue with potential contamination to the HAp may not be of concern. This result in fact indicates that potentially any calcium phosphate can be used as a calibrator/phantom. 

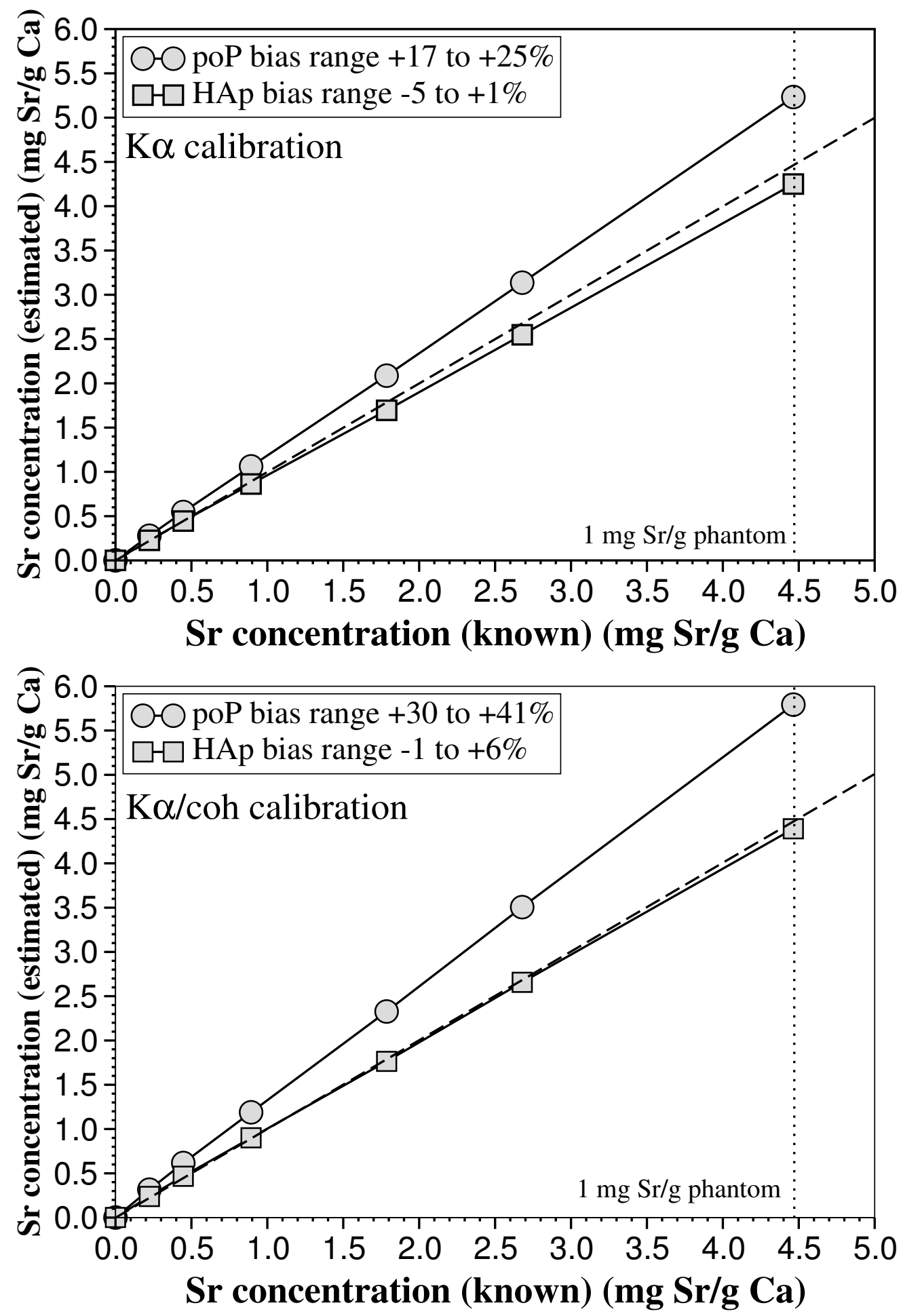

Figure 6.9: Determined strontium concentrations in relation to mass of calcium in the specimen, for cortical bone, as determined from poP and HAp calibration curves. Normalization to the $35.5 \mathrm{keV} \gamma$ results in excellent agreements for HAp calibration but not poP calibration. The dashed line represents the 1:1 point. 


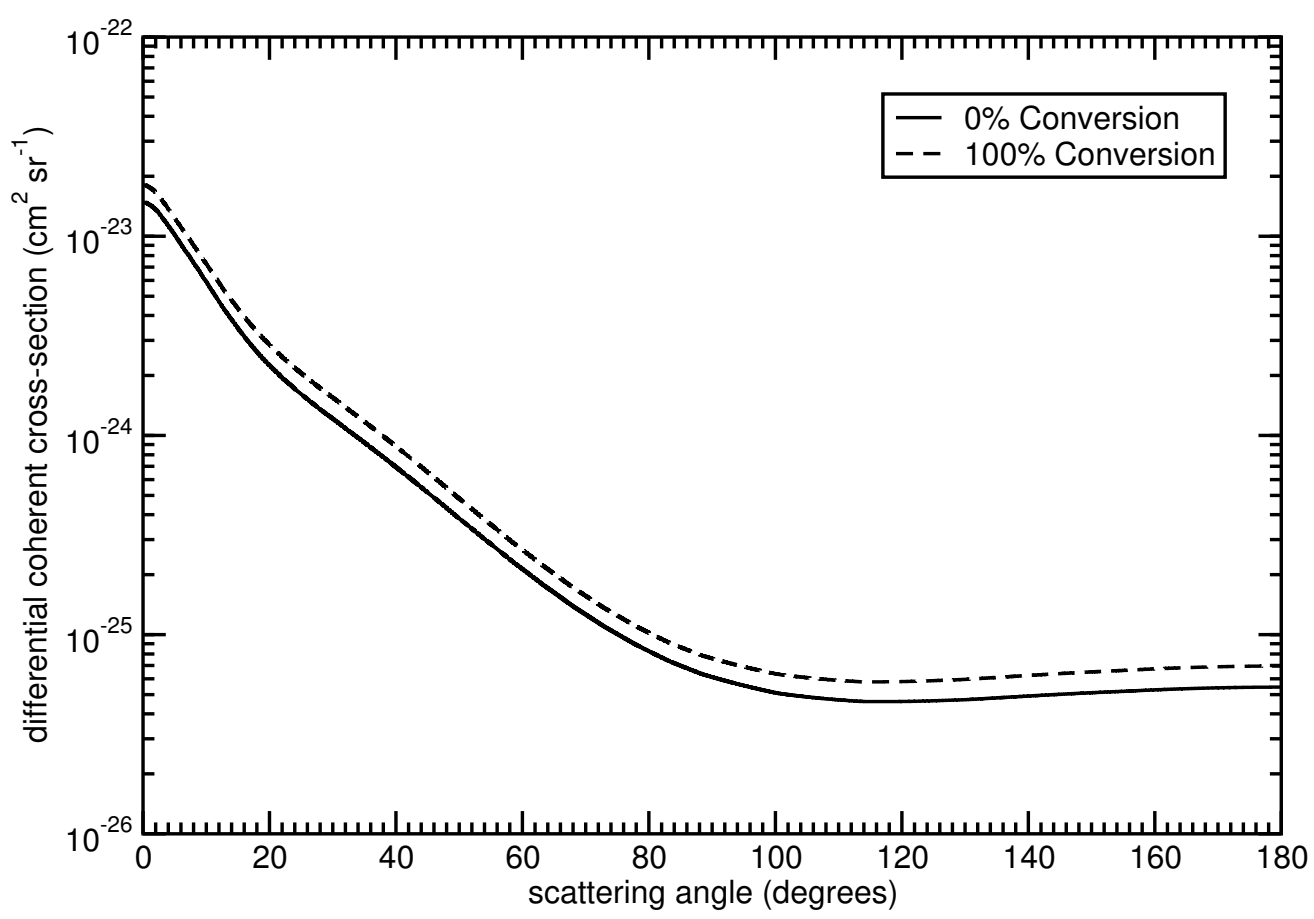

Figure 6.10: Differential coherent cross-sections for an HAp phantom with either a $0 \%$ of $100 \%$ conversion ratio to the reaction. A $100 \%$ conversion ration corresponds to pure HAp, while a conversion ratio of $0 \%$ corresponds to a mixture of brushite and calcium hydroxide in a proportion as to produce a $\mathrm{Ca} / \mathrm{P}$ mole ratio of 1.67 .

In the case of the HAp phantom materials designed for the purpose of calibration IVXRF bone strontium and lead system ${ }^{21,22}$, one aspect that has not been evaluated thoroughly has been the possibility that the conversion ratio for the reaction does not tend to unity, the conversion ratio being defined as the percentage of material actually produced by the pseudo-solid state reaction. That is, that the starting materials do not fully convert to HAp.

Figure 6.10 shows the computed differential coherent cross-sections for the two extrema of this scenario: when the conversion ratio is $100 \%$, that is the phantom material is pure HAp, and when the conversion ratio is $0 \%$, that is that the phantom is composed of a mixture of brushite and calcium hydroxide as to make a $\mathrm{Ca} / \mathrm{P}$ mole ratio of 1.67 . As can be seen, the influence in the differential cross-section is minor, amounting to $20 \%$ difference between the extreme cases of complete and fully incomplete reactions, at the $180^{\circ}$ backscatter mark 


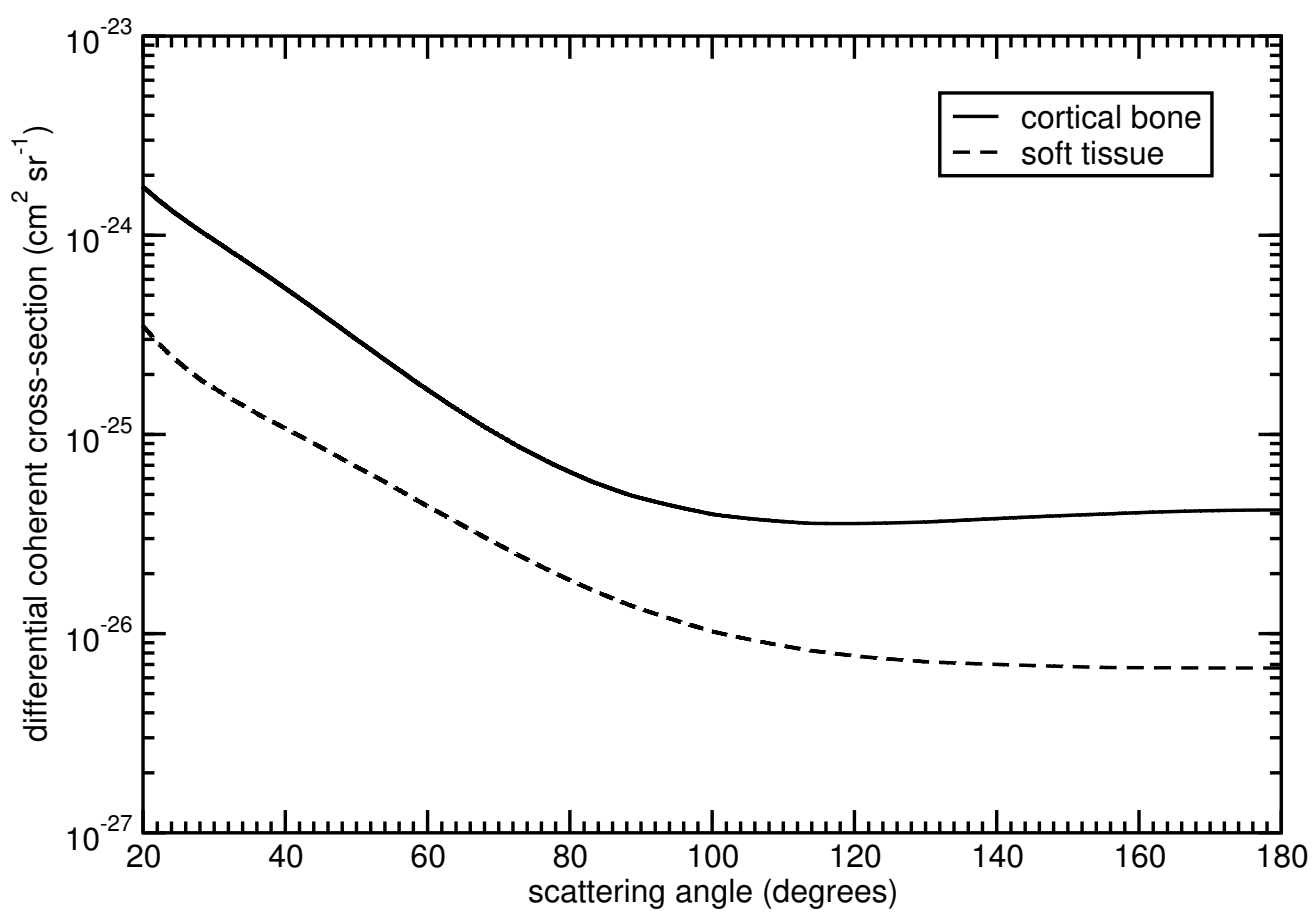

Figure 6.11: Differential coherent cross-sections for cortical bone and soft tissue at $35.5 \mathrm{keV}$. The ratio of the cortical bone cross-section to that of soft tissue at $180^{\circ}$ is 6.2 .

(Figure 6.10). This would indicate that the removal of the CCF is achievable when applying an HAp phantom material, in that uncertainty is removed from the protocol by removing any uncertainty on a compositional basis, but this also indicates that even if the HAp phantom is not completely pure HAp, that there will be little effect on the calibration protocol and the accuracy of any determined concentrations.

This work is however limited by two factors. Only the $35.5 \mathrm{keV}{ }^{125} \mathrm{I}$ coherently scattered $\gamma$-ray was evaluated for the purpose of normalization although various coherently scattered photons exist which are produced by interactions of the silver and tellurium X-rays emitted by the source with the sample being measured. The $35.5 \mathrm{keV}{ }^{125} \mathrm{I}$ coherently scattered $\gamma$-ray has been previously selected as the optimal photon for the purpose of coherent normalization. ${ }^{6,23}$ This photon was selected as it is the highest energy photon within the spectrum and is an isolated peak. As a result, the degree of influence that soft tissue attenuation would have 
on this photon is minimized in comparison to other coherently scattered X-rays from the emission spectrum as degree of attenuation is inversely proportional to the energy of the photon. Selection of the $35.5 \mathrm{keV}{ }^{125} \mathrm{I}$ coherently scattered $\gamma$-ray as the normalizing photon thus reduces any effects due to photon attenuation by the overlaying soft tissue, if only by a small fraction. The isolation of this peak also allows for a better ability to extract net intensities as there is no complication from overlapping Compton peaks in comparison to the location of the silver and tellurium coherent scattered X-rays which fall on top of Compton continua. This thereby results in a reduction in the total uncertainty brought into the measurement during the data reduction phase of the quantitative analysis.

This study was further limited as the influence of soft tissue was not evaluated on the coherent normalization procedure. This was the intention of this work as the effect of phantom material and a perfectly corrected signal was the intention of the evaluation. In reality, there is a coherent contribution from soft tissue to the total net intensity of the $35.5 \mathrm{keV}^{125} \mathrm{I}$ coherently scattered $\gamma$-ray observed of human measurements which cannot be necessarily ignored. In a real human measurement then, the $35.5 \mathrm{keV}{ }^{125} \mathrm{I}$ coherently scattered $\gamma$-ray intensity will have contributions from both the bone and the overlaying soft tissue. At $180^{\circ}$ the ratio of the differential coherent cross-sections between cortical bone and soft tissue is approximately 6 (Figure 6.11). That is, that the probability of scattering from the bone rather than the soft tissue is approximately one order of magnitude higher (Figure 6.11). This would thus inherently necessitate that in order to perform a quantification, the soft tissue thickness would need to be known, as this would influence the total number of coherent scattered photons, and a further normalization would have to occur in which the contribution of the soft tissue scattering to the net $35.5 \mathrm{keV}{ }^{125} \mathrm{I}$ coherently scattered $\gamma$-ray intensity is accounted for. This work thus shows that if this procedure is introduced, which requires 
further development, then, the application of HAp phantoms allows for a direct quantitative measure of bone strontium through the application of the coherent normalization procedure.

\subsection{Conclusions}

This study employed Monte Carlo simulation as a means of investigating the effect of using a HAp phantom material ${ }^{21}$ within the calibration protocol of the IVXRF system of bone strontium quantification. Simulations were performed on bare phantoms and the emanating signal used for the assessment would be equivalent to an IVXRF determination in which overlaying soft tissue attenuation has been accounted for. It was found that bone density does have a minor influence on the intensity of the of the $\mathrm{K} \alpha$ line and a major influence on the coherently scattered ${ }^{125} \mathrm{I} \gamma$-ray at $35.5 \mathrm{keV}$. Calibration against either poP, HAp or an cortical bone phantom resulted in major sensitivity differences and biases in the quantification which resulted from variations in the total mass attenuation coefficients between materials. Quantification against the mass of strontium to the total mass of bone was found not to be possible without knowledge of the bone density and bone mass attenuation coefficient which is not possibly known in a clinical environment for each patient. Coherent normalization was found to be successful in the case in which the strontium concentration was normalized to the mass of calcium in the sample and thereby the mass of bone mineral. In this case, calibration against this normalized concentration allows one to directly determine the concentration of strontium relative to calcium content in patients without the need to have a measure of the patients bone mineral content/density. Both HAp and bone phantoms produced standard curves which agreed well, while poP did not, resulting in excellent agreement of quantified results with minimal bias. This is attributed to the difference in differential cross-sections between the materials. This also indicates that it may be likely that the type 
of calcium phosphate used for calibration purposes is irrelevant and thus the removal of the CCF from the calibration protocol by the introduction of an HAp phantom material allows for the removal of a large area of uncertainty in the protocol. This study demonstrates that if a suitable soft tissue correction procedure is employed, that quantification is possible without the need of added matrix correction terms if an HAp calibrator is used. Further work however, must assess the coherent normalization procedure when overlaying soft tissue is present as a means of delineating the contributions from soft tissue and bare bone must be established for the normalization procedure to be useful.

\section{Acknowledgements}

The authors acknowledge the Natural Science and Engineering Research Council of Canada (NSERC) for their financial support of this work through a Alexander Graham Bell Canadian Graduate Scholarship (EDS) and a Discovery Grant (APM). The authors also acknowledge M. Forrest and G. Pearson (Department of Physics) for their technical support through the course of this work as well as A. Panagiotopoulos for his aid with more complex coding and code validation associated with this project. 


\section{References}

[1] L. J. Somervaille, D. R. Chettle, and M. C. Scott, "In vivo measurement of lead in bone using x-ray fluorescence," Physics in Medicine and Biology, vol. 30, no. 9, pp. 929-943, 1985.

[2] J. M. O'Meara, D. R. Chettle, F. E. McNeill, and C. E. Webber, "The feasibility of measuring bone uranium concentrations in vivo using source excited K x-ray fluorescence," Physics in Medicine and Biology, vol. 42, no. 6, pp. 1109-1120, 1997.

[3] J. M. O'Meara, D. R. Chettle, F. E. McNeill, and C. E. Webber, "In Vivo X-ray Fluorescence (XRF) Measurement of Uranium in Bone," Applied Radiation 83 Isotopes, vol. 49, no. 5-6, pp. 713-715, 1998.

[4] A. Pejović-Milić, I. M. Stronach, J. Gyorffy, C. E. Webber, and D. R. Chettle, "Quantification of bone strontium levels in humans by in vivo x-ray fluorescence," Medical Physics, vol. 31, no. 3, pp. 528-538, 2004.

[5] M. Zamburlini, A. Pejović-Milić, and D. R. Chettle, "Evaluation of geometries appropriate for ${ }^{125} \mathrm{I}$ in vivo bone strontium X-ray fluorescence measurement," Journal of Radioanalytical \&3 Nuclear Chemistry, vol. 269, no. 3, pp. 625-629, 2006.

[6] M. Zamburlini, A. Pejović-Milić, D. R. Chettle, C. E. Webber, and J. Gyorffy, "In vivo study of an x-ray fluorescence system to detect bone strontium non-invasively," Physics in Medicine and Biology, vol. 52, no. 8, pp. 2107-2122, 2007.

[7] M. Zamburlini, A. Pejović-Milić, and D. R. Chettle, "Coherent normalization of finger strontium XRF measurements: feasibility and limitations," Physics in Medicine and Biology, vol. 53, no. 15, pp. N307-N313, 2008. 
[8] C. M. Heirwegh, D. R. Chettle, and A. Pejović-Milić, "Ex vivo evaluation of a coherent normalization procedure to quantify in vivo finger strontium XRS measurements," Medical Physics, vol. 39, no. 2, pp. 832-841, 2012.

[9] J. M. O'Meara, J. Börjesson, D. R. Chettle, and S. Mattsson, "Normalisation with coherent scatter signal: improvements in the calibration protocol of the ${ }^{57} \mathrm{Co}$-based in vivo XRF bone-Pb measurement," Applied Radiation $\& 3$ Isotopes, vol. 54, no. 2, pp. 319$325,2001$.

[10] L. Ahlgren, K. Lidén, S. Mattsson, and S. Tejning, "X-ray fluorescence analysis of lead in human skeleton in vivo," Scandinavian Journal of Work $\&$ Environmental Health, vol. 2, no. 2, pp. 82-86, 1976.

[11] L. Ahlgren and S. Mattsson, "An X-ray Fluorescence Technique for in vivo Determination of Lead Concentration in a Bone Matrix," Physics in Medicine and Biology, vol. 24, no. 1, pp. 136-145, 1979.

[12] D. R. Chettle, M. C. Scott, and L. J. Somervaille, "Lead in Bone: Sampling and Quantitation Using K X-rays Excited by ${ }^{109}$ Cd," Environmental Health Perspectives, vol. 91, pp. 49-55, 1991.

[13] A. C. Todd, "Coherent scattering and matrix correction in bone-lead measurements," Physics in Medicine and Biology, vol. 45, no. 7, pp. 1953-1963, 2000.

[14] A. C. Todd, "L-shell x-ray fluorescence measurements of lead in bone: system development," Physics in Medicine and Biology, vol. 47, no. 3, pp. 507-522, 2002.

[15] A. C. Todd, S. Carroll, C. Geraghty, F. A. Khan, E. L. Moshier, S. Tang, and P. J. Par- 
sons, "L-shell x-ray fluorescence measurements of lead in bone: accuracy and precision," Physics in Medicine and Biology, vol. 47, no. 8, pp. 1399-1419, 2002.

[16] D. E. B. Fleming, M. R. Gherase, and K. M. Alexander, "A miniature X-ray tube approach to measuring lead in bone using L-XRF," X-ray Spectrometry, vol. 40, no. 5, pp. 343-347, 2011.

[17] L. H. Nie, S. Sanchez, K. Newton, L. Grodzins, R. O. Cleveland, and M. G. Weisskopf, "In vivo quantification of lead in bone with a portable x-ray fluorescence systemmethodology and feasibility," Physics in Medicine and Biology, vol. 56, no. 3, pp. N39N51, 2011.

[18] A. J. Specht, M. Weisskopf, and L. H. Nie, "Portable XRF Technology to Quantify Pb in Bone In Vivo," Journal of Biomarkers, vol. 2014, p. 398032, 2014.

[19] A. J. Specht, Y. Lin, M. Weisskopf, C. Yan, H. Hu, J. Xu, and L. H. Nie, "XRFmeasured bone lead $(\mathrm{Pb})$ as a biomarker for $\mathrm{Pb}$ exposure and toxicity among children diagnosed with Pb poisoning," Biomarkers, vol. 21, no. 4, pp. 347-352, 2016.

[20] E. E. Laird, D. R. Chettle, and M. C. Scott, "The factors affecting in vivo x-ray fluorescence measurements of lead in bone," Nuclear Instruments and Methods, vol. 193, no. 1-2, pp. 377-382, 1982.

[21] E. Da Silva, B. Kirkham, D. V. Heyd, and A. Pejović-Milić, "Pure Hydroxyapatite Phantoms for the Calibration of in Vivo X-ray Fluorescence Systems of Bone Lead and Strontium Quantification," Analytical Chemistry, vol. 85, no. 19, pp. 9189-9195, 2013.

[22] E. Da Silva, D. V. Heyd, B. Rizvi, and A. Pejović-Milić, "The preparation of 
strontium-substituted hydroxyapatite bone phantoms with high strontium concentrations," Biomedical Physics \&3 Engineering Express, vol. 2, p. 015006, 2016.

[23] M. Zamburlini, S. H. Byun, A. Pejović-Milić, W. V. Prestwich, and D. R. Chettle, "Evaluation of MCNP5 and EGS4 for the simulation of in vivo strontium XRF measurements," X-ray Spectrometry, vol. 36, no. 2, pp. 76-81, 2007.

[24] H. Moise, J. D. Adachi, D. R. Chettle, and A. Pejović-Milić, "Monitoring bone strontium levels of an osteoporotic subject due to self-administration of strontium citrate with a novel diagnostic tool, in vivo XRF: A case study," vol. 51, no. 1, pp. 93-97, 2012.

[25] H. Moise, D. R. Chettle, and A. Pejović-Milić, "Monitoring bone strontium intake in osteoporotic females self-supplementing with strontium citrate with a novel in-vivo Xray fluorescence based diagnostic tool," vol. 61, pp. 48-54, 2014.

[26] ICRP, "Basic Anatomical \& Physiological Data for use in Radiological Proetection The Skeleton," ICRP Publication 70, Annuals of the ICRP, vol. 25, no. 2, pp. —, 1995.

[27] J. H. Hubbell and I. Øverbø, "Relativistic atomic form factors and photon coherent scattering cross sections," Journal of Physical and Chemical Reference Data, vol. 69, pp. 60-105, 1979.

[28] J. Sherman, "The theoretical derivation of fluorescent x-ray intensities from mixtures," Spectrochimica Acta, vol. 7, no. 5, pp. 283-306, 1955.

[29] T. Shiraiwa and N. Fujino, "Theoretical calculation of fluorescent x-ray intensities in fluorescent x-ray spectrochemical analysis," Japanese Journal of Applied Physics, vol. 5, no. 10, pp. 886-899, 1966. 
[30] J. E. Fernández, "XRF Intensity in the Frame of the Transport Theory," X-ray Spectrometry, vol. 18, no. 6, pp. 271-279, 1989.

[31] A. C. Todd, "Contamination of in vivo bone-lead measurements," Physics in Medicine and Biology, vol. 45, no. 1, pp. 229-240, 2000. 
CHAPTER

SEVEN

\section{COMPTON-BASED SOFT TISSUE THICKNESS DETERMINATIONS IN THE CONTEXT OF AN ${ }^{125}$ I-INDUCED BONE STRONTIUM MEASUREMENT: A SIMULATION STUDY}

Working paper for publication: E. Da Silva, H. Sokoli, J. L. Gräfe, D. E. B. Fleming and A. Pejović-Milić, "Compton-based soft tissue thickness determinations in the context of an ${ }^{125}$ I-induced bone strontium measurement: A simulation study." $†$

${ }^{\dagger} \underline{E}$. Da Silva designed and carried out the experiments/simulations, performed the data analysis and wrote this manuscript/chapter. H. Sokoli aided with the collection of simulation data and data processing. J. L. Gräfe, D. E. B. Fleming and A. Pejović-Milić provided critical feedback as to its contents and assessed the manuscript/chapter critically. 


\subsection{Abstract}

In vivo bone strontium measurements require that the characteristic X-ray intensity from strontium be corrected for attenuation due to the overlaying soft tissue at the measurement site. This allows for the extrapolation back to a bare bone signal intensity which can be used against a standard curve for quantification. Overlaying soft tissue thickness determinations are currently made using imaging modalilties which can estimate the overlaying soft tissue thickness. Once the tissue thickness is known the attenuation corrections based on Lambert's law is completed. Although a useful method, soft tissue estimation by this means does introduce another step into the measurement process.

This work evaluates a Compton-based method of performing an estimation of overlaying soft tissue thickness using Monte Carlo simulations (EGS5). It was found that for the ${ }^{125}$ I-induced in vivo X-ray fluorescence system of bone strontium quantification in a $180^{\circ}$ backscatter geometry, that soft tissue correction may be possible if a HAp phantom material is used as the core of any phantoms used for preparation of standard curves and only if an approach of correcting for bone size variations is available. The correction based on the use of lucite and poP shows up to a $30 \%$ bias in soft tissue thickness estimations. This approach also requires the development of a soft tissue equivalent phantom material that will mimic soft tissue closely and allow for the production of transferable calibration functions. In return it would eliminate the need of overlaying tissue imaging at the measurement site, and thus simplify the in vivo bone strontium measurement. 


\subsection{Introduction}

In vivo X-ray fluorescence (IVXRF) measurements of bone strontium (and by extension lead, when considering the L-series as the analytical measure) requires that the measured intensity from the characteristic X-ray of interest (e.g. the strontium $\mathrm{K} \alpha_{1,2}$ line), acquired from a human subject, undergo a series of corrections. The calibration protocol of this system being based on the measurement of bare phantoms. ${ }^{1-7}$ For the calibration factors determined from phantom measurements to be useful, the analytical measure of interest is the intensity of characteristic X-rays as if they were emanating from a bare bone. Given the energy of these X-rays, for the case of strontium, $14.1 \mathrm{keV}$ for the $\mathrm{K} \alpha_{1,2}$ and $15.8 \mathrm{keV}$ for the $\mathrm{K} \beta_{1,3},{ }^{8}$ one of the more important required corrections is that for attenuation of the characteristic X-rays is the overlaying soft tissue around the bone being measured. ${ }^{5}$

Calibration is performed against a series of bare phantoms in order to determine the system's sensitivity factor, and thus, the measured intensities must undergo a correction to a bare bone, unattenuated intensity; the unattenuated intensity, thus being equivalent to the expected intensity if the measurement was made on bare bone. ${ }^{1,6,7}$ The calibration function in this case is however developed against the intensity of the $\mathrm{K} \alpha_{1,2}$ line normalized to the intensity of the ${ }^{125}$ I source $\gamma$-ray $(35.5 \mathrm{keV})$, which also requires an attenuation correction. ${ }^{4,6,7}$ In the practical sense then, for a human measurement, the measured coherently scattered peak must also be corrected for soft tissue attenuation given the energy of this photon. Proper calibration and quantification in the context of an IVXRF bone strontium measurement requires that the overlaying soft tissue thickness be known in order to make the an attenuation correction using Lambert's law.

Soft tissue thickness estimates for the purpose of this correction are currently made using medical imaging procedures in order to estimate soft tissue thickness. ${ }^{5-7}$ Several imaging 
modalilties have been evaluated for this purpose,${ }^{5}$ with ultrasound imaging currently the modality employed for soft tissue thickness estimates in human subjects ${ }^{6,7}$ due mostly to its simplicity and no need for any additional ionizing radiation exposures. Although imagingbased soft tissue thickness estimations offer a valid and direct way of estimating soft tissue thickness for soft tissue attenuation corrections, using an imaging modality as part of the calibration protocol adds another step to the quantification process, as well as a level of uncertainty in the estimation of soft tissue thickness. One of the possible sources of added uncertainty potentially being introduced by the fact that the estimate of soft tissue thickness is being made from an image of the anatomical site which encompasses the measurement site within a larger imaging site; thus, it is not providing a sole representative estimation of soft tissue thickness at the measurement site alone.

The use of scattered radiation, namely, Compton-scattered source radiation, for the purpose of soft tissue thickness estimation has been proposed by Nie et al. ${ }^{9}$ as a means of estimating soft tissue thickness directly from spectroscopic data. This method offers the potential for the direct estimation of soft tissue thickness at the time of measurement and data processing, and thus a means of performing a soft tissue attenuation correction, from spectroscopic data alone. This would thus allow for the removal of one step in the calibration protocol while also using data for soft tissue thickness estimation inherently from the measurement site alone. The method proposed by Nie et al. ${ }^{9}$ is based on the observation that Compton scattered source radiation is a function of soft tissue thickness (based on plaster of Paris and lucite phantom measurements). As such, the intensity of the Compton scattered radiation for any given collected human measurement can be used to extrapolate an estimate of soft tissue thickness from a suitably prepared calibration function produced using suitably prepared phantoms. This procedure of estimating soft tissue thickness has been further 
applied to phantom and human measurements. ${ }^{10,11}$ Undoubtedly, this proposal offers the potential for introducing a simple and elegant method of soft tissue thickness estimation and thus soft tissue attenuation correction which could be extrapolated to the IVXRF system of bone strontium quantification.

Nie et al.'s ${ }^{9}$ approach was however made in the context of a portable X-ray analyzer-based analysis of bone lead using a silver target X-ray tube. IVXRF bone strontium measurements are made using an ${ }^{125}$ I source in the form of brachytherapy seeds, which offers an array of Compton scattered photons due to the emission of the ${ }^{125} \mathrm{I}$, the silver beads that act as the support for the ${ }^{125} \mathrm{I}$ (thus emitting the silver K-series) and the tellurium X-rays (the daughter product of ${ }^{125} \mathrm{I} \beta^{-}$decay). For this reason, it is possible that this Compton-based method of $t_{s t}$ estimation could be extended to the IVXRF bone strontium measurement system as the energy of the strontium K-series is similar to that of the lead L-series and the silver $\mathrm{K} \alpha_{1,2}$ line emitted from the brachytherapy seeds offers a identical photon to that produced by a silver target X-ray tube for scattering.

This work thus evaluates, via Monte Carlo simulation, the potential of employing Comptonbased soft tissue thickness estimations in the context of ${ }^{125}$ I-induced IVXRF measurement made in the conventional $180^{\circ}$ geometry. This work focuses on this evaluation using the most prominent peak in the measured spectrum, the silver $\mathrm{K} \alpha_{1,2}$ Compton scattered peak, ${ }^{3}$ which is identical to that proposed by Nie et al. ${ }^{9}$ for this purpose.

\subsection{Methods}

Monte Carlo simulations were carried out using the EGS5 (Electron Gamma Shower) system using code developed as to simulate the the IVXRF bone strontium system with measurements made in a $180^{\circ}$ backscatter. ${ }^{3,6,7,12}$ To assess the Compton intensities as a function of 
soft tissue thickness simulations were made for cylindrical bone phantoms of various sizes ranging from a diameter of $0.5 \mathrm{~cm}$ to $1.5 \mathrm{~cm}$ which was considered to encompass cases of extrema; a diameter of $9 \mathrm{~mm}$ being a nominal diameter for the human phalanges. ${ }^{12}$ The inner bone core of the bone phantom used for simulations was composed of either bone or a phantom material (Table 7.1). The bone phantom materials evaluated were either plaster of Paris (poP), currently used for the purpose of calibrating IVXRF systems of bone strontium quantification, ${ }^{1-7}$ or HAp as has been proposed as an alternative. ${ }^{13,14}$ Chemical and physical parameters for each of the materials used in the simulations are found in Table 7.1.

To evaluate the influence of soft tissue thickness variations, soft tissue thicknesses were varied from 0 to $10 \mathrm{~mm}$, which was also expected to encompass extreme as nominal soft tissue thickness at the finger can be expected to be on the order of $5 \mathrm{~mm} .{ }^{12}$ Calibration of any system for soft tissue thickness estimations requires that the a series of external calibrations/phantoms be used. ${ }^{9}$ The effect of soft tissue surrogate material on the ability to perform soft tissue thickness estimations based on calibration data was performed by simulating phantoms using either soft tissue International Commission on Radiological Units (ICRU) ${ }^{15}$ as the tissue layer, or, lucite, as proposed by Nie et al. ${ }^{9}$ Physical and chemical parameters used for each soft tissue material within the simulations are shown in Table 7.1. For each soft tissue thickness and bone diameter combination, the samples-to-detector window distance was maintained at $5 \mathrm{~mm}$. A schematic of the simulation geometry can be found in Figure 1.1 and is intended to simulate a human measurement using the ${ }^{125}$ I-induced in vivo bone strontium system.

Simulations consisted of $10^{12}$ incident particles with a previously defined emission spectrum used for the ${ }^{125}$ I brachytherapy seed source. ${ }^{3}$ The surface-to-detector window distance was maintained at $5 \mathrm{~mm}$ throughout all simulations. The backscatter geometrical arrange- 
Table 7.1: Materials and associated physical properties used for the simulations: for HAp and poP data taken as basic physical/chemical properties whereby for cortical bone data taken from the ICRP ${ }^{16}$ and for soft tissue the ICRU. ${ }^{15}$

\begin{tabular}{|c|c|c|c|c|c|c|c|c|c|c|c|c|c|}
\hline \multicolumn{14}{|c|}{ Element and associated weight fraction } \\
\hline & $\mathrm{H}$ & $\mathrm{C}$ & $\mathrm{N}$ & $\mathrm{O}$ & $\mathrm{Na}$ & $\mathrm{Mg}$ & $\mathrm{P}$ & $\mathrm{S}$ & $\mathrm{Cl}$ & K & $\mathrm{Ca}$ & $\mathrm{Sr}$ & $\rho\left(\mathrm{g} / \mathrm{cm}^{3}\right)$ \\
\hline Cortical bone & 0.034 & 0.155 & 0.042 & 0.435 & 0.003 & 0.002 & 0.103 & 0.003 & - & - & 0.225 & 0.0004 & 1.9 \\
\hline Plaster of Paris (poP) & 0.002 & - & - & 0.496 & - & - & - & 0.221 & - & - & 0.276 & - & 2.31 \\
\hline Hydroxyapatite (HAp) & 0.002 & - & - & 0.414 & - & - & 0.185 & - & - & - & 0.399 & - & 3 \\
\hline Soft Tissue & 0.1 & 0.204 & 0.042 & 0.645 & 0.002 & - & 0.001 & 0.002 & 0.003 & 0.001 & - & - & 1.04 \\
\hline Lucite & 0.08 & 0.6 & - & 0.32 & - & - & - & - & - & - & - & - & 1.18 \\
\hline
\end{tabular}

ment of the simulations are shown in Figure 1.1.

Compton normalization was evaluated for the $20.39 \mathrm{keV}$ Compton peak which originates from Compton scattering of the source silver $\mathrm{K} \alpha_{1,2}$ line. ${ }^{2}$ This line was selected for this purpose as it is one of the least perturbed lines in an IVXRF bone strontium measurement spectrum ${ }^{17}$ and it is also equivalent to the line used by Nie et al. ${ }^{9}$ with the portable X-ray analyzer system. Other slightly perturbed peaks which may not be practical for this correction in practice were also evaluated including: the $27.4 \mathrm{keV}$ Te X-ray Compton scattered photon at $24.75 \mathrm{keV}$ and the $31 \mathrm{keV}$ Te X-ray Compton scattered photon at $27.65 \mathrm{keV} .^{2} \mathrm{~A}$ spectrum of a simulated spectrum in backscatter geometry is shown in Figure 4.4.

\subsection{Results and Discussion}

The proposed method of estimating overlaying soft tissue thickness using Compton scattered radiation requires the preparation of a calibration function based on phantoms composed of an inner-core of a bone surrogate material and an outer core of a soft tissue surrogate material. According to Nie et al.' ${ }^{9-11}$ original preparation this is prepared using plaster of Paris, of one given size, which are subsequently enveloped in various thicknesses of lucite which was proposed as the surrogate material for soft tissue. poP was likely selected as the inner core bone surrogate material given its extensive use as a phantom material in the 


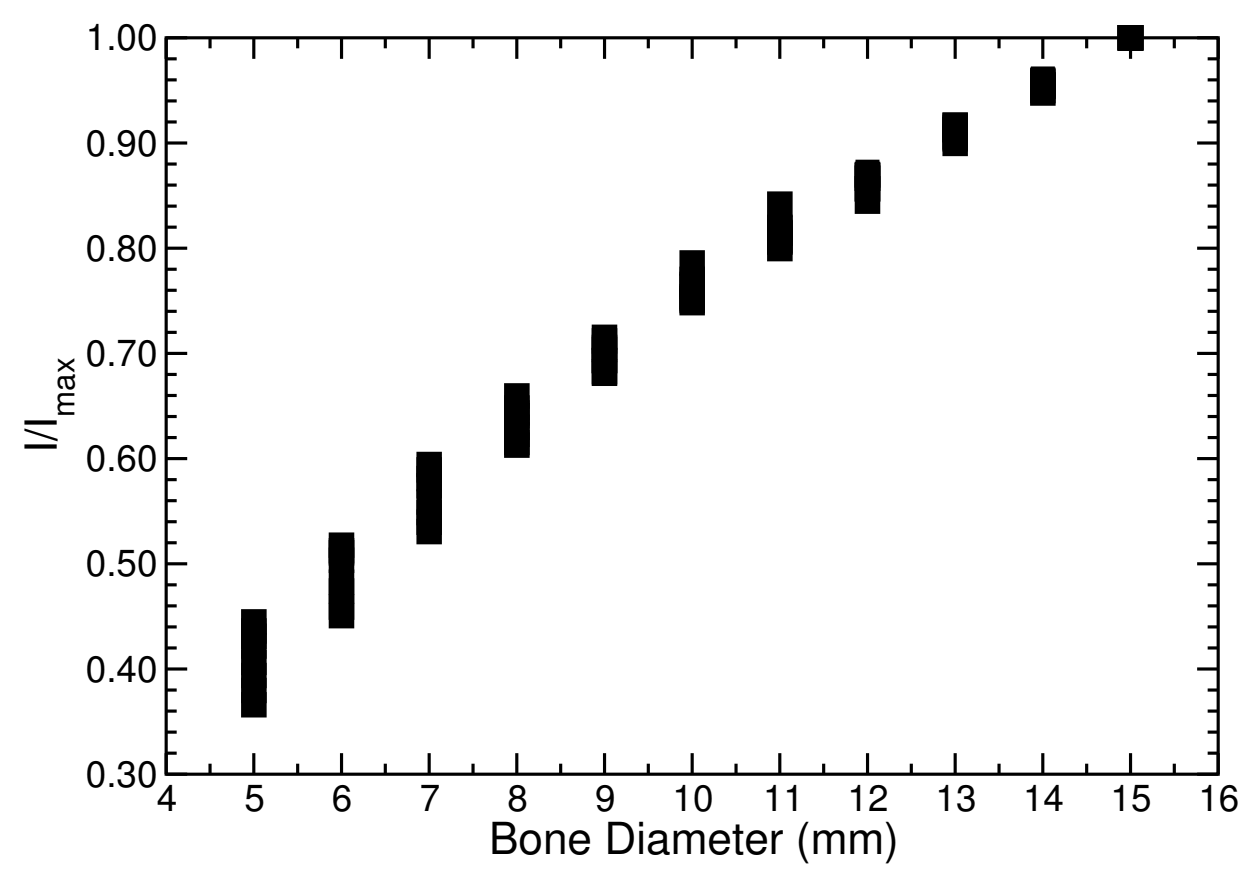

Figure 7.1: Effect of bone diameter on relative Compton intensity of the $20.30 \mathrm{keV}$ peak for a human bone matrix over all of the Compton energies detected in the case of an in vivo bone strontium measurement. Boxed points indicate the range of normalized values.

context of most IVXRF bone metal quantification systems. ${ }^{1-5,9,18-21}$ From measurements of these phantoms, with variation in the soft tissue thickness only, a non-linear relationship can be expected ${ }^{9}$ and a calibration function constructed between the soft tissue thickness and the intensity of the Compton scattered photons. From this calibration function, it is proposed that the soft tissue thickness from a human measurement can be extrapolated.

Compton scattering intensity in the context of an IVXRF bone strontium measurement is a function of various parameters, one, being the geometry of the sample, which is made apparent given the differential incoherent scattering cross-section that is scattering angle dependent. Considering even the simple case simulated here of concentric cylindrical fingers with only two material phases, if the bone diameter changes, then, for the broad-beam source which is produced from a collimated collection of ${ }^{125} \mathrm{I}$ brachytherapy seeds, the effective scattering angle also changes given the change in the overall curvature of the bone sample. 
For very large bone diameters, the source photons may be effectively observing a flat surface. This would also be the case if a portable X-ray analyzer is equipped with a highly focused primary beam, whereas for small bone diameters, the curvature relative to the primary beam becomes more apparent. In this regard, the actual angular values sampled through the differential incoherent cross-section would vary greatly, depending on bone geometry, and the Compton intensity would be expected to change as a function of bone size. Preparation of a calibration function based solely on soft tissue thickness variations without considerations for variations in bone diameter will thus likely bias the calibration function, or, limit its use greatly.

Figure 7.1 shows the relative Compton intensity determined for all Compton peaks simulated for a human bone matrix with various diameters. The broad beam largely subtends completely on the samples. The reduction which is observed in Compton intensity as a function of bone size-in the sample here up to approximately $40 \%$ decrease-can be attributed to the effect of bone curvature in the context of a broad beam excitation. In the case of Nie et al. ${ }^{9}$, who employed a silver target portable X-ray analyzer for measurements, the analyzer may have been equipped with a highly focused beam, and thus, does not represent the case of a broad beam geometry in which bone geometry may influence greatly the Compton intensity. With a focused beam, the samples surface would seem virtually flat regardless of size and shape. In the case of broad beam excitation as with the IVXRF system of bone strontium, or, the portable XRF systems evaluated by our group for bone strontium measurements (see Chapter 8), Compton-based normalization is hindered simply by the fact that bone and phantom geometries are not static and are not known and controllable factors. Variations in bone size or discrepancies between phantom and sample geometry will thus not allow for reliable Compton based soft tissue thickness estimations. 
If we consider the hypothetical case that geometries can be perfectly matched, which cannot be done in practice, other than by the method of taking orthoplanar X-rays of the finger ${ }^{22}$ then, the other factor which may hinder the ability to perform a soft tissue thickness estimation based on Compton scattered radiation comes from the differences in materials used between the phantoms and the bone being measured. In the case of producing a calibration function for soft tissue thickness estimation using phantoms with a poP core, what is ignored is the material dependence of Compton scattering which is apparent through the incoherent cross-sections' dependence on total electron density and through the incoherent scattering function. Given that is inevitable that some Compton contribution will be coming from the bone itself, this variation may produce calibration functions which are also dependent on the composition of the human bone. Calibration against poP or HAp phantoms may then produce calibration functions that are not transferable to human bone measurements given this material dependence.

Figure 7.2 shows the simulated Compton intensity for various soft tissue thicknesses when different bone surrogate core materials are used - either cortical bone itself, poP or HAp - the enveloping material being composed of soft tissue. The curves in Figure 7.2 being those from Compton peaks that are not perturbed, or minimally perturbed by other X-rays, which would allow for more practical real world application for IVXRF bone strontium measurements. In this case, it can be observed that the measurements made with HAp phantoms and bone match closely while those using poP as the core bone surrogate material does not produce a calibration function which matches that of bone as a core material. This could indicate issues of transferablilty in the calibration functions.

Although this finding would indicate that the measurements made using a soft tissue equivalent material and poP as a bone surrogate core would not allow for transferability in 


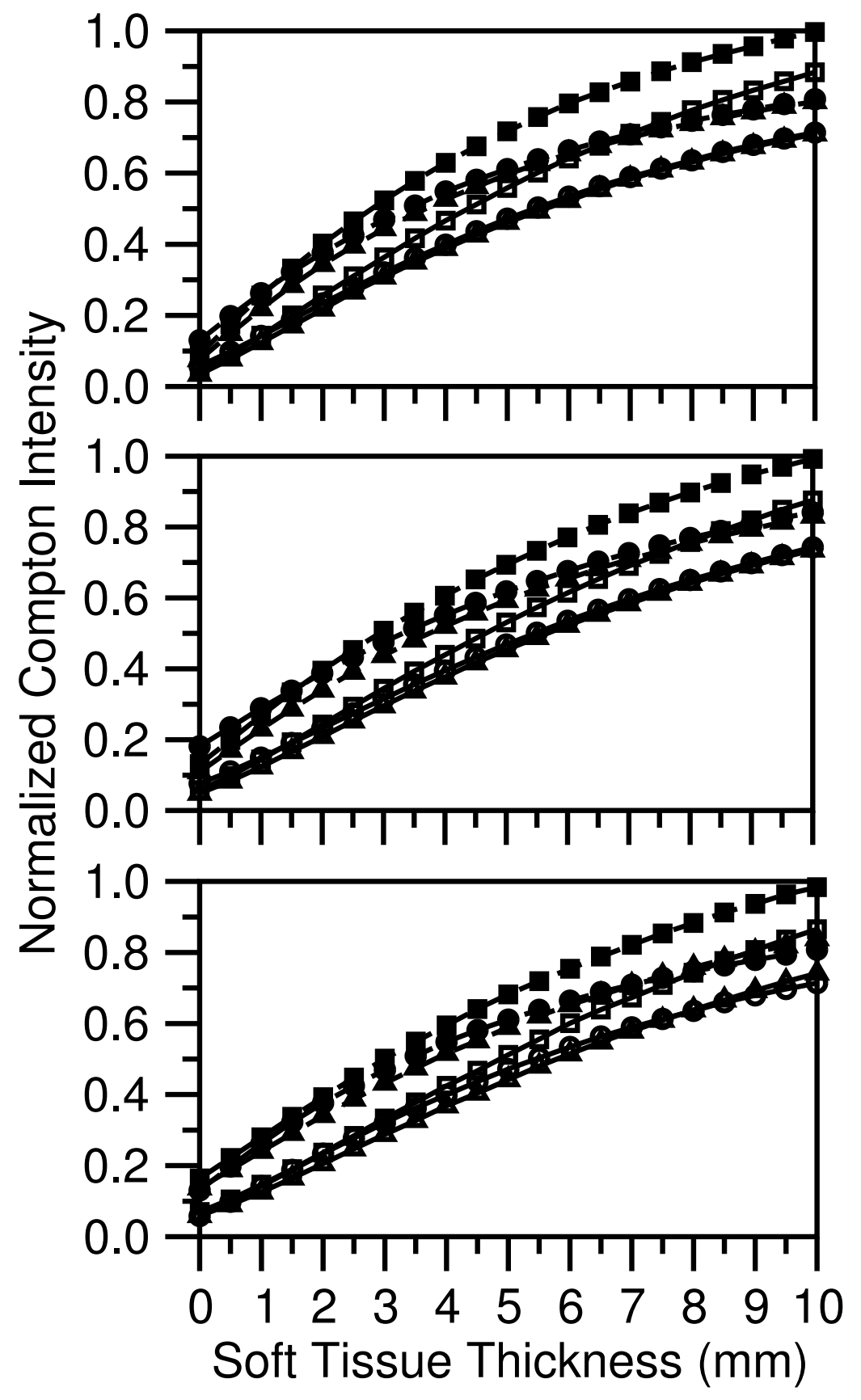

Figure 7.2: Normalized (to max) Compton intensities as a function of soft tissue thickness for various core materials and soft tissue as the envelope material. The top figure corresponds to the Compton intensity of the $22.16, \mathrm{keV}$ silver X-ray Compton scattered photon at $20.39 \mathrm{keV}$, the middle figure corresponds to the Compton intensity of the $27.4 \mathrm{keV}$ Te X-ray Compton scattered photon at $24.75 \mathrm{keV}$ and the bottom figure corresponds to the $31 \mathrm{keV} \mathrm{Te}$ $\mathrm{X}$-ray Compton scattered photon at $27.65 \mathrm{keV}$. These peaks were selected as they are the clearest peaks least perturbed by overlaying coherently scattered X-rays. 


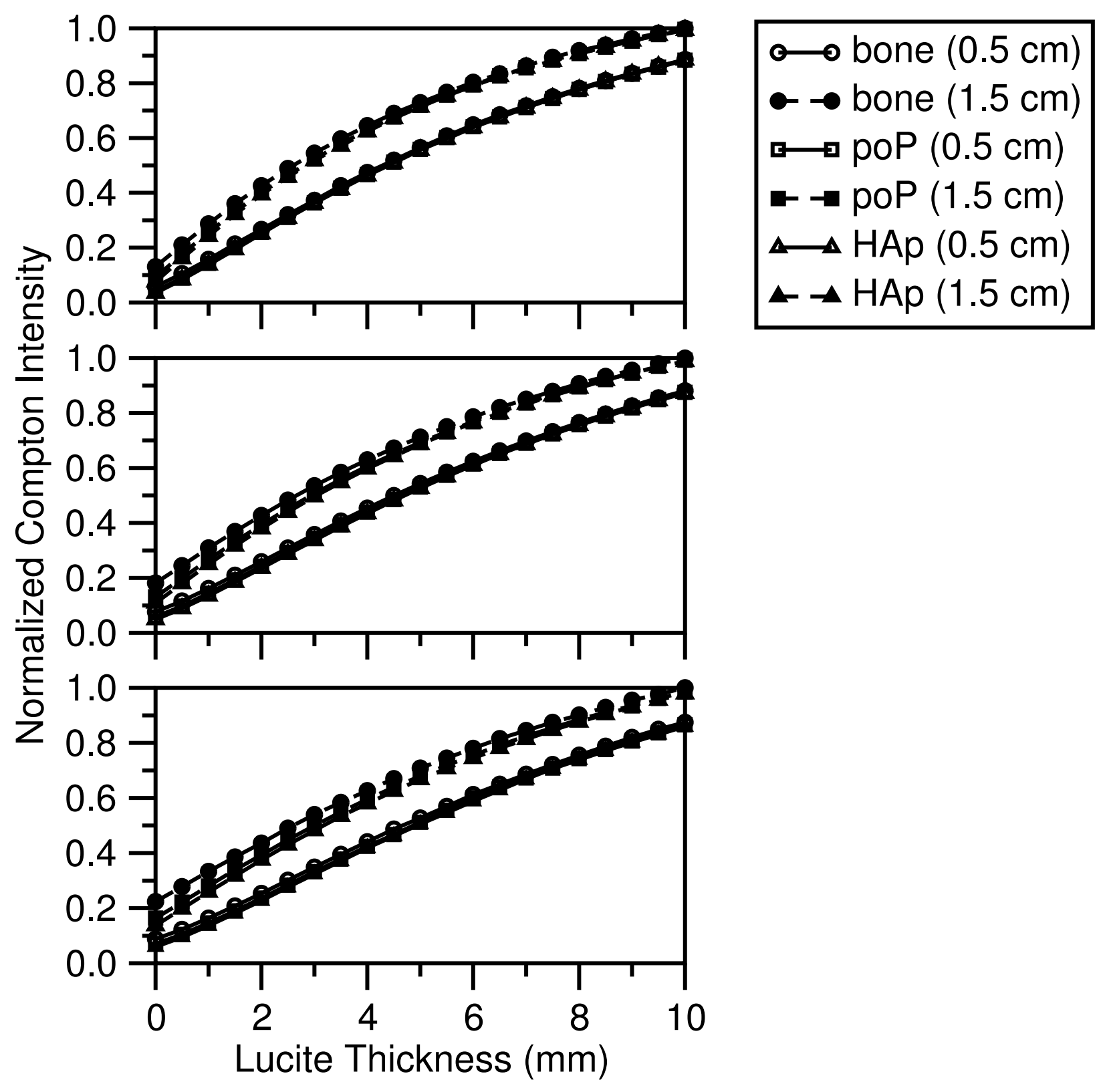

Figure 7.3: Normalized (to max) Compton intensities as a function of lucite thickness for various core materials and lucite as the envelope material. The top figure corresponds to the Compton intensity of the $22.16 \mathrm{keV}$ silver X-ray Compton scattered photon at $20.39 \mathrm{keV}$, the middle figure corresponds to the Compton intensity of the $27.4 \mathrm{keV}$ Te X-ray Compton scattered photon at $24.75 \mathrm{keV}$ and the bottom figure corresponds to the $31 \mathrm{keV}$ Te X-ray Compton scattered photon at $27.65 \mathrm{keV}$. These peaks were selected as they are the clearest peaks least perturbed by overlaying coherently scattered X-rays. 
terms of any calibration function devised using phantoms, more realistic soft tissue equivalent materials are currently not available for the purpose of producing Compton-based standard curves. Figure 7.3 shows the Compton intensity when lucite is used as a soft tissue surrogate material for various bone surrogate materials. In this case, all bone phantom materials show similar behaviour as a function of changing lucite thickness (Figure 7.3). This would indicate that any calibration function prepared from either poP or HAp and a bone surrogate core and lucite, would produce similar calibration functions for soft tissue thickness estimations, although the actual functional form is not equivalent to that determined using soft tissue as the enveloping material (Figures $7.2 \& 7.3$ ). The issue with calibration and soft tissue estimation using Compton scattered intensities then becomes the transferability of the calibration functions to measurements made on a human bone being enveloped in soft tissue (Figure 7.2) from the externally devised calibration functions based on a phantom produced from a bone surrogate material and a simulated soft tissue equivalent material such as lucite (Figure 7.3).

The differences between the Compton intensities from bone and soft tissue versus those from a bone surrogate material enveloped in lucite would not be the same when using a poPversus an HAp-based calibration to produce calibration functions for soft tissue thickness estimations. The differences between the Compton intensities produced from lucite and soft tissue for the various bone phantom materials are shown in Figures 7.4 \& 7.5. The HAp and bone measurements show a similar bias, with Compton intensities for soft tissue enveloped materials being approximately $70 \%$ that of lucite enveloped materials. Producing calibrations based on phantoms with poP cores would result in an inherent bias in the determination of of a soft tissue thickness estimation using the Compton scattered radiation. The results do however indicate that if a suitable soft tissue equivalent material were to be developed to 


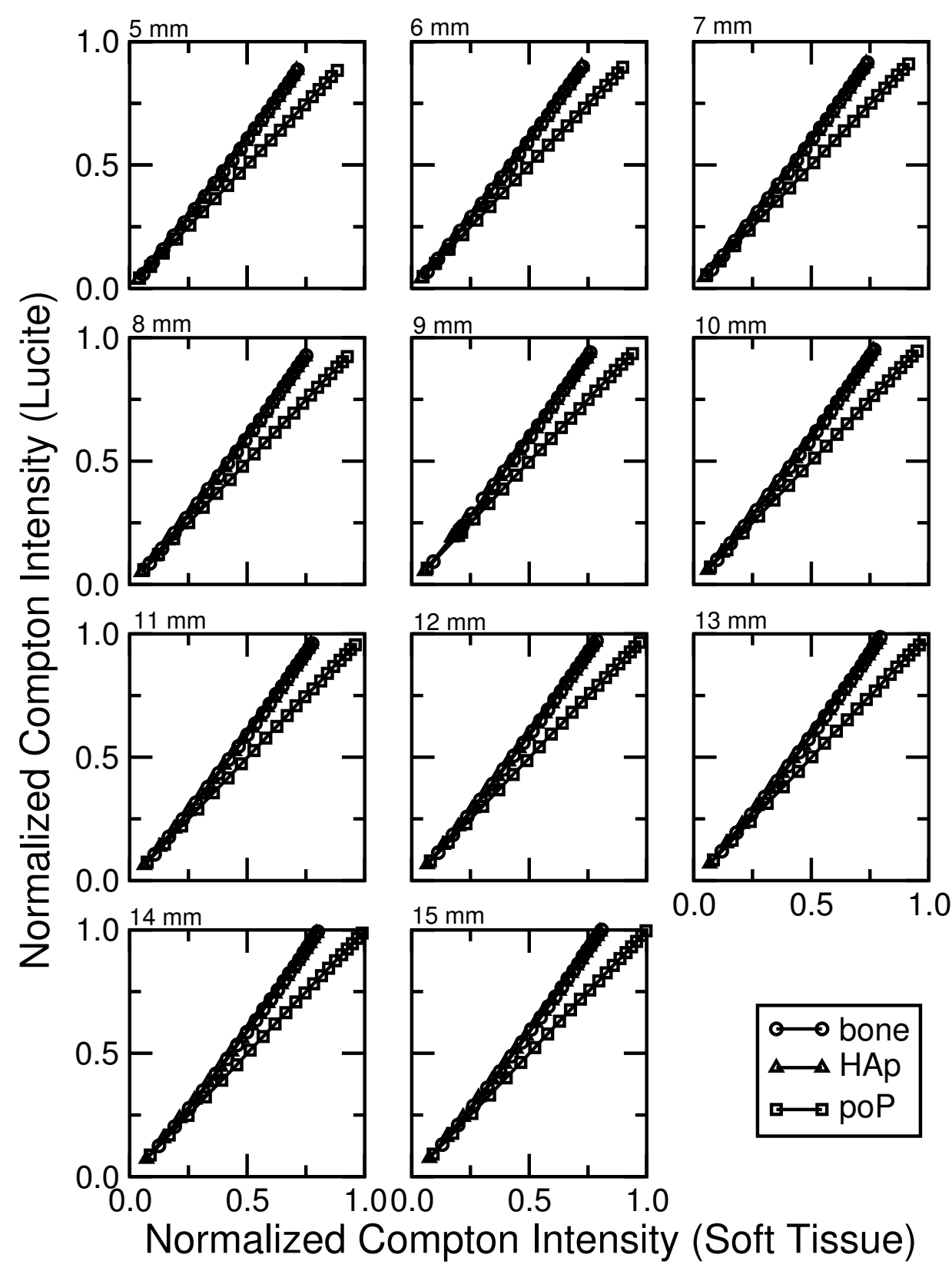

Figure 7.4: Normalized (to max) Compton intensities of the $22.16, \mathrm{keV}$ silver X-ray Compton scattered photon at $20.39 \mathrm{keV}$ determined using soft tissue as the enveloping material versus lucite as the enveloping material. 


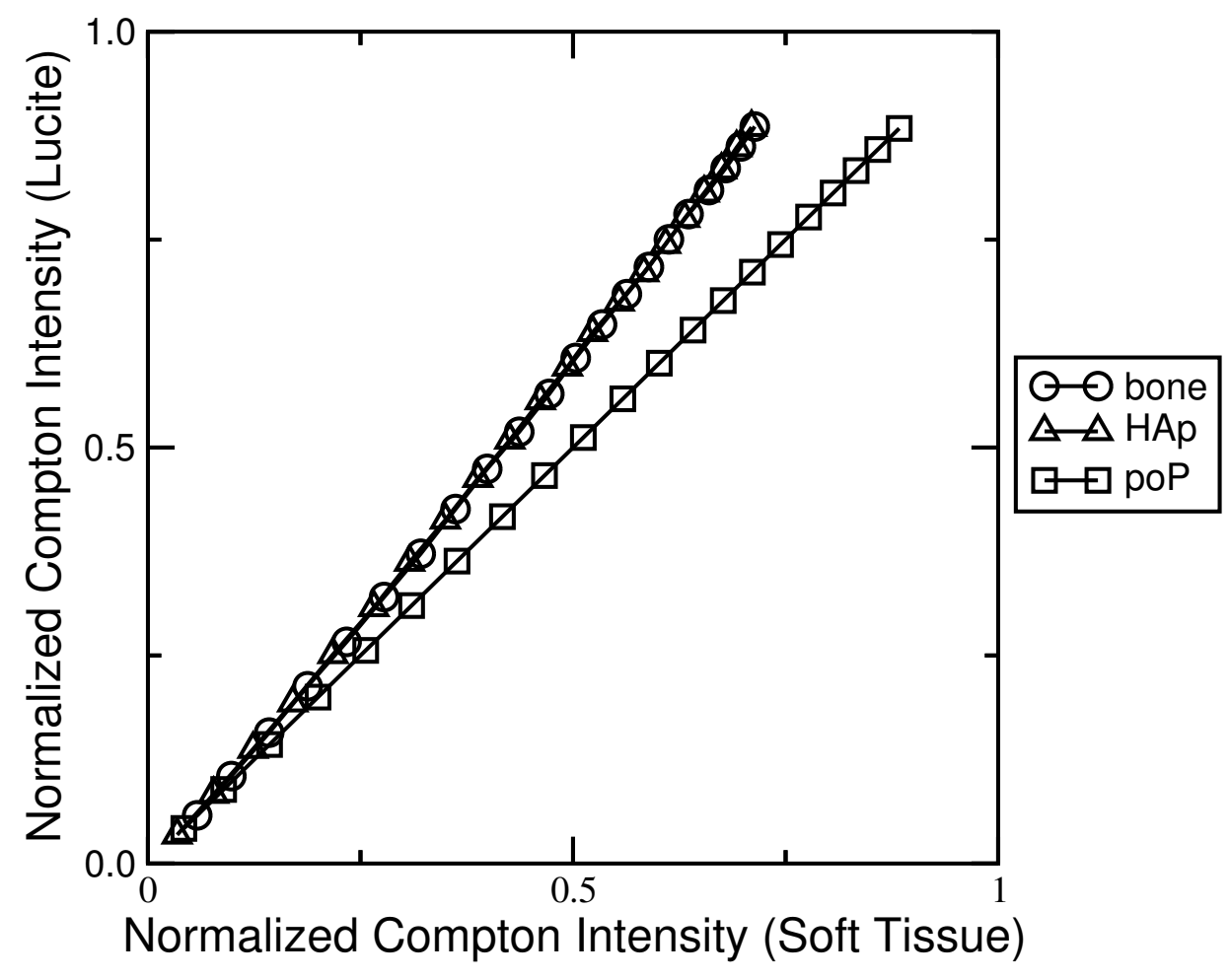

Figure 7.5: Normalized (to max) Compton intensities of the 22.16,keV silver X-ray Compton scattered photon at $20.39 \mathrm{keV}$ determined using soft tissue as the enveloping material versus lucite as the enveloping material for the $5 \mathrm{~mm}$ diameter bone specimen shown for clarity. 
be used for this purpose instead of lucite, then combined with a HAp phantom material as core,${ }^{13,14}$ a soft tissue thickness estimation may be determined using Compton intensities as long as the bone size can be ascertained, which may be possible using a coherent normalization procedure. ${ }^{12}$ The consistency in the biases also does seem to suggest that the similar to the coherent conversion factor $(\mathrm{CCF})$ that is required in order to traditionally correct for the differences in scattering properties between poP phantoms and human bone, it may be necessary to make a similar correction factor to account for incoherent scattering differences between the soft tissue equivalent material and the overlaying soft tissue. Development of such a material is however a focus of future work as the actual composition of soft tissue in humans, and whether more global incoherent scattering correction need to be made, needs to be assessed.

\subsection{Conclusions}

Monte Carlo simulations were employed to evaluate the feasibility of employing the intensities of Compton scattered source radiation for the estimation of soft tissue thickness in order to provide a means of performing soft tissue attenuation corrections for ${ }^{125}$ I-induced IVXRF bone strontium measurements in the $180^{\circ}$ backscatter geometry. It was found that bone size influences calibration functions determined using phantoms for the purpose of performing the soft tissue thickness estimation from human data. Soft tissue thickness estimations are however possible, at least theoretically, if the bone size can be determined and only if a suitable soft tissue surrogate material can be developed for calibration purposes. Lucite, the currently employed soft tissue surrogate material ${ }^{9}$ does not seem to match the Compton scattering characteristics of soft tissue sufficiently to allow for its direct use in the development of calibration functions for this purpose and can introduce an approximately $30 \%$ 
bias to the soft tissue thickness determination. The use of poP as a calibration material also biases the determinations; however, the use of HAp phantoms would allow for possible development in this type of soft tissue thickness determination method as biases, if present, are consistent with those produced with bone. Further work needs to focus on the development of a suitable soft tissue surrogate material for this application and investigations need to be made as to possible Compton correction factors to account for difference in true soft tissue and soft tissue surrogate materials.

\subsection{Acknowledgement}

The authors acknowledge the Natural Science and Engineering Research Council of Canada (NSERC) for financial support of this work through an Alexander Graham Bell Canadian Graduate Scholarship (EDS) and Discovery Grant (APM). Matthew Forrest and Graham Pearson (Department of Physics, Ryerson University) are gratefully acknowledged for their technical assistance during the course of this work. 


\section{References}

[1] A. Pejović-Milić, I. M. Stronach, J. Gyorffy, C. E. Webber, and D. R. Chettle, "Quantification of bone strontium levels in humans by in vivo x-ray fluorescence," Medical Physics, vol. 31, no. 3, pp. 528-538, 2004.

[2] M. Zamburlini, A. Pejović-Milić, and D. R. Chettle, "Evaluation of geometries appropriate for ${ }^{125} \mathrm{I}$ in vivo bone strontium X-ray fluorescence measurement," Journal of Radioanalytical \&3 Nuclear Chemistry, vol. 269, no. 3, pp. 625-629, 2006.

[3] M. Zamburlini, A. Pejović-Milić, D. R. Chettle, C. E. Webber, and J. Gyorffy, "In vivo study of an x-ray fluorescence system to detect bone strontium non-invasively," Physics in Medicine and Biology, vol. 52, no. 8, pp. 2107-2122, 2007.

[4] M. Zamburlini, A. Pejović-Milić, and D. R. Chettle, "Coherent normalization of finger strontium XRF measurements: feasibility and limitations," Physics in Medicine and Biology, vol. 53, no. 15, pp. N307-N313, 2008.

[5] C. M. Heirwegh, D. R. Chettle, and A. Pejović-Milić, "Ex vivo evaluation of a coherent normalization procedure to quantify in vivo finger strontium XRS measurements," Medical Physics, vol. 39, no. 2, pp. 832-841, 2012.

[6] H. Moise, J. D. Adachi, D. R. Chettle, and A. Pejović-Milić, "Monitoring bone strontium levels of an osteoporotic subject due to self-administration of strontium citrate with a novel diagnostic tool, in vivo XRF: A case study," vol. 51, no. 1, pp. 93-97, 2012.

[7] H. Moise, D. R. Chettle, and A. Pejović-Milić, "Monitoring bone strontium intake in osteoporotic females self-supplementing with strontium citrate with a novel in-vivo Xray fluorescence based diagnostic tool," vol. 61, pp. 48-54, 2014. 
[8] R. D. Deslattes, E. G. Kessler Jr., P. Indelicato, L. de Billy, E. Lindroth, J. Anton, J. S. Coursey, D. J. Schwab, J. Chang, R. Sukumar, K. Olsen, and R. A. Dragoset, "X-ray transition energies." http://www.nist.gov/pml/data/xraytrans/. Last Accessed: 02-May-2016. Last Updated: 2014.

[9] L. H. Nie, S. Sanchez, K. Newton, L. Grodzins, R. O. Cleveland, and M. G. Weisskopf, "In vivo quantification of lead in bone with a portable x-ray fluorescence systemmethodology and feasibility," Physics in Medicine and Biology, vol. 56, no. 3, pp. N39N51, 2011.

[10] A. J. Specht, M. Weisskopf, and L. H. Nie, "Portable XRF Technology to Quantify Pb in Bone In Vivo," Journal of Biomarkers, vol. 2014, p. 398032, 2014.

[11] A. J. Specht, Y. Lin, M. Weisskopf, C. Yan, H. Hu, J. Xu, and L. H. Nie, "XRFmeasured bone lead $(\mathrm{Pb})$ as a biomarker for $\mathrm{Pb}$ exposure and toxicity among children diagnosed with $\mathrm{Pb}$ poisoning," Biomarkers, vol. 21, no. 4, pp. 347-352, 2016.

[12] M. Zamburlini, S. H. Byun, A. Pejović-Milić, W. V. Prestwich, and D. R. Chettle, "Evaluation of MCNP5 and EGS4 for the simulation of in vivo strontium XRF measurements," X-ray Spectrometry, vol. 36, no. 2, pp. 76-81, 2007.

[13] E. Da Silva, B. Kirkham, D. V. Heyd, and A. Pejović-Milić, "Pure Hydroxyapatite Phantoms for the Calibration of in Vivo X-ray Fluorescence Systems of Bone Lead and Strontium Quantification," Analytical Chemistry, vol. 85, no. 19, pp. 9189-9195, 2013.

[14] E. Da Silva, D. V. Heyd, B. Rizvi, and A. Pejović-Milić, "The preparation of strontium-substituted hydroxyapatite bone phantoms with high strontium concentrations," Biomedical Physics \&6 Engineering Express. 
[15] ICRU, "Tissue Substitutes in Radiation Dosimetry and Measurement," Report 44 of the International Commission on Radiation Units and Measurements, vol. -, no. -, pp. -, 1989.

[16] ICRP, "Basic Anatomical \& Phsiological Data for use in Radiological Proetection The Skeleton," ICRP Publication 70, Annuals of the ICRP, vol. 25, no. 2, pp. -, 1995.

[17] M. Zamburlini, A. Pejović-Milić, and D. R. Chettle, "Spectrometry methods for in vivo bone strontium measurements," X-ray Spectrometry, vol. 37, no. 1, pp. 42-50, 2008.

[18] A. C. Todd, "L-shell x-ray fluorescence measurements of lead in bone: system development," Physics in Medicine and Biology, vol. 47, no. 3, pp. 507-522, 2002.

[19] A. C. Todd, S. Carroll, C. Geraghty, F. A. Khan, E. L. Moshier, S. Tang, and P. J. Parsons, "L-shell x-ray fluorescence measurements of lead in bone: accuracy and precision," Physics in Medicine and Biology, vol. 47, no. 8, pp. 1399-1419, 2002.

[20] D. E. B. Fleming, M. R. Gherase, and K. M. Alexander, "A miniature X-ray tube approach to measuring lead in bone using L-XRF," X-ray Spectrometry, vol. 40, no. 5, pp. 343-347, 2011.

[21] J. M. O'Meara, J. Börjesson, D. R. Chettle, and S. Mattsson, "Normalisation with coherent scatter signal: improvements in the calibration protocol of the ${ }^{57} \mathrm{Co}$-based in vivo XRF bone-Pb measurement," Applied Radiation $\&$ Isotopes, vol. 54, no. 2, pp. 319$325,2001$.

[22] L. Ahlgren and S. Mattsson, "An X-ray Fluorescence Technique for in vivo Determination of Lead Concentration in a Bone Matrix," Physics in Medicine and Biology, vol. 24, no. 1 , pp. 136-145, 1979. 
CHAPTER

EIGHT

\section{EVALUATION OF PORTABLE X-RAY FLUORESCENCE SPECTROMETERS FOR IN VIVO QUANTIFICATION OF BONE STRONTIUM AND LEAD}

Working paper for publication: E. Da Silva, B. Kirkham, G. Mankovskii, D. E. B. Fleming and A. Pejović-Milić, "Evaluation of portable X-ray fluorescence spectrometers for in vivo quantification of bone strontium and lead" $\dagger$

\footnotetext{
${ }^{\dagger}$ E. Da Silva carried out the experiments, performed the data analysis and wrote this manuscript/chapter. B. Kirkham aided with the fitting of the data for the silver system. G. Mankovskii aided with the data collection on the rhodium system. D. E. B. Fleming and A. Pejović-Milić conceptualized and designed this study, financed this project, provided critical feedback as to its contents and assessed the manuscript/chapter critically.
} 


\section{Abstract}

There has been a growing interest in the application of portable X-ray analyzers (pXAs) for in vivo bone metals analysis, namely, that of bone lead and bone strontium. Such systems offer flexible, portable and relatively low cost solutions for the potential monitoring of humans for such elements. To date, there has been some application of either tungstentarget pXA or silver target pXA systems for bone lead determinations. Most commercial systems, being design for the analysis of inanimate objects, generally come equipped with inherent primary filtration as no consideration is made for the possible flexibility necessary with regards to primary filtration design for dosimetric considerations, which is of importance to human measurements. In this work we assess and compare three commercially available pXAs: a tungsten target pXA, a silver target pXA and a rhodium target $\mathrm{pXA}$, for their performance as possible analyzers for the in vivo analysis of lead and strontium in bone. The MDLs were determined for counting times of 1, 10 and $30 \mathrm{~s}$ real time and it was found that 10 to 30 s measurement times are likely possible for bone strontium measurements. Lead measurements were maintained at $180 \mathrm{~s}$ real time given the low concentration of the element expected in bone tissue. The rhodium target pXA came equipped with various primary filtration options which were assessed separately. It was found that the tungsten target pXA is likely not suitable for said measurements given the lack of scattered source characteristic X-rays, which potentially show promise in various normalization processes. The silver and rhodium target pXAs performed similarly, with the silver target pXA showing a highly reduced background in the lower energy range likely resulting in a reduction of radiation dose to the subjects. 


\subsection{Introduction}

The in vivo X-ray fluorescence (XRF)-based measurement of bone strontium and lead has traditionally been performed using radioisotope-induced $\left({ }^{125} \mathrm{I}\right.$ and ${ }^{109} \mathrm{Cd}$, respectively) $\mathrm{K}$ XRF using either a liquid nitrogen cooled $\mathrm{Si}(\mathrm{Li})$ or HPGE detection system, respectively. ${ }^{1-3}$ Although in vivo measurements have been made with such systems, ${ }^{4-6}$ their cost, size and the need for liquid nitrogen as a coolant for the detector can limit their portability, and thereby, their use under certain circumstances. This becomes of particular importance when large scale epidemiological studies are desired (i.e. for bone lead as a biomarker for cumulative exposure), ${ }^{7,8}$ or, in the case of a bone strontium measurement, if clinical use is desired and portability becomes a convenient feature (i.e. to monitor patients undergoing strontium therapy for osteoporosis). ${ }^{5,6}$

In response to the need for a smaller and more portable means of performing in vivo XRF of bone lead, portable X-ray analysers (pXA) have been evaluated for this purpose. ${ }^{9,10}$ Similar to initial attempts by others, such a method requires the use of the L-series of lead as the analytical measure and the use of X-ray tube sources. ${ }^{11-14}$

Modern pXAs generally consist of a miniaturized X-ray tube as a source, in contrast to the radioisotope induced systems, and a miniaturized Peltier cooled solid state detector (e.g. an SiPiN or SDD). This allows for great flexibility with regards to their use as they are battery (or outlet power) operated and do not require any coolant at the level of either the detector or X-ray tube. Such systems are however designed for the measurement of inanimate objects. One limitation to such systems, in the context of a human measurement, then becomes one of radiation dosimetry as the X-ray tube may provide either a highly focused or broad source beam, and, they usually produce a significantly higher source fluence rate in comparison to radioisotope sources. 
Another consideration that needs to be made when applying a pXA to a human measurement, aside from the dosimetric aspects of such system applications, is which X-ray tube to select for the given measurement. This has an influence on both the potential sensitivity of the measurement (and system overall), which ultimately has an impact on the dosimetry due to necessary fluctuations in measurement counting time. Further, the selected source may produce a bremsstrahlung continuum as its main spectrum (as is the case of a higher $Z$ target material such as tungsten), or, the main excitation may originate from interactions with the characteristic lines from the tube target material. In such cases whereby a lower $Z$ material such as silver or rhodium are used as the X-ray tube target material, one must consider which tube to apply to the measurement to further increase sensitivity and reduce the measurement time thus the radiation dose received by the subject. This selection needs to be performed carefully to also include primary filtration options as a means of eliminating any superfluous radiation and as such reducing surface radiation dose.

In the context of in vivo applications of pXAs for bone metal analysis either tungsten ( $Z=74)$ or silver $(Z=47)$-based X-ray tubes have been used. ${ }^{9,10}$ Another quite common anode material is rhodium $(Z=45)$ which is available in commercial pXRF systems. In the case of bone lead measurements in which the L-series is measured and for bone strontium measurements in which the $\mathrm{K}$-series is measured, rhodium target X-ray tubes produce a characteristic X-ray series which are closer to the L-edge of lead and the K-edge of strontium, and thereby offer the potential of being an ideal source for both a bone strontium and bone lead measurements.

In this work, we compare the system performance of three commercially available pXAsystems in the context of a bone lead and bone strontium measurement using bare bone phantoms. The systems include a tungsten target system, a silver target system and a 
Table 8.1: Filter's available and investigated on the Trace III-SD pXA system. The filter composition is listed in order of material closest to the primary beam.

\begin{tabular}{ll}
\hline \hline Filter ID & Filter composition \\
\hline blue & $1 \mathrm{mil} \mathrm{Ti}$ \\
yellow & $12 \mathrm{mil} \mathrm{Al}+1 \mathrm{mil} \mathrm{Ti}$ \\
red & $12 \mathrm{mil} \mathrm{Al}+1 \mathrm{mil} \mathrm{Ti}+1 \mathrm{mil} \mathrm{Cu}$ \\
\hline \hline
\end{tabular}

rhodium target system. The comparison made in this work is focused on the target material used with the understanding that identical conditions (i.e. same detector and identical measurement geometry) cannot be controlled, nor are they necessarily known, to the consumer, being proprietary information.

\subsection{Experimental}

\subsubsection{Portable X-ray Analysers}

The rhodium target pXA system consisted of a Tracer-III SD system (Bruker-AXS, Madison, WI, USA). The system consisted of a miniaturized rhodium target X-ray tube operating at $40 \mathrm{kVp}$ and $30 \mu \mathrm{A}$, which resulted in the maximum power rating allowable given Ontario regulations. Photon detection was achieved with an XFlash $\mathrm{R}$ SDD system. The detector had a resolution of $145 \mathrm{eV}$ at the iron $\mathrm{K} \alpha$. The Tracer-III SD was equipped with an open broad beam with no inherent filtration (with the exception of an unknown thickness of beryllium as the X-ray tube's window). For this reason several miniaturized mono and multi-layer filtration arrangements were used and evaluated in this work (Table 8.1).

The silver target pXA system consisted of a Niton-XL3t 950 system (Thermo Scientific). The system consisted of a miniaturized silver target X-ray tube operating at $50 \mathrm{kVp}$ and $40 \mu \mathrm{A}$. Photon detection was achieved with an SDD system. The detector had a resolution 
of $<180 \mathrm{eV}$ at the iron $\mathrm{K} \alpha$. The primary beam had an static aluminum primary filter with unknown thickness.

The tungsten target pXA system used in this work was that used previously for the assessment of arsenic and selenium in biological specimens ${ }^{15}$ and also for that assessed for the possible quantification of lead in bone. ${ }^{10}$ The system was an Innov-X Alpha-4000S model portable X-ray analyzer (Innov-X Systems Canada, Mississauga, Ontario). The system consisted of a miniaturized tungsten target X-ray tube operating at $40 \mathrm{kVp}$ and $20 \mu \mathrm{A}$. Radiation detection was achieved using a silicon PiN diode detector with a full width half-maximum of approximately $235 \mathrm{keV}$ at the iron $\mathrm{K} \alpha$. The primary beam had an static aluminum primary filter with unknown thickness.

\subsubsection{Phantom preparation and measurements}

Phantoms used in this study were bare bone phantoms composed of hydroxyapatite as to mimic a bone mineral measurement more closely. Phantoms were prepared by the method described by Da Silva et al. ${ }^{16}$ using identical conditions and reagents. Strontium and lead phantoms were not prepared from pure materials and thus contain an inherent contamination of strontium of approximately $60 \mu \mathrm{g} / \mathrm{g}$ Ca. For bone strontium measurements, finger phantoms with a diameter of $10 \mathrm{~mm}$ and length of $3 \mathrm{~cm}$ were used as to mimic the bone size of the finger phalanges as closely as possible which ensuring a complete seal with the measurement window of the spectrometers. For bone lead measurements a $32 \mathrm{~mm}$ diameter phantoms with a length of $10 \mathrm{~cm}$ was employed as to mimic the tibia. Strontium phantoms were prepared within an upper concentration limit of $1000 \mathrm{ppm}$, while lead phantoms were prepared with an upper concentration limit of $200 \mathrm{ppm}$.

Measurements were made for $180 \mathrm{~s}$ real time for both strontium and lead phantoms on 
the tungsten target system. Measurements were made for 180 s real time for the lead measurements on the rhodium and silver target systems. Additionally, measurements were made for $1 \mathrm{~s}, 10 \mathrm{~s}$ and $30 \mathrm{~s}$ real time for the strontium phantoms on the rhodium and silver target systems. All measurements were made with five replicates re-positioning the phantom after each measurement to also assess phantom homogeneity.

\subsubsection{Data processing}

All spectra were processed using an in-house program for determining integrated peak areas written in GNU Octave. From these integrated areas, calibration curves were prepared as to determined the sensitivity for the element, $S$. the systems were compared based on the minimum detectable limit (MDL) calculated using the $3 \sigma$ criteria (Eqn. 8.1)

$$
M D L=\frac{3 \sigma_{0}}{S}
$$

where $\sigma_{0}$ is the standard deviation of the $0 \mathrm{ppm}$ phantom and $S$ is the sensitivity for the given element determined from the linear calibration prepared from the phantoms. MDLs were determined for the strontium $\mathrm{K} \alpha$ and lead $\mathrm{L} \alpha$ lines only. The MDL was selected as the figure of merit of choice in this study as it provides for the minimum concentration detectable for the given measurement conditions and thus acts a a measure of the feasibility of using the pXA system for an in vivo measurement. 


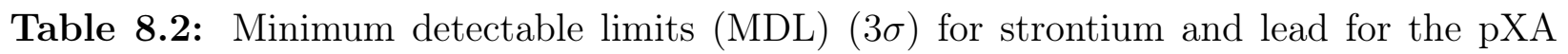
systems evaluated in this work. MDLs were determined on HAp phantoms.

\begin{tabular}{ll|llll|l}
\hline \hline & & \multicolumn{4}{|c|}{ MDL $(\mu \mathrm{g}$ Sr/g Ca $)$} & MDL $(\mu \mathrm{g} \mathrm{Pb} / \mathrm{g} \mathrm{Ca})$ \\
System & Primary Filtration & $1 \mathrm{~s}$ & $10 \mathrm{~s}$ & $30 \mathrm{~s}$ & $180 \mathrm{~s}$ & $180 \mathrm{~s}$ \\
\hline $\mathrm{W}$ & Thick Al & - & - & - & 36 & 2 \\
\hline $\mathrm{Ag}$ & Thick Al & 71 & 20 & 4 & - & 0.2 \\
\hline $\mathrm{Rh}$ & none & 95 & 47 & 14 & - & 3 \\
& blue & 77 & 71 & 17 & - & 7 \\
& yellow & 128 & 29 & 14 & - & 10 \\
& red & 36 & 21 & 23 & - & 7 \\
\hline \hline
\end{tabular}

\subsection{Results and Discussion}

All pXAs where compared on the basis of the MDL for the given conditions of the measurement. All MDLs were determined using the same HAp bone phantoms as to mimic the bone mineral matrix more closely ${ }^{16}$ in comparison to the traditional calibration material, plaster of Paris (poP). ${ }^{9,10}$ MDLs for all systems and conditions of interest, for strontium and lead, are presented in Table 8.2 and have been determined on the basis of bare bone measurements.

In the context of an in vivo XRF measurement the selection of a suitable pXA system requires various considerations. The system must be able to provide adequate analytical sensitivity while minimizing the radiation dose to the subject being measured, which may be reduced by controlling exposure via the measurement time and by filtering the primary beam of any superfluous radiation.

At the level of the excitation source, further consideration should be given to the presence or absence of scattered radiation from the characteristic lines emitted from the target. Such scattered radiation may render themselves useful within the calibration protocol as coherent and Compton scattered radiation may be useful for global matrix corrections and/or 


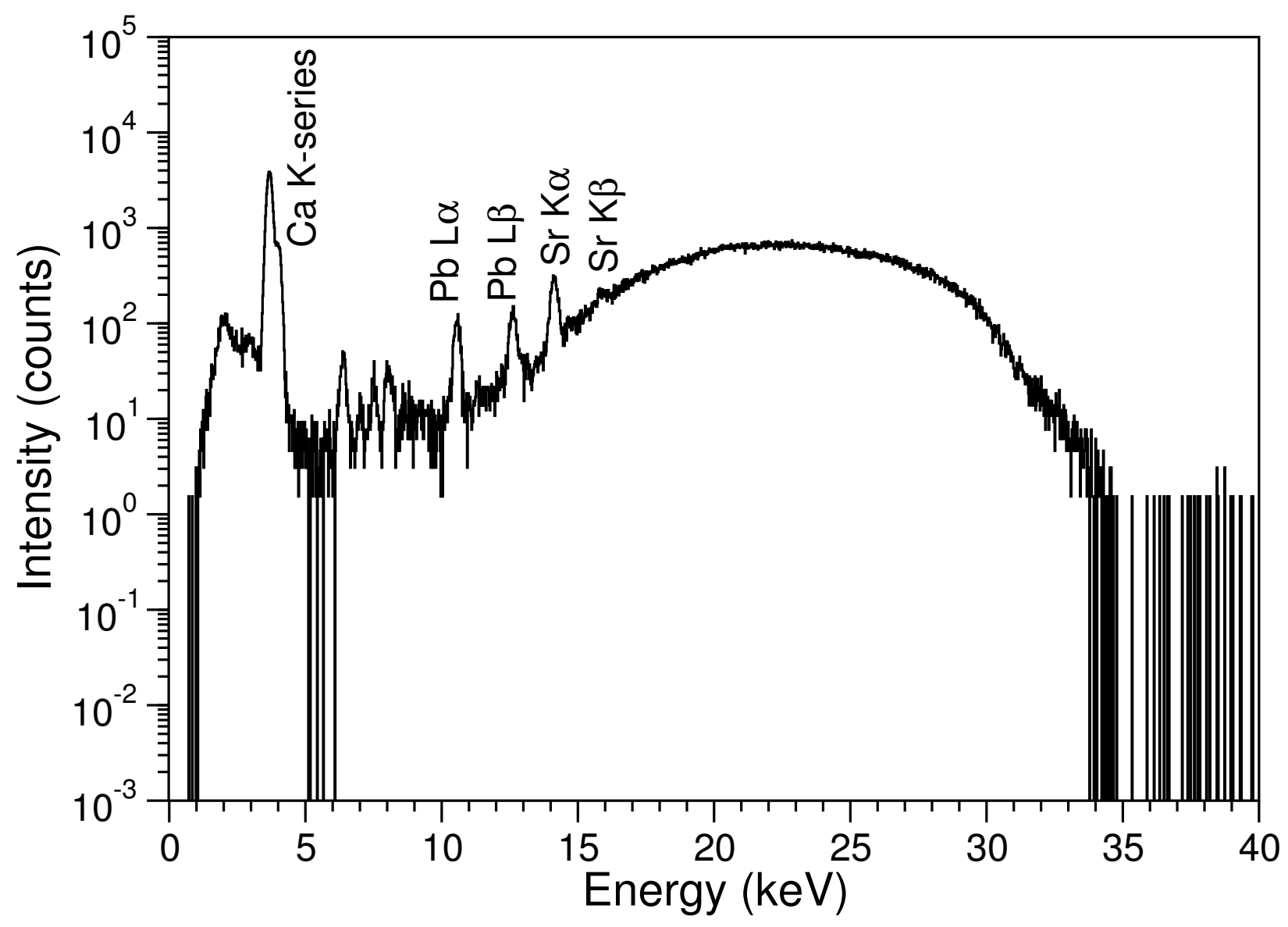

Figure 8.1: X-ray fluorescence spectra of a strontium (60 $\mu \mathrm{g} / \mathrm{g}$ Ca)- and lead (100 $\mu \mathrm{g} / \mathrm{g} \mathrm{Ca})$ containing HAp bone phantom measured using the tungsten target pXA system. Spectrum acquired for a real time of $180 \mathrm{~s}$. The spectrum is void of any characteristic lines from tungsten with the background being composed of largely scattered bremsstrahlung source photons.

overlaying soft tissue attenuation corrections. ${ }^{3,9}$

Figure 8.1 shows a spectrum acquired of a strontium- and lead-containing HAp bone phantom using the tungsten target pXA system; this system has been proposed as suitable for in vivo bone lead measurements using the lead L-series. ${ }^{10}$ The use of a tungsten target pXA system operating at $40 \mathrm{kVp}$ limits the X-ray tube's emission spectrum to consisting solely of the bremsstrahlung component, with the tungsten L-series being filtered from the emission spectrum by the primary filter. Although the high $Z$ dependence on bremsstrahlung 


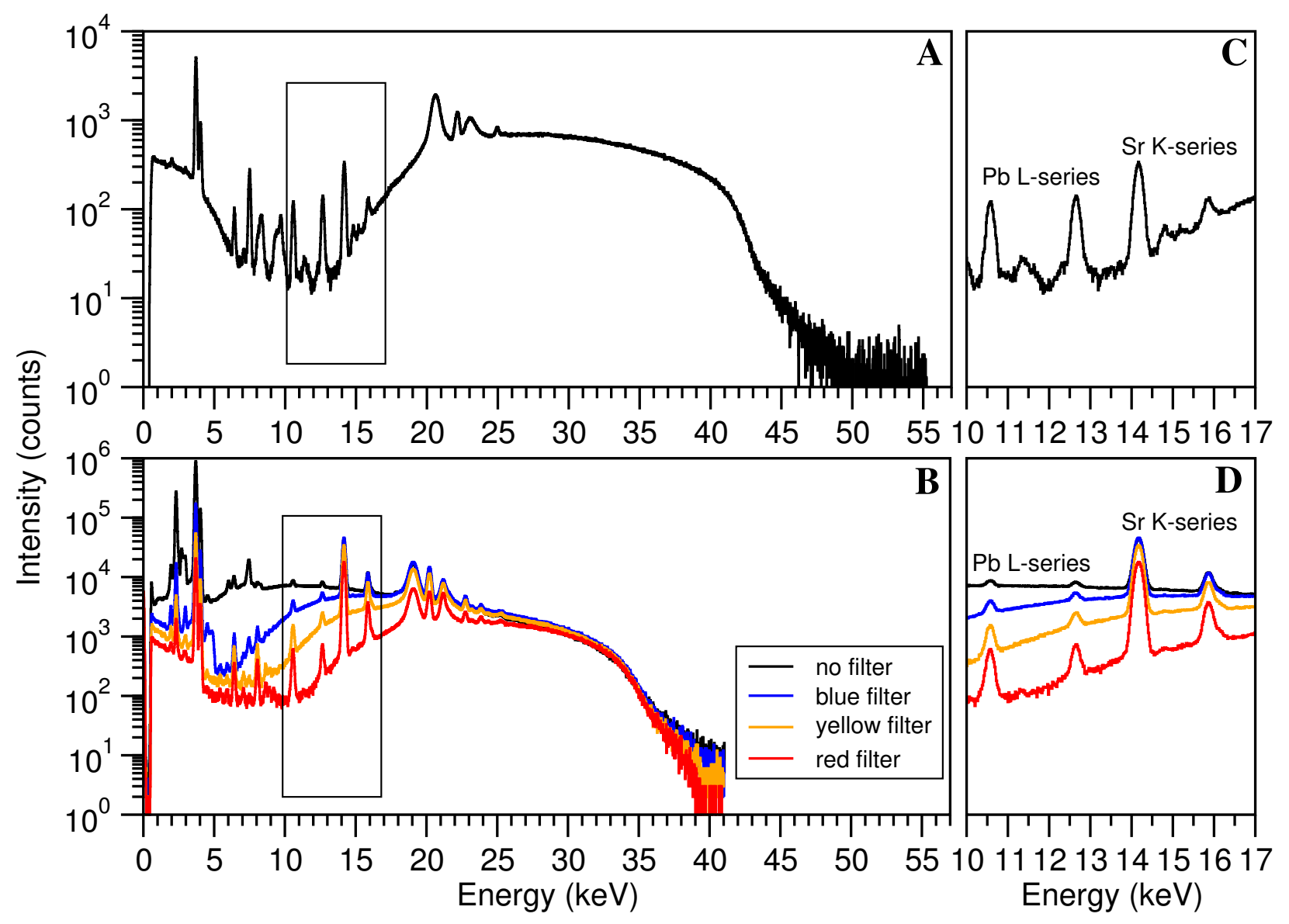

Figure 8.2: Spectra of a strontium $(60 \mu \mathrm{g} / \mathrm{g} \mathrm{Ca})$ - and lead $(100 \mu \mathrm{g} / \mathrm{g} \mathrm{Ca})$-containing HAp phantom collected with $\mathbf{A}$ ) the silver target pXA system; and B) the rhodium target pXA system over a 30 s real time measurement. Spectra C) and D) are the same spectra corresponding to $\mathbf{A}$ ) and $\mathbf{B}$ ), respectively, zoomed into the region of interest containing the lead L-series and the strontium K-series. For B) and D) the various spectra correspond to those collected with different primary filtration arrangements order according to Table 8.1.

production would suggest that a heavy target such as tungsten would produce a sufficient fluence above the strontium K-edge and lead L-edge, which may result in adequate analytical sensitivity for in vivo measurements, the lack of any scattered source characteristic X-rays was considered undesirable given the possible use of such radiations within the calibration protocol.

Figure 8.2 shows spectra of a strontium- and lead-containing HAp phantom collected with the silver target and rhodium target pXA systems over a 30 s real time measurement. 
Dead times in this case did not exceed $10 \%$. The two target materials presented markedly lower atomic numbers in comparison to tungsten, yet, the intensity of the bremsstrahlung component (as scattered radiation) was found to be comparable for a much shorter measurement time (Figures $8.1 \&$ 8.2). Figure 8.1 shows a spectrum collected over a 180 s real time while Figure 8.2 shows spectra collected over a $30 \mathrm{~s}$ real time. In all three cases, the intensity of the bremsstrahlung component of the spectra was comparable within approximately one order of magnitude (Figures $8.1 \& 8.2$ ). Coupled with the fact that the silver and rhodium target pXA's are composed of X-ray tubes with targets of lower atomic number, these targets do emit characteristic X-rays when operated at operating potentials employed within conventional pXAs (shown more clearly in Figures $8.3 \&$ 8.4). The higher apparent general fluence rate observed for the silver target and rhodium target pXA systems, the concentration of some fluence at energies closer to the analytes' $\mathrm{K}$ and L edges via the emitted target characteristic X-rays, and the presence of discrete scattered source characteristic radiation (Figures $8.3 \&$ 8.4), seem to make the silver and rhodium target pXA systems more suitable for in vivo measurements of bone strontium and lead.

This greater fluence also demonstrates the potential for a great reduction in the radiation dose to the subject being measured as it may allow for a large reduction in the measurement times. In the case of a bone lead measurement, the concentration and thus signal from lead is low (Figure 8.2) and thus a $180 \mathrm{~s}$ live time measurement was maintained when comparing all pXA systems. The decrease in radiation dose to the subject would be much more apparent in the case of a bone strontium measurement which is one of the reasons the application of a pXA for such purposes is desirable. Given that strontium is naturally present in bone at several hundred parts-per-million, being classified as a minor element, it may be possible to reduce radiation dose allowing for the safer long-term monitoring of individuals, such as 


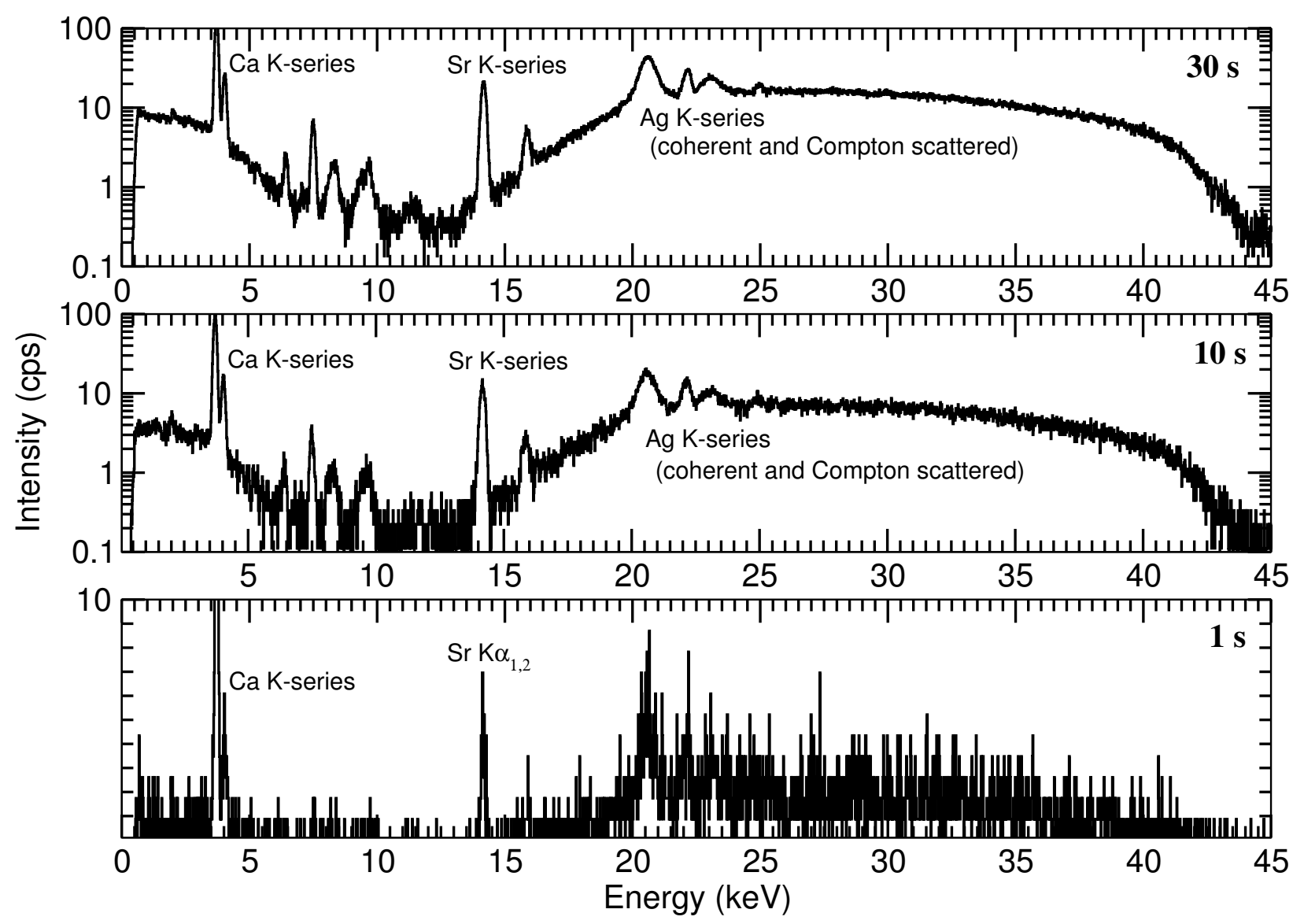

Figure 8.3: XRF spectra of a strontium $(60 \mu \mathrm{g} / \mathrm{g}$ Ca $)$ containing HAp bone phantom measured using the silver pXA system as a function of measurement time. 

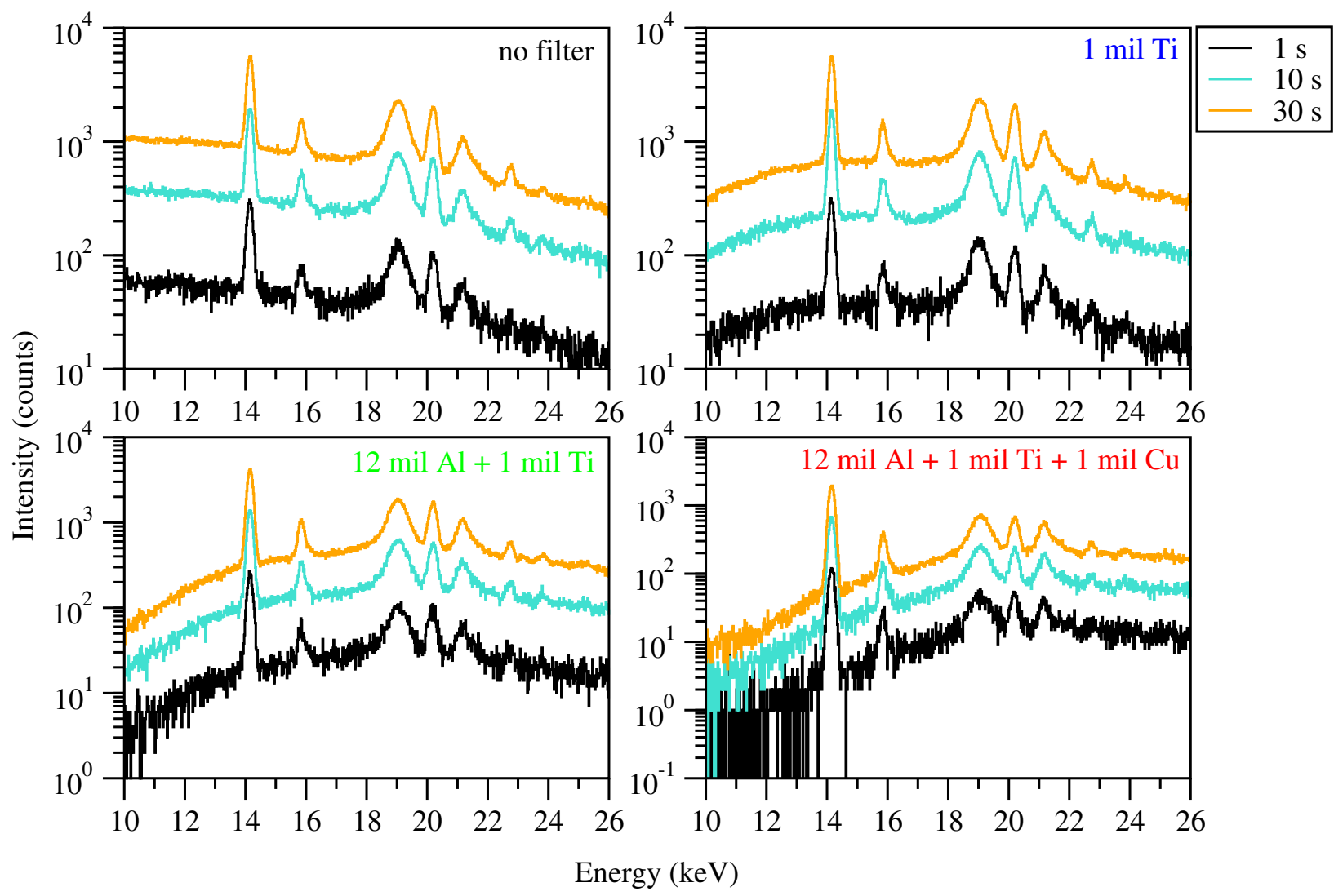

Figure 8.4: XRF spectrum of a strontium $(60 \mu \mathrm{g} / \mathrm{g} \mathrm{Ca})$ containing phantom for HAp phantoms for different filter combinations at at various counting times centred on the strontium K-series $\left(\mathrm{K} \alpha_{1,2}\right.$ at $14.1 \mathrm{keV}$ and $\mathrm{K} \beta_{1,3}$ at $\left.15.8 \mathrm{keV}\right)$ using the rhodium pXA system as a function of measurement time. 
those supplementing with strontium for the prevention/treatment of osteoporosis. ${ }^{5,6}$ For this reason, the analytical performance of the systems was evaluated for various counting times in the case of strontium as the analytical signal was found to be potentially useful even as low as a $1 \mathrm{~s}$ measurement time (Figures $8.3 \& 8.4$ ). The measurement time did have a direct effect on the MDL in the case of a strontium measurement (Table 8.2) as one would expect given that the signal-to-noise ratio would increase as a function of time. In the case of both the silver target and rhodium target pXA system, although it seems that it would be possible to make an in vivo bone strontium measurement with as low as a $1 \mathrm{~s}$ measurement, such measurements may be hindered by not taking into consideration subtle subject movement during the measurement which would be averaged out over an extended measurement period.

Although the fluence rate does play a role in the selection of the pXA system for the aforementioned reasons, a consideration that needs to be made when selecting a pXA system for an in vivo measurement is the primary filtration arrangement which has an influence on the ultimate dosimetry. Given that most modern pXA systems are X-ray tube based, a bremsstrahlung component to the emission spectrum will likely always be present unless care has been taken to monochromatize the primary X-ray beam. From the point of view of an XRF measurement alone, this spectral component, when scattered, will result in an possible increase in the MDL (if the sensitivities are unaltered by filtration). For human measurements, this bremsstrahlung component of the primary emission spectrum should be shaped such that the minimum of energy fluence is being emitted below the edges of interest as to minimize radiation dose to the subject; that is, the beam should be hardened effectively.

The pXAs evaluated in this study are designed for general purpose XRF analysis of inanimate objects, and thus, little regard is given to the optimization of primary filtration arrangements for human measurements. The tungsten and silver target pXA systems are 
equipped with a thick aluminum primary filter. This results in a great reduction in the background below the respective edges (Figure $8.1 \& 8.2$ ). Although this is the case for the tungsten pXA system, the background was still substantial in the energy region corresponding to the strontium K-series resulting in poor analytical performance per unit of measurement time in comparison to the other pXA systems (Table 8.2). The bremsstrahlung background resulted in a relatively high spectral background in comparison to the other systems used in this study in the case of both analytes (Figure $8.1 \& 8.2$ ).

The primary filtration in the silver pXA system, also a thick aluminum primary filter, was found to reduce the background considerably near the strontium and lead regions providing good analytical performance (Table 8.2) as well as a large reduction in the low energy photons, which would only deposit radiation dose to the subject.

The rhodium tube pXA system is unique amongst the systems evaluated in this work, as it is provided to the user with no added primary filtration other than the inherent filtration provided by the X-ray tube window. For this reason, it is potentially advantageous for in vivo applications of various different analytes as primary filtration arrangements can be custom designed. Three filter combinations were evaluated in this work (provided by the manufacturer, Table 8.1) as an initial assessment and prior to the design of any custom primary filters. From the point of view of dosimetry, however, the greater the hardening of the beam, the greater reduction in radiation dose, as one will remove the majority of the lower energy photons not useful for the excitation of the analyte of interest, in this case lead and strontium. The addition of primary filters was however found to have a minimal effect when it came to the MDL for strontium and lead (Table 8.2). The addition of the filter with the highest half-value layer (red filter, Table 8.1) did show an increase in the MDL which is attributed to a compensatory effect. In this case, the reduction of 
background is counteracted by a reduction in sensitivity due to the hardening of the photons above the edges of interest. In any case, the limits of detection for strontium and lead, for as low as a $1 \mathrm{~s}$ long measurement in the case of strontium, are sufficient for an in vivo measurement when considering no soft tissue attenuation. In the average strontium content in humans naturally is approximately $350 \mathrm{ppm},{ }^{17,18}$ whereby, any of the systems evaluated would be sufficient for clinical measurements, even if soft tissue attenuation reduces the overall sensitivity. Although beam hardening was achievable for the rhodium pXA system using the primary filtration arrangements, given the operating potential of the pXA, and thus, the location of the bremsstrahlung mean energy, the heaviest of the filtrations still produced a background approximately one order of magnitude larger than the silver pXA system in the low energy region (Figure 8.3). For this reason, the silver X-ray tube system performed marginally better than the rhodium pXA system (Table 8.2) however every system seems to be sufficient for a clinical measurement when considered strictly on the basis of the determined MDLs. This feature may also have consequences dosimetrically, which needs to be further assessed.

When comparing the silver target versus rhodium pXA systems, the rhodium target system becomes potentially attractive given that the rhodium $\mathrm{K} \alpha$ line is closer to the $\mathrm{K}$ edge of strontium and L-edge of lead. However, the total spectral output of an X-ray tube is known to follow the relation in Eqn. 8.2, where $I$ is the intensity, $k$ a constant and $V$ the applied voltage.

$$
I=k Z V^{2}
$$

Thus, from the point of view of the target material, for the same applied voltage, there is a linear relationship to total spectral output with the atomic number of the target material. 
In this case, even though the Rh line is closer in energy to the strontium and lead edges, this physical feature (Eqn. 8.2) will always result in a higher total number of silver photons which likely compensates for the distance in energy. In this particular study, the silver system was operating at $50 \mathrm{kVp}$. The rhodium target system was limited in its operation, given Ontario regulations with regards to pXA spectrometers, to $40 \mathrm{kVp}$. The square dependence on total output would suggest that increasing this voltage to $50 \mathrm{kVp}$ would result a $36 \%$ increase in the total spectral output. Coupled with the spread in energy distribution, the MDLs could be comparable. Aside from the lower MDLs the shape of the bremsstrahlung distribution also results in a larger amount of radiation below the edges which will impart dose to the subject in the case of a rhodium target system. Dosimetry was not completed in this work however and remains a point of investigation. Although dosimetry was not performed in this study as it was intended to evaluate performance strictly in the context of the analytical figures of merit, dosimetry must be considered carefully. For the clinical in vivo XRF system of bone strontium quantification effective doses have been determined to be on the order of $(64-76) \times 10^{-6} \mathrm{mSv}$ for a 3600 live time measurement. ${ }^{19}$ Specht et al. ${ }^{7}$ have reported an effective dose for an in vivo bone lead determination using a portable silver target system of $2 \mu \mathrm{Sv}$ for a $180 \mathrm{~s}$ live time measurement. Although one can thus apply these spectrometers such that it allows for greater portability, the dosimetric aspects must be considered given that such systems deliver dose much higher than those expected of isotope-induced systems.

\subsection{Conclusions}

Three pXA spectrometers were evaluated as potential candidates for the in vivo quantification of bone strontium and lead: a tungsten target pXA, a rhodium target pXA and a silver target pXA. It was found that the tungsten target pXA, which presented no characteristic 
X-rays of tungsten, but only a bremsstrahlung continuum, was inferior to the other two systems in determined MDL. The rhodium and silver target pXAs performed equally well with counting times as low as $1 \mathrm{~s}$ for strontium. Although $1 \mathrm{~s}$ scans would not be acceptable for measurements due to issues with signal averaging over a period of time to compensate of patient movement, limits of detection were found to be suitable for time period up to $30 \mathrm{~s}$ real time. A similar trend was observed for lead measurements. From a dosimetric point of view, the silver target system produced a flatter background than that for any filtration arrangement investigated for for the rhodium system. This may have a consequence with regards to the dosimetry to subjects and is a point of further investigation.

\section{Acknowledgements}

The authors acknowledge the Natural Science and Engineering Research Council of Canada (NSERC) for financial support of this work through an Alexander Graham Bell Canadian Graduate Scholarship (EDS), a Discovery Grant (APM) and Research Tools and Instruments Grant (APM). The authors also acknowledge A. Panagiotoupolos, M. Forrest for their technical support throughout the course of this work. 


\section{References}

[1] A. Pejović-Milić, I. M. Stronach, J. Gyorffy, C. E. Webber, and D. R. Chettle, "Quantification of bone strontium levels in humans by in vivo x-ray fluorescence," Medical Physics, vol. 31, no. 3, pp. 528-538, 2004.

[2] M. Zamburlini, A. Pejović-Milić, and D. R. Chettle, "Spectrometry methods for in vivo bone strontium measurements," X-ray Spectrometry, vol. 37, no. 1, pp. 42-50, 2008.

[3] L. J. Somervaille, D. R. Chettle, and M. C. Scott, "In vivo measurement of lead in bone using x-ray fluorescence," Physics in Medicine and Biology, vol. 30, no. 9, pp. 929-943, 1985.

[4] D. R. Chettle, "Three decades of in vivo x-ray fluorescence of lead in bone," X-ray Spectrometry, vol. 34, no. 5, pp. 446-450, 2005.

[5] H. Moise, J. D. Adachi, D. R. Chettle, and A. Pejović-Milić, "Monitoring bone strontium levels of an osteoporotic subject due to self-administration of strontium citrate with a novel diagnostic tool, in vivo XRF: A case study," vol. 51, no. 1, pp. 93-97, 2012.

[6] H. Moise, D. R. Chettle, and A. Pejović-Milić, "Monitoring bone strontium intake in osteoporotic females self-supplementing with strontium citrate with a novel in-vivo Xray fluorescence based diagnostic tool," vol. 61, pp. 48-54, 2014.

[7] A. J. Specht, M. Weisskopf, and L. H. Nie, "Portable XRF Technology to Quantify Pb in Bone In Vivo," Journal of Biomarkers, vol. 2014, p. 398032, 2014.

[8] A. J. Specht, Y. Lin, M. Weisskopf, C. Yan, H. Hu, J. Xu, and L. H. Nie, "XRFmeasured bone lead $(\mathrm{Pb})$ as a biomarker for $\mathrm{Pb}$ exposure and toxicity among children diagnosed with Pb poisoning," Biomarkers, vol. 21, no. 4, pp. 347-352, 2016. 
[9] L. H. Nie, S. Sanchez, K. Newton, L. Grodzins, R. O. Cleveland, and M. G. Weisskopf, "In vivo quantification of lead in bone with a portable x-ray fluorescence systemmethodology and feasibility," Physics in Medicine and Biology, vol. 56, no. 3, pp. N39N51, 2011.

[10] D. E. B. Fleming, M. R. Gherase, and K. M. Alexander, "A miniature X-ray tube approach to measuring lead in bone using L-XRF," X-ray Spectrometry, vol. 40, no. 5, pp. 343-347, 2011.

[11] L. Wielopolski, J. F. Rosen, D. N. Slatkin, R. Zhang, J. A. Kalef-Ezra, J. C. Rothman, M. Maryanski, and S. T. Jenks, "In vivo mesurement of cortical bone lead using polarized x rays," Medical Physics, vol. 16, no. 4, pp. 521-528, 1989.

[12] L. Wielopolski, J. F. Rosen, D. N. Slatkin, D. Vartsky, K. J. Ellis, and S. H. Cohn, "Feasibility of noninvasive analysis of lead in human tibia by soft x-ray fluorescence," Medical Physics, vol. 10, no. 2, pp. 248-251, 1983.

[13] L. Wielopolski, D. N. Slatkin, D. Vartsky, K. J. Ellis, and S. H. Cohn, "Feasibility study for the in vivo measurement of lead in bone using L-X-ray fluorescence," IEEE Transactions on Nuclear Science, vol. NS-28, no. 1, pp. 114-116, 1981.

[14] A. C. Todd, S. Carroll, C. Geraghty, F. A. Khan, E. L. Moshier, S. Tang, and P. J. Parsons, "L-shell x-ray fluorescence measurements of lead in bone: accuracy and precision," Physics in Medicine and Biology, vol. 47, no. 8, pp. 1399-1419, 2002.

[15] D. E. B. Fleming and M. R. Gherase, "A rapid, high sensitivity technique for measuring arsenic in skin phantoms using a portable x-ray tube and detector," Physics in Medicine and Biology, vol. 52, no. 19, pp. N459-N465, 2007. 
[16] E. Da Silva, B. Kirkham, D. V. Heyd, and A. Pejović-Milić, "Pure Hydroxyapatite Phantoms for the Calibration of in Vivo X-ray Fluorescence Systems of Bone Lead and Strontium Quantification," Analytical Chemistry, vol. 85, no. 19, pp. 9189-9195, 2013.

[17] S. P. Nielsen, "The biological role of strontium," Bone, vol. 35, no. 3, pp. 583-588, 2004.

[18] W. E. Cabrera, I. Schrooten, M. E. De Broe, and P. C. D'Haese, "Strontium and bone," Journal of Bone and Mineral Research, vol. 14, no. 5, pp. 661-668, 1999.

[19] M. Zamburlini, A. Pejović-Milić, D. R. Chettle, C. E. Webber, and J. Gyorffy, "In vivo study of an x-ray fluorescence system to detect bone strontium non-invasively," Physics in Medicine and Biology, vol. 52, no. 8, pp. 2107-2122, 2007. 
CHAPTER

NINE

\section{CONCLUSIONS AND FUTURE DIRECTIONS}

This work aimed at designing and evaluating a hydroxyapatite (HAp) phantom material for the purpose of calibrating in vivo X-ray fluorescence (IVXRF) systems of bone metal quantification. ${ }^{1,2}$ Although the HAp phantom material can potentially be used for the preparation of phantoms for any particular metal to be quantified in bone via IVXRF, this work focused

on its application to IVXRF bone strontium quantification using the ${ }^{125}$ I-induced clinical IVXRF bone strontium system ${ }^{3-9}$ and its application to the assessment of portable X-ray analyzers (pXAs) for the purpose of bone strontium and lead quantification. This chapter provides a review of conclusions drawn and recommendations for future work.

\subsection{Development of Phantom Materials}

Chapter 2 of this work presents a method of preparing chemically pure $\mathrm{HAp}\left[\mathrm{Ca}_{5}\left(\mathrm{PO}_{4}\right)_{3} \mathrm{OH}\right]$ bone phantoms for the said purpose. In the case of strontium-containing bone phantoms a major problem in the determination of proper sensitivity factors as well as analytical figures of merit has been the inherent contamination of calcium compounds by strontium. ${ }^{10}$ This results in the inability to prepare a blank phantom and thus does not allow for a true 
system contamination assessment or the determination of the analytical figures of merit of the system properly. ${ }^{10}$ This is due to the fact that any signal which is present from the inherent contamination brings about another source of uncertainty to the background which is not purely due to the system itself. This work itself found that for the calcium compounds used, which were purchased as high purity compounds, the strontium concentrations ranged from approximately $286-773 \mu \mathrm{g} \mathrm{Sr} / \mathrm{g}$ Ca. The calcium compounds were also found to contain contamination from various other elements including lead in lower concentrations of contamination (see Chapter $2^{1}$ ). It was found to be possible to prepare purified calcium by simply precipitating calcium from a calcium chloride solution in the case in which the number of equivalents of hydroxide ions were much small than those of the calcium. In this case, the solubilities of the calcium hydroxide which is formed and in equilibrium with a solution containing a high concentration of calcium are different than those for strontium hydroxide. As a result, pure calcium can be prepared at a great sacrifice for calcium in solution. The resultant calcium hydroxide was free from the contaminants found in the original reagent (calcium chloride used for the precipitation). As assessed by total reflection X-ray fluorescence spectrometry, the calcium hydroxide produced after precipitation was found to contain $<0.7$ and $<0.3 \mu \mathrm{g} / \mathrm{g}$ Ca for strontium and lead, respectively. This purified calcium hydroxide can then be used for the preparation of strontium-free brushite which can be produced by the dissolution of the calcium hydroxide and reaction with a solution of $\mathrm{Na}_{2} \mathrm{HPO}_{4}$ and $\mathrm{NaH}_{2} \mathrm{PO}_{4} \cdot \mathrm{H}_{2} \mathrm{O}$. The calcium hydroxide and brushite formed by these reactions were found by powder X-ray diffraction to be identical to those of purchased precipitated reagents. The phantoms can thus be prepared pure by using these reagents to prepare a hydroxyapatite cement to form the final phantom.

By mixing the calcium hydroxide and brushite as to prepare a powdered mixture with a 
$\mathrm{Ca} / \mathrm{P}$ mole ratio of 1.67 , that of HAp, the reaction can proceed by the addition of a suitable setting solution. The calcium phosphate cement mixture being based on the solubility properties of calcium phosphates. In the case in which a high phosphate ion concentration is maintained in the setting solution, the solubility of the brushite increases. The result is a precipitation to hydroxyapatite whereby the calcium hydroxide is added as to maintain the stoichiometry of the final product. The phantoms can thus be prepared by mixing the powered mixture with the a setting solution consisting of $1 \mathrm{M} \mathrm{HPO}_{4}{ }^{2-}$. It was found that a 2:1 mass ratio of powder mixture-to-liquid was ideal for the preparation of a cement which was sufficiently fluid for moulding of phantoms. The analyte can be added directly by doping to the setting solution mixture. The phantoms, when suitably set, were found to have a crystal phase similar to that of the mineral phase of bone as compared to NIST bone meal though a powder X-ray diffraction assessment. The reaction was found to produce a phantom with a mass density of $(2.0 \pm 0.6) \mathrm{g} / \mathrm{cm}^{3}$. The phantom density was lower than that of pure hydroxyapatite $\left(3 \mathrm{~g} / \mathrm{cm}^{3}\right)$ but close to that of bone, ${ }^{11}$ of $1.9 \mathrm{~g} / \mathrm{cm}^{3}$ (nominal). The reaction is, however, not $100 \%$ efficient whereby contamination was observed as unreacted brushite. It is anticipated that the conversion ratio (a measure of the degree of the reaction) can be to some degree assessed by mass difference given that the calcium hydroxide seemed to be the limiting reagent in the reaction and from a preliminary assessment, the amount of brushite left after reaction seems small. This should however be assessed through a proper conversion ratio assessment.

The phantoms produced by this route seem to be suitable for the calibration of IVXRF systems of bone metal quantification as they are more suitable to mimicking bone mineral than plaster of Paris (poP), and become further more so suitable in the context of a coherent normalization-based calibration procedure. By the addition of the analyte into the 
phantom through doping linear calibration curves were produced for both lead and strontium with intercepts through the $(0,0)$ point which indicates that the phantoms seem to be taking up the analyte in a predictable fashion (Figure 2.5). This thus suggests that the phantoms are suitable for IVXRF system calibration and is also the first, to the author's knowledge, production of a true analytical blank for strontium. The phantoms produced by this method are however not truly bone equivalent and should be used with caution outside of a coherent normalization-based calibration protocol. The phantom produced here are bone mineral phantoms and were designed as a replacement for poP in the context of a coherent normalization-based calibration procedure. The mass attenuation coefficient of the material in comparison to bone is different and this may have an influence in the case that $\mathrm{XRF}$ quantification is to be employed in a more general sense (i.e. through the application of fundamental parameters approaches). This was the focus of a separate part of the work. This portion of this work thus demonstrates the suitability of a method for the preparation bone mineral equivalent phantoms as discussed in Chapter 2.

The pure HAp phantoms as well as the purified calcium compounds can also be used for other purposes outside of general calibration of IVXRF systems of bone metal quantification. Although the method of preparing phantoms here does present the possibility of removing a correction factor from IVXRF systems based on calibration through a coherent normalization procedure (the coherent conversion factor or CCF, see Chapter 6), their use has not yet been fully established. As such, in the case that poP-based calibrations are to continue, this method of calcium purification can be used for the preparation of strontium-free poP. Although not the focus of this work, this can likely occur by the formation of gypsum from reaction of the pure calcium hydroxide which can then be dehydrated to plaster of Paris. Caution should be used if this method is employed. Like the CPC system, the common 
ion effect holds for poP ${ }^{12}$ and care should be taken to evaluate a suitable methodology for the preparation of purified poP phantoms as it is likely that the addition of a common ion be required for the preparation of phantoms suitable for long term calibration of IVXRF systems of bone metal quantification.

Further the purified HAp material can be potentially used for a purpose outside of calibration, and this is validation. Currently, validation of IVXRF bone metal systems requires that animal bone be used as a means of performing the validation after cross-validation with secondary methods of analysis. ${ }^{13-19}$ The major problem associated with this route becomes and limited range of concentrations which are attainable with animal or human bone whereby a true validation should use a matrix reference material with as wide a concentration range as possible. This is possible if the HAp phantoms are used for this purpose.

Although it is possible to prepare HAp phantoms using commercially available reagents, one of the areas that requires further work is the scaling up of the procedure for the purification. In order to prepare pure calcium hydroxide in sufficient quantities as to prepare a full set of phantoms, a very large loss of calcium is required and the time commitment is vast. Future work within the area of purification should thus focus largely on procedures to scale up the purification while re-using as much of the calcium as possible. Without such future work, the cost of producing a phantom set from purified calcium compounds is rather large. The alternative of preparing phantoms using commercially available calcium compounds and reserving the purified calcium compounds for a blank along would also require further quantitative confirmation of the true concentrations in each phantom as to account for the contamination levels, which, to some degree, removes the point of producing pure calcium compounds. Proceeding with calibration using phantoms with confirmed concentrations necessitates the need to introduce uncertainty into the concentration direction 
of the calibration curve, which, complicates the analysis substantially. Future work thus should focus on either alternative methods of purification, or, methods of preparing pure calcium compounds by precipitation while salvaging more calcium and reducing total time of production.

Chapter 2 of this work focuses on the preparation of phantoms which are pure of the analyte, namely, strontium; however, this is only one extrema of the problem in phantom preparation in the context of IVXRF for bone strontium. Unlike lead, strontium levels in bone can, theoretically, reach the percentage mass levels, whereby, lead will generally only be present in bone mineral in the parts-per-million level. This is due to the fact that strontium is ubiquitous to calcium from dietary sources but also is used as a supplement/medication for therapy against osteoporosis. ${ }^{20,21}$ From a purely hypothetical point of view, then, it would be desirable to have phantoms which can be prepared with high concentrations of strontium. This is particularly of importance in producing calibration protocols as standard curves must by definition extend over a large concentration as to produce curves with the middle point being that of the concentration expected to be quantified. Regardless of the phantom material which is selected for calibration, this posses a problem. For both poP, or the HAp phantoms, if strontium is to be added in large concentrations a stoichiometric problem ensues. Doping the phantom material with strontium can become a problem in terms of the volumes required of standard solutions in both cases. In the case of the HAp phantom material, this would result in a great decrease in the total phosphate concentration which would result in ill-setting phantoms. In the case of both poP and HAp phantoms, if the calcium content is not adjusted, the stoichiometry may skew. This is one reason why HAp phantoms are desirable for the preparation of high strontium concentrations phantoms as they do allow for control over the total composition of the phantom and an adjustment to the 
calcium/phosphate content of the phantom. In contrast to poP, it would be required to add a material, such as strontium sulphate which will likely not set in the same fashion as plaster of Paris. The next step of this work thus investigates the suitability of the proposed phantom synthesis procedure for the preparation of high strontium concentration phantoms. In this way, strontium phantoms with the formula of $\left(\mathrm{Ca}_{1-\mathrm{x}} \mathrm{Sr}_{\mathrm{x}}\right)_{5}\left(\mathrm{PO}_{4}\right)_{3} \mathrm{OH}$ can be directly prepared as to mimic the strontium substitution within the mineral phase of bone more closely and while keeping the $(\mathrm{Ca}+\mathrm{Sr}) / \mathrm{P}$ mole ratio at 1.67 , that of a presumed strontium-substituted apatite.

The preparation of apatitic phantoms which are high in strontium content but maintain $\mathrm{a}(\mathrm{Ca}+\mathrm{Sr}) / \mathrm{P}$ mole ratio at 1.67 requires that, instead of doping with a standard solution, that the powder phase be modified. Instead of a binary mixture of $\mathrm{CaHPO}_{4} \cdot 2 \mathrm{H}_{2} \mathrm{O}$ and $\mathrm{Ca}(\mathrm{OH})_{2}$, a portion of either fraction needs to be replaced by a strontium salt which will react sufficiently as to form a strontium-substituted hydroxyapatite. During the course of this work, attempts were made to find a suitable replacement for the brushite. There was however no success in finding an equivalent strontium compound which would inherently react after solubilization to form an apatitic product. The hydroxide fraction can however be easily replaced. Strontium hydroxide hexahydrate was selected given its large mass in order to minimize weighing error when producing the phantoms. In this way the phantom powder mixture can be prepared from $\mathrm{CaHPO}_{4} \cdot 2 \mathrm{H}_{2} \mathrm{O}, \mathrm{Ca}(\mathrm{OH})_{2}$ and finely ground $\mathrm{Sr}(\mathrm{OH})_{2} \cdot 8 \mathrm{H}_{2} \mathrm{O}$ as to produce a mixture with a $(\mathrm{Ca}+\mathrm{Sr}) / \mathrm{P}$ mole ratio of 1.67 . The production of a calcium phosphate cement $(\mathrm{CPC})$ is based on the solubility properties of brushite as previous mentioned and requires that the phosphate concentration in the setting solution be sufficiently high as to increase the solubility of the brushite. ${ }^{22,23,23-25}$ Chapter 2 employed a setting solution consisting of $\mathrm{HPO}_{4}{ }^{2-}$ ion for this purpose, but it is possible to use a high concen- 
tration of $\mathrm{OH}^{-}$ion for the same purpose. ${ }^{23} \mathrm{An}$ issue with employing a $\mathrm{CPC}$ cement mixture consisting of $\mathrm{CaHPO}_{4} \cdot 2 \mathrm{H}_{2} \mathrm{O}, \mathrm{Ca}(\mathrm{OH})_{2}$ and finely ground $\mathrm{Sr}(\mathrm{OH})_{2} \cdot 8 \mathrm{H}_{2} \mathrm{O}$ comes from the solubility differences between the calcium and strontium hydroxides. When mixed with a setting solution, calcium hydroxide is relatively insoluble with a solubility of $0.160 \mathrm{~g} / 100 \mathrm{~g}$ $\mathrm{H}_{2} \mathrm{O}\left(\right.$ at $20^{\circ} \mathrm{C}$ ) while the solubility of strontium hydroxide hexahydrate is $1.77 \mathrm{~g} / 100 \mathrm{~g} \mathrm{H}_{2} \mathrm{O}$ (at $20^{\circ} \mathrm{C}$ ). The consequence of this difference in the context of a phantom preparation is as follows. It was found that when considering isolated $\mathrm{Ca}(\mathrm{OH})_{2}$ mixed with a setting solution consisting of $\mathrm{OH}^{-}$ion the final product after curing is largely unreacted $\mathrm{Ca}(\mathrm{OH})_{2}$ with some residual $\mathrm{CaCO}_{3}$. The carbonate being integrated due to the presence of the $\mathrm{NaOH}$ which is known to trap $\mathrm{CO}_{2}$. When a $\mathrm{HPO}_{4}{ }^{2-}$ ion containing setting solution is used in the same system, the final product after curing is largely unreacted $\mathrm{Ca}(\mathrm{OH})_{2}$ with some residual hydroxyapatite. This indicates that the use of a $\mathrm{OH}^{-}$ion-containing setting solution brings about a source of contamination to the phantom which is undesirable in controlling the composition. Given the large solubility of $\mathrm{Sr}(\mathrm{OH})_{2} \cdot 8 \mathrm{H}_{2} \mathrm{O}$, the final product independent of the setting solution used is mostly $\mathrm{SrCO}_{3}$ when considering an isolated $\mathrm{Sr}(\mathrm{OH})_{2} \cdot 8 \mathrm{H}_{2} \mathrm{O}$ system, with the $\mathrm{HPO}_{4}{ }^{2-}$ ion containing setting solution producing a small amount of $\mathrm{Sr}_{5}\left(\mathrm{PO}_{4}\right)_{3} \mathrm{OH}$. This indicated the potential for a large amount of residual contamination as strontium carbonate. Another concern was the possibility that the phantom would set by first creating $\mathrm{Sr}_{5}\left(\mathrm{PO}_{4}\right)_{3} \mathrm{OH}$ with the available brushite given the solubility of $\mathrm{Sr}(\mathrm{OH})_{2} \cdot 8 \mathrm{H}_{2} \mathrm{O}$ relative to $\mathrm{Ca}(\mathrm{OH})_{2}$ and then the formation of pure hydroxyapatite after the exhaustion of the added $\mathrm{Sr}(\mathrm{OH})_{2} \cdot 8 \mathrm{H}_{2} \mathrm{O}$. This would then result in not a strontium-substituted phantom but an undesirable biphasic phantom. It was however found that as a whole system, the phantom does in fact set into a strontium-substituted hydroxyapatite and there was no evidence of a large degree of contamination from carbonate of either species. Further, a vibrational spec- 
troscopy study (Raman spectroscopy) found that the phosphate groups stretching behaviour indicates an overall strontium substitution resembling that expected of a strontium substitution hydroxyapatite with formula $\left(\mathrm{Ca}_{1-\mathrm{x}} \mathrm{Sr}_{\mathrm{x}}\right)_{5}\left(\mathrm{PO}_{4}\right)_{3} \mathrm{OH}$ (as seen through an energy shift in the phosphate group $\nu_{1}$ mode) which is that which would be expected in bone if strontium is substituted for calcium in the mineral phase when bone mineral is forming. Chapter 3 thus demonstrates that it is possible to prepare high strontium concentration phantoms while maintaining a $(\mathrm{Ca}+\mathrm{Sr}) / \mathrm{P}$ mole ratio at 1.67 ; and that it can be presumed that even in cases in which low concentrations of divalent metals are used for phantom preparation that they likely integrate into the apatite lattice.

Chapter 3 thus introduces a case in which the HAp phantom material may be a necessity in comparison to the poP phantoms given the flexibility in their preparation while maintaining a mineral phase component which is similar to that in bone. In cases in which high strontium phantoms may be needed for calibration/validation purposes, the HAp series may be recommended. This requires further investigation as to their suitability as well as a more thorough study of the general integration behaviour of divalent metals (and possibly trivalent metals such as gadolinium ions) into the hydroxyapatite lattice. This was hindered in this study by the sensitivity of the powder X-ray diffraction spectrometry system which would not allow for the visualization of say lead apatites. The substitution of lead into the system as a lead hydroxide was also complicated as lead hydroxide is not generally stable in the solid phase. ${ }^{\dagger}$ As a result, this chapter leaves the question open as to whether or not lead and other divalents also integrate in the expected fashion as this would require a much more sensitive spectrometer to what was available and it was not possible to produce phantoms of high lead concentration with the same substitution for the hydroxide fraction.

\footnotetext{
${ }^{\dagger}$ Generally present as lead basic carbonate and lead oxide mixtures.
} 


\subsection{Application to quantification methodology}

The design and production of the hydroxyapatite phantom material as described in Chapter 2 was largely focused on the development of a blank phantom material. A blank being necessary for the purpose of determining analytical figures of merit while also allowing one to assess spectral interferences with the analyte signal. Chapter 4 of this work demonstrates the need for a blank phantom in the context of an IVXRF ${ }^{125}$ I-induced bone strontium measurement. The excitation source for the current clinical system being brachytherapy seeds which are not intended for the purpose of analytical spectrometry but rather for radiation therapy. Given that these seeds are composed of titanium capsules, which, as is well established, are generally either coated with, or formed into an alloy of, zirconium, as a means of ensuring a minimum of corrosion when implanted. Indeed, a direct measurement of the excitation source was found to include the characteristic K-series of zirconium which overlaps directly with the $\mathrm{K} \beta$ line of strontium and is thus a spectral interference that needs to be assessed via a blank phantom as a means of controlling the interference during the calibration protocol. Monte Carlo simulations demonstrated however that in the $180^{\circ}$ backscatter geometry used for measurements, that scattering back into the detector is largely due to Compton scattering rather than coherent scatter-expected result given the heavy forward directedness of coherent scatter. As a result, the main zirconium peaks which would be detected by the system would resemble rubidium $\mathrm{K} \beta_{1,3}$ lines which preclude the strontium $\mathrm{K} \alpha$ line as well as the strontium $\mathrm{K} \beta_{1,3}$ line. A blank measurement was carried out which demonstrated the possibility of detecting the zirconium Compton scattered line however the statistical nature of this measurement would indicate it should be verified. In any case, Chapter 4 demonstrated the necessity of a blank bone phantom, with a focus on a problem related to spectral interference, in the context of an IVXRF bone strontium measurement. 
Further work should thus focus not only on the application of a blank for the assessment of spectral interferences and background but also on the impact the availability of a true blank phantom will have on the assessment of analytical figures of merit. This was not assessed in this work as the topic becomes complicated given the observed spectral interference. The ultimate result would be the ability to determine $\sigma_{0}$ without the contribution of the counting statistics from the K-lines of strontium as currently present. This would result in a reduction in the limit of detection and quantification. That being said, the current limit of detection of the clinical system, determined with contaminated phantoms, is already sufficient for human measurements. ${ }^{8,9}$ The limit of detection also being dependant on scatter from the soft tissue component in humans and phantoms would also require further development in this area to calculate, if anything, the limit of detection on a subject-by-subject basis, which is customary in the context of XRF analyses in a general sense.

Chapters 2 through 4 focus on the development of apatitic phantoms materials and the demonstration of the application of the blank for a rather important step in any analytical methodology-interference and background assessment. Thus, a HAp phantom material with no strontium has been developed as a blank phantom for the purpose of analytical figure of merit determinations and spectral background assessment, this material can be doped with strontium or other analytes to produce standard curves and the material can be further produced with high strontium concentrations by a modification to the original formulation. Chapter 5 of this work assess a case in which strontium concentrations may become high in bone mineral and a possible consideration when considering analytical methodology. The two elements which can be potentially assessed in bone my XRF in the lower energy region is that of strontium via the K-series and lead via the L-series. In this case, given the known influence "high" bone strontium levels have on dual energy X-ray absortiometry (DXA) measurements, 
namely, a sufficient change in the mass attenuation coefficient such that a bias is observed in the determined BMDs, ${ }^{26-30}$ one would reason that these same levels of strontium may result in signal enhancement when trying to quantify lead in bone via XRF in the presence of high bone strontium concentrations. Thus, this is another application and need for the high concentration bone strontium phantoms as presented in chapter 3 as it would be necessary to quantify strontium alongside lead if reliable concentrations are be extracted. Monte Carlo simulations were employed to assess this possible phenomenon whereby a terminal high lead concentration in human bone of $1000 \mathrm{ppm}$ was employed and strontium concentrations as high as $5 \% \mathrm{w} / \mathrm{w}$. No enhancement effect was observed which would indicate that lead can be assessed freely without the need to known the concentration of strontium in bone. This is not a surprising finding as the enhancement is heavily dependant on the product of the concentrations of both analytes of interest. Given that the lead concentration will always be low, the probability of enhancement becomes vanishingly small. It was also observed that the mass attenuation coefficient for strontium within this $5 \% \mathrm{w} / \mathrm{w}$ range does not change significantly. Non-linearity was observed with respect to the strontium signal which indicates the need for the phantoms produced in Chapter 3 as this needs to be assessed experimentally during calibration of IVXRF systems as non-linearity may result in the need to move away from the external phantom calibration which assumes the signal changes in a linear fashion. ${ }^{10}$ The minimal change in signal in the context of lead however can be attributed to the fact that the measurements are made on infinitely thick samples, whereby, the observed biases using DXA measurements are based on intermediately thick samples in transmission mode. In any case, this work demonstrates the need for the phantoms developed in Chapter 3 for thorough calibration of IVXRF systems for bone strontium calibration as a means of providing linearity assessment while also demonstrating the lead can theoretically 
be quantified in bone via the L-series without any need to quantify strontium.

Chapter 6 of this work employed Monte Carlo simulations to assess the impact a change in phantom material (from poP to HAp) would have in the calibration protocol of the ${ }^{125}$ induced IVXRF bone strontium measurements. Monte Carlo simulations were employed on bare bone phantoms of various compositions to make this assessment. Although bare bone human measurements are clearly not possible in the IVXRF case, as it would be impossible to remove overlaying soft tissue from the measurement site on a living individual, a bare bone signal is what is desirable after overlaying soft tissue attenuation correction of the signal. Thus a bare bone-based simulation provides an unbiased view of the emission signal which is desired for quantification-that at the surface of the bone. Monte Carlo simulations showed the the application of either poP of HAp as a phantom material does not allow for quantification of bone strontium in the sense of obtaining bone strontium quantification on a per mass of bone basis. Coherent normalization alone was also found not to correct for this phenomenon as the sensitivities remain a function of the materials mass attenuation coefficient. Although Compton-based global matrix corrections are known to make these corrections for variations in mass attenuation coefficients in cases with large dark matrices, this was ignored in this context as the Compton scattering signal also arises, in a significant way, from interactions of photons within the soft tissue. ${ }^{31}$ Coherent normalization, which is currently applied within the context of a bone strontium measurement calibration, ${ }^{8,9}$ was found to be successful in normalization of the signal if the concentration of strontium is represented on a mass of bone mineral basis. This is a well established mode of calibration in the context of IVXRF which arises from early work on the K-XRF bone lead system $\left({ }^{109} \mathrm{Cd}\right.$-induced).${ }^{13}$ This work did however find that the application of HAp as a phantom material does remove the need to apply the CCF to the calibration protocol as the sensitivity determined for both 
bone and HAp were similar. The application of HAp as a phantom material thus removed the need to apply a factor to the calibration protocol and thus allows for direct transferability of the calibration sensitivity factor between calibrator and the matrix - a factor which has been known to be a source of uncertainty when applied to poP-based calibrations. ${ }^{32}$ It was also found that the sensitivity was, by default, to be independent of the phantom conversion ratio. That is, even if the material produced as per Chapter 2 were to be the product of an incomplete reaction, the sensitivity factors are not influenced. This is attributed to the fact that the coherent scatter, being predominately from calcium, normalized signal sufficiently well that any calcium phosphate material can be used as a calibration material as long as coherent scatter is used as a normalization factor in the calibration protocol. Thus, the phantom material developed in this work is suitable for calibration of IVXRF bone strontium systems without the need for worry about incomplete reaction and also allows one to remove the CCF simplifying the calibration protocol as well as reducing the introduction of uncertainty given that the true composition of poP materials is unknown, thus, introducing uncertainty into the CCF.

Chapter 7 of this work expanded on Chapter 6 whereby soft tissue attenuation correction was evaluated, more specifically, the use of spectroscopic information alone for the determination of the overlaying soft tissue thickness - a required piece of information in order to correct for signal attenuation. In the context of an IVXRF bone strontium measurement employing the current ${ }^{125}$ I-induced clinical system, ${ }^{8,9}$ Compton intensities of scattered source photons were evaluated as a means of determining the soft tissue thickness. This method being previously proposed by Nie et al. ${ }^{31}$ in the context of measurement made using a portable X-ray analyzer. It was found, via Monte Carlo simulation, that the choice of calibration material used as to mimic the bone as well as the soft tissue plays a significant role in the 
applicability of this method of soft tissue thickness determination. Lucite, a proposed soft tissue surrogate in the context of a IVXRF measurements, ${ }^{31}$ when coupled with poP as a calibration material was found to produce standard curves which were non-linear and nontransferable to soft tissue and bone. If HAp were to be used as a phantom material, similar Compton intensities were observed to that of bone. Compton scattering was found to be heavily dependant on the bone surrogate used as well as the soft tissue phantom material used. With this regard, if a soft tissue equivalent material can be developed to be used in conjunction with the HAp material developed in this work, it does seem to be possible to be able to use the Compton intensity as a means of determining the soft tissue thickness directly from spectroscopic data. This fact, coupled with the fact that the coherent normalization can be applied for matrix correction/normalization, indicates the possibility of producing direct bone strontium quantification using spectroscopic data alone. Further work however would be needed in order to devise this quantification algorithm, as it would need to be iterative by its very nature in the sense the Compton scattered intensity is also a function of bone size. Thus, given that coherent normalization can correct for bone size, this may become another unknown parameter which would render Compton-based soft tissue correction unusable and this thus remains an area of future work alongside the design of more suitable soft tissue equivalent materials for in vivo XRF applications.

Chapters 4 through 7 of this work focus on applications using the current clinical IVXRF system of bone strontium when discussing quantification and calibration. Although the system has been well applied to human subjects, ${ }^{8,9}$ and is, in theory, portable, it does require liquid nitrogen cooling and by extension a large dewar making it cumbersome. Chapter 8 of this work evaluates the potential of applying portable X-ray analyzers for the purpose of bone strontium and lead quantification. The chapter was a comparison of commercially available 
portable X-ray analyzers for this purpose. It was found that the target material applied does play a role in the sensitivity of the system and may have an impact on the dosimetry. Commercially available silver target X-ray tube systems seem to produce a sufficiently high fluence such that heavier filtration can be applied while maintaining good sensitivity in comparison to rhodium tube-based systems. The result is a high fluence of photons in the region below the strontium K-edge of lead L-edge which will only result in added dose to the subject. The systems were found to be rather equivalent when considering strontium as the analyte with sensitivity sufficient to produce measurements with a $30 \mathrm{~s}$ real time measurement. In the case of lead, the silver target X-ray tube system out performed the rhodium system which is largely attributed to the higher background in the strontium and lead characteristic X-ray energy region. Although rhodium is slightly closer to the K-edge of strontium and L-edge of lead, the lower atomic number results in sufficiently lower fluence such that the silver target X-ray tube system does outperform and will likely result in a smaller dose to subjects. Either the silver target or rhodium target X-ray tube systems seem suitable for the purpose, however, and dosimetric studies are needed in future work.

\subsection{Future Recommendations}

As a point for future investigation, quantification methodology and associated algorithms should be considered more carefully. Namely, within this work and within the framework of a coherent normalization procedure, various assumptions need to be taken into account including those associated with sample homogeneity. As was found in this work, issues with soft tissue thickness correction remain and it was found that the coherently scattered ${ }^{125}$ I $\gamma$-ray carries significant contributions from both the bone as well as the overlaying soft tissue, as does Compton scattered radiation from the sample, which in turn complicates 
quantification. It is thus difficult to delineate contributions from each tissue as a means of extrapolating to an analytical measure determined directly from bone tissue in this case. Two possible methods can potentially be investigated as a means of improving the quantification methodology for the in vivo bone strontium system in particular. Both of these methods, however, would require future development alongside novel instrumentation as a means of acquiring the required data, in the required form, for quantification to be possible. In both cases, this may mean a re-evaluation of the broad-beam geometries suggested, as with the current clinical in vivo XRF bone strontium system and the portable X-ray analyzers evaluated in this work.

It may be possible, with suitable instrumentation, to perform tomographic analysis of the site being measured, if sufficiently small, such as the finger. In this case, acquired spectra, taken at various angles throughout the finger, can be used to develop a series of Radon transforms based on not only the strontium K-series intensities but also those of the coherent and Compton scattered radiation. In this case, it may be possible to reconstruct both soft tissue thickness and concentration information from the sample performing a more robust quantification which can take into account true sample geometry as well as any inhomogeneities present in the sample being measure - both at the soft tissue and bone level. This method carries the inherent limitation that instrumentation would need to be fully developed for this purpose, likely requiring a tomographic system to be designed using pencil beam sources rather than the broad beam sources used throughout this work. Further, the fact that the bone sample is infinitely thick for strontium K X-rays would inherently result in a series of incomplete Radon transforms which would complicate the quantification, if it would even be possible. Such an approach would however potentially allow for quantification in a more robust sense. 
The second proposed future investigation would be to the development and application of Monte Carlo-based procedures for quantification. In this case, it may be possible to develop a system in which imaging information can be used to model the geometry of the sample while applying a Monte Carlo procedure as to perform quantification. In this way, quantification can proceed using an iterative approach as to match spectral intensities of not only the strontium K-series but also that of the scattered radiation to measured spectra. The total space of unknowns with this approach, however, would require future work in evaluating the feasibility of a Monte Carlo-based procedure for this purpose, as there may be far too many unknown parameters to allow for a convergence of concentration information. This method would however be more akin to what is currently been applied to radiation therapy treatment planning. If sufficient information is obtained via imaging of the measurement site, it may be possible to delineate tissue types which would aid in the Monte Carlobased quantification procedure as a means of both defining tissue composition regions as well as direct implementation of geometrical information into the algorithm. The Monte Carlo package used throughout this work, EGS5, is a predecessor to EGSnrc which is used for the purpose of evaluating radiation therapy treatment planning. Both Monte Carlo code packages are suitable to the Monte Carlo simulation of radiative transport within the photon energies of interest and can also be modified to perform dose calculations by suitably following any released charged particles. In this case, application of either code, with modification and suitable system design, may allow for quantification to proceed while also allowing for a direct computation of radiation dose to the subject on a measurement by measurement basis. Although this work developed phantom materials as well as evaluated quantification in the context of the current in vivo XRF system of bone strontium quantification future work may require a re-consideration of quantification algorithms which should be performed 
alongside novel system design. 


\section{References}

[1] E. Da Silva, B. Kirkham, D. V. Heyd, and A. Pejović-Milić, "Pure Hydroxyapatite Phantoms for the Calibration of in Vivo X-ray Fluorescence Systems of Bone Lead and Strontium Quantification," Analytical Chemistry, vol. 85, no. 19, pp. 9189-9195, 2013.

[2] E. Da Silva, D. V. Heyd, B. Rizvi, and A. Pejović-Milić, "The Preparation of strontium-substituted hydroxyapatite bone phantoms with high strontium concentrations," Biomedical Physics and Engineering Express, vol. 2, no. 1, p. 015006, 2016.

[3] A. Pejović-Milić, I. M. Stronach, J. Gyorffy, C. E. Webber, and D. R. Chettle, "Quantification of bone strontium levels in humans by in vivo x-ray fluorescence," Medical Physics, vol. 31, no. 3, pp. 528-538, 2004.

[4] M. Zamburlini, A. Pejović-Milić, and D. R. Chettle, "Evaluation of geometries appropriate for ${ }^{125} \mathrm{I}$ in vivo bone strontium X-ray fluorescence measurement," Journal of Radioanalytical \&3 Nuclear Chemistry, vol. 269, no. 3, pp. 625-629, 2006.

[5] M. Zamburlini, A. Pejović-Milić, D. R. Chettle, C. E. Webber, and J. Gyorffy, "In vivo study of an x-ray fluorescence system to detect bone strontium non-invasively," Physics in Medicine and Biology, vol. 52, no. 8, pp. 2107-2122, 2007.

[6] M. Zamburlini, A. Pejović-Milić, and D. R. Chettle, "Coherent normalization of finger strontium XRF measurements: feasibility and limitations," Physics in Medicine and Biology, vol. 53, no. 15, pp. N307-N313, 2008.

[7] C. M. Heirwegh, D. R. Chettle, and A. Pejović-Milić, "Ex vivo evaluation of a coherent normalization procedure to quantify in vivo finger strontium XRS measurements," Medical Physics, vol. 39, no. 2, pp. 832-841, 2012. 
[8] H. Moise, J. D. Adachi, D. R. Chettle, and A. Pejović-Milić, "Monitoring bone strontium levels of an osteoporotic subject due to self-administration of strontium citrate with a novel diagnostic tool, in vivo XRF: A case study," vol. 51, no. 1, pp. 93-97, 2012.

[9] H. Moise, D. R. Chettle, and A. Pejović-Milić, "Monitoring bone strontium intake in osteoporotic females self-supplementing with strontium citrate with a novel in-vivo Xray fluorescence based diagnostic tool," vol. 61, pp. 48-54, 2014.

[10] M. Zamburlini, A. Pejović-Milić, and D. R. Chettle, "Spectrometry methods for in vivo bone strontium measurements," X-ray Spectrometry, vol. 37, no. 1, pp. 42-50, 2008.

[11] ICRP, "Basic Anatomical \& Phsiological Data for use in Radiological Proetection The Skeleton," ICRP Publication 70, Annuals of the ICRP, vol. 25, no. 2, pp. -, 1995.

[12] K. D. Jørgensen and A. S. Posner, "Study of the Setting of Plaster," Clinical Materials, vol. 38, no. 3, pp. 491-499, 1956.

[13] L. J. Somervaille, D. R. Chettle, and M. C. Scott, "In vivo measurement of lead in bone using x-ray fluorescence," Physics in Medicine and Biology, vol. 30, no. 9, pp. 929-943, 1985.

[14] L. J. Somervaille, U. Nilsson, D. R. Chettle, I. Tell, M. C. Scott, A. Schütz, S. Mattsson, and S. Skerfving, "in vivo measurements of bone lead-a comparison of two x-ray fluorescence techniques used at three different bone sites," Physics in Medicine and Biology, vol. 34, no. 12, pp. 1833-1845, 1989.

[15] J. A. Hoppin, A. C. A. Aro, P. L. Williams, H. Hu, and P. B. Ryan, "Validation of K-XRF Bone Lead Measurement in Young Adults," Environmental Health Perspectives, vol. 103, no. 1, pp. 78-83, 1995. 
[16] A. Aro, C. Amarasiriwardena, M.-L. Lee, R. Kim, and H. Hu, "Validation of K x-ray fluorescence bone lead measurements by inductively coupled plasma mass spectrometry in cadaver legs," Medical Physics, vol. 27, no. 1, pp. 119-123, 2000.

[17] A. C. Todd, E. L. Moshier, S. Carroll, and S. W. Casteel, "Validation of X-Ray Fluorescence-Measured Swine Femur Lead Against Atomic Absorption Spectrometry," Environmental Health Perspectives, vol. 109, no. 11, pp. 1115-1119, 2001.

[18] A. C. Todd, P. J. Parsons, S. Carroll, C. Geraghty, F. A. Khan, S. Tang, and E. L. Moshier, "Measurements of lead in human tibiae. A comparison between K-shell x-ray fluorescence and electrothermal atomic absorption spectrometry," Physics in Medicine and Biology, vol. 47, no. 4, pp. 673-687, 2002.

[19] D. J. Bellis, A. C. Todd, and P. J. Parsons, "An interlaboratory comparison of bone lead measurements via $\mathrm{K}$-shell X-ray fluorescence spectrometry: validation against inductively coupled plasma mass spectrometry," Journal of Analytical Atomic Spectrometry, vol. 27, no. 4, pp. 595-603, 2012.

[20] S. P. Nielsen, "The biological role of strontium," Bone, vol. 35, no. 3, pp. 583-588, 2004.

[21] W. E. Cabrera, I. Schrooten, M. E. De Broe, and P. C. D'Haese, "Strontium and bone," Journal of Bone and Mineral Research, vol. 14, no. 5, pp. 661-668, 1999.

[22] P. W. Brown, N. Hocker, and S. Hoyle, "Variations in Solution Chemistry During the Low-Temperature Formation of Hydroxyapatite," Journal of the American Ceramics Society, vol. 74, no. 8, pp. 1848-1854, 1991.

[23] S. Takagi, L. C. Chow, and K. Ishikawa, "Formation of hydroxyapatite in new calcium phosphate cements," Biomaterials, vol. 19, no. 17, pp. 1593-1599, 1998. 
[24] E. Fernández, M. G. Boltong, M. P. Ginebra, O. Bermúdez, F. C. M. Driessens, and J. A. Planell, "Common Ion Effect on Some Calcium Phosphate Cements," Clinical Materials, vol. 16, no. 2, pp. 99-103, 1994.

[25] L. C. Chow, M. Markovic, and S. Takagi, "Formation of Hydroxyapatite in Cement Systems: Effects of Phosphate," Phosphorous, Sulfur and Silicon, vol. 144-146, no. 1, pp. 129-132, 1999.

[26] J. Christoffersen, M. R. Christoffersen, N. Kolthoff, and O. Bärenholdt, "Effects of strontium ion on growth and dissolution of hydroxyapatite and on bone mineral detection," Bone, vol. 20, no. 1, pp. 47-54, 1997.

[27] S. P. Nielsen, D. Slosman, O. H. Søorensen, B. Basse-Cathalinat, P. De Cassin, C. Roux, and P. J. Meunier, "Influence of Strontium on Bone Mineral Density and Bone Mineral Content Measurements by Dual X-Ray Absorptiometry," Journal of Clinical Densitometry, vol. 2, pp. 371-379, 1999.

[28] G. M. Blake and I. Fogelman, "Effect of Bone Strontium on BMD Measurements," Journal of Clinical Densitometry, vol. 10, no. 1, pp. 34-38, 2006.

[29] G. M. Blake, E. M. Lewiecki, D. L. Kendler, and I. Fogelman, "A Review of Strontium Renelate and Its Effect of DXA Scans," Journal of Clinical Densitometry, vol. 10, no. 2, pp. 113-119, 2007.

[30] G. M. Blake and I. Fogelman, "The Correction of BMD Measurements for Bone Strontium Content," Journal of Clinical Densitometry, vol. 10, no. 3, pp. 259-265, 2007.

[31] L. H. Nie, S. Sanchez, K. Newton, L. Grodzins, R. O. Cleveland, and M. G. Weisskopf, "In vivo quantification of lead in bone with a portable x-ray fluorescence system- 
methodology and feasibility," Physics in Medicine and Biology, vol. 56, no. 3, pp. N39N51, 2011.

[32] A. C. Todd, "Contamination of in vivo bone-lead measurements," Physics in Medicine and Biology, vol. 45, no. 1, pp. 229-240, 2000. 